\title{
PONTES EM PÓRTICO DE PEQUENOS VÃOS COM SUPERESTRUTURA \\ FORMADA DE ELEMENTOS PRÉ-MOLDADOS: ESTUDO DE CASO
}

\author{
BRUNO DE MORAIS PRETTI \\ Dissertação apresentada à Escola de Engenharia \\ de São Carlos, da Universidade de São Paulo, \\ como parte dos requisitos para obtenção do \\ título de Mestre em Estruturas. \\ ORIENTADOR: Prof. Dr. Mounir Khalil El Debs
}




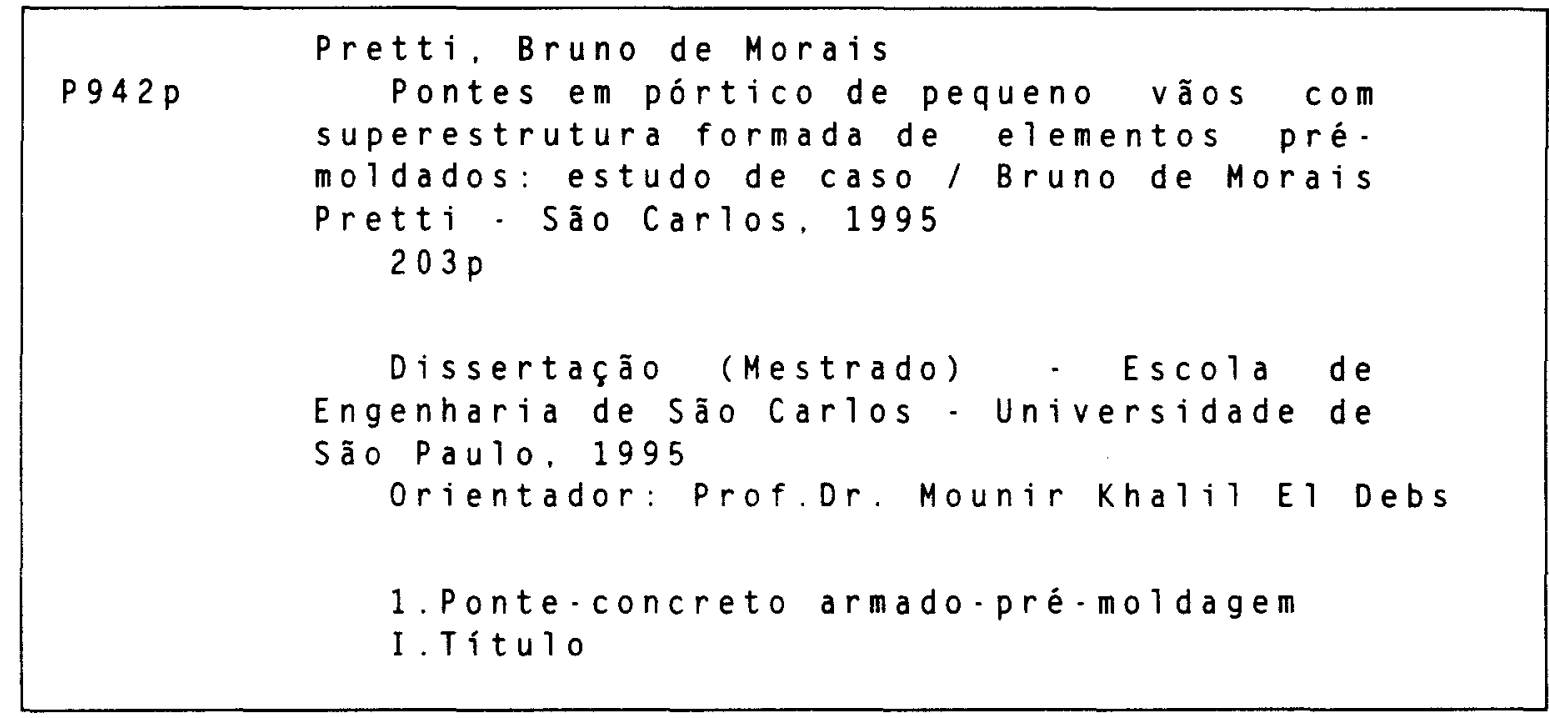


Aos meus pais Nilza e Nelson, que com grande carinho e incentivo contribuiram para a realização deste trabalho. 


\section{AGRADECIMENTOS}

Ao Professor Mounir Khalil El Debs pelas diretrizes seguras e excelente orientação fornecida durante a elaboração deste trabalho.

A Coordenadoria de Aperfeiçoamento de Pessoal de Nível Superior - CAPES, pela bolsa de estudo concedida.

Ao Conselho Nacional de Pesquisa - CNPq, pelo auxílio financeiro na forma de Bolsa de Mestrado.

Ao Banco de Desenvolvimento do Espírito Santo BANDES, pelo financiamento concedido.

Ao Professor João Bento de Hanai pelo grande incentivo.

Ao Professor Norberto Costardi pelo constante auxílio.

Ao Júlio e Obede pelos desenhos.

A todos os colegas, professores e funcionários do Departamento de Estruturas da EESC/USP pelo apoio e amizade.

Finalmente, a todos aqueles que direta ou indiretamente contribuiram para a realização deste trabalho. 


\section{SUMÁRIO}

1 - INTRODUÇÃO

página

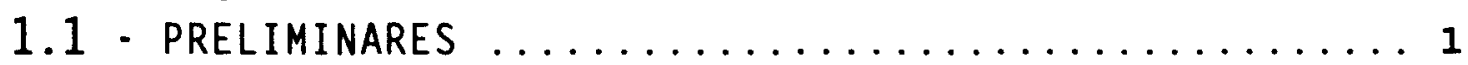

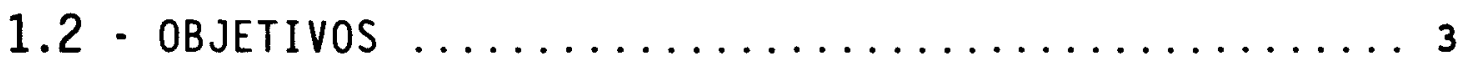

1.3 - APRESENTAÇÃO DO TRABALHO $\ldots \ldots \ldots \ldots \ldots \ldots \ldots \ldots \ldots \ldots \ldots \ldots \ldots$

2 - TIPOLOGIA DAS PONTES DE PEQUENOS VÃOS COM UTILIZAÇ̃̃O

DE ELEMENTOS PRÉ-MOLDADOS NA SUPERESTRUTURA ........ 5

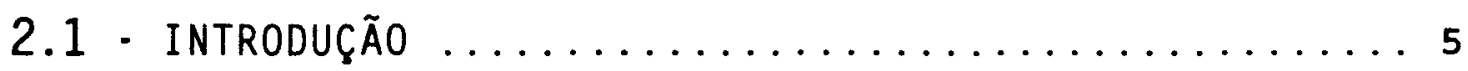

2.2 - SISTEMAS ESTRUTURAIS $\ldots \ldots \ldots \ldots \ldots \ldots \ldots \ldots \ldots$

2.2 .1 - CONSIDERAÇÕES PRELIMINARES $\ldots \ldots \ldots \ldots \ldots 6$

2.2.2 - PONTES DE PEQUENOS VÃOS EM VIGA ....... 8

2.2.3 - PONTES DE PEQUENOS VÃOS EM PÓRTICO ..... 10

2.3 - SEÇÕES TRANSVERSAIS ..................... 14

3 - TIPO CONSTRUTIVO ESCOLHIDO $\ldots \ldots \ldots \ldots \ldots \ldots \ldots \ldots$

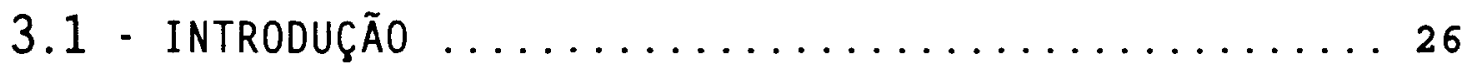

3.2 - ESCOLHA DA SEÇÃO TRANSVERSAL DO ELEMENTO

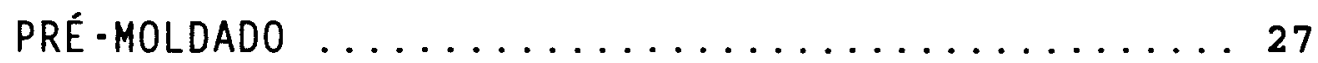

3.3 - UNIÃO ENTRE SUPERESTRUTURA E INFRAESTRUTURA $\ldots 28$

3.4 - CONSIDERAÇÕES SOBRE 0 PROJETO $\ldots \ldots \ldots \ldots \ldots \ldots \ldots$

3.4 .1 - COM RELAÇÃO ÀS UNIÕES ............. 30

3.4.2 - COM RELAÇÃO À LIGAÇÃO ENTRE OS

CONCRETOS COM IDADES DIFERENTES ....... 32

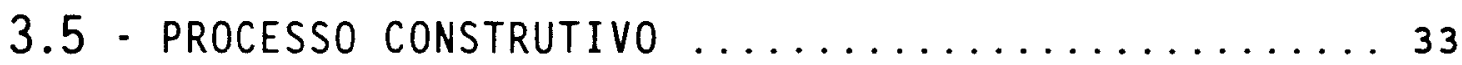

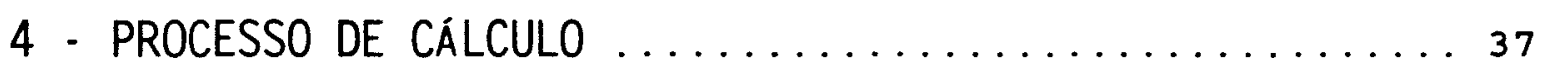

4.1 - CONSIDERAÇÕES PRELIMINARES $\ldots \ldots \ldots \ldots \ldots \ldots \ldots \ldots \ldots \ldots \ldots$

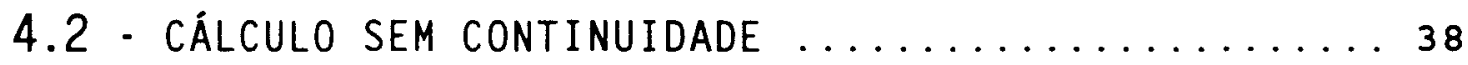

4.2 .1 - CÁLCULO DA SUPERESTRUTURA ............ 39

4.2.1.1 - PRÉ-DIMENSIONAMENTO DA LAJE ....... 39

4.2.1.2 - CÁLCULO DA LAJE SEGUNDO RÜSCH ......4 41

4.2 .2 - CÁLCULO DA INFRAESTRUTURA $\ldots \ldots \ldots \ldots \ldots 48$

4.2.2.1 - PRÉ-DIMENSIONAMENTO DOS ENCONTROS ... 49

4.2.2.2 - CÁLCULO DOS ENCONTROS ........... 52

4.2.2.3 - PRÉ - DIMENSIONAMENTO DOS BLOCOS ....66 61

4.2.2.4 - CÁLCULO DOS ESFORÇOS NOS BLOCOS .... 62

4.3 - CÁLCULO COM CONTINUIDADE ................. 69 
4.3.1 - CÁlCULO dA PONTE EM PÓRTICO -

CARREgAMENTO Móvel ................... 71

4.3.1.1 - CÁLCULO DA LAJE ISOLADA ........... 71

4.3.1.2 - CÁLCULO COMO VIGA ISOLADA .......... 72

4.3.1.3 - CÁLCULO DAS LARGURAS COLABORANTES ...7 75

4.3.1.4 - CÁLCULO DOS ESFORÇOS COMO PÓRTICO PLANO ....................... 76

4.3.1.5 - CÁLCULO DOS ESFORÇOS NA PONTE EM PÓRTICO ....................... 77

4.3.2 - CÁLCULO DA PONTE EM PÓRTICO -

CARREgAMENTO PERMANENTE ............... 77

4.3.2.1 - ESFORÇOS DEVIDOS AO PESO PRÓPRIO E SOBRECARGAS PERMANENTES ........... 78

4.3.2.2 - ESFORÇOS DEVIDOS AO EMPUXO DE TERRA E SOBRECARGA DOS VEÍCULOS ADJACENTES AOS ENCONTROS ................... 78

4.3.2.3 - ESFORÇOS DEVIDOS À VARIAÇÃO DA TEMPERATURA E RETRAÇÃO DO CONCRETO $\ldots 79$

4.3.2.4 - CÁLCULO DOS BLOCOS DE FUNDAÇÃO ...... 80 4.4 - Dimensionamento dOS Elementos EStRUtuRAis ...... 81

4.5 - VERIFICAÇÕES .......................... 85

4.5.1 - VERIFICAÇÃO DO ESTADO LIMITE ÚLTIMO DE RESISTÊNCIA À FADIGA ................. 85

4.5.2 - VERIFICAÇÃO DAS FASES CONSTRUTIVAS ..... 88

4.5.3 - VERIFICAÇÃO DO FENDILHAMENTO NO NÓ DO PÓRTICO ....................... 89

4.5.4 - VERIFICAÇÃO DA LIGAÇÃO DOS CONCRETOS COM IDADES DIFERENTES .................. 90

4.5.5 - VERIFICAÇÃO DO ESTADO DE DEFORMAÇÃO EXCESSIVA ........................ 95

4.5.6 - VERIFICAÇÃO DO ESTADO DE FISSURAÇÃO INACEITÁVEL $\ldots \ldots \ldots \ldots \ldots \ldots \ldots \ldots \ldots . \ldots 9$

4.6 - DetalHamento da ESTRUTURA $\ldots \ldots \ldots \ldots \ldots \ldots \ldots$

5 - EXEMPLO ILUSTRATIVO .......................... 101

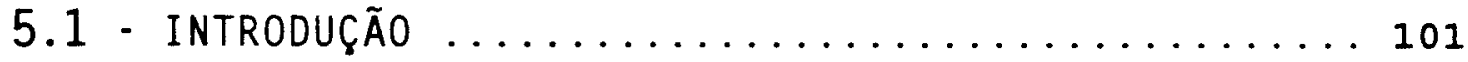

5.2 - CARACTERÍSTICAS GEOMÉTRICAS DA PONTE .......... 101

5.3 - CÁLCULO SEM CONTINUIDADE ................... 102

5.3 .1 - CÁlCULO dA SUPERESTRUTURA $\ldots \ldots \ldots \ldots \ldots 102$ 
5.3.1.1 - PRÉ-DIMENSIONAMENTO DA LAJE ....... 102

5.3.1.2 - CÁLCULO DA LAJE SEGUNDO RÜSCH ...... 103

5.3 .2 - CÁLCULO DA INFRAESTRUTURA .............. 108

5.3.2.1 - PRÉ-DIMENSIONAMENTO DOS ENCONTROS ... 108

5.3.2.2 - CÁLCULO DOS ENCONTROS ............. 109

5.3.2.3 - PRÉ-DIMENSIONAMENTO DOS BLOCOS .... 113

5.3.2.4 - CÁLCULO DOS ESFORÇOS NOS BLOCOS .... 113

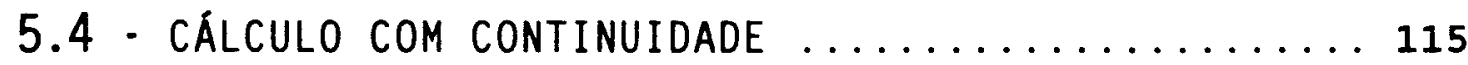

5.4.1 - CÁLCULO DA PONTE EM PÓRTICO -

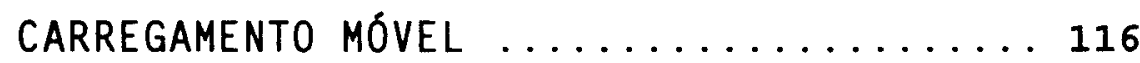

5.4.1.1 - CÁLCULO DA LAJE ISOLADA ......... 116

5.4.1.2 - CÁLCULO DOS ESFORÇOS COMO VIGA

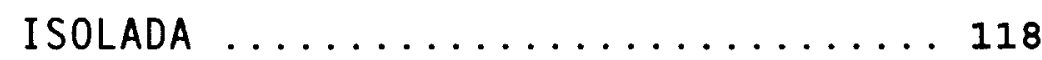

5.4.1.3 - CÁLCULO DAS LARGURAS COLABORANTES ... 120

5.4.1.4 - CÁLCULO DOS ESFORÇOS COMO PÓRTICO PLANO ....................... 121

5.4.1.5 - CÁLCULO DOS ESFORÇOS DA PONTE

EM PÓRTICO ...................... 122

5.4.2 - CÁLCULO DA PONTE EM PÓRTICO -

CARREgAMENTO PERMANENTE $\ldots \ldots \ldots \ldots \ldots 123$

5.4.2.1 - ESFORÇOS DEVIDOS AO PESO PRÓPRIO E SOBRECARGAS PERMANENTES .......... 123

5.4.2.2 - ESFORÇOS DEVIDOS AO EMPUXO DE TERRA E SOBRECARGA DOS VEÍCULOS ADJACENTES AOS ENCONTROS ................ 124

5.4.2.3 - ESFORÇOS DEVIDOS À VARIAÇÃO DE

TEMPERATURA E RETRAÇÃO DO CONCRETO $\ldots 125$

5.4 .3 - CÁLCULO DA INFRAESTRUTURA .......... 128

5.4.3.1 - PRÉ-DIMENSIONAMENTO DOS BLOCOS ..... 128

5.4.3.2 - CÁLCULO DOS ESFORÇOS NOS BLOCOS .... 128

5.5 - AVALIAÇÃO DOS ESFORÇOS ATRAVÉS DA TÉCNICA DOS

ELEMENTOS FINITOS ................... 130

5.6 - DIMENSIONAMENTO DOS ELEMENTOS ESTRUTURAIS ..... 135

5.6.1 - DIMENSIONAMENTO DA ESTRUTURA CALCULADA

SEM CONTINUIDADE ............... 136

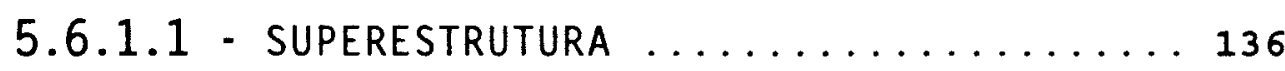

5.61 .2 - INFRAESTRUTURA $\ldots \ldots \ldots \ldots \ldots \ldots \ldots \ldots$

5.6.2 - DIMENSIONAMENTO DA ESTRUTURA CALCULADA 
COM CONTINUIDADE ................. 137

5.6.2.1 - SUPERESTRUTURA E INFRAESTRUTURA.... 137

5.7 - VERIFICAÇÕES ...................... 139

5.7.1 - VERIFICAÇÃO DO ESTADO LIMITE ÚLTIMO DE RESISTENNCIA À FADIGA .............. 139

5.7.1.1 - SISTEMA ESTRUTURAL ISOSTÁTICO $\ldots \ldots 139$

5.7.1.2 - SISTEMA ESTRUTURAL HIPERESTÁTICO $\ldots 140$

5.7 .2 - VERIFICAÇÃO DAS FASES CONSTRUTIVAS .... 142

5.7 .3 - VERIFICAÇÃO DO FENDILHAMENTO NO NÓ DO PÓRTICO ......................... 143

5.7.4 - VERIFICAÇÃO DA LIGAÇÃO DOS CONCRETOS COM IDADES DIFERENTES ............. 144

5.7.5 - VERIFICAÇÃO DO ESTADO DE DEFORMAÇÃOO EXCESSIVA ..................... 146

5.7.6 - VERIFICAÇÃO DO ESTADO DE FISSURAÇÃO

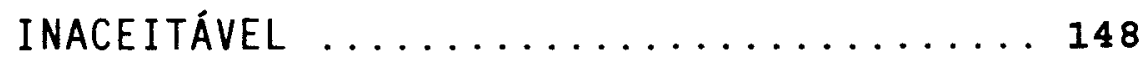

5.8 - DETALHAMENTO DA ESTRUTURA $\ldots \ldots \ldots \ldots \ldots \ldots \ldots \ldots$

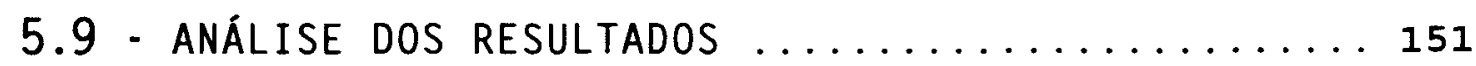

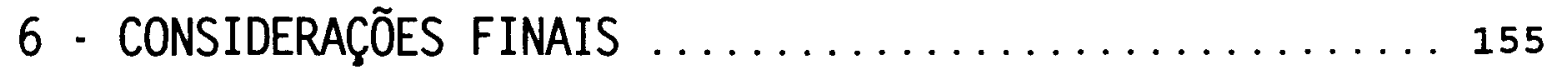

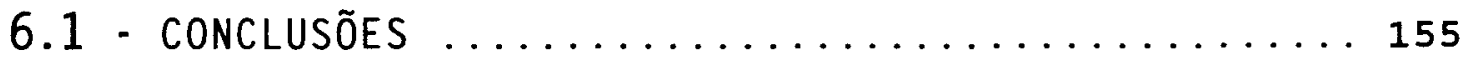

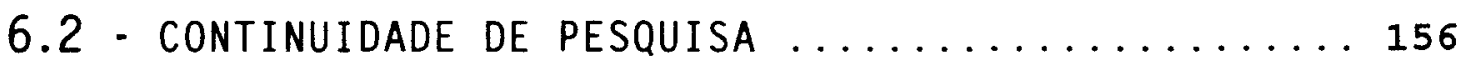

ANEXO A - DIMENSIONAMENTO DE APARELHOS DE APOIO ELASTOMÉRICOS SEGUNDO O SERVICE D'ETUDES TECHNIQUES

ANEXO B - GRÁFICOS DE ISO-MOMENTOS OBTIDOS ATRAVÉS DA TÉCNICA DOS ELEMENTOS FINITOS

ANEXO C - DETALHAMENTO DAS ESTRUTURAS UTILIZANDO OS ESFORÇOS OBTIDOS COM O MÉTODO APROXIMADO 181 ANEXO D - GRÁFICOS DE MOMENTOS FLETORES E FORÇAS CORTANTES - MÉTODO APROXIMADO 


\section{LISTA DE FIGURAS}

Figura 2.1 - Pontes de pequenos vãos em viga ......... 9

Figura 2.2 - Distribuição dos momentos fletores nos pórticos ..................... 10

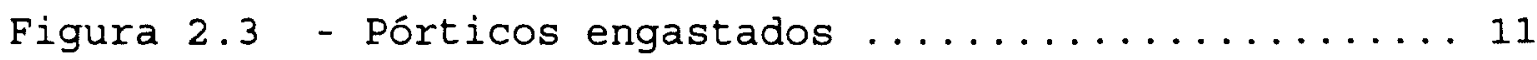

Figura 2.4 - Pórticos biarticulados .............. 12

Figura 2.5 - Pórticos fechado ................. 13

Figura 2.6 - Rendimento mecânico de algumas seções

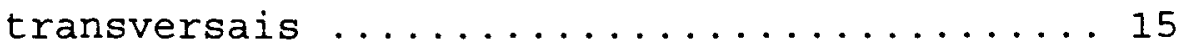

Figura 2.7 - Elementos pré-moldados de seção retangular maciça ..................... 17

Figura 2.8 - Elementos pré-moldados de seção retangular vazada ...................... 19

Figura 2.9 - Elementos pré-moldados de seção caixão .... 20

Figura 2.10 - Elementos pré-moldados de seção $\mathrm{T}$ e suas variações ...................... 21

Figura 2.11 - Elementos pré-moldados de seção duplo T . .. 23

Figura 2.12 - Elementos pré-moldados de seção $T$ invertido 24

Figura 2.13 - Elementos pré-moldados de seção trapezoidal 25

Figura 3.1 - Procedimentos adotados para possibilitar a distribuicão transversal das cargas ..... 27

Figura 3.2 - União rígida entre pilar e viga .......... 29

Figura 3.3 - União rígida entre pisos e paredes ........ 30

Figura 3.4 - Montagem dos elementos pré-moldados ...... 33

Figura 3.5 - Processo construtivo de ponte de pequeno vão em pórtico com o emprego de elementos pré-moldados na superestrutura ........ 34

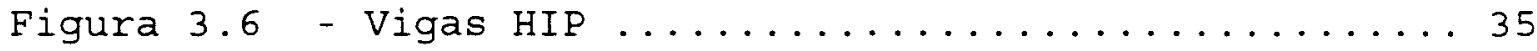

Figura 3.7 - Processo para execução dos bordos do tabuleiro; soluções usuais .......... 36

Figura 4.1 - Estrutura idealizada para o cálculo sem continuidade ...................... 39

Figura 4.2 - Largura de distribuição $(t) \ldots \ldots \ldots \ldots \ldots 42$

Figura 4.3 - Superfícies de influência para lajes bi-apoiadas e bi-engastadas com bordo livre 47

Figura 4.4 - Triângulo de forças na cunha de terra ..... 50 
Figura 4.5 - Pressão de terra atuante no muro ........ 51

Figura 4.6 - Cálculo da rigidez de pilares com inércia variável ........................ 54

Figura 4.7 - Efeito da carga móvel nos encontros ....... 56

Figura 4.8 - Ponto de deslocamento nulo (PDN) ........60

Figura 4.9 - Dimensões mínimas do bloco ........... 62

Figura 4.10 - Estaqueamento plano com estacas paralelas .. 63

Figura 4.11 - Treliça idealizada no interior do bloco ... 65

Figura 4.12 - Características geométricas necessárias ao cálculo dos blocos segundo o CEB ......66 66

Figura 4.13 - Seções de referência $S 1$ e $S 2 \ldots \ldots \ldots \ldots . \ldots 6$

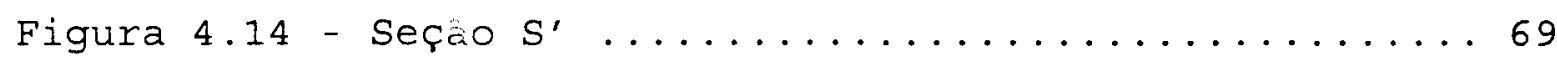

Figura 4.15 - Estrutura idealizada para o cálculo com continuidade ................ 70

Figura 4.16 - Conceito de linha de influência ......... 72

Figura 4.17 - Ações que surgem nos apoios restritos por ocasião da aplicação de uma força unitária. 73

Figura 4.18 - Trem-tipo atuante na viga; trem-tipo simplificado .................. 75

Figura 4.19 - Carregamento do pórtico: empuxo unilateral e empuxo equilibrado ............... 79

Figura 4.20 - Diagrama de momentos fletores devido à uma variação de temperatura $\Delta t$ (negativa) .... 80

Figura 4.21 - Situações de baixas solicitações cisalhantes ................... 92

Figura 4.22 - Situações de altas solicitações cisalhantes 92

Figura 4.23 - Área de concreto (Acr) ................ 99

Figura 5.1 - Seção transversal do tabuleiro da ponte ... 102

Figura 5.2 - Dimensões do guarda-corpo ............. 104

Figura 5.3 - Seção considerada para o cálculo dos esforços provenientes das cargas

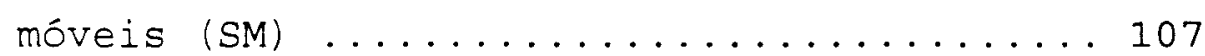

Figura 5.4 - Dimensões e seções definidas nos encontros 110

Figura 5.5 - Pré-dimensionamento dos blocos ......... 113

Figura 5.6 - Características geométricas e carregamento nos blocos .................... 114

Figura 5.7 - Seções definidas no pórtico para o traçado 
dos diagramas de momento fletor e esforço

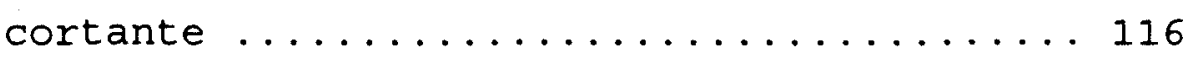

Figura 5.8 - Trem-tipo atuante na viga; trem-tipo simplificado ................ 119

Figura 5.9 - Pré-dimensionamento dos blocos ........ 128

Figura 5.10 - Características geométricas dos blocos ... 128

Figura 5.11 - Carregamento nos blocos .............. 129

Figura 5.12 - Discretização dos sistemas estruturais ... 132

Figura 5.13 - Distribuição das cargas provenientes das rodas do veículo tipo pelos nós da estrutura discretizada ............ 133

Figura 5.14 - Seção transversal da viga pré-moldada .... 142

Figura A.1 - Deformação de uma almofada de neoprene fretado sob ação de um esforço horizontal. 160

Figura C.la - Detalhamento das vigas pré-moldadas da ponte em pórtico ................. 195

Figura C.1b - Tabela de ferros das vigas pré-moldadas da ponte em pórtico .............. 195

Figura C.2a - Detalhamento da ponte: encontros e nós do pórtico .................... 196

Figura C.2b - Tabela de ferros da ponte em pórtico relativa ao detalhamento dos encontros e do nó do pórtico ............... 197

Figura C.3a - Detalhamento da fundação da ponte em pórtico ..................... 198

Figura C.3b - Tabela de ferros da fundação da ponte em pórtico ................... 198

Figura C.4a - Detalhamento das vigas pré-moldadas da ponte em viga .................. 199

Figura C.4b - Tabela de ferros das vigas pré-moldadas da ponte em viga ............... 199

Figura C.5a - Detalhamento dos muros da ponte em viga ... 200

Figura C.5b - Tabela de ferros dos muros da ponte em

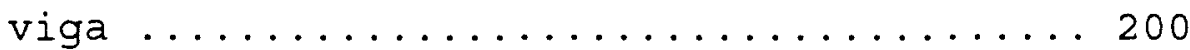

Figura C.6a - Detalhamento da fundação da ponte em viga . 201

Figura C.6b - Tabela de ferros da fundação da ponte em viga ..................... 201 
Figura D.1 - Diagrama de Momento Fletor

- Carga Permanante .................. 203

Figura D.2 - Diagrama de Momento Fletor

- Carga Móvel ....................... 203

Figura D.3 - Diagrama de Força Cortante

- Carga Permanante ................... 204

Figura D.4 - Diagrama de Força Cortante

- Carga Móvel ....................... 204

Figura D.5 - Diagrama de Momento Fletor

- Empuxo de Terra .................... 205

Figura D.6 - Diagrama de Momento Fletor

- Temperatura/Retração ................ 205

Figura D.7 - Diagrama de Momento Fletor

- Aceleração/Frenagem ................. 206

Figura D.8 - Diagrama de Força Cortante

- Empuxo de Terra .................... 206

Figura D.9 - Diagrama de Força Cortante

- Temperatura/Retração ................ 207

Figura D.10 - Diagrama de Força Cortante

- Aceleração/Frenagem ................. 207

Figura D.11 - Diagrama de Momento Fletor

- Peso Próprio ....................... 208

Figura D.12 - Diagrama de Momento Fletor

- Empuxo Ativo ..................... 209

Figura D.13 - Diagrama de Momento Fletor

- Empuxo Repouso ..................... 210

Figura D.14 - Diagrama de Momento Fletor

- Aceleração e Frenagem ................ 211

Figura D.15 - Diagrama de Momento Fletor

- Carregamento Móvel ................. 212

Figura D.16 - Diagrama de Momento Fletor

- Temperatura/Retração ................ 213

Figura D.17 - Diagrama de Força Cortante

- Peso Próprio ...................... 214

Figura D.18 - Diagrama de Força Cortante

- Empuxo Ativo ....................... 215

Figura D.19 - Diagrama de Força Cortante 
- Empuxo Repouso .................... 216

Figura D.20 - Diagrama de Força Cortante

- Aceleração/Frenagem ................ 217

Figura D.21 - Diagrama de Força Cortante

- Carregamento Móvel ................. 218

Figura D.22 - Diagrama de Força Cortante

- Temperatura/Retração ................ 219 


\section{LISTA DE TABELAS}

Tabela 4.1

Tabela 4.2

Tabela 4.3

Tabela 4.4

Tabela 4.5

Tabela 4.6

Tabela 4.7

Tabela 4.8

Tabela 4.9

Tabela 4.10

Tabela 4.11

Tabela 4.12

Tabela 5.1

Tabela 5.2

Tabela 5.3

Tabela 5.4

Tabela 5.5

Tabela 5.6

Tabela 5.7

Tabela 5.8

Tabela 5.9
- Valores do índice de esbeltez $\ell$ /h para seção transversal de laje maciça ........40

- Cargas dos veículos ............... 44

- Características dos veículos .......... 45

- Coeficientes de ponderação para ações permanentes de grande variabilidade ......88 83

- Coeficientes de ponderação para ações permanentes de pequena variabilidade .....8 83

- Coeficientes de ponderação para efeitos de recalques de apoio e de retração dos materiais .................. 84

- Coeficientes de ponderação para ações variáveis ................... 84

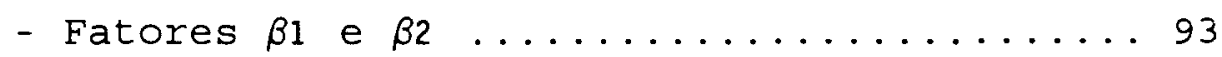

- Valores dos coeficientes $\beta s$ e $\beta c$......... 94

- Valores de Ir/Ic para vigas de seção retangular .................. 97

- Coeficientes para obter a flecha final em função da flecha inicial .......... 98

- Valores simplificados da relação al/d ... 100

- Coeficientes para o cálculo dos momentos fletores devidos à carga $\mathrm{P} \ldots \ldots \ldots \ldots \ldots$

- Coeficientes para o cálculo dos momentos fletores devidos às cargas $p$ e p'....... 106

- Coeficientes para o cálculo das forças cortantes devidas às cargas P, p e p' . . 107

- Esforços nas seções definidas na laje ... 108

- Cálculo da flexibilidade do pilar $\left(\delta_{p}\right) \ldots 110$

- Esforços nas seções definidas nos encontros ................... 112

- Coeficientes para o cálculo dos momentos fletores devidos à carga $\mathrm{P} \ldots \ldots \ldots \ldots \ldots 117$

- Coeficientes para o cálculo dos momentos fletores devidos às cargas $p$ e $p^{\prime} \ldots \ldots \ldots 118$ - Coeficientes para o cálculo das forças 
cortantes devidos às cargas $\mathrm{P}, \mathrm{p}$ e $\mathrm{p}^{\prime} \ldots \ldots 118$

Tabela 5.10 - Ordenadas das linhas de influência da viga ...................... 120

Tabela 5.11a - Linhas de influência dos momentos fletores .................... 121

Tabela 5.11b - Linhas de influência das forças cortantes ................... 122

Tabela 5.12 - Esforços nas seções do pórtico plano ..... 122

Tabela 5.13a - Momentos fletores na seção SM da ponte em pórtico .................... 126

Tabela 5.13b - Forças cortantes na seção SM da ponte em pórtico ................... 127

Tabela 5.14 - Envoltória dos momentos fletores para o cálculo sem continuidade ........... 135

Tabela 5.15 - Envoltória dos momentos fletores para - cálculo com continuidade ........... 135

Tabela 5.16 - Solicitações de cálculo (Fd) na laje.... 136

Tabela 5.17 - Solicitações de cálculo (Fd) nos encontros e áreas de aço necessárias (longitudinal) ................ 137

Tabela 5.18 - Solicitações de cálculo nas seções do pórtico e áreas de aço necessárias (longitudinal) ................. 138

Tabela 5.19 - Cálculo do grau de engastamento do nó ponte .................... 148

Tabela 5.20 - Consumos para o sistema com continuidade . 151

Tabela 5.21 - Consumos para o sistema sem continuidade . 151

Tabela 5.22 - Índices de consumo para o sistema com continuidade ................. 152

Tabela 5.23 - Índices de consumo para o sistema sem continuidade .................. 152

Tabela 5.24 - Consumos para o sistema com continuidade Cálculo utilizando os esforços obtidos através da Técnica dos Elementos Finitos. 154

Tabela 5.25 - índices de consumo para o sistema com continuidade. Cálculo utilizando esforços obtidos com a Técnica dos Elementos 
Finitos ..................... 154

Tabela A.1 - Módulo de cisalhamento do neoprene à $20^{\circ} \mathrm{C}$, em função da dureza shore ....... 160 


\title{
LISTA DE ABREVIATURAS E SIGLAS
}

\author{
AASHTO - American Association of State Highway and \\ Transportation officials \\ CEB - Comité Euro-International du Betón \\ EUA - Estados Unidos da América \\ FIP - Federation Internationale de la Precontrainte \\ NBR - Norma Brasileira Registrada \\ PCI - Prestressed Concrete Institute \\ TRR - Transportation Research Record
}




\section{LISTA DE SIMBOLOS}

a - espaçamento entre rodas de um mesmo eixo, cm

$A_{C r}$ - área de concreto interessada pela fissuração, $\mathrm{cm}^{2}$

$A_{s}$ - área de armadura longitudinal, $\mathrm{cm}^{2}$

$A_{s w}$ - área de armadura transversal, $\mathrm{cm}^{2}$

$a_{v}$ - distância entre os pontos de momento nulo e máximo na peça, cm

$\mathrm{b}_{1}$ - largura de contato de cada roda dianteira, cm

$\mathrm{b}_{2}$ - largura de contato de cada roda intermediária, cm

$\mathrm{b}_{3}$ - largura de contato de cada roda traseira, cm

$b_{e m}$ - largura colaborante para o momento fletor no meio do engaste, $m$

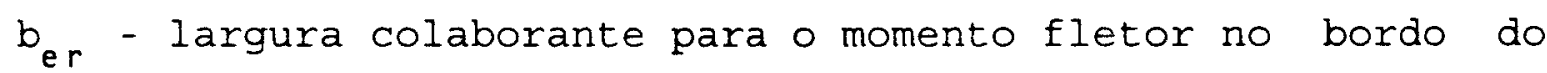
engaste, $m$

$b_{x m}$ - largura colaborante para o momento fletor no meio do vão, m

$b_{x r}$ - largura colaborante para o momento fletor no meio do bordo livre, m

b(.xm) - largura colaborante para o momento fletor no meio do vão para cargas que provocam momentos negativos, $m$

d - altura útil da seção, cm

E - resultante do empuxo ativo atuante no muro ou encontro, $\mathrm{kN} / \mathrm{m}$

$\mathrm{E}_{\mathrm{c}}$ - módulo de elasticidade longitudinal do concreto, $\mathrm{kN} / \mathrm{cm}^{2}$

$\mathrm{E}_{5}$ - módulo de elasticidade longitudinal do aço, $\mathrm{kgf} / \mathrm{cm}^{2}$

$e_{1}$ - altura da seção transversal da laje da ponte, cm

$e_{m}$ - altura da seção transversal do muro ou encontro, cm

F - carga de uma roda do veículo tipo 45 ou $30, \mathrm{kN}$

$\mathrm{F}_{1}$ - carga de uma roda traseira do veículo tipo 12, $\mathrm{kN}$

$\mathrm{F}_{2}$ - carga de uma roda dianteira do veículo tipo 12, $\mathrm{kN}$

$F_{m d}$ - valor médio da força de compressão ou de tração acima da ligação, ao longo do comprimento $a_{v}, \mathrm{kN}$

$f_{c d}$ - resistência de cálculo do concreto à compressão, $\mathrm{MPa}$

$f_{c k}$ - resistência característica do concreto à compressão, $\mathrm{MPa}$

$f_{c k}$. - resistência característica do concreto à compressão 
medida em cubos de $15 \mathrm{~cm}, \mathrm{MPa}$

$\mathrm{f}_{\text {td }}$ - resistência de cálculo do concreto à tração, $\mathrm{MPa}$

$f_{t d}$ - resistência de cálculo do concreto à tração obtida a partir da resistência característica à compressão medida em cubos de $15 \mathrm{~cm}, \mathrm{MPa}$

$f_{y k}$ - resistência característica do aço à tração, $\mathrm{MPa}$

$\mathrm{f}_{\text {ycd }}$ - resistência de cálculo do aço à compressão, $\mathrm{MPa}$

$\mathrm{f}_{y c k}$ - resistência característica do aço à compressão, $\mathrm{MPa}$

$\mathrm{f}_{y d}$ - resistência de cálculo do aço à tração, $\mathrm{MPa}$

$\mathrm{G}$ - módulo de elasticidade transversal, $\mathrm{kN} / \mathrm{cm}^{2}$

$q$ - carga permanente, $\mathrm{kN} / \mathrm{m}$ ou $\mathrm{kN} / \mathrm{m}^{2}$

$q_{e} \quad$ - carga estática equivalente, $\mathrm{kN} / \mathrm{m}$

$\mathrm{H}$ - força horizontal, $\mathrm{kN}$

h - altura teórica dos muros ou encontros, m

I - momento de inércia, $\mathrm{m}^{4}$

$I_{c}$ - momento de inércia da seção bruta de concreto, $\mathrm{cm}^{4}$

$I_{e}$ - momento de inércia dos pilares, $\mathrm{m}^{4}$

$I_{r}$ - momento de inércia da seção fissurada, multiplicando-se a área de armação por $8, \mathrm{~cm}^{4}$

$I_{t r}$ - momento de inércia do tramo, $\mathrm{m}^{4}$

$\mathrm{K}$ - coeficiente de empuxo ou de Coulomb

k - coeficiente fornecido pela tabela de RÜSCH para os esforços provenientes do carregamento permanente

$\mathrm{k}_{\mathrm{r}}$ - coeficiente de rigidez, $\mathrm{kN} / \mathrm{cm}$

$k_{\text {sup }}$ - distância da extremidade superior do núcleo central ao centróide da seção, cm

$k_{\text {inf }}$ - distância da extremidade inferior do núcleo central ao centróide da seção, cm

$\ell \quad$ - vão teórico da ponte, m

$\ell_{i} \quad$ - distância aproximada entre os pontos de momento nulo do diagrama de momentos devidos à carga permanente, $\mathrm{cm}$ ou $\mathrm{m}$

$\ell_{x} \quad$ - comprimento teórico da placa na direção principal, m

$\ell_{y}$ - comprimento teórico da placa na direção secundária, m

$M_{L}, M_{L}^{\prime}, M_{p}, M_{p}^{\prime}$ - coeficientes fornecidos pela tabela de RÜSCH

$\mathrm{M}_{\mathrm{g}}$ - momentos fletores devidos à carga permanente, $\mathrm{kNm} / \mathrm{m}$

$\mathrm{M}$ - momentos fletores provenientes do tráfego, $\mathrm{kNm} / \mathrm{m}$

$M_{r}$ - momento de fissuração da seção, $\mathrm{kNcm}$ 


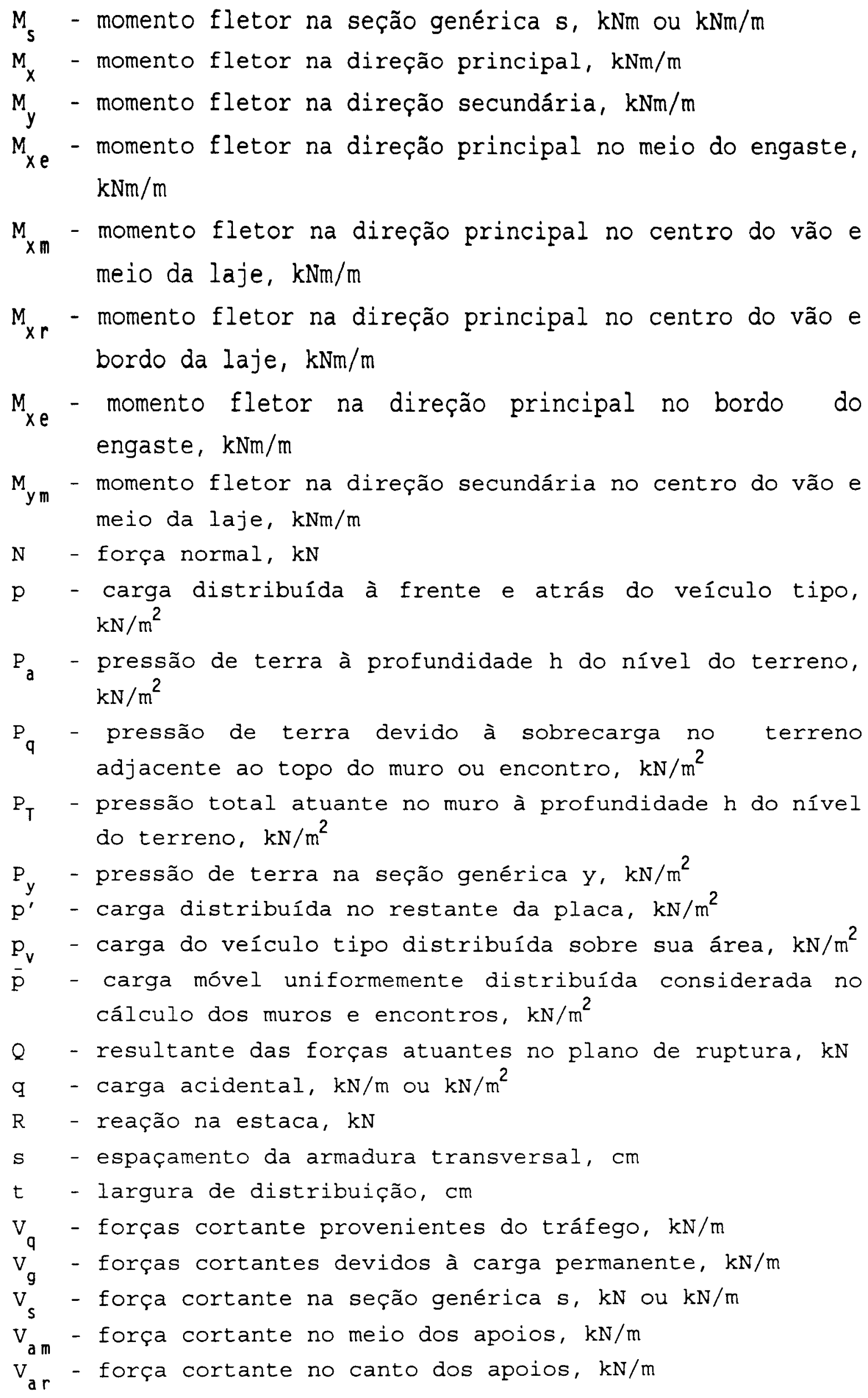


$y_{1}$ - distância do centro de gravidade da seção bruta de concreto à fibra mais tracionada, cm

$\alpha$ - ângulo de inclinação do terreno adjacente, graus

$\alpha_{c}$ - coeficiente de dilatação térmica do concreto, ${ }^{\circ} \mathrm{C}^{\cdot 1}$

$\beta_{a}$ - coeficiente de ação dinâmica

$\beta_{s}$ e $\beta_{c}$ - coeficientes de minoração aplicados à armadura e ao concreto, respectivamente

$\beta_{1}$ e $\beta_{2}$ - fatores multiplicativos do aço e do concreto, respectivamente

$\delta$ - coeficiente de flexibilidade, $\mathrm{cm}^{\mathrm{kN}}{ }^{-1}$

$\Delta t$ - variação de temperatura, ${ }^{\circ} \mathrm{C}$

$\epsilon_{c t}$ - deformação específica axial

$\theta$ - ângulo de inclinação do paramento interno do muro com a vertical, graus

$\psi_{1}$ - ângulo de atrito entre a terra e o muro, graus

$\kappa$ - rendimento mecânico da seção

$\rho_{r} \quad$ - taxa geométrica da armadura na seção transversal de concreto Acr, :

$\eta_{b}$ - coeficiente de aderência do aço

$\varphi$ - coeficiente de impacto, ângulo de atrito interno, graus

$\gamma$ - peso específico do material, $\mathrm{kN} / \mathrm{m}^{3}$

$\gamma_{c}$ - coeficiente de minoração da resistência do concreto

$\gamma_{e}$ - coeficiente de minoração da resistência do aço

$\sigma$ - tensão normal, $\mathrm{kN} / \mathrm{cm}^{2}$ ou $\mathrm{kN} / \mathrm{m}^{2}$

$\sigma_{\mathrm{s}}$ - tensão em serviço na armadura, $\mathrm{kgf} / \mathrm{cm}^{2}$

$\tau^{\mathrm{s}}$ - tensão tangencial, $\mathrm{kN} / \mathrm{cm}^{2}$ ou $\mathrm{kN} / \mathrm{m}^{2}$

$\phi \quad$ - diâmetro do agregado, $\mathrm{cm}$ 


\section{RESUMO}

A possibilidade de redução ou até mesmo da eliminação do uso de formas e escoramento, diminuição do tempo e melhoria da qualidade da obra, são alguns aspectos que têm levado à adoção da pré-moldagem em superestruturas de pontes. Recentes estudos relatam que as chamadas pontes integrais - pontes sem juntas - estão tornando-se cada vez mais utilizadas nos Estados Unidos e Canadá, pois minimizam os custos com manutenção e prolongam a vida útil da obra. Procurando associar os benefícios conseguidos com a utilização dos elementos pré-moldados aos da ausência de juntas, apresenta-se neste trabalho um tipo construtivo para pontes de pequenos vãos em pórtico, com utilização de elementos pré-moldados na superestrutura ligados rigidamente à infraestrutura. Um processo aproximado de cálculo é apresentado e, a partir de um exemplo desenvolvido, compara-se esta alternativa com uma construção similar em viga, verificando-se que os custos diretos são basicamente iguais. Através da avaliação dos esforços provenientes do carregamento móvel com a técnica dos elementos finitos, chega-se a momentos fletores até $50 \%$ menores que os obtidos pelo método aproximado, resultando assim numa considerável redução dos custos diretos quando se utiliza o sistema estrutural em pórtico. 


\section{ABSTRACT}

The possibility of reduction or even the elimination of the use of forms and bearings, reducing the time and improving the qualitity of the work, are some aspects which have led to the use of precasting in bridges superstructure. Recent studies report that the so-called integral bridges, jointless bridges, are becoming more used in the United States of America and in Canada because they reduce the costs of maintenance and prolonge the useful life of the constructions. Trying to associate the benefits which have resulted from the utilization of precast elements to the ones from the absence of joints, it is present in this work a constructive proposal to small span frame bridges using the precast elements in the superstructure strictly connected to the infrastructure. A design process for bending moments is presented. The comparation between the construtive proposal and similar with joint between the superestructure and infrastructure, by using this design process, shows that the direct cost is basically the same. Through the evaluation of the efforts that come from the mobile carrying with the technique of finite elements, it can reach bending moments that are even 50\% lower than those gotten from the presented method. In this case, a significative direct cost reduction can gotten with frame structure system. 


\section{1 - INTRODUÇÃO}

\section{1 - PRELIMINARES}

No Brasil as estruturas das construções de concreto armado são, na sua maioria, moldadas no local. As técnicas da pré-moldagem do concreto aparecem como uma alternativa para o aumento da produtividade e da qualidade dessas construços. possibilitam também a redução do tempo de obra e dos desperdicios com materiais.

É evidente que não há uma delimitação precisa do que seja adequado para a construção monolítica, para a pré-fabricação ou para a pré-moldagem junto à obra. Isto depende sempre de circunstâncias locais como também depende da economia do país, de seu desenvolvimento técnico, de suas condicões de transporte e de muitos outros fatores.

A utilização da pré-moldagem no Brasil, apesar de haver muito terreno a percorrer, tem avançado muito, e o seu emprego nas superestruturas de pontes tem se intensificado cada vez mais. Isto talvez se deva ao fato de que um maior controle de qualidade assegura menores problemas com manutenção e de que muitas vezes o tempo é um fator prioritário, como no caso em que há interrupção de tráfego. Além disso, normalmente as pontes são implantadas em locais que podem apresentar certas adversidades, como a dificuldade 
de acesso de equipamentos, presença de água e possibilidade de inundações. Excetuando-se a dificuldade de acesso de equipamentos, as demais adversidades favorecem o emprego da pré-moldagem.

Notadamente nestes tipos construtivos, o projeto estrutural tem grande importância pois praticamente toda construção resume-se na estrutura, não havendo uma interação com as outras partes da construção, tais como vedações, instalações, etc. Este fato também contribui para o emprego da pré-moldagem.

As solicitações correspondentes às situações finais de projeto nas pontes normalmente são elevadas. Como consequência disto, as situações de transporte e montagem dos elementos pré-moldados não acarretam, na maioria das vezes, acréscimos de armaduras ou das seções resistentes.

A faixa de vãos que melhor se aplica a pré-moldagem de fábrica tem $\circ$ limite convencional de 30 metros. Este limite é fornecido pelo PRESTRESSED CONCRETE INSTITUTE (PCI) (1975), e corresponde a vãos de pontes construídas com elementos pré-moldados que podem ser produzidos em fábricas e transportados para o local de implantação da obra.

Pelo fato de serem comumente empregados, as pontes de pequenos vãos chegam a representar uma parcela significativa no custo de implantação das estradas. Segundo o PCI (1975), dois terços das 600.000 pontes existentes nos Estados Unidos da América e Canadá são localizadas em estradas secundárias, municipais ou rurais, o que permite presumir que a maior parte delas sejam pontes de pequenos vãos.

A necessidade de construções mais duráveis e que requeiram o mínimo de manutenção, associado a um melhor comportamento estrutural, tem levado recentemente os projetistas a optarem por pontes sem juntas.

Em recentes trabalhos, BURKE (1990) e GREIMANN (1989) discutem sobre a tendência atual de implantação dessas obras, questionando-se aspectos de projeto e até mesmo 
soluções para se converter pontes com juntas nas denominadas pontes integrais.

o presente trabalho é voltado para as pontes rodoviárias, porém, excetuando-se algumas aplicações específicas, aplica-se também a outros tipos de pontes.

Utiliza-se, no decorrer do trabalho, a denominação "ponte em viga" e "ponte em pórtico" para a classificação do sistema estrutural da superestrutura, diferenciando-se da classificação quanto à seção transversal de "ponte de laje" e "ponte de viga".

\section{2 - OBJETIVOS}

Visando associar os benefícios da utilização de elementos pré-moldados em pontes de pequenos vãos àqueles obtidos com a construção sem juntas, tem este trabalho os seguintes objetivos:

a) apresentação de um tipo construtivo de ponte de pequeno vão com utilização de elementos pré-moldados na superestrutura ligados rigidamente à infraestrutura, o desenvolvimento de uma metodologia de cálculo e as verificações necessárias ao caso;

b) comparação dos custos diretos, através de um exemplo desenvolvido, do tipo construtivo escolhido com uma ponte similar em viga (sistema isostático);

c) comparação dos esforços obtidos através do procedimento de cálculo apresentado (aproximado) com os mesmos obtidos através da utilização do método dos elementos finitos.

\section{3 - APRESENTAÇÃO DO TRABALHO}

o trabalho está dividido em seis capítulos e quatro anexos descritos a seguir.

No capítulo 1 é feita a introdução, enunciados os objetivos e descrita a apresentação do trabalho.

No capítulo 2 é apresentado uma descrição dos tipos 
de pontes existentes, destacando-se os sistemas estruturais comumente empregados e as seções transversais das vigas pré-moldadas utilizadas.

o capítulo 3 é destinado à descrição do tipo construtivo escolhido, ponte em pórtico de pequeno vão com superestrutura formada de elementos pré-moldados, procurando-se justificar a escolha do sistema estrutural e da seção transversal da viga pré-moldada. Discute-se também sobre alguns problemas relativos à utilização de seções compostas de concreto/concreto.

No capítulo 4 é apresentada uma metodologia para o cálculo de pontes de concreto armado tanto para o tipo construtivo escolhido quanto para um similar em viga (sistema estrutural isostático).

No capítulo 5 um exemplo é desenvolvido para ambos os sistemas estruturais discutidos no capítulo 4. Uma comparação entre os consumos de materiais é feita para a análise dos custos diretos da obra. Os esforços (momentos fletores) devidos ao carregamento móvel são comparados com os esforços obtidos com a utilização do Método dos Elementos Finitos.

conclusões e sugestões.

- capítulo 6 destina-se à apresentação de Quatro anexos são desenvolvidos com $\circ$ conteúdo descrito a seguir:

Anexo A - dimensionamento de aparelhos de apoio elastoméricos segundo O SERVICE CENTRAL D'ETUDES TECHNIQUES;

Anexo B - gráficos de iso-momentos obtidos com o cálculo utilizando o Método dos Elementos Finitos (ítem 5.5);

Anexo C - detalhamento das estruturas utilizando os esforços obtidos no capítulo 5 (método aproximado).

Anexo D - gráficos de momentos fletores e forças cortantes (método aproximado) para as duas alternativas estudadas, devidos aos vários carregamentos a que estão submetidas (Tabelas 5.4, 5.6 e 5.13). 


\section{2 - TIPOLOGIA DAS PONTES DE PEQUENOS VÃOS COM UTILIZAÇÃO DE ELEMENTOS PRÉ-MOLDADOS NA SUPERESTRUTURA}

\section{1 - INTRODUÇÃO}

Uma das maiores aplicações de pré-moldados de fábrica no Brasil está na construção de superestruturas de pontes. Entretanto essas aplicações ainda estão aquém daquelas de outros países mais desenvolvidos, como os Estados Unidos da América (EUA) e a Inglaterra, onde já existe uma padronização de elementos [PCI (1975) e SOMERVILLE (1971)].

Em trabalho sobre substituições de pontes no estado de Minnesota, EUA, HILL \& SHIROLE (1984) concluem existir uma tendência definitiva em não se realizar construções que exijam: trabalho e tempo excessivos, optando-se pela utilização da pré-moldagem em relação a construção moldada no local. O levantamento realizado pelos autores op cit, baseado em 3692 substituições no período de 11 anos, indicou que as vigas pré-moldadas protendidas são comumente utilizadas nas rodovias estaduais, sendo que as seções que possibilitam a eliminação de fôrmas para a constituição do tabuleiro (seções tipo $T)$, mostraram-se mais econômicas que as demais. Além disso, as menores alturas destas seções possibilitam a redução do trabalho de movimento de terra nas rampas de acesso à ponte. Para vãos de até 15 metros o governo do estado de Minnesota, EUA, tem adotado estruturas do tipo laje 
moldada no local. Embora estas estruturas sejam economicamente viáveis, o trabalho dispendido com fôrmas e escoramento torna a sua execução lenta e os problemas com a cura e o controle de qualidade em campo também estão presentes [HILL \& SHIROLE (1984)].

SOMERVILLE (1971), a partir de estudos comparativos de custos entre diferentes tipos de construções com vãos entre 12 e 18 metros, diz ser muito difícil obter dados reais de custo partindo-se de realizações práticas prévias, podendo-se, no entanto, observar certas tendências gerais:

- para vãos de até 18 metros construções com laje maciça oferecem maior economia;

- para casos em que não se tem exigências especiais para minimizar a interferência do tráfego por baixo da ponte, 0 tabuleiro de concreto moldado no local é preferível sendo que naqueles casos em que se dá tal exigência ou em que os trabalhos provisórios devam reduzir-se ao mínimo, o tabuleiro misto empregando vigas com seção $T$ invertida, resulta-se, geralmente, mais econômico.

Ainda segundo SOMERVILLE (1971), a máxima economia conseguida com a utilização de pré-moldados resulta da industrialização das vigas, devendo-se haver intima colaboração entre projetista e fabricante.

\section{2 - SISTEMAS ESTRUTURAIS}

\subsection{1 - CONSIDERAÇÕES PRELIMINARES}

$\mathrm{Na}$ concepção dos sistemas estruturais deve-se observar dois aspectos: construtivos e estruturais. Para 0 caso de estruturas pré-moldadas de concreto, na maioria das vezes, os aspectos construtivos preponderam sobre os aspectos estruturais. Isto porque a concepção do sistema estrutural deve objetivar facilidade de execução, manuseio e transporte dos elementos pré-moldados e facilidade de montagem e execução das ligações destes elementos para formar a estrutura. 
Face a importância dos aspectos construtivos, os sistemas estruturais empregados em estruturas pré-moldadas de concreto nem sempre são aqueles mais apropriados às estruturas moldadas no local. Dessa forma, escolhe-se normalmente para sistemas estruturais formados a partir de elementos pré-moldados, aqueles obtidos a partir de ligações mais simples. Isto, no entanto, acarreta certos inconvenientes, como a necessidade de utilização de juntas, sem dúvida alguma, indesejáveis a qualquer tipo de ponte.

\section{BURKE (1990) discute sobre a construção de pontes} sem juntas, denominadas pontes integrais, nos Estados Unidos da América (EUA) e Canadá. Em breve relato sobre a evolução dos projetos e construções de pontes, ele comenta sobre a utilização do elastômero no fechamento de juntas do tabuleiro, instalado pela primeira vez no início dos anos sessenta em pontes dos EUA. Desde os primeiros usos, numerosos tipos de juntas de elastômero foram desenvolvidas visando o fechamento tanto efetivo quanto durável. A maioria dos projetos desapontaram, pois algumas juntas necessitaram maior manutenção que as pontes originais sem o elastômero, levando os engenheiros a buscar novas opções.

A análise dos custos de vários tipos de pontes tem mostrado diferenças marcantes. Entretanto, para duas pontes construídas essencialmente iguais, exceto que uma foi concebida com encontros separados e juntas de tabuleiro e a outra com encontros integrais, a ponte com juntas era usualmente mais cara. Soma-se o fato de que muitas pontes construídas com juntas nos encontros foram e ainda estão sendo seriamente danificadas com as pressões geradas pela pavimentação. Consequentemente mais engenheiros passaram a apreciar os méritos das pontes integrais para pontes de pequenos a médios vãos.

A continuidade conseguida por essas construções irá sujeitar a superestrutura a tensões causadas pela resposta da mesma à fixação da infraestrutura, aos gradientes e às mudanças de temperatura, à retração do concreto, etc. A justificativa para a sua adoção está baseada no 
reconhecimento de que para pontes de pequenos e médios vãos, significativamente maiores danos e infortúnios tem sido causados pelo uso de juntas no tabuleiro do que pelas tensões que estas juntas pretendem previnir. A eliminação de juntas caras e aparelhos de apoio e dos detalhes e procedimentos necessários para permitir seus usos, geralmente resulta em pontes mais econômicas.

BURKE (1990) relata que comumente, em muitos estados dos EUA, as superestruturas concebidas com a utilização do concreto pré-moldado estão substituindo pequenas pontes moldadas no local. Consequentemente os problemas associados com a retração inicial do concreto estão sendo gradualmente eliminados.

Em muitos aspectos as pontes sem juntas - pontes integrais - tem tido seu desempenho relativamente às similares com juntas, mais efetivos, pois elas permanecem em serviço por longos períodos de tempo com apenas moderadas manutenções e reparos ocasionais.

A viabilidade das ligações que possibilitem a distribuição de momentos fletores deve, portanto, ser cuidadosamente analisada, considerando-se todos os aspectos positivos e negativos do caso em questão.

Os sistemas estruturais comumente empregados no projeto e construção de pontes de pequenos vãos são os de vigas, pórtico e arcos. Discute-se a seguir alguns aspectos dos sistemas estruturais em vigas e pórtico.

\subsection{2 - PONTES DE PEQUENOS VÃOS EM VIGA}

As pontes em viga caracterizam-se por apresentarem ligações que não permitem a transmissão de momentos fletores da superestrutura para a infraestrutura.

Para o emprego de elementos pré-moldados a utilização de vigas simplesmente apoiadas é a mais adequada sob o aspecto construtivo. Entretanto constituem um sistema estrutural relativamente pobre, pois fixado o comprimento do vão, restam poucas possibilidades de melhoria da distribuição 
dos esforços.

As vigas simplesmente apoidas com balanços possibilitam uma melhor distribuição dos esforços, pois introduzindo-se momentos negativos nos apoios reduz-se os momentos positivos no meio do vão. Além disso possibilitam, de uma forma simples, a eliminação dos encontros. Contudo esta solução se justificaria para vãos maiores e dificultaria a aplicação dos elementos pré-moldados e o emprego da protensão. Deve-se também tomar precauções para que não haja fuga de material nas extremidades da ponte, junto aos aterros.
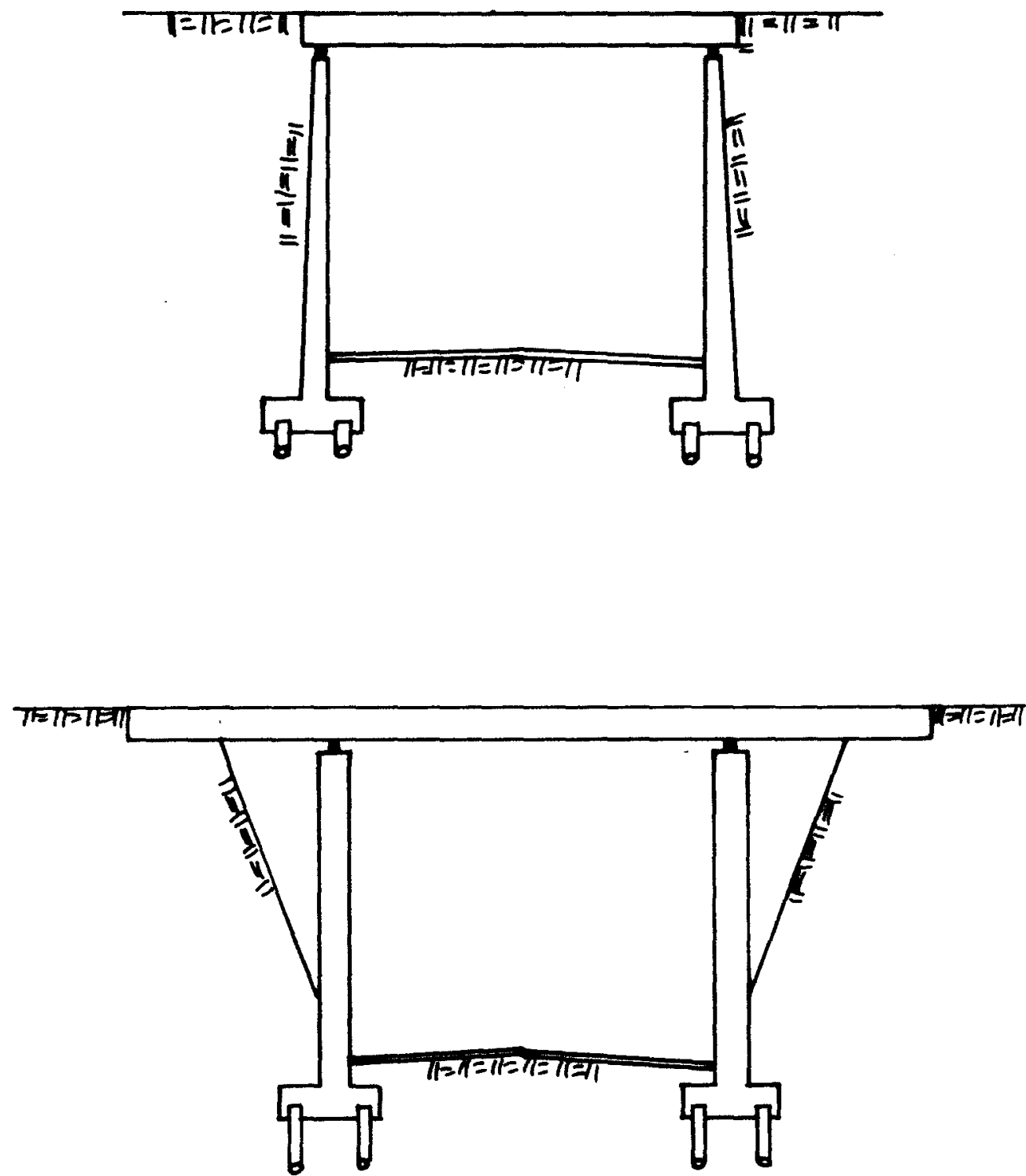

Figura 2.1 - Pontes de pequenos vãos em viga:

a) Simplesmente apoiada sem balanços;

b) simplesmente apoiada com balanços. 


\subsection{3 - PONTES DE PEQUENOS VÃOS EM PÓRTICO}

$\mathrm{Na}$ construção de pontes, os pórticos surgem pela ligação, com rigidez à flexão, das vigas da ponte (superestrutura) com as paredes dos encontros ou com os pilares (infraestrutura).

Neste tipo estrutural, parte da flexão da viga é transmitida para os pilares, o que possibilita a redução das solicitações na superestrutura à custa da flexão da infraestrutura.

pela adoção de rigidezas diferentes, pode-se influir na distribuição dos momentos fletores. No caso dos pilares do pórtico serem mais rígidos, o momento no vão é pequeno; no caso de serem mais flexíveis, o momento no vão é grande.
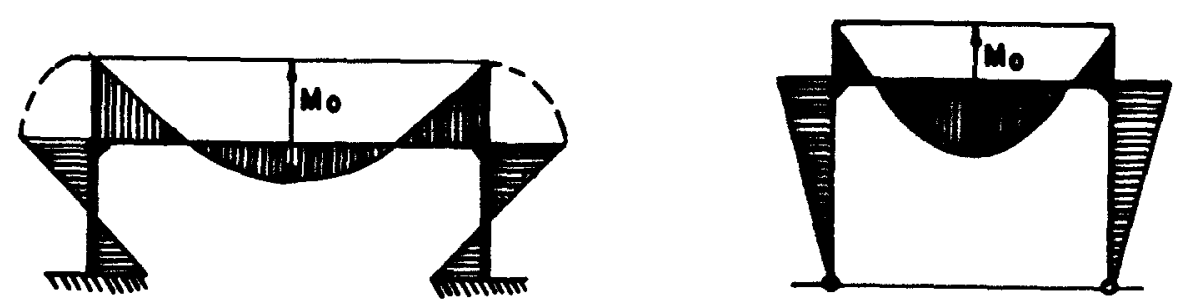

Figura 2.2 - Distribuição dos momentos fletores nos pórticos: a) bi-engastado; b) biapoiado Fonte: LEONHARDT (1979)

As alternativas possíveis dos esquemas estáticos para as pontes de pequenos vãos em pórtico são:

a) Pórtico bi-engastado - especialmente indicados para o caso de viadutos com passagem inferior e pequenas travessias. Embora de uso pouco comum no país, variações com tramos adjacentes podem ser utilizadas em viadutos sobre rodovias, aproveitando-se a seção do terreno disponível e vencendo vãos relativamente maiores;

b) pórtico biarticulado - com aplicações análogas ao bi-engastado. É possível que existam tramos adjacentes 

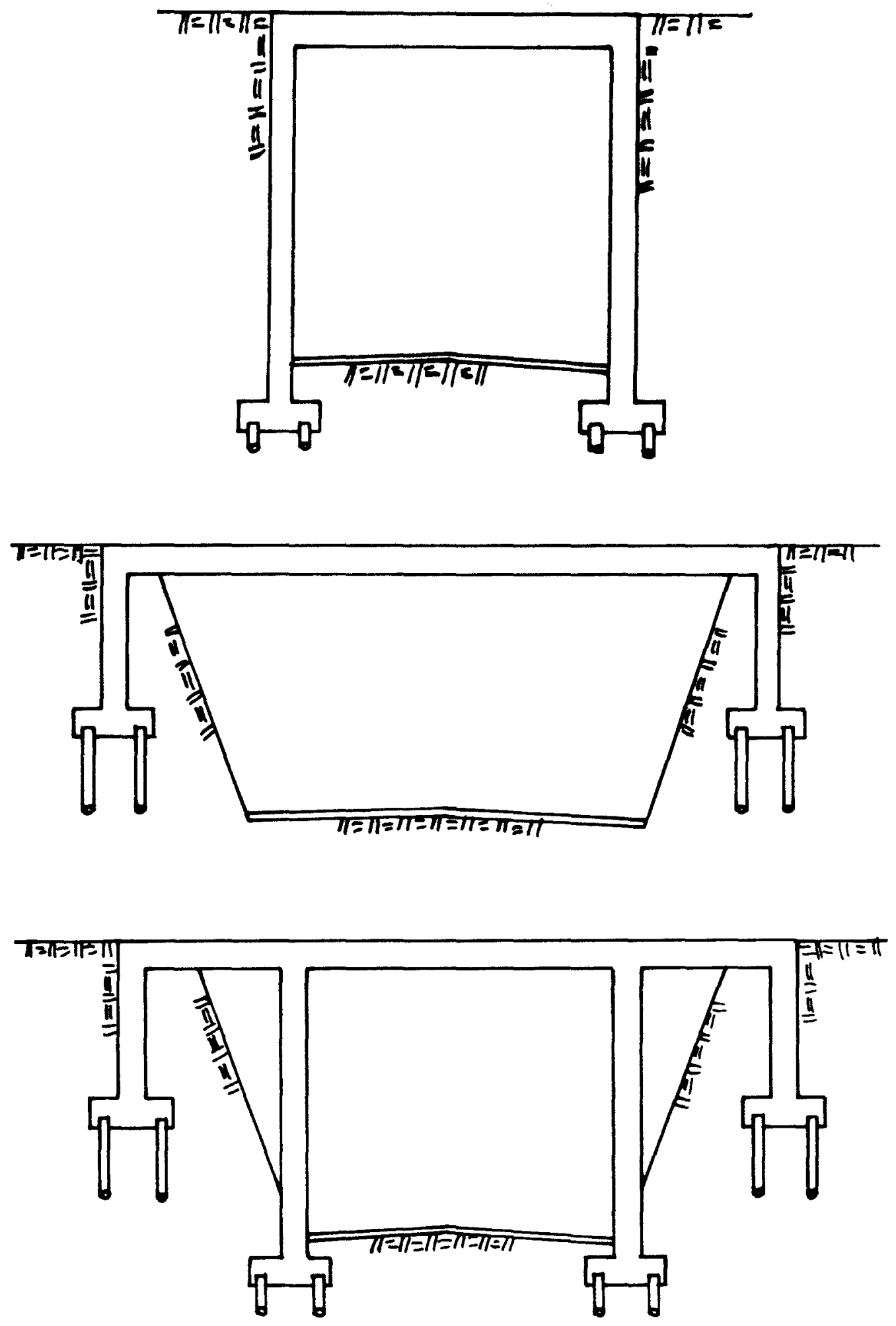

Figura 2.3 - Pórticos engastados 
apoiados, conforme o caso anterior. As articulações são na maioria das vezes, apenas articulações elásticas (com forte armadura de cintamentol;
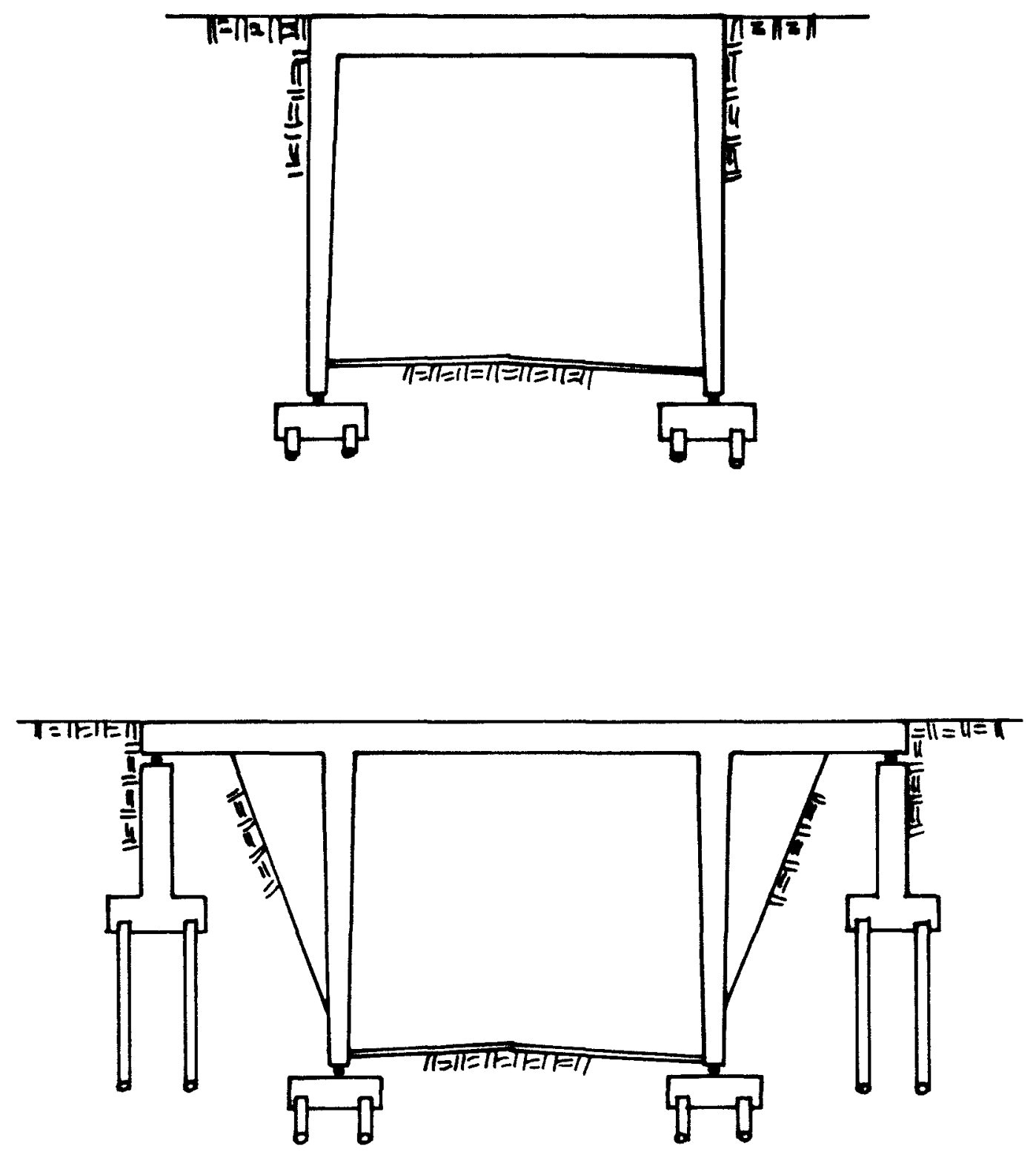

Figura 2.4 - Pórticos articulados 
c) pórticos fechados ou quadros - são adequados para passagens inferiores, sobre terrenos de muito má qualidade. Podem ser de uma ou mais células e são utilizados para vãos bastante pequenos.
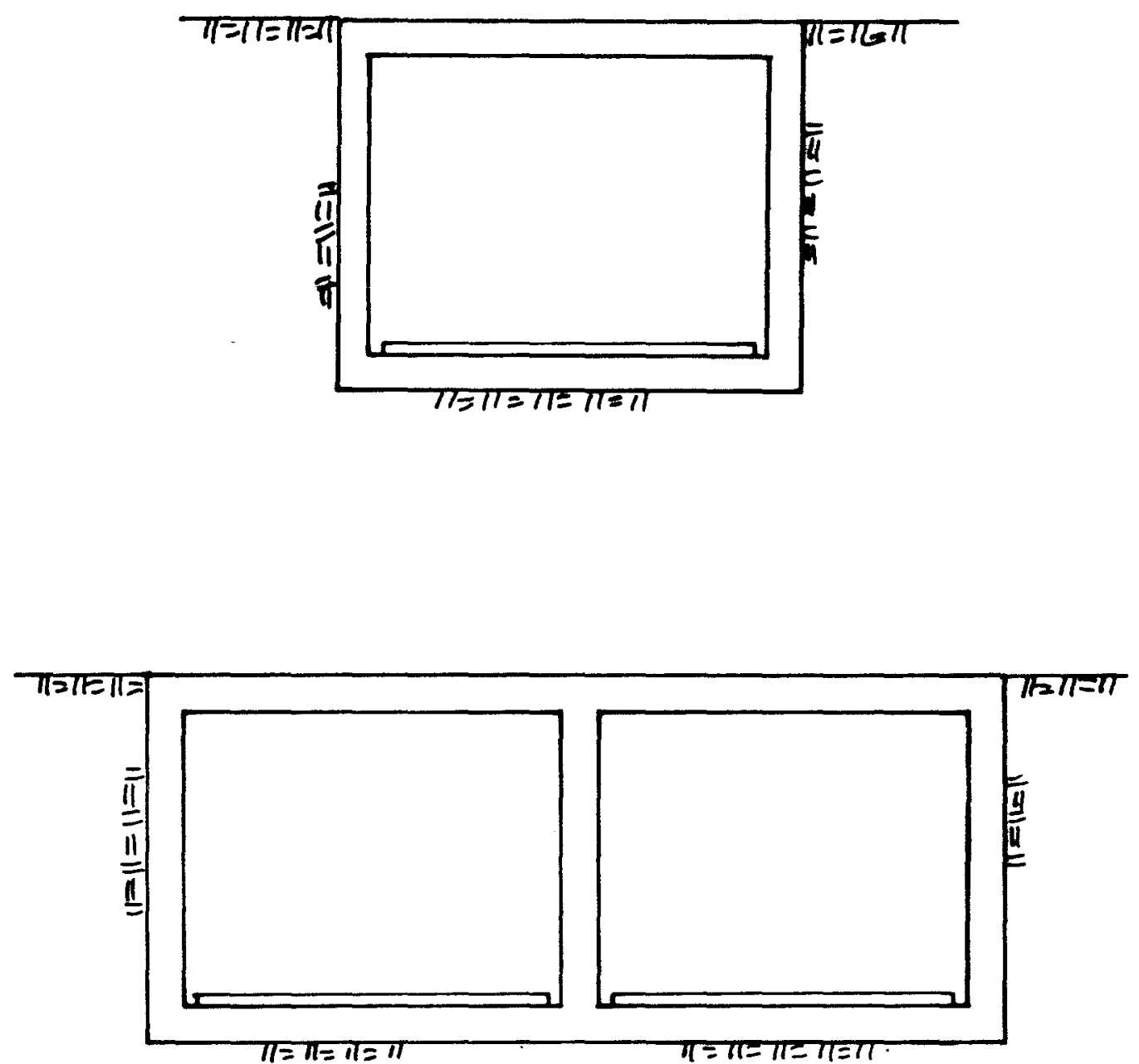

Figura 2.5 - Pórticos fechados 


\section{3 - SEÇÕES TRANSVERSAIS}

- tabuleiro de uma ponte, na sua integridade, é muito difícil de se prefabricar. Isso leva a uma partição ou divisão de elementos, que possibilitem o seu transporte $e$ montagem, e a uma posterior solidarização para formar a ponte completa.

Tradicionalmente tem-se optado por uma partição paralela ao eixo da ponte devido as vantagens resistentes, originando-se as vigas cuja dimensão preponderante é a longitudinal. Existem casos em que a dimensão preponderante escolhida é a transversal, como na adoção de aduelas para balanços sucessivos, não sendo a preferível para os vãos $e$ tipos estruturais a que se destina o presente trabalho.

$\mathrm{Na}$ escolha da seção transversal das vigas deve-se optar por aquela que maior economia ofereça. Segundo KONCZ (1975), a maior ou menor economia das seções de vigas submetidas à flexão é avaliada pelo material necessário e pelo custo de sua produção.

- custo de sua produção depende do tamanho da série, do grau de dificuldade de execução do elemento e do seu tamanho e peso.

o total aproveitamento do material utilizado em um elemento resistente tem sido sempre uma das metas dos projetistas. A seção é tanto mais econômica quanto maiores forem os momentos fletores resistidos com igual área de seção transversal de armadura.

Basler desenvolveu um índice de rendimento para $\circ$ estudo de seções de concreto protendido de iguais alturas [KONCZ (1975)]. Ele é definido a partir do parâmetro m, obtido da seguinte forma:

$$
\mathrm{m}=\frac{\mathrm{M}}{\mathrm{h} g}
$$

onde :

$M=$ momento resistente da seção; 
$h=$ altura da seção;

$g=$ peso do elemento por unidade de comprimento

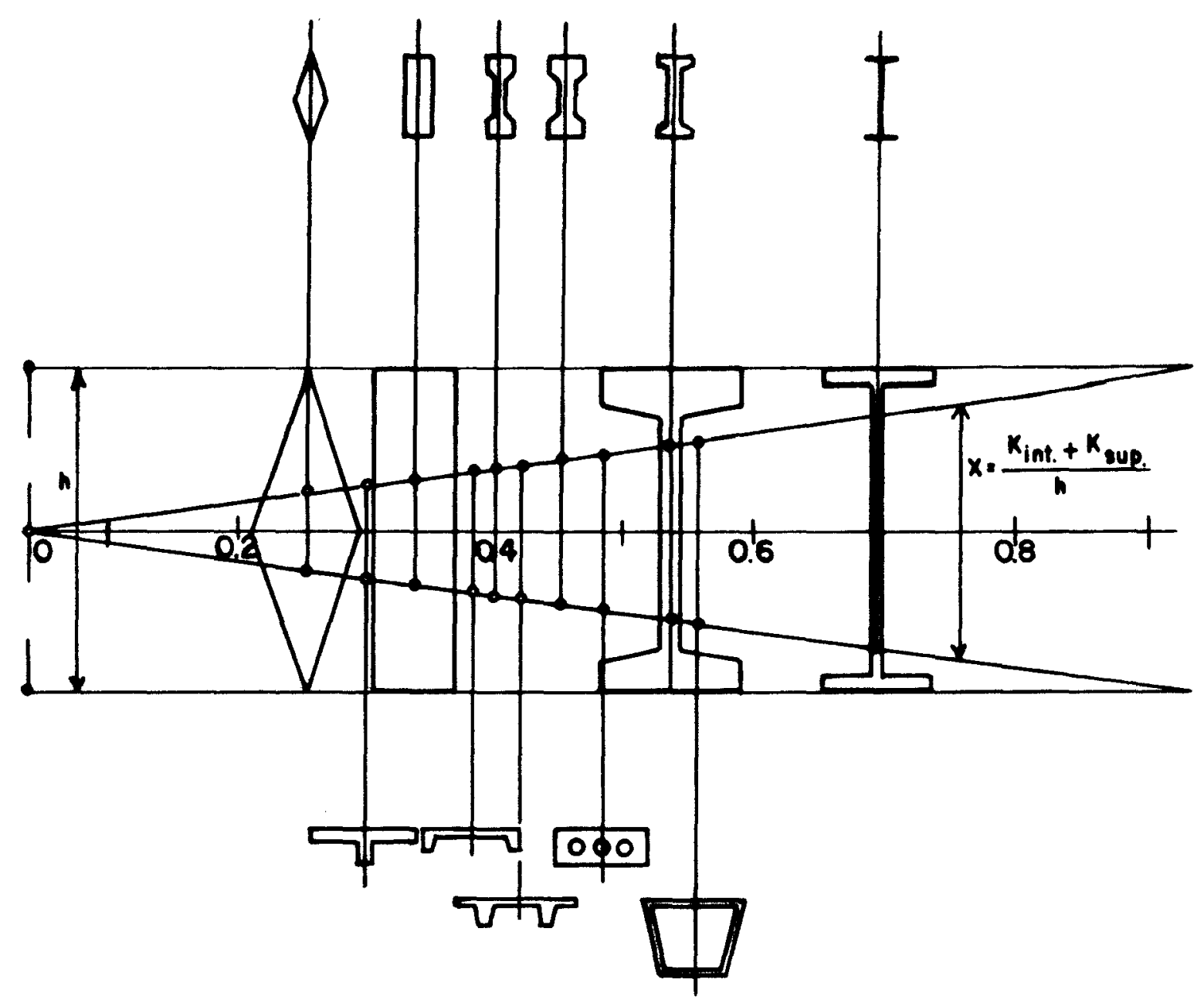

Figura 2.6 - Rendimento mecânico de algumas seções transversais

Fonte: KONCZ (1975)

Admitindo-se comportamento elástico linear do material composto, o valor de $m$ pode ser expresso da seguinte maneira:

$$
m=\frac{\sigma}{2 \gamma} \kappa
$$

sendo:

$$
\kappa=\frac{k_{\text {inf }}+k_{\text {sup }}}{h}
$$

onde:

$\kappa$ = rendimento mecânico da seção; 
$k_{\text {inf }}+k_{\text {sup }}=$ distâncias das extremidades do núcleo central ao centróide da seção;

$\sigma=$ tensão admissível determinada em função da resistência do concreto;

$\gamma=$ peso específico do material composto.

0 coeficiente de rendimento $k$ depende somente da geometria da seção transversal. A variação do seu valor para algumas seções transversais pode ser observada na Figura 2.6.

As pontes são normalmente classificadas, quanto à seção transversal, em pontes de laje e pontes de vigas. Deve-se, no entanto, lembrar que em consequência da partição do tabuleiro as pontes pré-fabricadas são caracterizadas por um grande número de elementos unidos. Desse modo, a distribuição das cargas concentradas entre os distintos elementos que a compõem conduz a uma disposição construtiva que favoreça esta distribuição. Isto permitirá reduzir os esforços suportados por cada elemento, com as consequentes economias em material e peso próprio. Por outro lado a melhor solidarização entre os elementos para se conseguir uma distribuição equilibrada, somente se consegue incrementando-se o trabalho em obra, que é onde se realiza a união dos elementos pré-fabricados.

A forma das ligações transversais pode então conferir comportamento estrutural variando do das pontes de laje até o do das pontes de vigas.

As principais seções transversais dos elementos que utilizam o concreto armado ou protendido e a forma de se prover a ligação entre eles são apresentadas a seguir [Fernandez Ordoñez, Fernandez Casado, Leonhardt, PCI, Sommerville apud El Debs (1991)]:

a) Seção retangular maciça (Figura 2.7) - de fabricação e montagem muito simples podendo-se prever bancadas de fabricação com largura variável possibilitando adaptação a qualquer largura de tabuleiro. Possui elevado peso por $\mathrm{m}^{2}$, - que limita a sua aplicação a vãos bastante pequenos; 


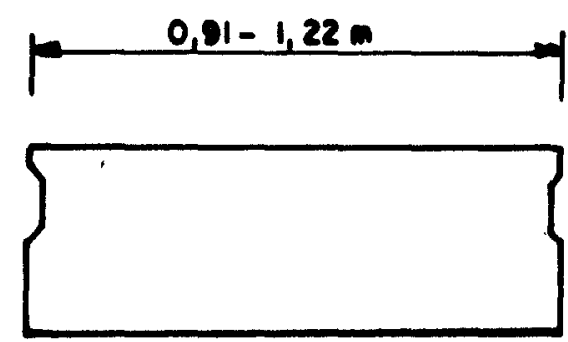

Vos ate $9,1 \mathrm{~m}$

101

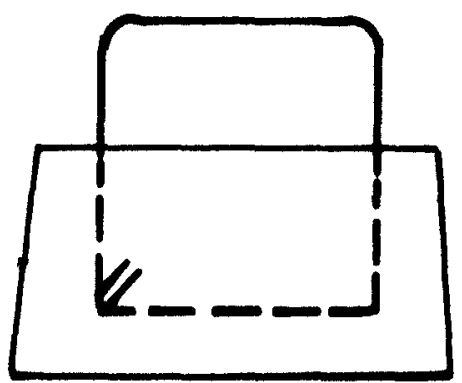

101

TIPOS DE ELEMENTOS

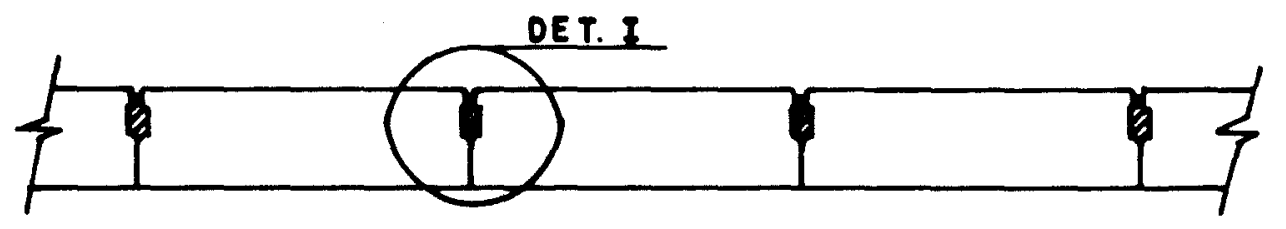

(c) 1
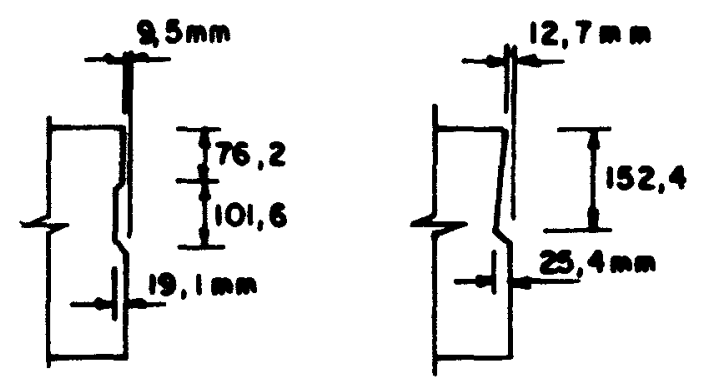

OETALNE I

TIPOS DE JUNTAS

chaves de CISALHAMENTO

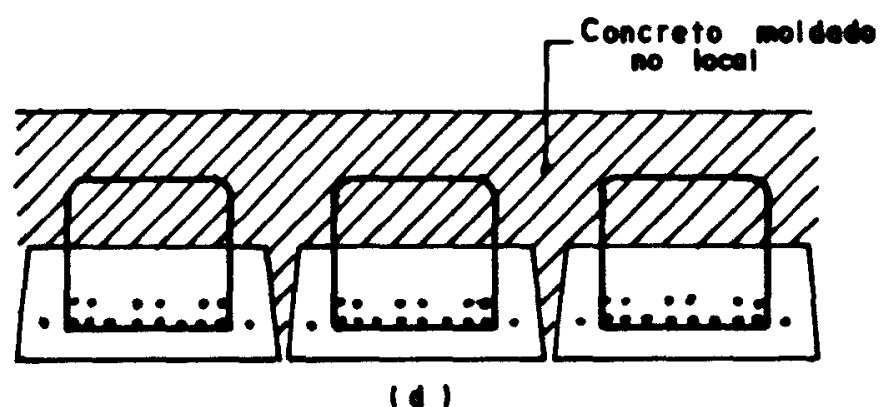

ARRANJO DOS ELEMENTOS

Figura 2.7 - Elementos pré-moldados de seção retangular maciça. Fonte: (a) e (c) PCI (1975); (b) e (d) FERNANDEZ CASADO (1965) 
b) seção retangular vazada (Figura 2.8) - os vazamentos proporcionam maiores valores de rendimento mecânico que as seções do caso anterior, entretanto continuam sendo muito pesadas e, segundo FERNANDEZ ORDOÑEZ et alli (1974), não conseguem competir com as seções de vigas para vãos maiores que 10 metros. Pode-se obter os vazamentos a partir de fôrmas perdidas, tubos infláveis ou por meio de extrusão, sendo que as duas últimas alternativas inviabilizam o emprego de diafragmas;

c) seção caixão (Figura 2.9)- possui flexibilidade para vencer vãos variáveis adequando-se sua altura ou separando-se as vigas, sendo que esta última alternativa anula as principais vantagens da seç̃o relativas à facilidade de execução. Possui altos índices de rendimento mecânico porém apresenta certas dificuldades construtivas necessitando de 2 etapas de concretagem. O vazamento é obtido com formas perdidas ou através de procedimentos sofisticados. Podem ou não ser concebidas com diafragmas em suas extremidades sendo mais comum a última opção. Existem variações como a seção trapezoidal vazada e a seção com dois vazamentos, raramente empregadas;

d) seção $T$ e suas variações (Figura 2.10) - as seções T, TT, múltiplos $T$ e canal são de fabricação simples, de fácil desforma e com flexibilidade para variar a altura. Por possuirem a laje incorporada são pesadas e possuem 0 centro de gravidade da seção alto, o que causa inconvenientes para a situação em vazio (peso próprio e protensão antes das perdas), no caso de concreto protendido. Existe ainda a seção $U$ invertido, que pode ser considerada como mais uma das variações da seção $\mathrm{T}$;

e) seção duplo T (Figura 2.11) - também chamada de seção I e seção "bulb tee", dependendo da variação das larguras das mesas inferior e superior. Possuem altos indices de 

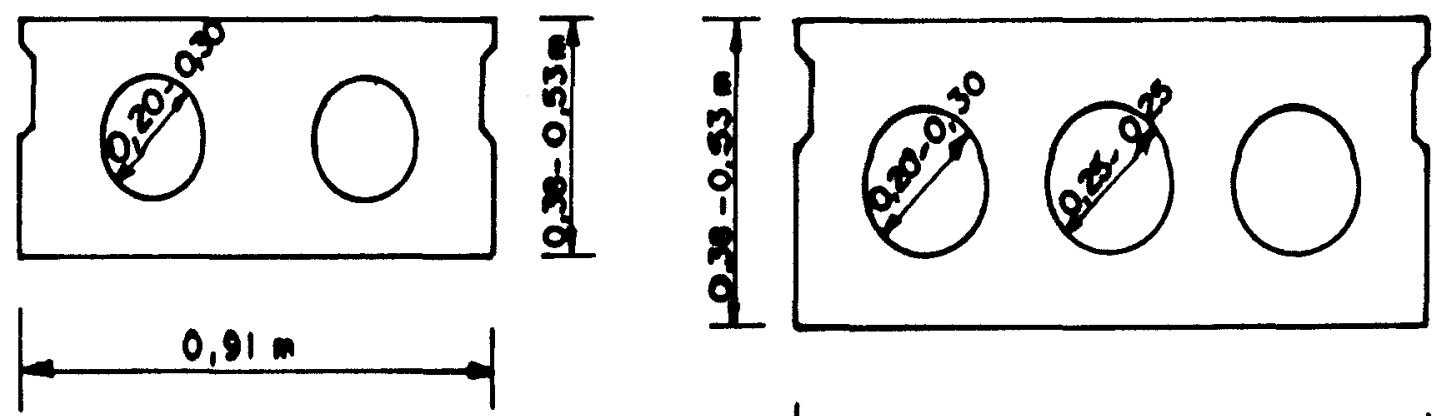

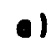

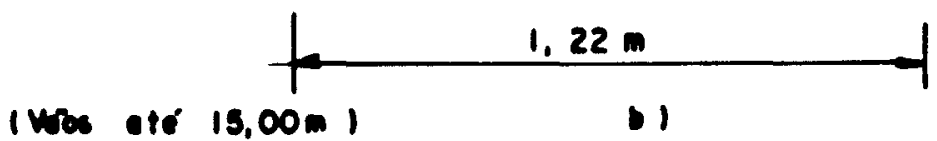

TIPOS DE ELEMENTOS

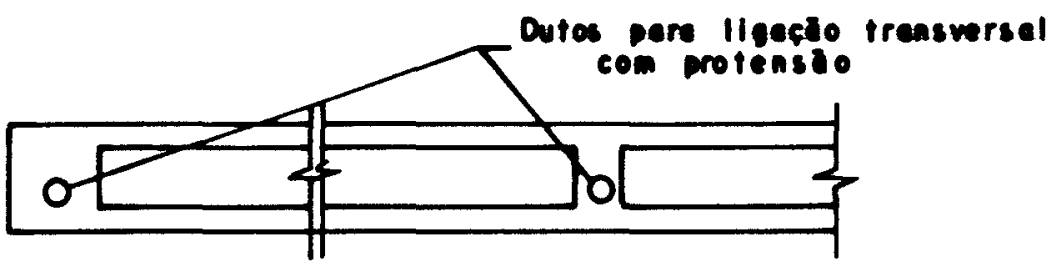

c) alternativa de seç̃o longitudinal

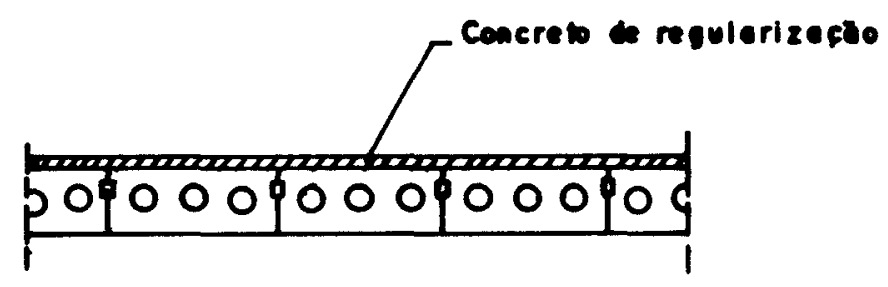

1

ARRANJO DOS ELEMENTOS

Figura 2.8 - Elementos pré-moldados de seção retangular vazada. Fonte: PCI (1975) 

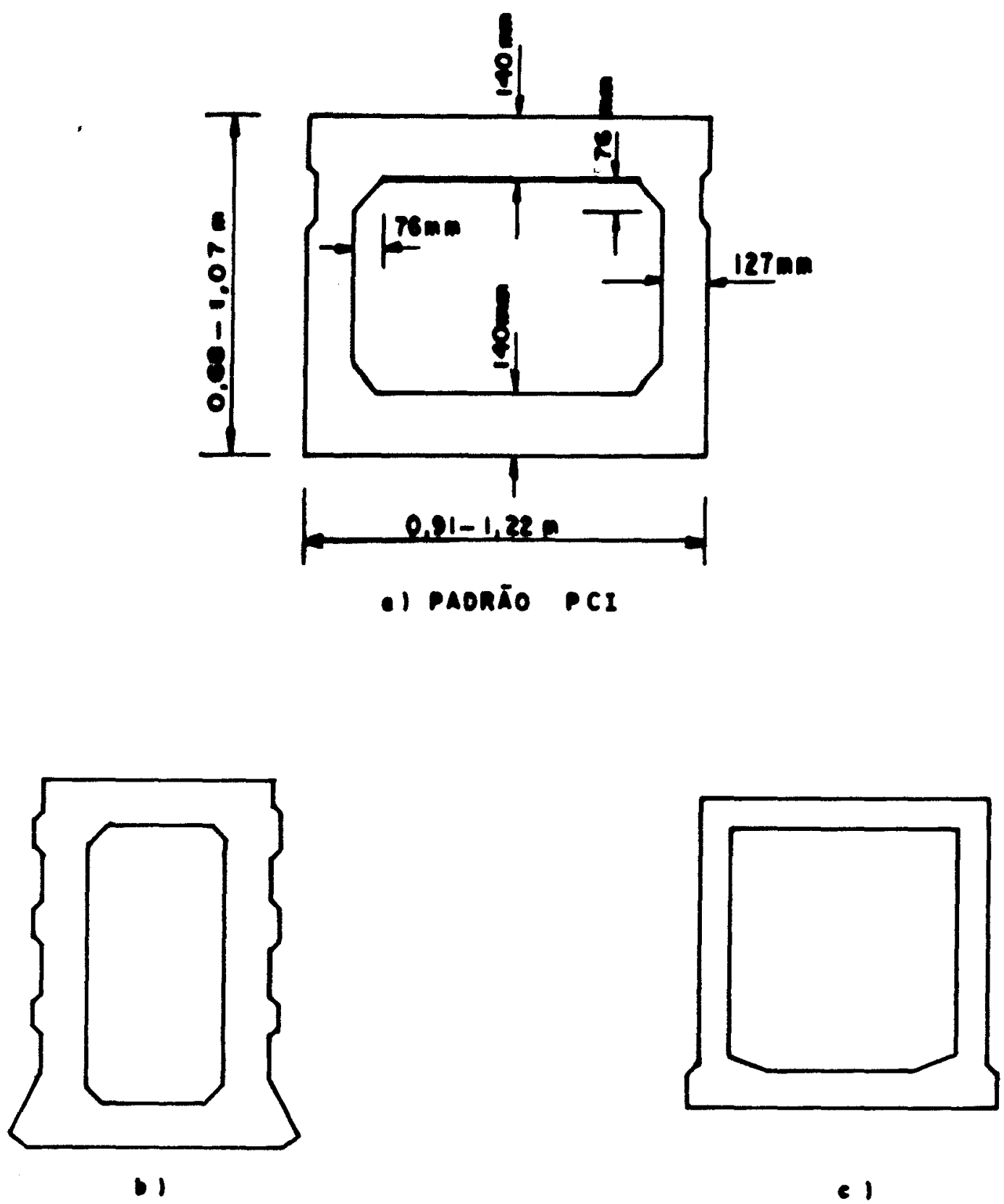

e 1

TIPOS OE ELEMENTOS
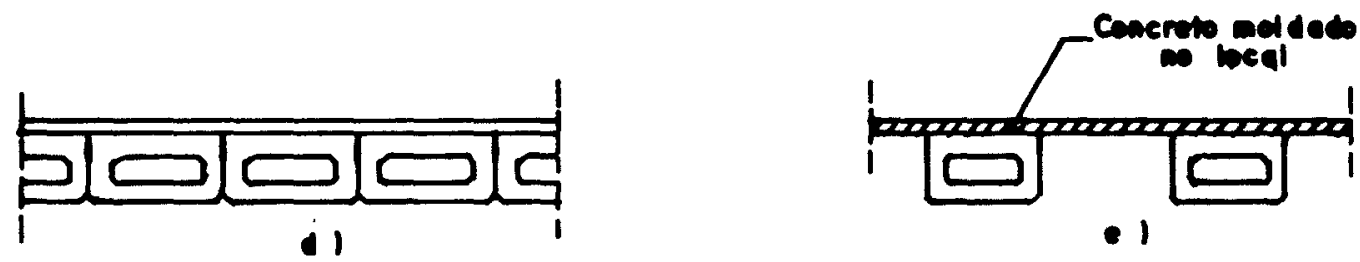

ARRANJO DOS ELEMENTOS

Figura 2.9 - Elementos pré-moldados de seção caixão Fonte: (a) PCI (1975); (b) e (c) FERNANDEZ ORDONEZ et al1i (1974) 


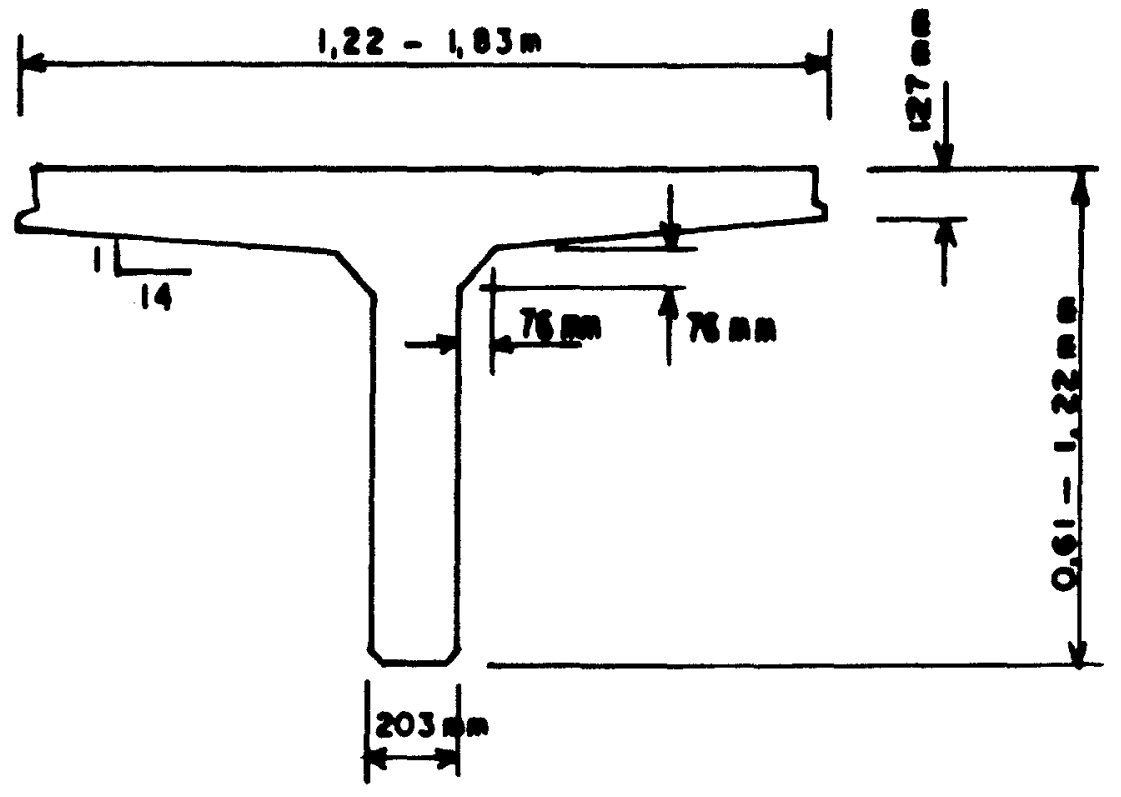

- I SEçiont"i vebs ad $30 \mathrm{~m} 1$

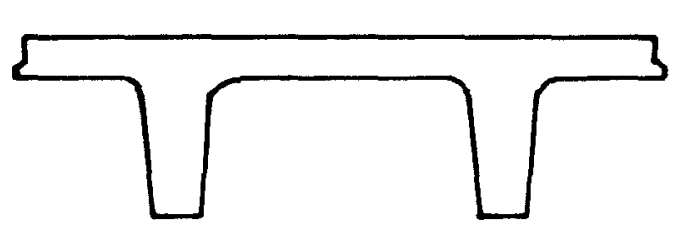

- SECÃo "tT"

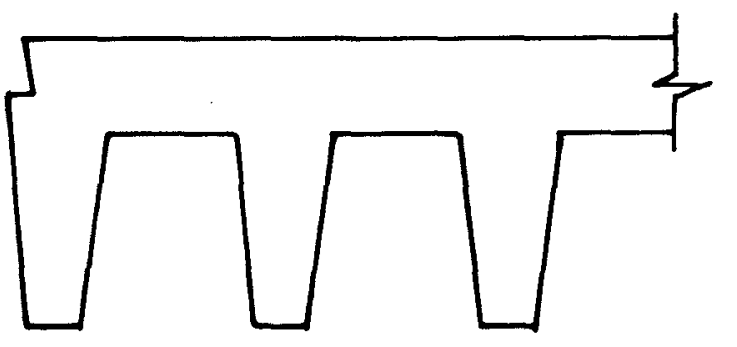

c) SEcĩo multiplos "T"
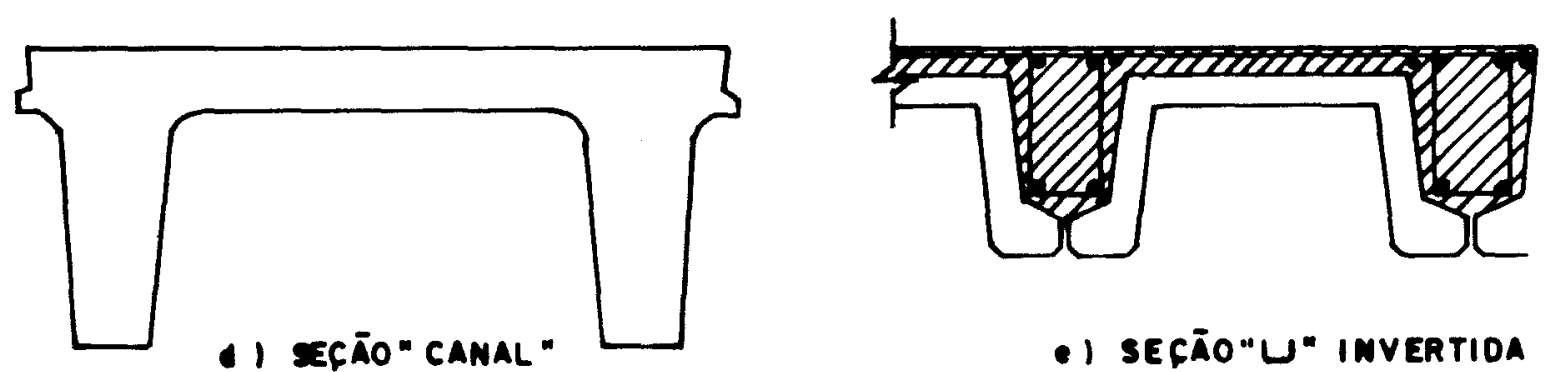

-) SECÃo"u" inVERTIDa

Figura 2.10 - Elementos pré-moldados de seção T e suas variações. Fonte: (a) a (d) PCI (1975): (e) FERNANDEZ ORDONEZ et al1i (1974) 
rendimento mecânico, sendo consideradas ideais para resistir à flexão. São largamente empregadas e cobrem uma faixa bastante grande de vãos, "entretanto a variação da altura é complicada tendo-se, normalmente, os moldes definidos em três partes: mesa inferior, alma e mesa superior;

f) seção $T$ invertido (Figura 2.12) - apresenta maiores dificuldades para fabricação em relação à seção $T$ normal. A concretagem é difícil necessitando de muita vibração e a variação da altura requer moldes múltiplos. Sua versatilidade de emprego e facilidade de realizar-se a ligação transversal entre os elementos, faz com que ela seja bastante utilizada. Podem, por exemplo, ser utilizadas para execução de lajes maciças ou vazadas.

g) seções trapezoidais e U (Figura 2.13)-podem ser vistas como variações da seção $T$ invertida, com vantagens $e$ desvantagens em relação a ela. Oferecem maior facilidade de execução do bordo do tabuleiro e necessitam de menos peças para formálo, pois podem ser mais largas. Porém possuem maiores dificuldades de fabricação e estão mais suscetíveis a danos com o transporte e a montagem. 


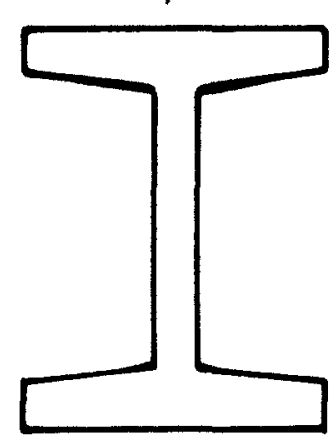

-) SEÇÃo OUPLO "T "

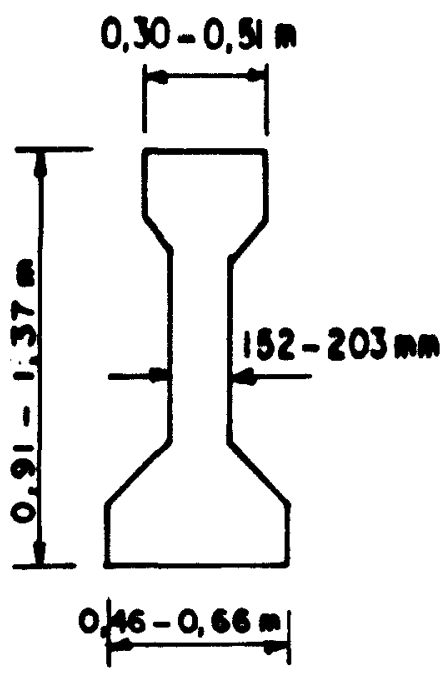

DSES̆̃̃o I"

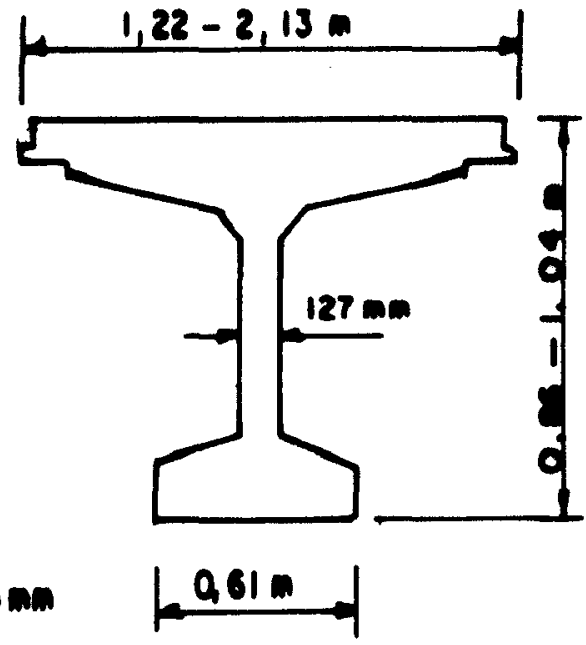

CISEÇÃo "QULO TEE"

TIPOS DE ELEMENTOS

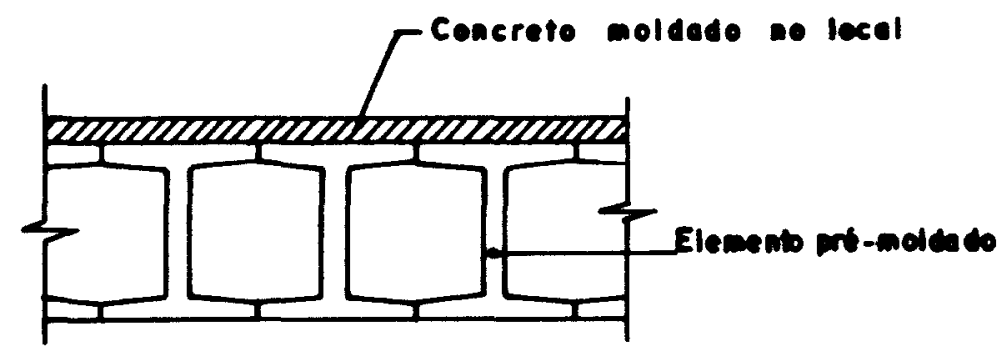

1) arramjo oe vigas de seção OUPLO"T"

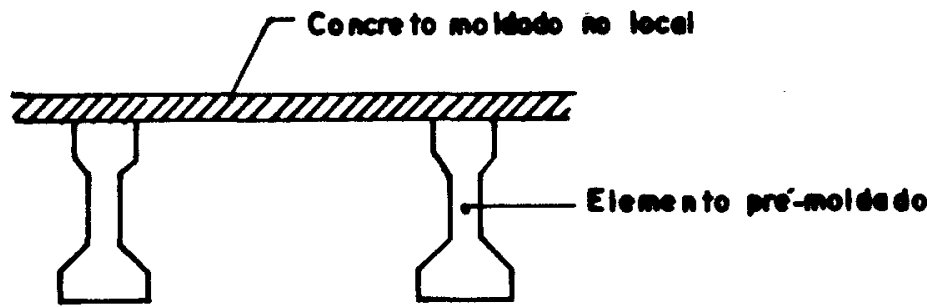

- I arranjo oe vigas ee seção "I"

Figura 2.11 - Elementos pré-moldados de seção duplo T Fonte: (a). (d) e (e) EL DEBS (1991): (b) e (c) PCI (1975) 


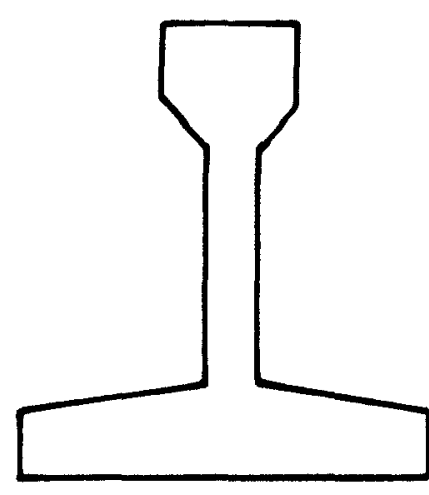

- 1

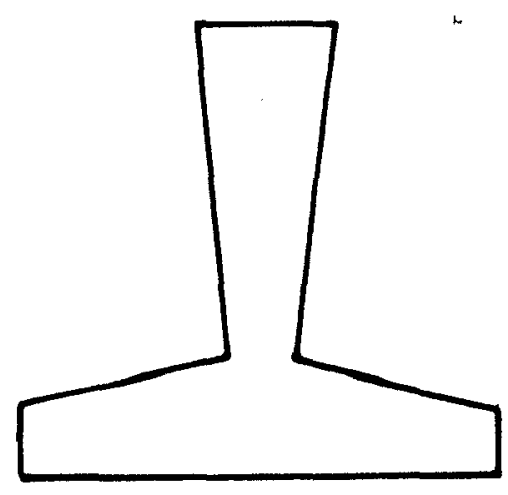

1

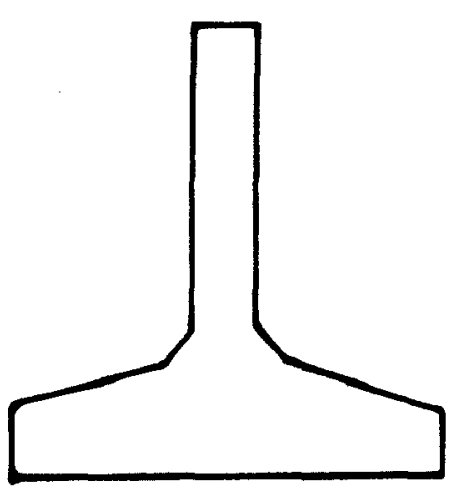

$\mathbf{1}$

TIPOS OE ELEMENTOS
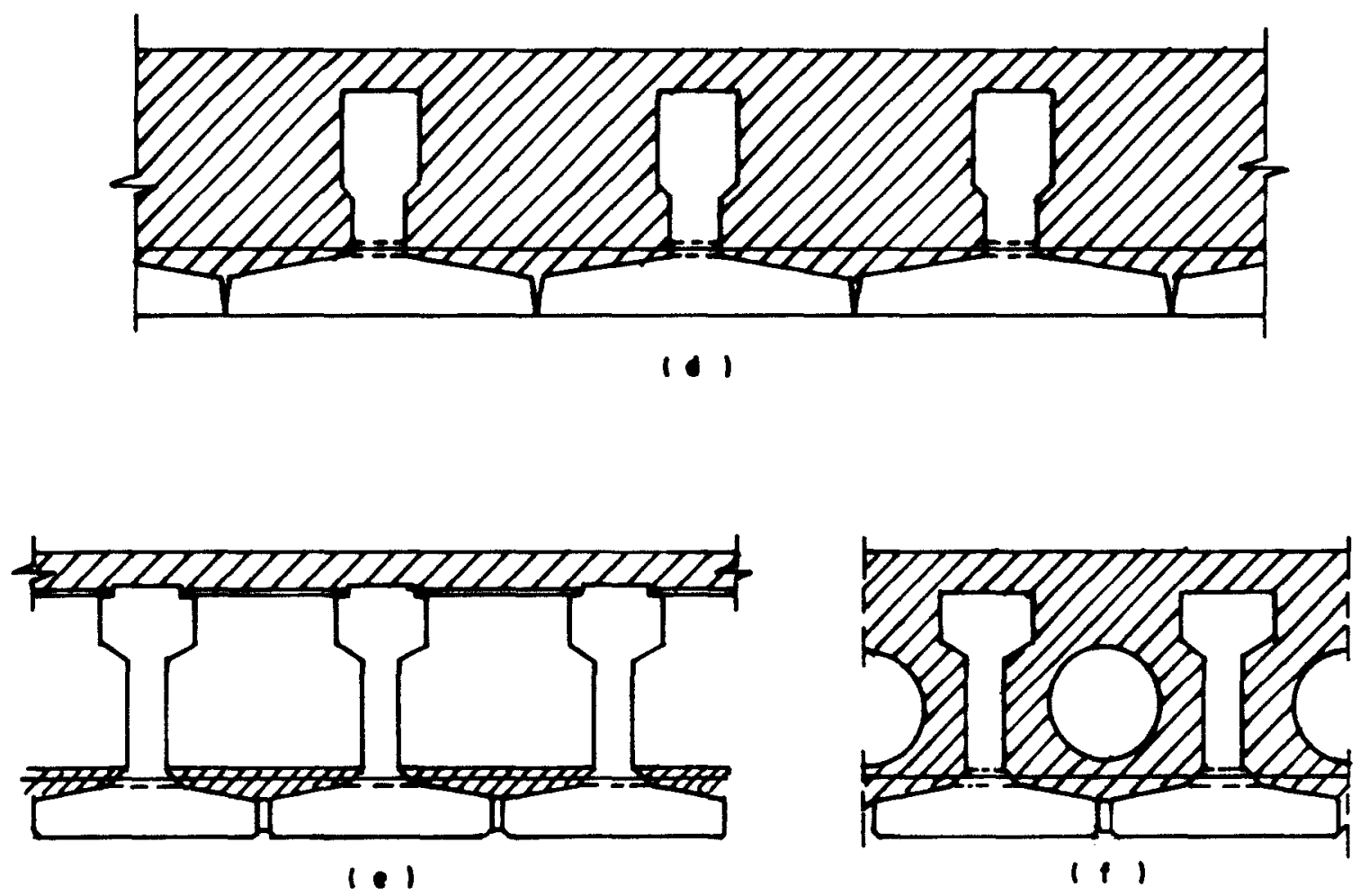

ARRANJOS DOS ELEMENTOS

Figura 2.12 - Elementos pré-moldados de seção T invertido Fonte: (a) SOMERVILLE (1971): (b) LEONHARDT (1979): (c) FERNANDEZ ORDONEZ et a11i (1974) 


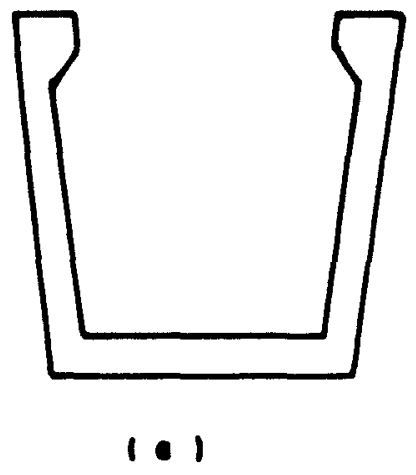

SECÃ̃o TRAPEZOIDAL
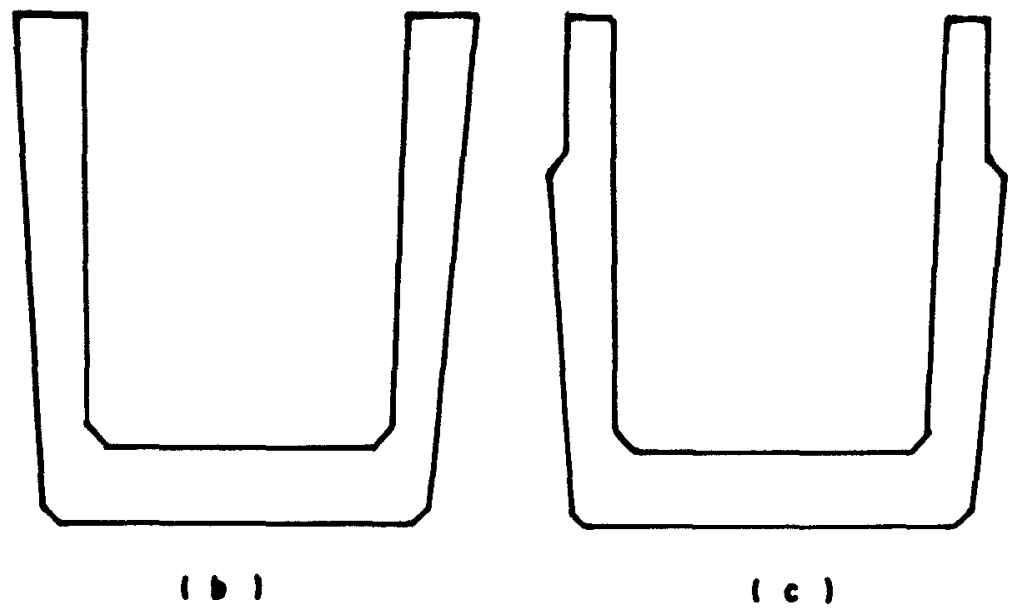

SECOËS "U"

TIPOS DE ELEMENTOS
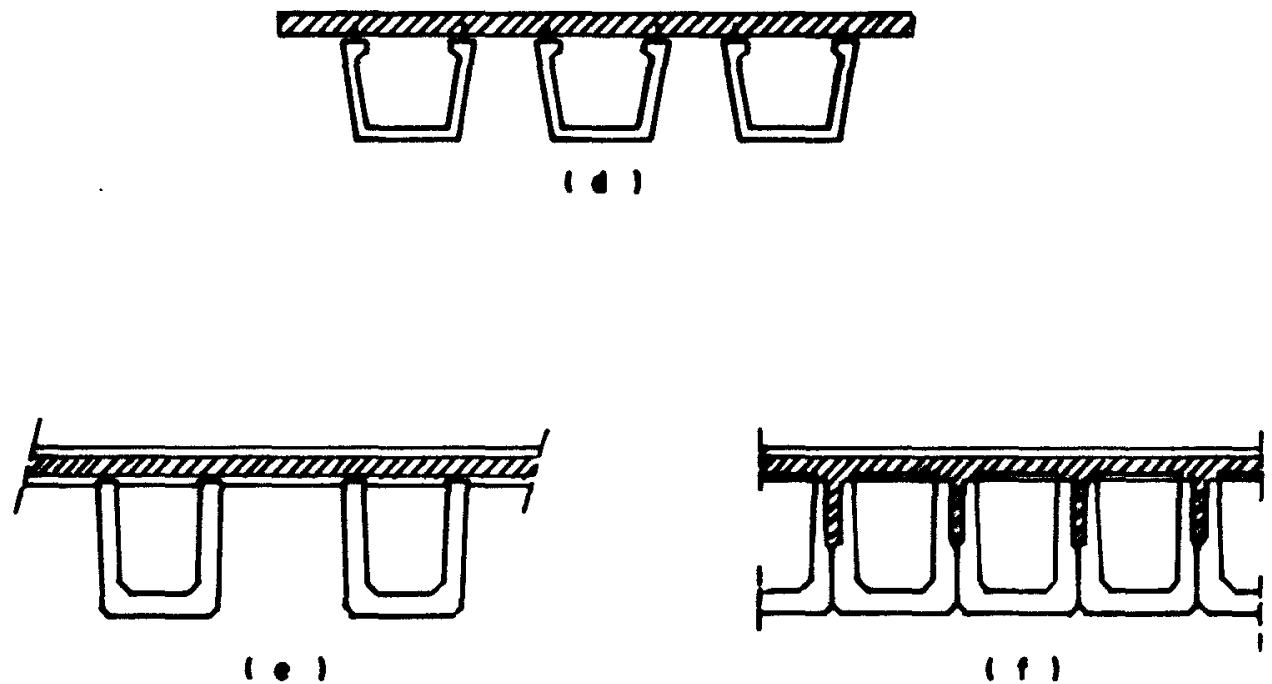

Figura 2.13 - Elementos pré-moldados de seção trapezoidal e U Fonte: (a) FERNANDEZ ORDONEZ et a 11 i (1974): (b) e (c) EL DEBS (1991) 


\section{3 - TIPO CONSTRUTIVO ESCOLHIDO}

\section{1 - INTRODUÇ̃̃o}

Adota-se no presente trabalho o sistema estrutural em pórtico com superestrutura constituída por elementos pré-moldados de seção $T$ invertido.

Procurando-se simplificar os aspectos construtivos das estruturas pré-moldadas, a adoção de ligações mais simples entre os elementos que a compõem é, na grande maioria das vezes, objetivada. Desse modo, as pequenas pontes, cuja superestrutura é formada por elementos pré-moldados, usualmente são construídas com vigas biapoiadas.

A escolha do sistema estrutural em pórtico é feita na tentativa de, a custo de maior necessidade de mão-de-obra e consequentemente de tempo, na realização da ligação entre a superestrutura e infraestrutura, obter-se economia a partir do melhor comportamento estrutural e da durabilidade da construção.

Segundo LEONHARDT (1979), para pontes pequenas (até 20 metros) de apenas um vão, a superestrutura em laje maciça é apropriada. Para pontes pequenas em pórtico, o autor op cit diz ser também a laje maciça adequada, sendo que os encontros, do mesmo modo, são constituídos por lajes maciças. Estando-se diante de ambas as situações, adota-se o 
sistema estrutural em pórtico com encontros e superestrutura em laje maciça.

E interessante salientar que do ponto de vista da estrutura esta proposta construtiva é, em princípio, tanto mais apropriada quanto menor for o vão e maior for a altura dos encontros, pois é nestas situações que mais benefícios se obtém com o uso do sistema estrutural em pórtico.

\section{2 - ESCOLHA DA SEÇÃO TRANSVERSAL dO ELEMENTO PRÉ-MOLDADO}

Tendo-se estabelecido a superestrutura em laje maciça, a escolha da secão tranversal do elemento pré-moldado que a formará fica simplificada.

Tomando-se como referência as seções apresentadas no ítem 2.3, conclui-se que aquelas que melhor servem ao presente propósito são a seção retangular maciça, a seção $T$ invertido e a seção $U$, pois todas elas possibilitam redução significativa do trabalho e gastos com formas na execução da laje. Estas seções podem ser produzidas com a armadura principal longitudinal e de combate ao cisalhamento necessárias à ponte, o que reduz o trabalho de armação na obra.

Para se conseguir a distribuição transversal das cargas e dessa forma manter o efeito de laje, são adotados procedimentos como a execução de uma capa de concreto moldado no local, a utilização de chaves de cisalhamento (shear key) e de barras de aço passantes por furos previamente executados nos elementos.

Segundo LEONHARDT (1979), os elementos pré-moldados devem ser protendidos transversalmente em conjunto, no mínimo nas proximidades dos apoios e a $\ell / 2$ ou $\ell / 3$, sendo $\ell$ o vão teórico, para se obter o efeito de laje.

A escolha da seção em $T$ invertido se faz através das próprias características desta e das demais seções (maciça e U), já discutidas no ítem 2.3. Assim, a seção em 


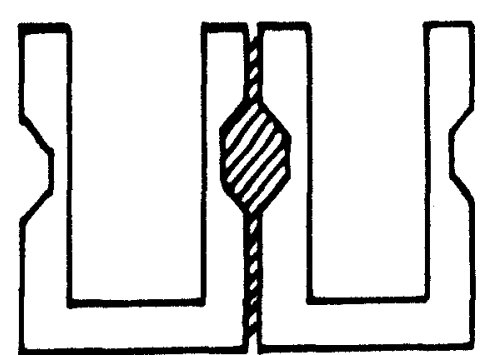

juntas chave

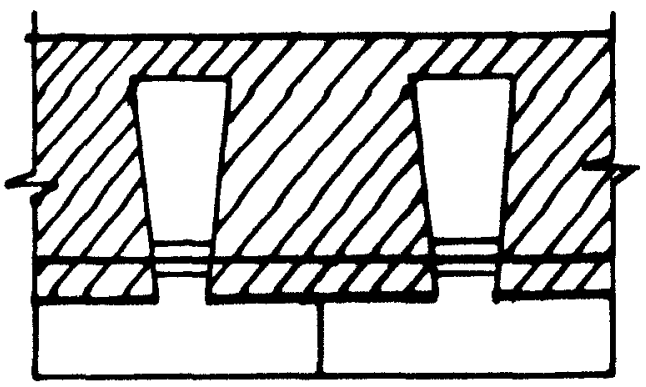

CONCRETO MOLOADO NO LOCAL E ARMAOUINA TRAMSVERSAL

Figura 3.1 - Procedimentos adotados para possibilitar a distribuição transversal das cargas

laje maciça pode causar incovenientes com $\circ$ transporte e principalmente a montagem, devido ao elevado peso próprio. A preferência pela seção $T$ invertido com relação a seção $U$ dá-se pela maior facilidade de se prover a ligação tranversal entre os elementos, possibilitando até mesmo a eliminação da protensão transversal, aliadas as vantagens com relação à fabricação, transporte e montagem. Esta seção também possibilita uma certa facilidade de se prover a ligação rígida entre a superestrutura e a infraestrutura.

Os problemas que surgem na execução dos bordos do tabuleiro e da dificuldade em se variar a altura desta seção ( $T$ invertido) são discutidos no ítem 3.5, onde analisa-se o processo construtivo para o caso em questão.

\section{3 - UNIÃO ENTRE SUPERESTRUTURA E INFRAESTRUTURA}

Um dos problemas mais difíceis, tanto no projeto como na construção de estruturas formadas por peças pré-fabricadas de concreto é o da união destas últimas. É muito importante que a construção das uniões seja cômoda e que as pequenas e inevitáveis imprecisões e desvios, dentro das tolerâncias nas dimensões, não influenciem nas tensões previstas de modo prejudicial nem produzam trocas inadmissíveis na distribuição de tensões da estrutura. 
É desejável que a estrutura esteja apta a suportar as cargas $\circ$ quanto antes possível, de preferência imediatamente após efetuar-se as uniões. No entanto esta é uma característica das uniões secas, uniões realizadas por simples colocação de duas peças uma sobre a outra, sem adição de material de ligação.

- método mais simples para se formar uma união rígida em ligações entre pilar e viga de edifícios, é, segundo MOKK (1969), através do prolongamento das barras de aço das peças a unir e, por traspasse ou solda destas, prover a continuidade da estrutura com uma adequada concretagem posterior. Este tipo de união é classificada como união úmida.

As uniões úmidas tem o caráter do material das estruturas que se unem. Seu uso evita descontinuidades entre as pecas, de modo que se conserva o caráter essencial das estruturas de concreto armado. Desse modo, as estruturas unidas mediante uniões úmidas tem o caráter monolítico. Em adição, estas uniões são mais adequadas para suportar forças maiores e são muito menos sensíveis à imprecisões que as uniões secas.
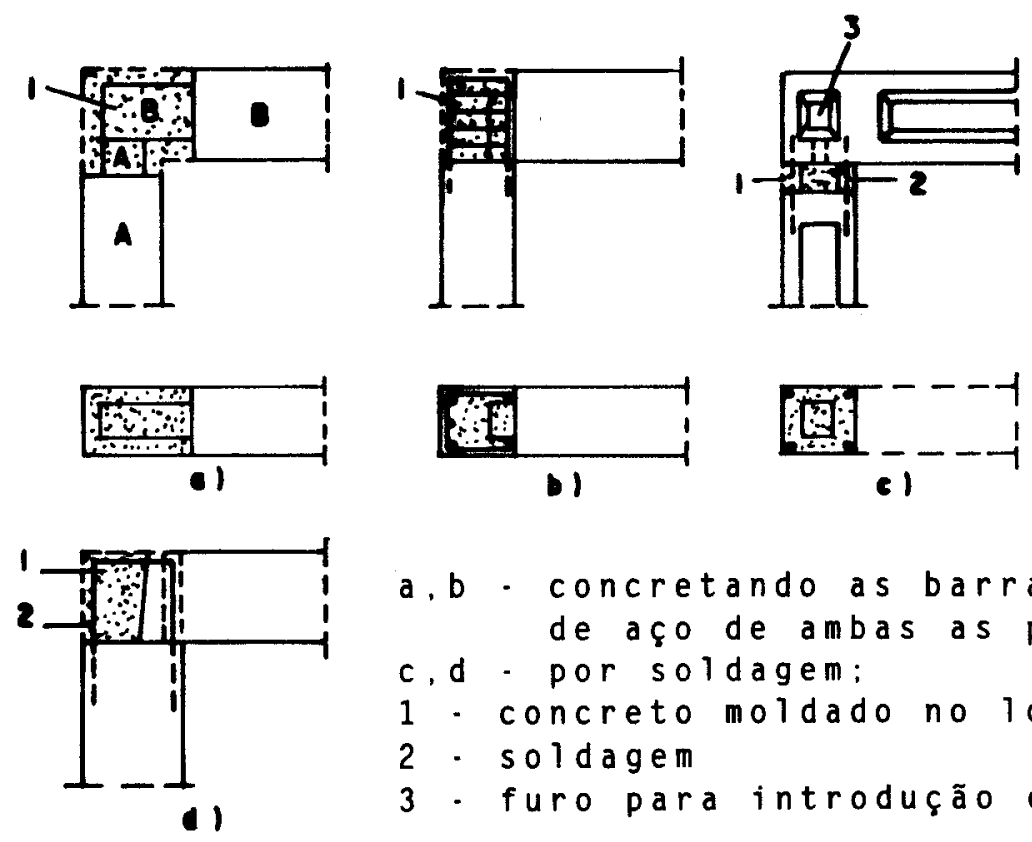

a, b concretando as barras salientes de aço de ambas as peças:

$c, d$ - por soldagem:

1 . concreto moldado no local

2 - soldagem

3 - furo para introdução do concreto

Figura 3.2 - União rigida entre pilar e viga

Fonte: MOKK (1969) 
Ainda em MOKK (1969), é comentado o método de se prover uma união rígida através da soldagem. Este método, embora tecnicamente apropriado, : exige muito esmero e destreza. A colocação das barras de aço requer um cuidado particular para se evitar que uma interfira na outra. A execução fica complicada pois o trabalho deve efetuar-se no local da união. Uma desvantagem adicional deste método está no uso excessivo de aço.

Em LEONHARDT (1978), é apresentada uma forma de se realizar uniões rígidas entre pisos e paredes executando-se emendas por traspasse de laços em gancho (Figura 3.3).

No caso da ponte este método possibilita a interrupção da concretagem, realizando-se juntas de construção entre os encontros e a laje.
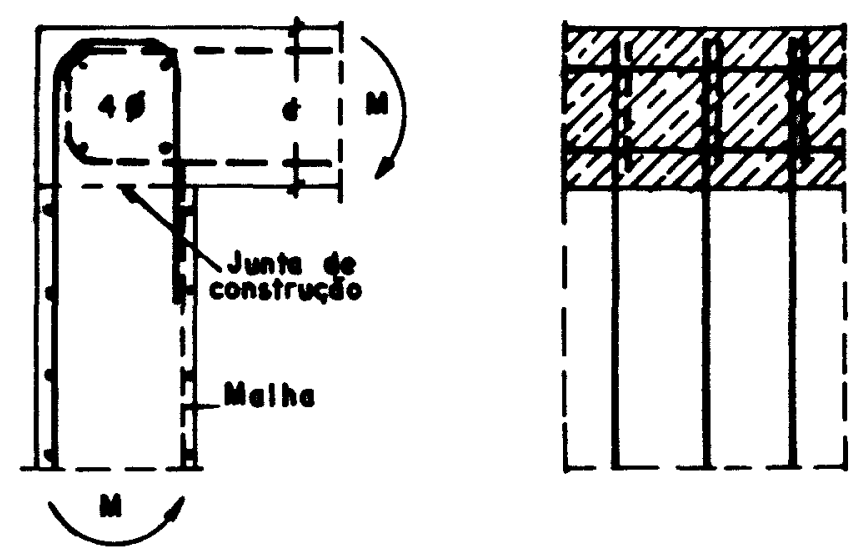

\footnotetext{
Figura 3.3 - União rígida entre pisos e paredes Fonte: LEONHARDT (1978)
}

Propõem-se a realização da união entre a superestrutura e a infraestrutura da ponte efetuando-se emendas por traspasses de laços em gancho, conforme LEONHARDT (1978), executando-se posteriormente uma concretagem da mesma, constituindo, desta forma, uma união úmida. 


\section{4 - CONSIDERAÇÕES SOBRE O PROJETO}

\section{-3.4.1 - COM RELAÇÃO ÁS UNIÕES}

Quando uma estrutura exteriormente hiperestática é obtida mediante a união rígida entre estruturas isostáticas, especial atenção deve ser dada ao projeto da mesma. Para os seus pesos próprios os elementos a serem unidos devem ser dimensionados como isostáticos e para as cargas que atuarão após o estabelecimento da continuidade da estrutura o dimensionamento deve realizar-se levando-se em conta a hiperestaticidade.

Sempre que se unem estruturas isostáticas submetidas ao peso próprio ou a alguma outra carga para formar estruturas hiperestáticas ocorre uma redistribuição de tensões devido à fluência. No presente caso isso significa que a ação do peso próprio provocará, devido à fluência, momentos negativos sobre os nós do pórtico.

Em certos casos a fluência gradual devida à ação da carga permanente pode exceder cerca de cinco vezes as deformações elásticas iniciais. Como exemplo tem-se uma viga contínua formada unindo-se vigas simplesmente apoiadas que, flete devido à fluência. A deformada resultante não é de uma viga simplesmente apoiada e sim de uma viga contínua, sendo sua curvatura contínua. As flechas anteriores dão lugar a momentos negativos nos apoios, cujas magnitudes dependem do grau de fluência. Quanto mais idade tenha o concreto ao aplicar-se o carregamento e melhor for a sua qualidade, menor será a fluência.

Para o caso de uma viga contínua submetida ao peso próprio, os momentos negativos devidos à fluência podem, segundo MOKK (1969), aproximar-se dos momentos negativos que se produzem em uma viga contínua monolítica análoga carregada do mesmo modo.

De acordo com o exposto, ao projetar-se uma estrutura maior deve-se considerar dois estados: o estado 
inicial sem fluência e o estado final uns dois ou três anos depois, transcorrido o tempo geralmente necessário para que a fluência tenha se dado por completo.

Com respeito à retração: pode-se distinguir dois casos:

a) Quando a união das peças pré-fabricadas dá-se imediatamente após sua fabricação: deve-se considerar a retração na estrutura final hiperestática;

b) Quando armazenam-se as peças por longo tempo antes de empregá-las: a maior parte da retração ocorre durante o período de armazenamento, de modo que seus efeitos serão muito menores.

Sendo assim, pode-se considerar que, com respeito às uniões a retração não tem particular importância. Seus efeitos podem ser levados em conta da mesma forma que nas estruturas usuais hiperestáticas monolíticas.

\subsection{2 - COM RELAÇÃO À LIGAÇÃO ENTRE OS CONCRETOS COM IDADES DIFERENTES}

Para que se possa considerar o tabuleiro misto, obtido com a utilização dos pré-moldados de seção $T$ invertido e posterior concretagem, como sendo um elemento íntegro, deve-se verificar se existe perfeita ligação entre ambos os concretos que o formam.

Esta ligação entre os componentes pré-moldados e moldados no local deve ser feita através de estribos, juntas tipo chave ou superfícies rugosas (Figura 3.1).

Os procedimentos de cálculo para a verificação das tensões nesta interface, decorrentes do peso próprio e sobrecargas, são descritos no ítem 4.5.4.

Os efeitos da retração diferencial, deformação e temperatura também podem causar tensões de cisalhamento e tração na interface.

Segundo a FEDERATION INTERNATIONALE DE LA PRECONTRAINTE - FIP (1982), essas tensões são pequenas e 
podem ser desconsideradas. Entretanto no final do vão e nos bordos das lajes podem ocorrer tensões altas que podem algumas vezes levar à ruina. Para interfaces armadas pode-se utilizar uma armadura extra no final dos vãos. No entanto, quando a interface não é armada, fica difícil estimar que tipo de tensões as deformações diferenciais podem causar. $\mathrm{Na}$ maioria destes casos a aderência entre os concretos pré-moldado e moldado no local é grande o suficiente para prevenir a ruína.

\section{5 - PROCESSO CONSTRUTIVO}

O processo construtivo aqui apresentado destina-se a pontes de pequenos vãos em pórtico construídos com $\circ$ emprego de elementos pré-moldados na superestrutura que vencem todo o vão. Embora seja dada ênfase para o sistema estrutural de um só vão, vale ressaltar a possibilidade de se aplicar o processo apresentado para uma sucessão de tramos, através de uma mudança no detalhamento dos nós do pórtico.

os encontros podem ser executados com concreto moldado no local ou com elementos pré-moldados. Utiliza-se o concreto moldado no local pois esta alternativa facilita a realização das uniões entre a laje e o encontro. Em seguida apoia-se os elementos em seção $T$ invertida sobre os encontros. Executa-se posteriormente, com concreto moldado no local, a ligação rígida, juntamente com o preenchimento dos espaços entre as vigas pré-moldadas e consequente formação da laje do tabuleiro (Figura 3.5).

A montagem dos elementos deve ser feita aproveitando-se ao máximo os equipamentos existentes, sendo portanto a utilização de uma ou mais gruas, que podem movimentar-se pelos acessos aos encontros ou sob a ponte, a maneira mais apropriada para o problema em questão.

A variação da espessura da laje pode ser feita de duas maneiras:

a) Variando-se a espessura do concreto acima das vigas - esta 


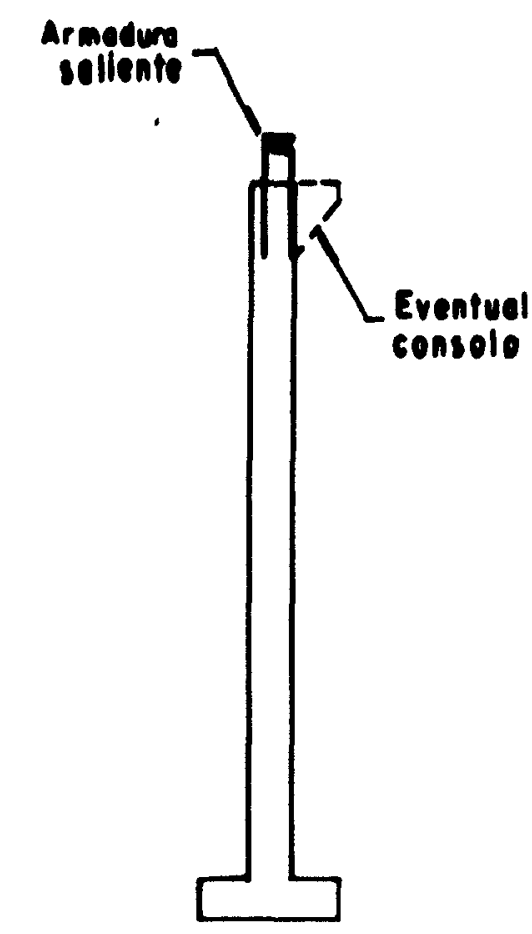

- Execucdo los encontros can concreto moldedo

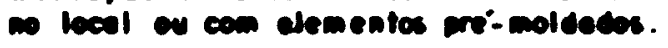

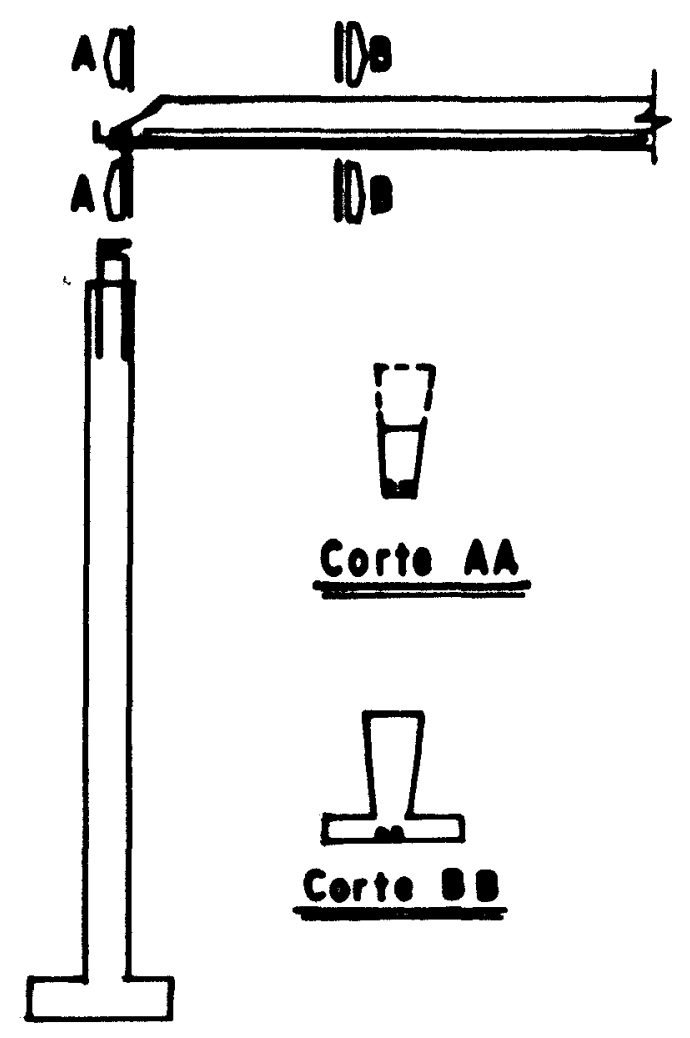

b) Colo ceclo des etementos int-moldodos to superestruture.

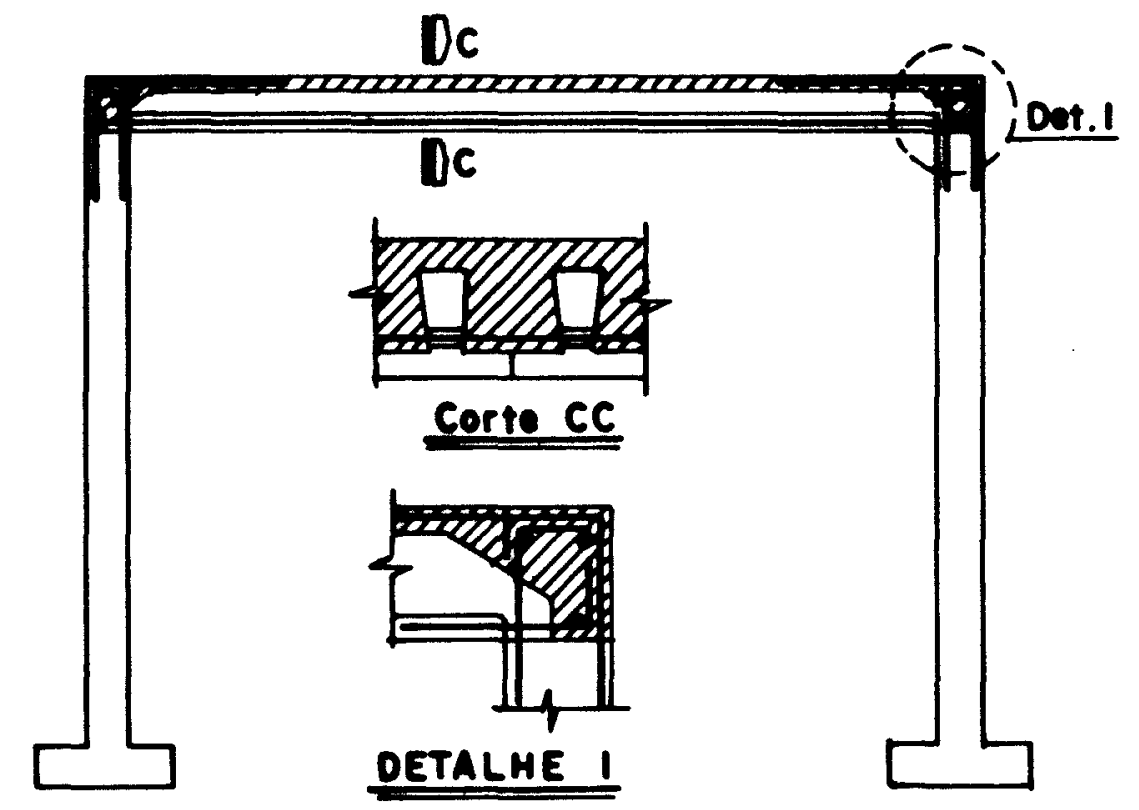

cl Concretagem de ligagdo, puntamente com o restente de laje, formendo ponte en portico.

Figura 3.5 - Processo construtivo de ponte de pequeno vão em pórtico com o emprego de elementos prémoldados na superestrutura 


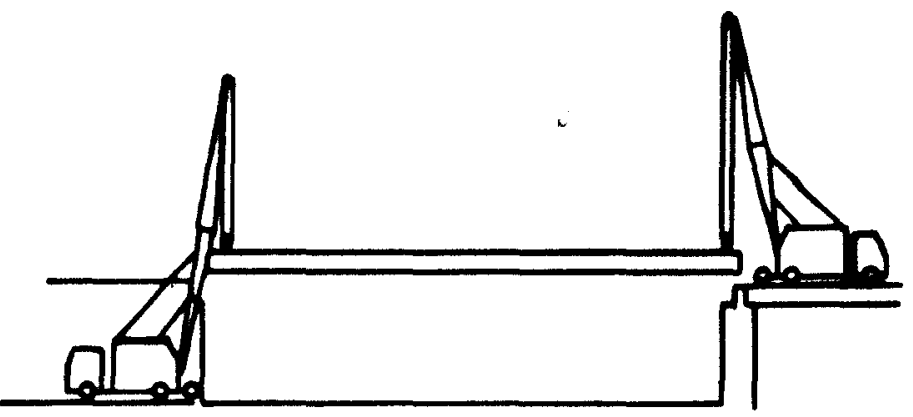

\section{Figura 3.4 - Montagem dos elementos pré-moldados \\ Fernandez Casado (1965)}

solução não serve para grandes variações, uma vez que as vigas antes da cura do concreto moldado no local, devem suportar toda a carga morta, funcionando estruturalmente como vigas bi-apoiadas;

b) variando-se a altura da viga pré-moldada - embora as vigas em seção $T$ invertida requeiram moldes múltiplos para que se possa variar a sua altura, existem alternativas, como as vigas HIP apresentadas em FERNANDEZ ORDONEZ et alii (1974).

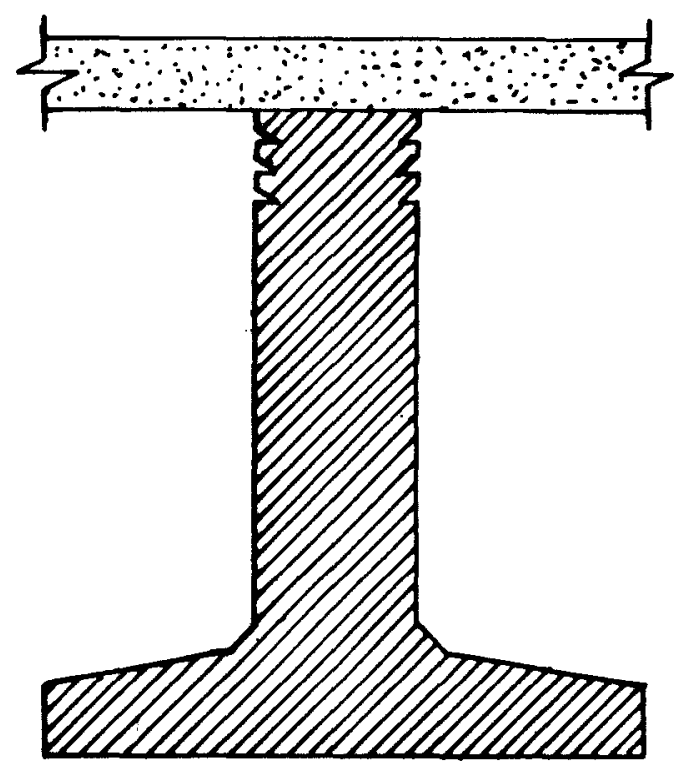

Figura 3.6 - Vigas HIP (Fernandez Ordonez et alli (1974) 
Os bordos da laje devem ser executados com a utilização de formas, as quais podem ser fixadas na estrutura já existente (vigas pré-moldadas).

c)

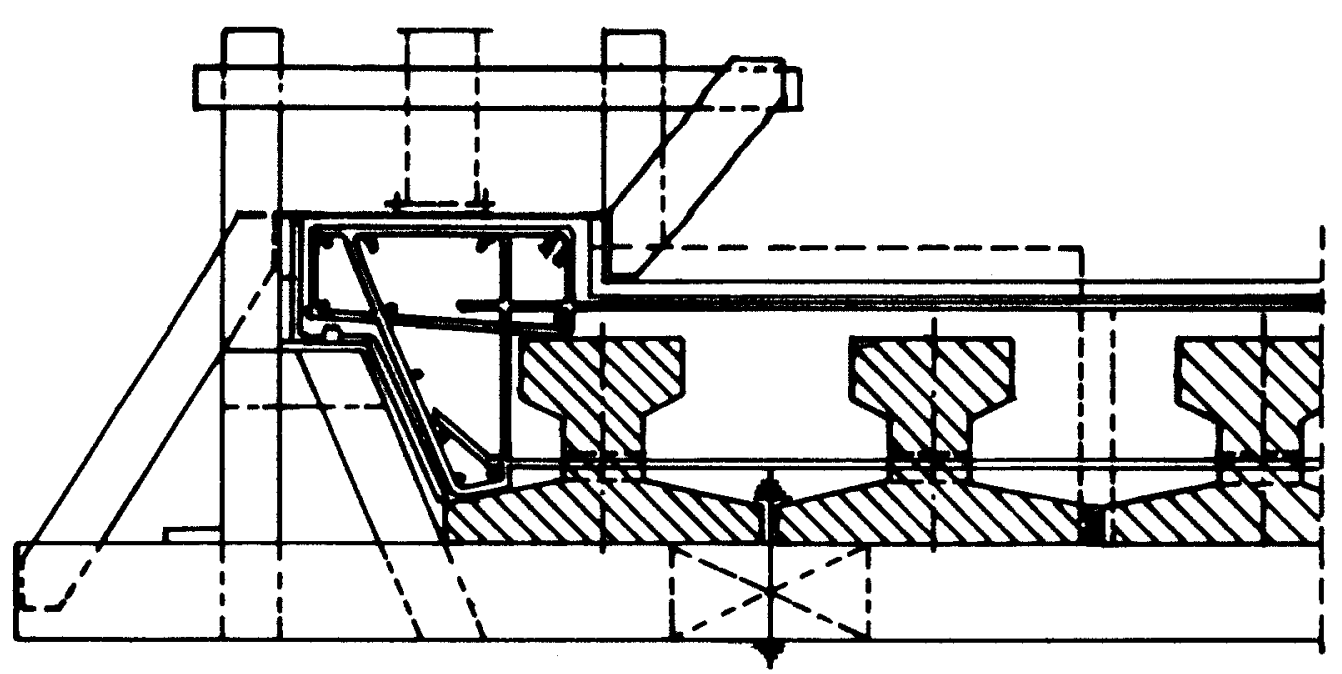

)
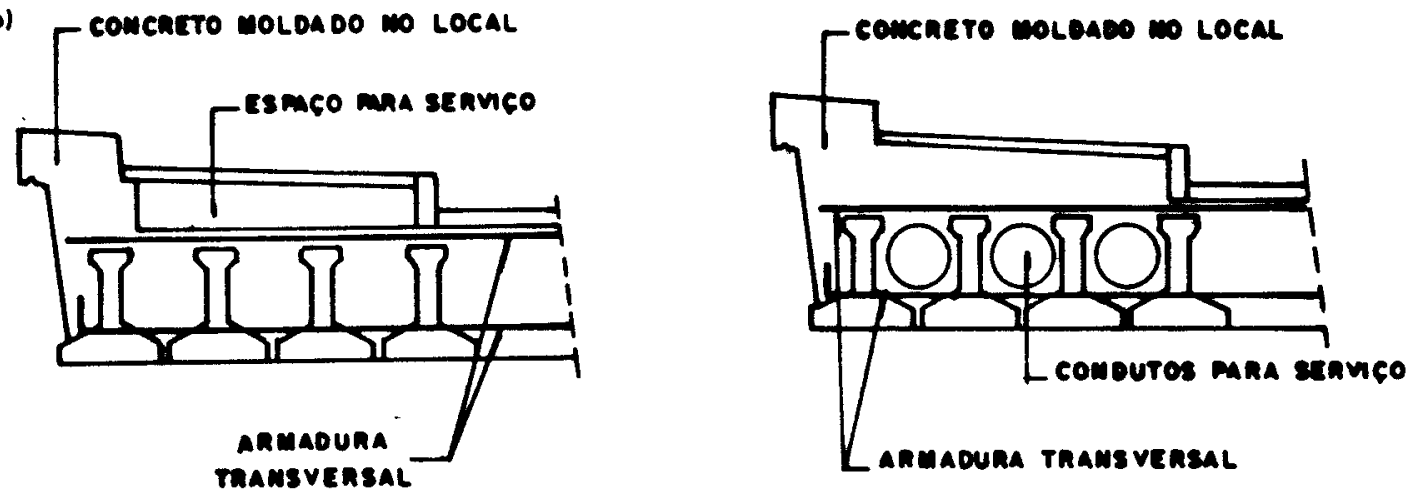

Figura 3.7 - a) Processo para execução dos bordos do tabuleiro construido com vigas de seção $T$ invertido:

b) soluções usuais para bordos de pontes

Fontes: a)Fernandez ordonez et alli (1974);

b) Somervi11e (1971). 


\section{4 - PROCESSO DE CÁLCULO}

\section{$4.1 \cdot$ CONSIDERAÇÕES PRELIMINARES}

o projeto de uma ponte inicia-se, naturalmente, pelo conhecimento de sua finalidade, da qual decorrem os elementos geométricos definidores do estrado e as cargas para os quais será procedido seu dimensionamento. Os elementos geométricos da via dependem das condicões técnicas estabelecidas pelo orgão público a cuja jurisdição pertence, por exemplo, o Departamento Nacional de Estradas de Rodagem, os Departamentos Estaduais de Rodagem, as Prefeituras Municipais, etc.

Torna-se necessário também o conhecimento da topografia da região e estudos hidrológicos e geotécnicos.

Uma vez que o presente trabalho se destina ao estudo de pontes de pequenos vãos $e$, embora não necessariamente, para integrar rodovias, tem-se definidos a magnitude dos vãos que pretende-se vencer e as cargas úteis a suportar. Seguindo a proposta construtiva, tem-se definida a seção transversal em laje maciça.

Pretende-se assim, desenvolver neste capítulo, de forma clara e ordenada, uma metodologia para o cálculo dessas estruturas, as verificações necessárias, procurando-se apresentar também as informações necessárias para 0 seu 
dimensionamento.

Admitindo-se que a laje da superestrutura possa estar simplesmente apoiada sobre os muros de encontro, formando um sistema estrutural igostático, ou rigidamente ligada aos mesmos, formando um sistema estrutural hiperestático, serão desenvolvidas duas sistemáticas de cálculo de forma a atender a ambas as situações. Denomina-se aqui, para a primeira situação, cálculo sem continuidade e para a segunda, cálculo com continuidade, fazendo-se uma analogia ao caso de vigas simplesmente apoiadas e continuas, respectivamente.

Para efeito de cálculo divide-se a estrutura em duas partes principais: superestrutura e infraestrutura.

A superestrutura, composta geralmente de lajes e vigas principais e secundárias, é o elemento de suporte imediato do estrado, que constitui a parte útil da obra, sob - ponto de vista de sua finalidade.

A infraestrutura é composta pelos encontros e fundação. Os encontros são elementos de características extremamente variáveis, cuja principal função é receber o empuxo dos aterros de acesso. Com o sistema estrutural adotado possuem também a função de transmitir os esforços da superestrutura à fundação. A fundação, é a parte da ponte por meio do qual são transmitidos ao terreno de implantação da obra os esforços recebidos dos encontros. Constituem a fundação: os blocos, as sapatas, as estacas, os tubulões etc., assim como as peças de ligação de seus diversos elementos entre si, e destes com os encontros como, por exemplo, os blocos de cabeça de estacas e vigas de travamento.

\section{2 - CÁLCULO SEM CONTINUIDADE}

O sistema estrutural considerado será o de uma laje com seção transversal maciça, bi-apoiada sobre os muros de encontro. 
A superestrutura, constituida por uma laje reta ortogonal, será calculada mediante o emprego das tabelas desenvolvidas por RÜSCH (1965) para o cálculo das lajes de pontes rodoviárias.

Os encontros serão tratados como muros em balanço supondo-se engaste perfeito com a fundação.

Admitindo-se a necessidade do uso de estacas para a transmissão das cargas ao solo, o cálculo da fundação será desenvolvido para o caso de bloco sobre estacas em toda a extensão dos encontros.

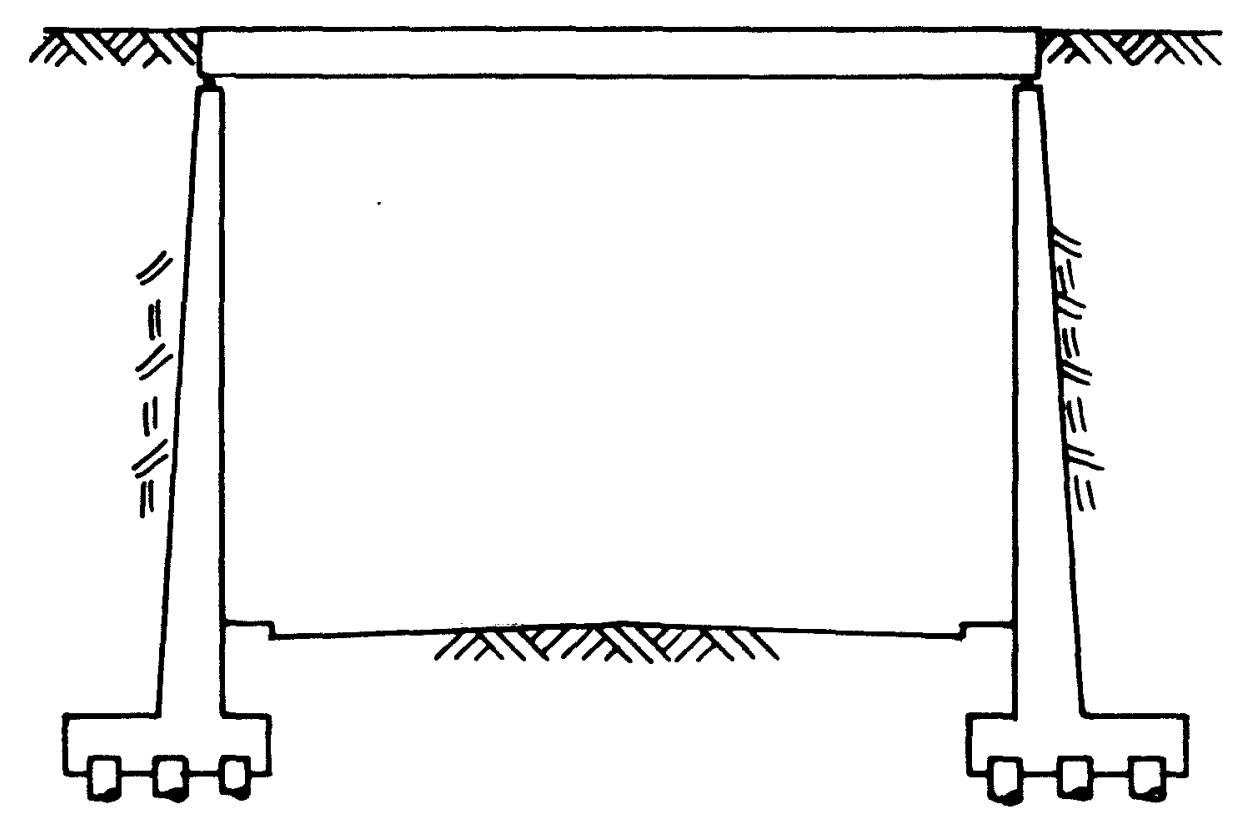

Figura 4.1 Estrutura idealizada para o cálculo sem continuidade

\subsection{1 - CÁLCULO DA SUPERESTRUTURA}

\subsubsection{1 - PRÉ-DIMENSIONAMENTO DA LAJE}

Segundo LEONHARDT (1979), a altura da seção transversal $\left(e_{1}\right)$ de pontes de lajes maciças pode ser adotada a partir dos índices de esbeltez $\ell_{i} / e_{1}$, onde $\ell_{i}$ é a distância aproximada entre os pontos de momento nulo do diagrama de momentos provocado pela carga permanente. No caso em questão, 
por tratar-se de uma laje bi-apoiada, o valor de $\ell$ coincide com o valor do vão teórico.

- Esses indices, adaptados para as categorias de pontes nacionais, estão apresentados na Tabela 4.1.

Tabela 4.1 - Valores do indice de esbeltez $l_{i} / e$, para seção
transuersal de laje macica

\begin{tabular}{cc}
\hline Classe da ponte & Valores de $\ell_{\mathfrak{j}} / \mathrm{e}_{\mathrm{l}}$ \\
\hline 45 ou 30 & 15 a 22 para concreto armado \\
& 18 a 30 para concreto protendido \\
12 & 20 a 25 para concreto armado \\
& 26 a 36 para concreto protendido
\end{tabular}

Fonte: LEONHARDT (1979)

Os valores maiores são utilizados para o caso de vãos maiores e, portanto, para relações entre cargas variáveis e permanentes, $\frac{q}{q}$, menores.

As pontes com seção tranversal de laje maciça possuem elevado consumo de concreto e, consequentemente, elevado peso próprio. Em face disto, quando a altura requerida da seção transversal for da ordem de 60 centímetros ou mais, torna-se conveniente adotar lajes ocas com fôrmas perdidas na forma de tubos ou perfilados retangulares. Aumenta-se assim a faixa de vãos atingidos pelas pontes em laje. Cabe destacar que esse procedimento irá diminuir as vantagens de execução, mas o bom comportamento transversal é pouco afetado.

Existem muitas formas de se desenvolver o cálculo da laje da superestrutura, seja por métodos numéricos, através da analogia de grelha ou pelo uso de tabelas. Procurando-se apresentar uma metodologia que se possa empregar cotidianamente e que seja simples e segura, opta-se neste trabalho pelo uso das Tabelas de RÜSCH (1965). 


\subsubsection{2 - CÁLCULO DA LAJE SEGUNDO RÜSCH}

As lajes de pontes modernas construidas com concreto armado e protendido são dimensionadas com armações diferentes em duas direções ortogonais. Entretanto, considera-se para efeito de cálculo de solicitações, que a rigidez seja igual nas duas direções (laje isotrópica).

As solicitações das lajes isotrópicas são calculadas com a teoria elástica das lajes. Para diversos tipos de cargas e condições de apoio, existem tabelas fornecendo os principais valores dos momentos fletores e esforços cortantes.

Dentre as tabelas existentes, as mais conhecidas são as de RÜSCH (1965), que fornecem as solicitações de lajes retangulares, com apoios simples ou engastados, para os carregamentos estipulados nas normas alemãs de pontes rodoviárias. Os valores fornecidos são os maiores, já considerando as posições mais desfavoráveis das cargas móveis.

As normas brasileiras de cargas rodoviárias adotaram carregamentos com a mesma geometria das cargas de cálculo das normas alemãs, de modo que as tabelas de RÜsCH podem ser utilizadas.

Para a sua utilização deve-se primeiramente fixar as condições de apoio e a relação entre os lados da placa em estudo. Designa-se de um modo prático por $\ell_{x}$ a direção principal da placa (momentos máximos). Fixado $\ell_{x}$, está também fixado se a direção do tráfego é a mesma de $\ell_{x}$ ou se é a direção de $\ell_{y}$. Com $\circ$ valor da relação $\ell_{y} / \ell_{x} e$ a direção do tráfego escolhe-se a tabela a utilizar para $\circ$ caso em questão.

As tabelas levam em conta o espaçamento "a" entre rodas de um mesmo eixo do veículo de cálculo e a largura $t$ de distribuição, através das seguintes relações: $\ell_{x} / a$ e t/a.

Para a obtenção, da largura de distribuição, introduz-se 0 conceito de superfície de distribuição de 
carga, obtida por um alongamento da superfície de contato das rodas do veículo tipo segundo um ângulo de $45^{\circ}$ até $O$ plano médio da laje. Essas superfícies de contato podem ser substituídas por superfícies de contato de quadrados de áreas equivalentes. A NBR 7188 (1984) fixa as dimensões das larguras de contato das rodas dos veículos tipo em função da classe a que este pertence $(45,30$ ou 12).

Obtém-se então a largura $t$ da superfície de distribuição, somando-se à largura da superfície de contato equivalente (quadrado) $\circ$ dobro do valor da altura de recobrimento acima do plano médio da laje.

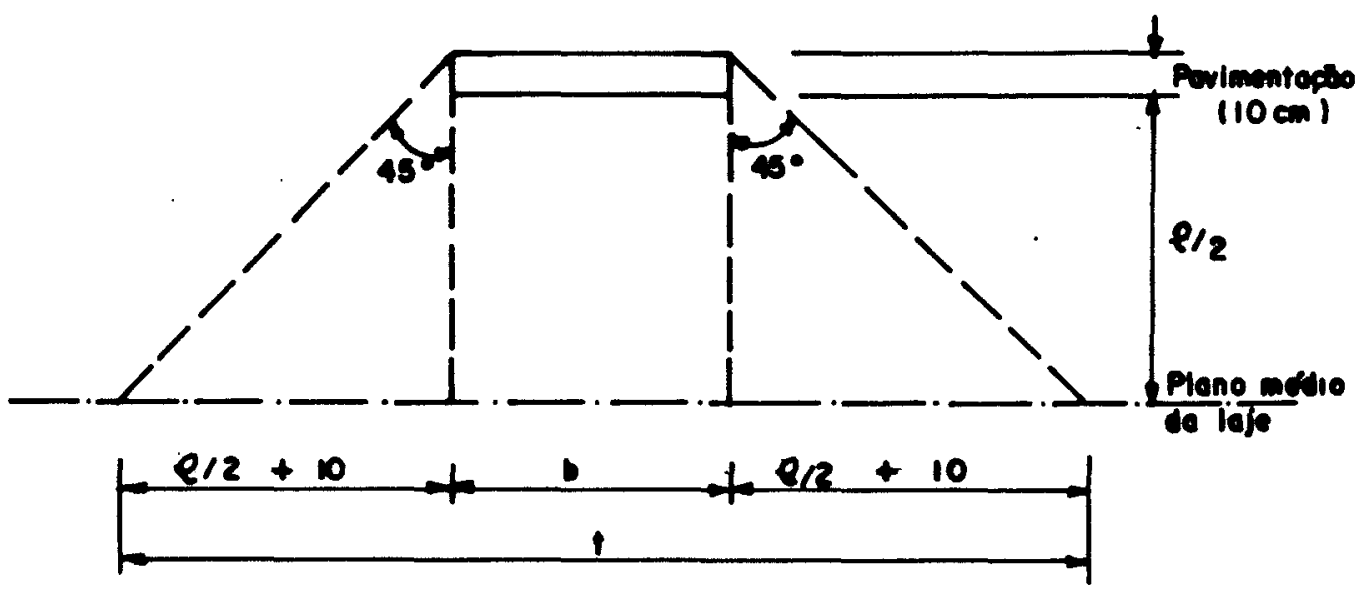

Figura 4.2 - Largura de distribuição (t)

A distância entre rodas de um mesmo eixo é fixada pela NBR 7188 (1984) em a $=2.00$ metros.

Calculando-se assim as relações $\ell_{x} / a$ e $t / a$, geralmente chega-se a valores que não correspondem aos que existem nas tabelas. Neste caso calcula-se os valores dos coeficientes interpolando-se linearmente entre os valores constantes da tabela consultada. O mesmo deve ser feito para - caso em que a relação entre os lados da placa se situe entre dois valores existentes.

Os coeficientes contidos nas tabelas para o cálculo dos momentos fletores foram obtidos para carga unitária. Assim, eles devem conforme a classe da ponte, ser majorados 
com os fatores de carga correspondentes.

o movimento dos veículos sobre a ponte provoca um acréscimo das cargas dos mesmos. Este acréscimo, quer seja provocado pelo simples efeito do deslocamento das cargas ou pelas irregularidades no pavimento é quantificado através da multiplicação das cargas estacionárias por um coeficiente denominado coeficiente de impacto.

Assim, para o cálculo dos momentos fletores devidos às cargas móveis, tem-se segundo RÜSCH (1965):

a) Para pontes com tráfego pesado (Classe 45 e 30)

$$
\mathrm{M}_{\mathrm{q}}=\varphi\left(\mathrm{FM}_{\mathrm{L}}+\mathrm{pM}_{\mathrm{p}}+\mathrm{p}^{\prime} \mathrm{M}_{\mathrm{p}}^{\prime}\right)
$$

b) para pontes com tráfego leve (Classe 12)

$$
M_{q}=\varphi\left(F_{1} M_{L}+F_{2} M_{L}^{\prime}+p M_{p}+p^{\prime} M_{p}^{\prime}\right)
$$

onde:

$\mathrm{M}_{\mathrm{q}}=$ momentos fletores provenientes do tráfego $(\mathrm{kNm} / \mathrm{m})$;

$\varphi=$ coeficiente de impacto;

$F$ = carga de uma roda do veículo tipo 45 ou 30 (kN);

$F_{1}$ = carga de uma roda traseira do veículo tipo $12(\mathrm{kN}) ;$

$F_{2}$ = carga de uma roda dianteira do veículo tipo $12(\mathrm{kN})$;

$\mathrm{p}=$ carga distribuía à frente $e$ atrás do veículo tipo $\left(\mathrm{kN} / \mathrm{m}^{2}\right)$

$\mathrm{p}^{\prime}=$ carga distribuída no restante da placa $\left(\mathrm{kN} / \mathrm{m}^{2}\right)$;

$M_{L}, M_{L}^{\prime}, M_{p}, M_{p}^{\prime}=$ coeficientes fornecidos pela tabela em função dos parâmetros $\ell_{x} / a$ e $t / a$.

Os valores das cargas $F, F_{1}, F_{2}, p$ e $p^{\prime}$ são fixados pela NBR 7188 (1984) de acordo com a classe pertencente ao veículo tipo.

A carga distribuída p, após a revisão da norma NB 6 em 1982, passou a ser utilizada também ao lado do veículo tipo sendo a carga $\mathrm{p}^{\prime}$ considerada apenas nos passeios, não majorada de impacto. Desse modo, as equações $4.1 \mathrm{a}$ e $4.1 \mathrm{~b}$ passam a ter ambos os coeficientes $M_{p}$ e $M_{p}^{\prime}$ multiplicados pela carga distribuida $p$. 
Tabela 4.2 - Cargas dos veículos.

\begin{tabular}{|c|c|c|c|c|c|}
\hline \multirow{2}{*}{$\begin{array}{c}\text { Classe } \\
\text { da } \\
\text { ponte }\end{array}$} & \multicolumn{2}{|c|}{ Veículo } & \multicolumn{3}{|c|}{ Carga uniformemente distribuida } \\
\hline & Tipo & $\begin{array}{l}\text { Peso total } \\
(\mathrm{kN})\end{array}$ & $\begin{array}{c}\mathrm{p} \\
\left(\mathrm{kN} / \mathrm{m}^{2}\right)\end{array}$ & $\begin{array}{c}\mathrm{p}^{\prime} \\
\left(\mathrm{kN} / \mathrm{m}^{2}\right)\end{array}$ & $\begin{array}{c}\text { Disposição } \\
\text { da carga }\end{array}$ \\
\hline 45 & 45 & 450 & 5 & 3 & Carga p em \\
\hline 30 & 30 & 300 & 5 & 3 & $\begin{array}{l}\text { Loda pista } \\
\text { Carga p'nos }\end{array}$ \\
\hline 12 & 12 & 120 & 4 & 3 & passeios \\
\hline
\end{tabular}

Fonte: NBR $7188(1984)$

- valor do coeficiente de impacto é, segundo a NBR 7187 (1986), dado por:

$$
\varphi=1.4-0.007 \ell_{\mathrm{x}} \geq 1.00
$$

onde $\ell_{x}=$ vão teórico $(m)$.

- esforço cortante resultante da carga móvel somente é tratado para quatro casos especiais apresentados nas tabelas 99 à 102 [RÜSCH (1965)]. Para o seu cálculo a equação (4.1) é empregada analogamente, substituindo-se oportunamente, $O \mathrm{M}$ por $Q$.

A carga permanente, constituída pelo peso próprio dos elementos portantes (estrutura) e de outros materiais colocados sobre a ponte (sobrecargas fixas) tais como pavimentação, guarda corpo, canalizações etc, tem seus esforços quantificados com 0 auxilio das seguintes fórmulas:

a) Momentos fletores

$$
M_{g}=k g \ell_{x}^{2}
$$

b) forças cortantes

$$
\mathrm{V}_{\mathrm{g}}=\mathrm{kg} \ell_{\mathrm{x}}
$$

onde:

$k=$ coeficiente para os esforços provenientes de carregamento permanente unitário (fornecido no topo das tabelas); 
$g$ = carga uniformemente distribuída $\left(\mathrm{kN} / \mathrm{m}^{2}\right)$.

Tabela 4.3 - Caracterfsticas dos veículos

\begin{tabular}{|c|c|c|c|c|}
\hline & Unidade & $\begin{array}{c}\text { Tipo } \\
45\end{array}$ & $\begin{array}{c}\text { Tipo } \\
30\end{array}$ & $\begin{array}{c}\text { Tipo } \\
12\end{array}$ \\
\hline Quantidade de eixos & eixo & 3 & 3 & 2 \\
\hline Peso total do veículo & $\mathrm{kN}$ & 450 & 300 & 120 \\
\hline Peso de cada roda dianteira & $\mathrm{kN}$ & 75 & 50 & 20 \\
\hline Peso de cada roda traseira & $\mathrm{kN}$ & 75 & 50 & 40 \\
\hline $\begin{array}{l}\text { Peso de cada roda intermediária } \\
\text { Largura de contato } b \text { de cada }\end{array}$ & $\mathrm{kN}$ & 75 & 50 & \\
\hline roda dianteira 1 & $\mathrm{~m}$ & 0.50 & 0.40 & 0.20 \\
\hline $\begin{array}{l}\text { Largura de contato } b_{3} \text { de cada } \\
\text { roda traseira } \\
\text { Larqura de contato } b_{3} \text { de cada }\end{array}$ & $\mathrm{m}$ & 0.50 & 0.40 & 0.30 \\
\hline $\begin{array}{l}\text { roda intermediária } \\
\text { Comprimento de contato de cada }\end{array}$ & $\mathrm{m}$ & 0.50 & 0.40 & - \\
\hline & $\mathrm{m}$ & 0.20 & 0.20 & 0.20 \\
\hline Área de contato de cada roda & $\mathrm{m}$ & $0.2 \mathrm{~b}$ & $0.2 \mathrm{~b}$ & $0.2 \mathrm{~b}$ \\
\hline $\begin{array}{l}\text { Distância entre eixos } \\
\text { Distância entre os centros de }\end{array}$ & $\mathrm{m}$ & 1.50 & 1.50 & 3.00 \\
\hline rodas de cada eixo & $m$ & 2.00 & 2.00 & 2.00 \\
\hline
\end{tabular}

Fonte: NBR $7188(1984)$

Para placas livremente apoiadas ou engastadas em dois lados, compreendendo o caso em questão, o valor máximo de $M_{x}$ devido à carga móvel não se dá no meio da placa, mas sim, no meio dos bordos livres. As tabelas dão os valores para ambos os casos. O momento $M_{y}$ atinge seu valor máximo no meio da placa e decresce na direção do meio dos bordos livres. Com os valores fornecidos pelas tabelas pode-se, com - auxilio das superfícies de influência elaboradas por RÜsCH (1965) e aqui reproduzidas na Figura 4.3, ter uma boa idéia da atuação dos momentos fletores em toda a placa.

Placas estreitas com $\ell_{y} / \ell_{x} \leq 0.25$ podem ser calculadas como vigas. Isto, no entanto, somente é válido para os momentos no sentido longitudinal $M_{x} e$ os momentos transversais devidos às cargas uniformementes distribuidas que, devido à contração transversal sem dúvida existente, são tão pequenos que podem ser desprezados.

os momentos transversais provenientes do 
carregamento móvel, mesmo para placas muito estreitas, não são mais desprezíveis pois a espessura da placa e a superfície de contato das rodas são pequenas em relação à largura da placa. Analisando-se estes momentos para placas de igual largura e variando-se a distância entre apoios observa-se que estes convergem para um valor que mais ou menos corresponde à placa cuja relação entre os lados $\ell_{y} / l_{x}=$ 0.5 . Isto significa que para placas infinitamente compridas com relação $\ell_{y} / \ell_{x} \cong 0$, o momento transversal $M_{y}$ devido à carga móvel aproxima-se daquele calculado para $\ell_{y} / \ell_{x}=0.5$. Assim, para placas muito estreitas, com $\ell_{y} / \ell_{x} \leq 0.5$, os momentos transversais devidos à carga móvel são determinados com uma placa de substituição cujo comprimento $\ell_{x}$ tem $\circ$ dobro da largura $\ell_{y}$.

A influência da contração transversal nas placas apoiadas em dois lados, após comparações entre resultados obtidos com adoção do Coeficiente de Poisson $v=0$ e $v=\frac{1}{6}$, foi considerada adotando-se para a dimensão do momento devido à mesma desde o valor $v\left(M_{x}-M_{y}\right)$ até zero.

Merecem ainda consideração os momentos negativos $M_{y}$ que originam-se pela colocação da carga móvel nas proximidades do bordos. Para isto não puderam ser dados valores numéricos, pois, para pontos notáveis, não existem suficientes superfícies de influência disponíveis. Desta forma, também as superfícies aqui transpostas não fornecem nenhuma indicação para estes momentos. Apesar disso, devem ser considerados no dimensionamento e detalhamento das placas os momentos negativos $M_{y}$, prevendo-se uma armadura na proximidade dos bordos livres.

Para cargas permanentes, na forma de força ou momento por unidade de comprimento, aplicadas ao longo dos bordos livres, pode-se utilizar a tabela 103 de RÜSCH (1965). Nestas estão tabeladas, em função da relação $\ell_{y} / \ell_{x}$ e do tipo de apoio, os acréscimos de momento na laje provocados pela atuação de tais carregamentos. 

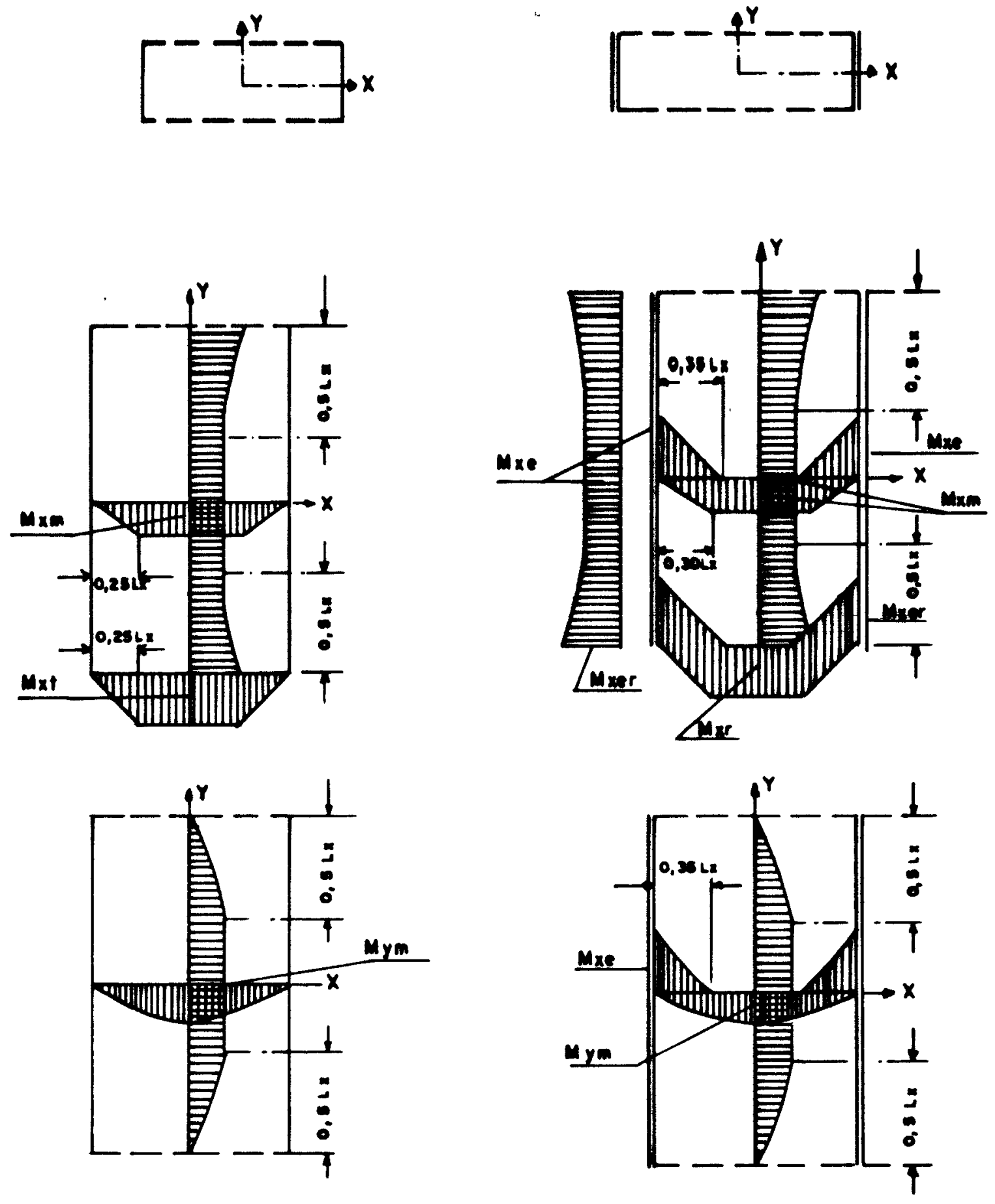

Figura 4.3 - Superficies de influência para lajes bi-apoiadas e bi.engastadas com bordo livr Fonte: RÜSCH (1965) 


\subsection{2 - CÁLCULO DA INFRAESTRUTURA}

- Os encontros, terão como finalidade além de receber - empuxo dos aterros de acesso, receber também as cargas horizontais e verticais provenientes da superestrutura. São estas:

a) Cargas provenientes da aceleração e frenagem dos veículos sobre o estrado;

b) cargas devidas à variação de temperatura e retração do concreto;

c) reações devidas ao peso próprio e carregamento móvel.

A fundação, seguindo a hipótese assumida da necessidade da utilização de estacas, estará aqui representada pelos blocos contínuos situados sob os encontros e pelas próprias estacas.

As estacas são utilizadas quando o terreno é consistente em camadas profundas, quando existe grande quantidade de água no mesmo ou quando existe a necessidade de resistir ações horizontais de importância.

Será considerada a existência de vigas de travamento ligando os blocos. Estas ficarão responsáveis pela absorção dos esforços horizontais aí ocorrentes, bem como por uma maior solidarização do conjunto. Ocorrendo o aterro dos acessos separadamente, deve-se verificar a influência desta carga nas estacas. Os procedimentos de cálculo aqui mostrados não incluirão as vigas de travamento, pois as mesmas não apresentam nenhuma particularidade referente ao estudo em questão, podendo seu dimensionamento ser normalmente obtidos a partir da teoria das vigas. Na ausência de esforços horizontais nas estacas, admite-se que estas serão cravadas na vertical.

Considerando-se que 0 projeto das estacas (verificações de transporte, levantamento e cravação) será feito por firma especializada, restringe-se o cálculo da fundação à distribuição do carregamento pelas estacas e posterior obtenção dos esforços atuantes nos blocos. 


\subsubsection{1 - PRÉ-DIMENSIONAMENTO DOS ENCONTROS}

0 empuxo de terra constitui, na prática, quase que a totalidade das cargas atuantes nos encontros. Sendo assim, para efeito de pré-dimensionamento, pode-se simplesmente considerar os esforços provocados pela ação de sua resultante sobre o muro (empuxo ativo).

Como simplificação, desde que as solicitações assim determinadas estejam a favor da segurança, pode-se supor que - solo não tenha coesão e considerar o paramento do muro liso (cimentado ou pintado com pixe), de forma que não haja atrito entre este e o solo.

- peso específico do solo úmido deve ser considerado, no mínimo, igual à $18 \mathrm{kN} / \mathrm{m}^{3}$.

Para a determinação do empuxo ativo adota-se a teoria de Coulomb, baseada na hipótese de que o esforço exercido no paramento do muro é proveniente da pressão do peso parcial de uma cunha de terra, que desliza pela perda de resistência a cisalhamento ou atrito.

o deslizamento ocorre frequentemente ao longo de uma superfície de curvatura, em forma de espiral logarítmica. Nos casos práticos, é válido substituir esta curvatura por uma superfície plana, chamada plano de ruptura ou plano de deslizamento.

Segundo COULOMB apud MOLITERNO (1980), o empuxo faz com a normal ao paramento do lado da terra, um ângulo $\psi_{1}$, cuja tangente é igual ao coeficiente de atrito entre a terra e o muro.

A direção da componente $Q$ do peso da cunha, forma com a normal ao plano de ruptura um ângulo $\varphi$, cuja tangente é igual ao coeficiente de atrito do terreno (terra contra terra).

Tem-se, portanto, o peso $\mathrm{P}$ da cunha decomposto em $\mathrm{E}$ e $Q$. Onde:

$E$ = resultante do empuxo ativo atuante no muro; 
$Q=$ resultante das forças atuantes no plano de ruptura.

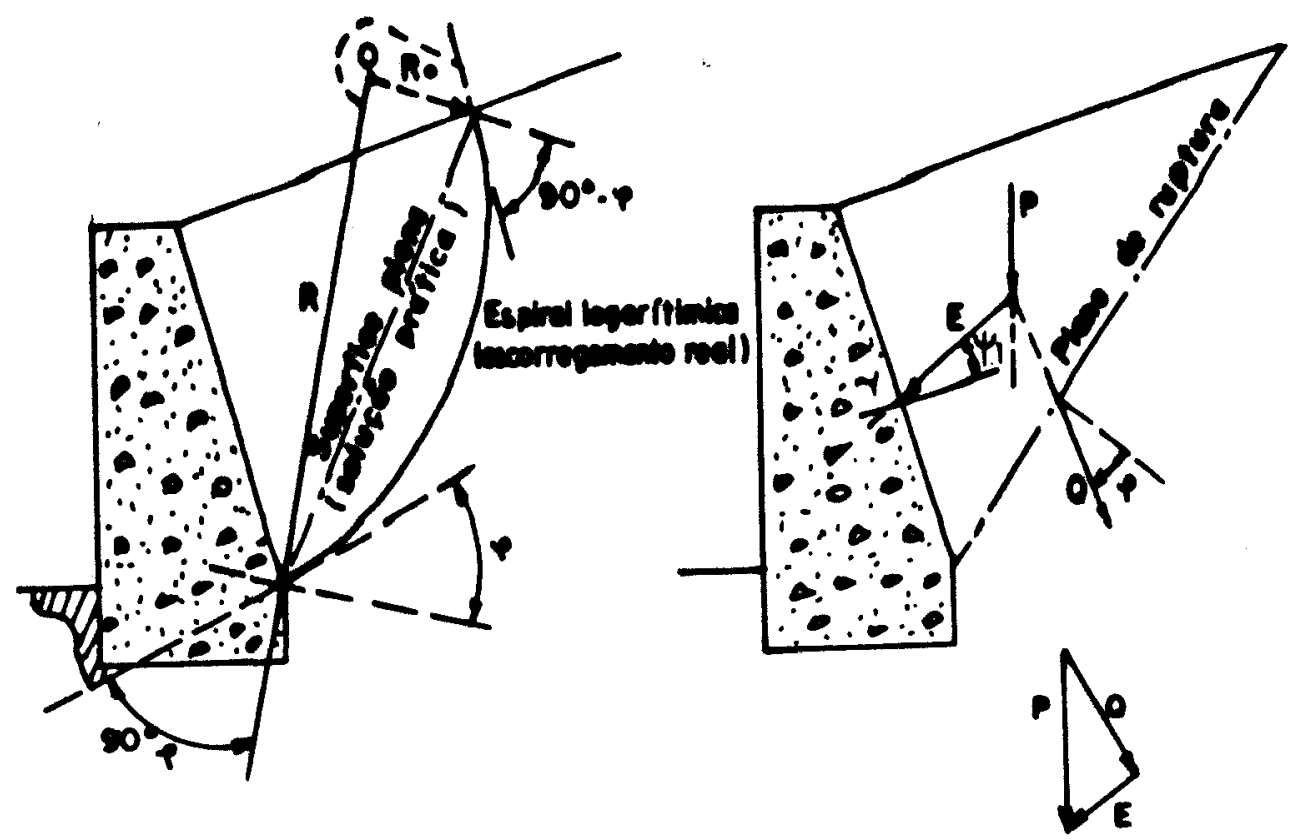

Figura 4.4 - Triângulo de forças na cunha de terra Fonte: MOLITERNO ( 1980$)$

A grandeza de $E$ pode ser considerada como uma pressão distribuída ao longo da altura do muro, cujo diagrama de distribuição, para simplificação de cálculo, admite-se linear, em analogia com 0 empuxo proveniente da pressão hidrostática, e cuja área representa o valor de $\mathrm{E}$.

Assim, para uma coluna de líquido: $\mathrm{E}=\frac{1}{2} \gamma \mathrm{h}^{2}$. Corrigindo-se esta expressão, levando-se em conta o atrito entre as partículas do solo, rugosidade do muro e inclinação do terreno, através de um coeficiente $K$, tem-se:

$$
E=\frac{1}{2} K \gamma_{t} h^{2}
$$

onde:

$\gamma_{t}=$ peso específico da terra $\left(\mathrm{kN} / \mathrm{m}^{3}\right)$;

$\mathrm{h}$ = altura teórica do muro (m). 


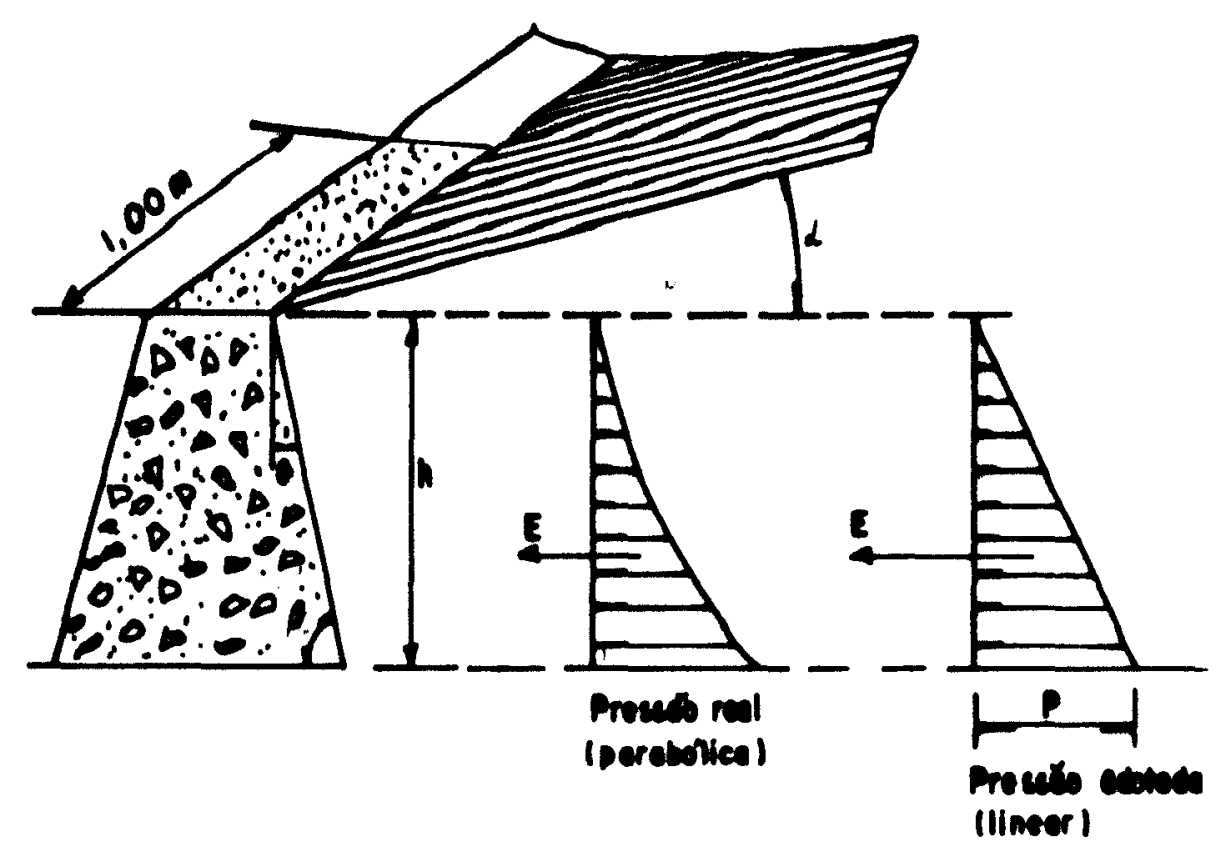

Figura 4.5 - Pressao de terra atuante no muro
Fonte: MOLITERNO $(1980)$

Segundo REBHANN apud MOLITERNO (1980) o valor deste coeficiente, designado por coeficiente de empuxo ou de Coulomb, é dado pela expressão:

$\mathrm{K}=\frac{\operatorname{sen}^{2}(\beta+\varphi)}{\operatorname{sen}^{2} \beta \operatorname{sen}\left(\beta-\psi_{1}\right)\left[1+\sqrt{\frac{\operatorname{sen}(\varphi-\alpha) \operatorname{sen}\left(\varphi+\psi_{1}\right)}{\operatorname{sen}\left(\beta-\psi_{1}\right) \operatorname{sen}(\beta+\alpha)}}\right]}$

onde:

$\alpha$ ângulo de inclinação do terreno adjacente (graus);

$\theta=$ ângulo de inclinação do paramento interno do muro com a vertical (graus);

$\beta=90-\theta$;

$\varphi=$ ângulo de atrito interno (terreno) (graus);

$\psi 1$ = ângulo de atrito entre a terra e o muro ou ângulo de rugosidade do muro (graus).

Considerando-se $\circ$ paramento interno do muro liso $\left(\psi_{1}=0\right)$, vertical $(\theta=0)$ e o terreno adjacente horizontal, $(\alpha=0)$, simplifica-se a expressão (4.6), que assume a forma:

$$
K=\operatorname{tg}^{2}\left(45^{\circ}-\frac{\varphi}{2}\right)
$$


Para efeito de cálculo o ângulo de atrito interno $\psi$ não deve ser tomado maior que $30^{\circ}$.

Pode-se, portanto, calcular o valor do momento fletor na base do muro devido ao empuxo : $M=E y$. Onde:

$y=$ distância entre $\circ$ ponto de aplicação da resultante do empuxo e a base do muro;

Com as mesmas simplificações adotadas para 0 cálculo do coeficinte de empuxo, tem-se: $y=\frac{h}{3}$.

Segundo MOLITERNo (1980) espessura útil (d) na base do muro pode ser estimada pela relação:

$$
d=10 \sqrt{M}
$$

com $M$ em $t \mathrm{fm} / \mathrm{m}$ e d obtido em centímetros.

A espessura no topo do muro deverá ser fixada em função de diâmetro $\phi$ do agregado, $d \geq 4 \phi$ segundo a NBR 6118 (1982), das cargas provenientes da superestrutura e de razões construtivas.

\subsubsection{2 - CÁLCULO DOS ENCONTROS}

Os esforços nos encontros serão calculados em seções definidas a cada metro da base do muro. Obtém-se, desta forma, os diagramas de momento fletor e esforço cortante necessários ao projeto de armação.

Os esforços transversais nos encontros, no caso de pontes de eixo reto ortogonal, se reduzem aos provenientes das cargas de vento na superestrutura. Estas, face à grande rigidez dos encontros na direção transversal, podem ser desprezadas.

- cálculo da distribuição do esforço longitudinal entre os pilares é geralmente feito admitindo-se que 0 esforço horizontal longitudinal seja aplicado no eixo de simetria do estrado. Esta simplificação é admissivel, considerando serem, em geral, pequenas as larguras das pontes em relação aos seus comprimentos. Embora tratar-se o presente estudo de pontes de pequeno vão, o que pode fazer com que 
esta relação entre as dimensões do tabuleiro se modifique devido à pequena dimensão do vão, será aqui adotada esta simplificação.

o esforço aplicado ao topo de cada pilar é igual ao produto do deslocamento por um coeficiente, denominado coeficiente de rigidez ou rigidez do pilar (k).

Em uma ponte de estrado contínuo, isto é, sem juntas deslocáveis, todos os pilares ficam presos ao vigamento da estrutura, estando, portanto, sujeitos a certas condições de compatibilidade de deformação. Se todos os pilares sofrem o mesmo deslocamento, o esforço transmitido a cada pilar será proporcional à uma respectiva rigidez. O esforço $H_{i}$, em um pilar genérico $i$, é dado pela expressão:

$$
H_{i}=\frac{k_{i}}{\sum k_{j}} H
$$

onde:

$k_{i}=$ rigidez do pilar i $(\mathrm{kN} / \mathrm{cm}) ;$

$\mathrm{H}=$ esforço

longitudinal no estrado $(\mathrm{kN})$;

$\sum k_{j}=$ somatório das rigidez dos $j$ pilares constituintes da infraestrutura.

Para o cálculo do coeficiente de rigidez, considere-se o caso de um pilar engastado na base e livre no topo. Denomina-se coeficiente de flexibilidade ( $\delta$ ), a deformação no topo do pilar quando submetido a um esforço unitário. A rigidez $\mathrm{k}$ do mesmo pilar é o esforço que produz uma deformação unitária no topo do pilar.

A deformação $\Delta$ do pilar pode ser expressa em função do coeficiente de flexibilidade: $\Delta=H \delta$. Da definição de rigidez tem-se: $H=k_{r} \Delta$. Comparando-se as duas expressões, obtém-se :

$k_{r}=\frac{1}{\delta}$

Para o caso de um pilar com inércia constante: 


$$
\delta=\frac{1}{E I} \frac{L^{3}}{3} \quad \therefore \quad k_{r}=\frac{3 E I}{L^{3}}
$$

onde:

$E=$ módulo de elasticidade $\left(\mathrm{kN} / \mathrm{cm}^{2}\right) \tilde{i}$

$I=$ momento de inércia da seção transversal do pilar $\left(\mathrm{cm}^{4}\right)$;

$L=$ altura do pilar $(\mathrm{cm})$.

- cálculo da flexibilidade de pilares com inércia variável se faz por integração numérica, ao longo do eixo do pilar. Aplicando o Princípio dos Trabalhos Virtuais, chega-se (figura 4.6):

$$
\delta=\int_{0}^{L} \frac{M \bar{M}}{E I} d y=\int_{0}^{L} \frac{y^{2}}{E I} d y=\frac{1}{E} \int_{0}^{L} \frac{y^{2}}{I} d y
$$

aplicando integração numérica, obtém-se:

$$
\delta=\frac{1}{E} \sum \frac{y^{2} \Delta y}{I}
$$
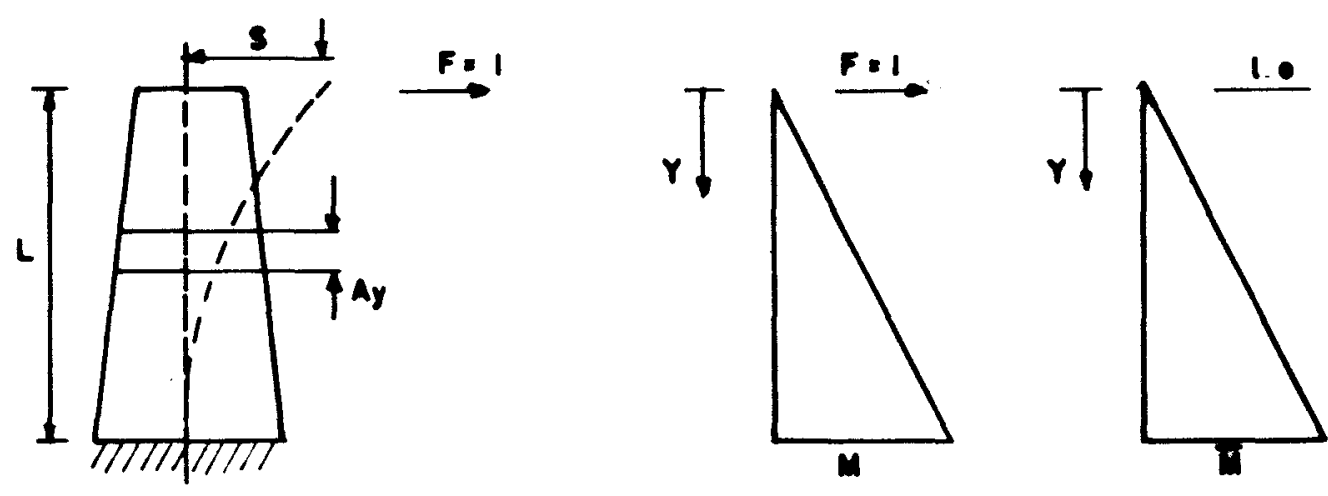

Figura 4.6 - Cálculo da rigidez de pilares com inércia variável

Considerando-se 0 apoio da superestrutura feito através de articulações de neoprene, a rigidez do pilar deve ser obtida levando-se em consideração a contribuição do neoprene para a deformação total do pilar.

Os apoios elastoméricos podem ser constituídos por uma lâmina de neoprene simples ou por diversas camadas intercaladas com chapas metálicas. Neste caso o neoprene é vulcanizado juntamente com as chapas metálicas, de modo que 
se estabelece uma boa aderência entre os dois materiais, condição necessária para o trabalho conjunto dos mesmos.

Aplicando-se no topo da placa de neoprene uma força horizontal unitária, esta provocara no aparelho de apoio uma deformação $\delta_{n}$; como o aparelho de apoio está ligado ao pilar, a força solicitará, também, o topo do pilar, deslocando-o de $\delta_{p}$, de modo que 0 conjunto, pilar mais aparelho de apoio, sofrerá uma deformação total $\delta_{n}+\delta_{p}$.

A rigidez do conjunto é, segundo a equação 4.10, igual a:

$$
k_{n+p}=\frac{1}{\delta_{n}+\delta_{p}}
$$

A deformação angular de uma placa de neoprene sujeita a um esforço horizontal unitário vale $\gamma_{a}=\frac{\delta_{n}}{h_{n}}$, sendo $h_{n}$ a sua altura. Sendo $G_{n} \circ$ módulo de elasticidade transversal da borracha, conhecido como módulo de cisalhamento, e $A_{n}$ a área da projeção horizontal da placa de neoprene, obtém-se:

$$
\delta_{n}=\frac{h_{n}}{G_{n} A_{n}}
$$

Para o dimensionamento desses apoios, pode-se seguir as indicações do SERVICE CENTRAL D'ETUDES TECHNIQUES (França) apud PFEIL (1990) (ver Anexo A).

Para o cálculo dos esforços atuantes nos encontros, serão considerados os seguintes carregamentos:

a) Dos aterros de acesso e sobrecarga dos veículos adjacentes ao muro;

b) da variação da temperatura e retração do concreto;

c) da aceleração e frenagem dos veículos sobre o estrado.

\section{a) Aterros de acesso e sobrecarga dos veículos adjacentes ao muro}

Os esforços introduzidos pela pressão de terra dos aterros de acesso serão supostos absorvidos por cada encontro 
individualmente.

Além desta pressão, podem ocorrer nos encontros pressões devidas à carga móvel que está adentrando ou deixando a ponte. Estas pressões „deverão ser somadas às anteriores.
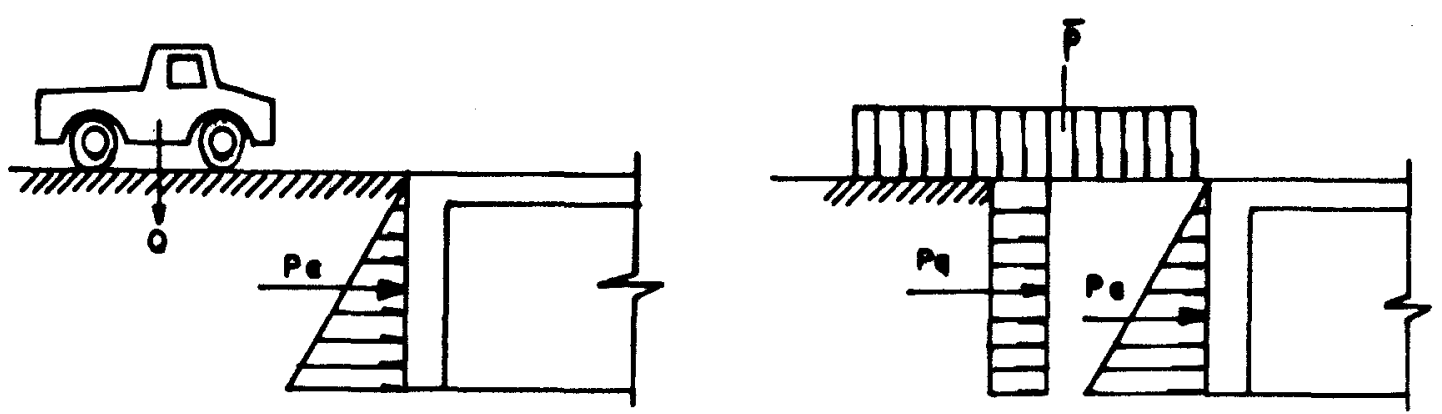

Figura 4.7 - Efeito da carga móvel nos encontros

Para efeito de cálculo, esta carga móvel colocada junto à cabeceira da ponte, é considerada uniformemente distribuída e não majorada pelo coeficiente de impacto.

Conforme EL DEBS e TAKEYA (1990), o seu valor é estimado transformando-se o carregamento do veículo tipo em carga uniformemente distribuída, dividindo-se seu peso pela sua área, e compondo-o com a carga distribuída $p$ que considera o efeito dos demais veículos.

$$
\begin{aligned}
& p_{v}=\frac{\text { peso do veículo tipo }}{3.0 \times 6.0} \\
& \bar{p}=\frac{p_{v} \times 3.0+p\left(\ell_{y}-3.0\right)}{\ell_{y}}
\end{aligned}
$$

onde:

$p_{v}=$ carga do veículo tipo distribuída sobre sua área $\left(\mathrm{kn} / \mathrm{m}^{2}\right)$;

$\mathrm{p}=$ carga uniformemente distribuída que compõem o trem tipo, $\left(p=5.0 \mathrm{kN} / \mathrm{m}^{2}\right.$, segundo a NBR 7188 (1984);

$\overline{\mathrm{p}}=$ carga móvel uniformemente distribuída considerada no cálculo dos encontros $\left(\mathrm{kN} / \mathrm{m}^{2}\right)$; 
$\ell_{y}=$ largura do encontro $(\mathrm{m})$.

- carregamento assim obtido pode ser considerado como um aterro adicional, de altura $h_{\circ}$, dividindo-se 0 seu valor pelo peso específico do solo $\left(\gamma_{t}\right)$ :

$$
h_{0}=\frac{\bar{p}}{\gamma_{t}}
$$

Considerando-se a ação simultânea das cargas devidas ao aterro com essas devidas às cargas móveis, tem-se atuando no muro um carregamento trapezoidal cuja base menor terá valor $\mathrm{P}_{\mathrm{q}}$, base maior $\mathrm{P}_{\mathrm{T}} \mathrm{e}$ altura $\mathrm{h}$ igual à altura teórica do muro. Sendo:

$$
\begin{aligned}
& \mathrm{P}_{\mathrm{q}}=\mathrm{K} \gamma_{\mathrm{t}} \mathrm{h}_{0} \\
& \mathrm{P}_{\mathrm{a}}=\mathrm{K} \gamma_{\mathrm{t}} \mathrm{h} \\
& \mathrm{P}_{\mathrm{T}}=\mathrm{P}_{\mathrm{q}}+\mathrm{P}_{\mathrm{a}}
\end{aligned}
$$

onde:

$\mathrm{P}_{\mathrm{q}}=$ pressão de terra devido à sobrecarga no terreno adjacente ao topo do muro $\left(\mathrm{kN} / \mathrm{m}^{2}\right)$;

$\mathrm{P}_{\mathrm{a}}=$ pressão de terra à profundidade $\mathrm{h}$ do nível do terreno $\left(\mathrm{kN} / \mathrm{m}^{2}\right)$;

$\mathrm{P}_{\mathrm{T}}=$ pressão total atuante no muro à profundidade $\mathrm{h}$ do nível do terreno $\left(\mathrm{kN} / \mathrm{m}^{2}\right)$.

De posse do carregamento atuante no muro pode-se, então, avaliar os esforços nas seções consideradas.

Para uma seção genérica $s$, localizada à uma profundidade y do nível do terreno, tem-se segundo MOLITERNo (1980):

$$
\begin{aligned}
& P_{y}=P_{q}+\frac{y}{h} P_{a} \\
& V_{s}=\frac{y}{2}\left(P_{q}+P_{y}\right) \\
& M_{s}=\frac{y^{2}}{6}\left(2 P_{q}+P_{y}\right)
\end{aligned}
$$


onde:

$P_{y}=$ pressão de terra na seção genérica $s\left(\mathrm{kN} / \mathrm{m}^{2}\right)$;

$\mathrm{V}_{\mathrm{s}}=$ cortante na seção genérica $\mathrm{s}(\mathrm{kN} / \mathrm{m})$;

$\mathrm{M}_{\mathrm{s}}=$ momento fletor na seção genérića $\mathbf{s}(\mathrm{kNm} / \mathrm{m})$.

\section{b) Variação de temperatura e retração do concreto}

o efeito da variação de temperatura nas pontes pode ser subdividido em:

b.1) Variação de temperatura ao longo da altura da seção transversal (gradiente térmico);

b.2) variação uniforme de temperatura.

A variação de temperatura ao longo da altura da seção transversal irá produzir flexão na superestrutura da ponte. Face ao pequeno gradiente térmico a que se submeterá a laje do tabuleiro esses esforços não serão considerados.

Para efeito da variação uniforme de temperatura, a NBR 7187 recomenda que seja considerada uma variação de $\pm 15^{\circ} \mathrm{C}$. Sabe-se que a seção de uma peça submetida à uma variação uniforme de temperatura igual à $\Delta t^{\circ} \mathrm{C}$ terá uma deformação específica, axial $\left(\epsilon_{c t}\right)$, dada por:

$$
\epsilon_{c t}=\alpha \Delta t
$$

sendo $\alpha$ o coeficiente de dilatação térmica linear do material. A NBR 6118 recomenda a adoção do valor $\alpha=10^{-5} /{ }^{\circ} \mathrm{C}$ para o concreto armado.

A retração do concreto é uma deformação independente de carregamento, ocorrendo devido à perda da água que não está quimicamente associada ao mesmo no contato do concreto com o ar. A denominação retração decorre do fato de fenômeno significar uma redução de volume da peça de concreto.

Os esforços oriundos da retração do concreto devem ser calculados de acordo com a NBR 7187 (1986). Permite-se, no entanto, nos casos correntes, considerar a deformação específica por retração igual a $15 \times 10^{-5}$. Isto corresponde, 
na prática, a considerar a retração como uma queda de temperatura de $15^{\circ} \mathrm{C}$.

Vê-se que os esforços introduzidos pela retração do concreto são bastante análogos aos introduzidos pela variação da temperatura, com uma única diferença de não se poder atenuar os efeitos da variação de temperatura, ao passo que uma cura prolongada e cuidadosa, bem como a adoção de juntas (provisórias) adequadas de concretagem, conseguem minimizar os efeitos da retração.

No presente trabalho, os esforços provenientes da retração e temperatura serão avaliados conjuntamente, admitindo-se, de maneira mais desfavorável, uma queda de temperatura de $30^{\circ} \mathrm{C}$.

Esta queda de temperatura provocará, através de uma variação no comprimento da laje da superestrutura, uma força horizontal cujo valor é dado por:

$$
F_{i}=k_{i} \epsilon_{c t} Y_{i}
$$

onde:

$F_{i}=$ força introduzida no pilar $i$ a partir da deformação do tabuleiro $(\mathrm{kN} / \mathrm{m})$;

$k_{i}=$ rigidez do pilar $i(\mathrm{kN} / \mathrm{m}) ;$

$y_{i}=$ distância do pilar $i$ ao ponto de deslocamento nulo (m).

- ponto de deslocamento nulo (PDN) é obtido a partir das rigezas de todos os pilares, fixando-se um eixo de referência a partir do qual:

$$
x=\frac{\sum k_{i} l_{i}}{\sum k_{i}}
$$

onde :

$x$ = distância do ponto de deslocamento nulo ao eixo de referência (m);

$l_{j}=$ distância do pilar $i$ ao eixo de referência (m). 


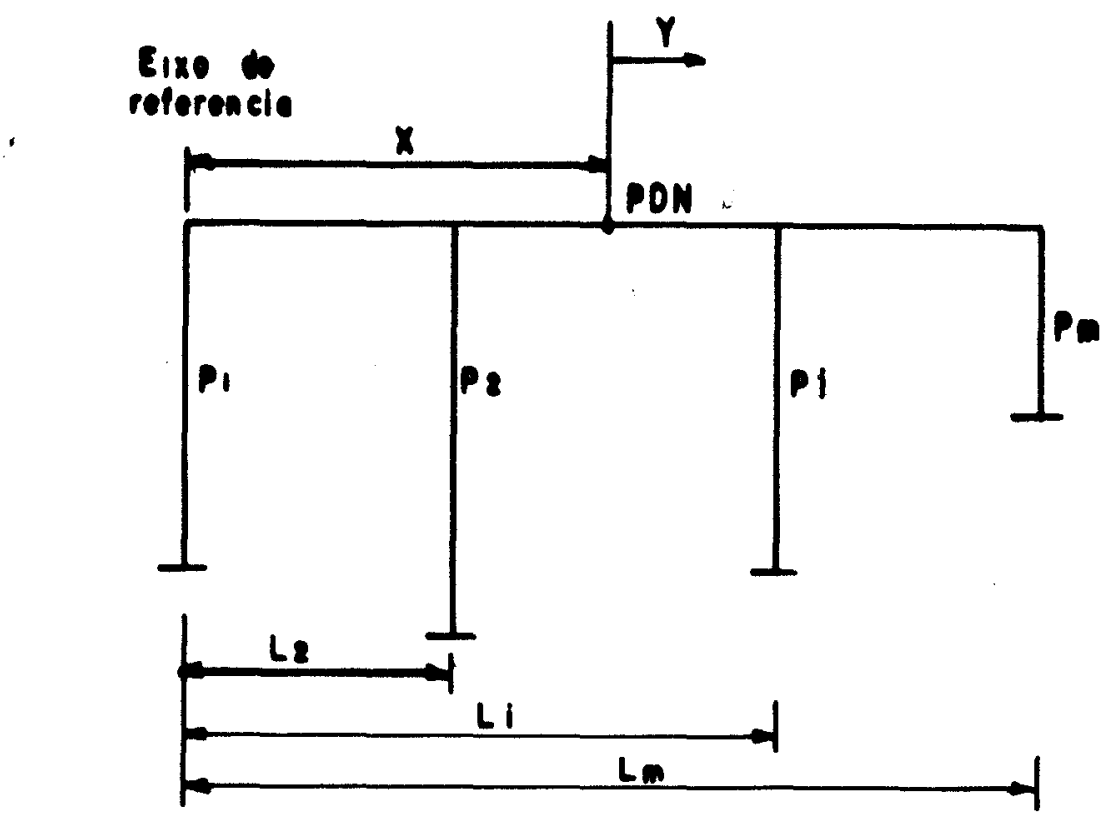

Figura 4.8 - Ponto de deslocamento nulo (PDN)

\section{c) Aceleração e frenagem}

Segundo PFEIL (1990), os esforços longitudinais de aceleração e frenagem obedecem a fórmula fundamental da dinâmica: $F=m a=Q \frac{a}{g}$. Sendo:

$\mathrm{m}=$ massa do veículo $\left(\mathrm{kg} \times 10^{3}\right)$;

$a=$ aceleração do veículo $\left(\mathrm{m} / \mathrm{s}^{2}\right)$;

$Q=$ peso do veículo $(\mathrm{kN})$;

$g=$ aceleração da gravidade $\left(\mathrm{m} / \mathrm{s}^{2}\right)$.

Admitindo-se um certo valor para a aceleração do veículo, suposta constante, verifica-se que o esforco longitudinal H representa uma fração (igual à relação $\frac{a}{g}$ ) do peso do veículo).

Para pontes rodoviárias, a norma NBR 7187 (1986) adota os seguintes valores para o cálculo dos esforços longitudinais, devendo-se adotar o maior dos dois:

c.1) Aceleração - 5\% da carga móvel aplicada sobre o tabuleiro;

c.2) frenagem - 30\% do peso do veículo tipo.

A alínea (c.1) corresponde à aceleração $\mathrm{a}=5 \% \mathrm{~g} \cong$ $0.5 \mathrm{~m} / \mathrm{s}^{2}$, com a qual a velocidade de $80 \mathrm{~km} / \mathrm{h}$ é atingida na 
extensão de 500 metros.

A frenagem de $30 \%$ corresponde à aceleração negativa $a=-30 \% \mathrm{~g} \cong-3 \mathrm{~m} / \mathrm{s}^{2}$, com a qual um veículo a $80 \mathrm{~km} / \mathrm{h}$ pode ser imobilizado numa extensão de 82 metros.

\subsubsection{3 - PRÉ -DIMENSIONAMENTO DOS BLOCOS}

- pré-dimensionamento se fará a partir das recomendações de alguns autores sobre as dimensões mínimas que se deve ter no caso em questão.

GUERRIN (1955) propõem o dimensionamento dos blocos como elemento rígido. Para isso, recomenda a utilização da relação $h_{b} / e \geq \frac{1}{2}$, sendo $h_{b} a$ altura do bloco e "e" a distância entre eixos das estacas. Este autor determina ainda um cobrimento de 15 centímetros para as estacas.

Segundo MOLITERNO (1980), para se verificar a condição de engastamento do muro no bloco, este último deverá ter altura maior ou igual à espessura do muro $\left(e_{m}\right)$.

MONTOYA (1973) recomenda que a altura do bloco se fixe, por condições econômicas, em função das cargas e dimensões em planta. Para se poder calculá-lo como rígido, é necessário que a distância entre a face do pilar ao eixo da estaca mais afastada (c) seja menor ou igual a uma vez e meia a sua altura $\left(h_{b}\right): c \leq 1.5 h_{b}$. Esta última não deve ser menor que 30 centímetros e as estacas deverão penetrar no bloco pelo menos 10 centímetros, devendo-se ter ainda, um mínimo de 20 centímetros de concreto sobre as suas cabeças.

Ainda segundo MONTOYA (1973), a forma $e$ as dimensões em planta dos blocos dependem do número de estacas, das dimensões destas e de sua separação. A distância mínima entre eixos de estacas (e), deve ser de 2 vezes o seu diâmetro ( 1.75 vezes a diagonal se forem de seção quadrada) e não menor que 75 centímetros. Esta separação deve manter-se ao longo de toda a estaca, o que se deve verificar para estacas inclinadas. De qualquer forma, para evitar-se problemas de alinhamento, convém que a separação não seja 
inferior a $\frac{1}{15}$ do comprimento das estacas.

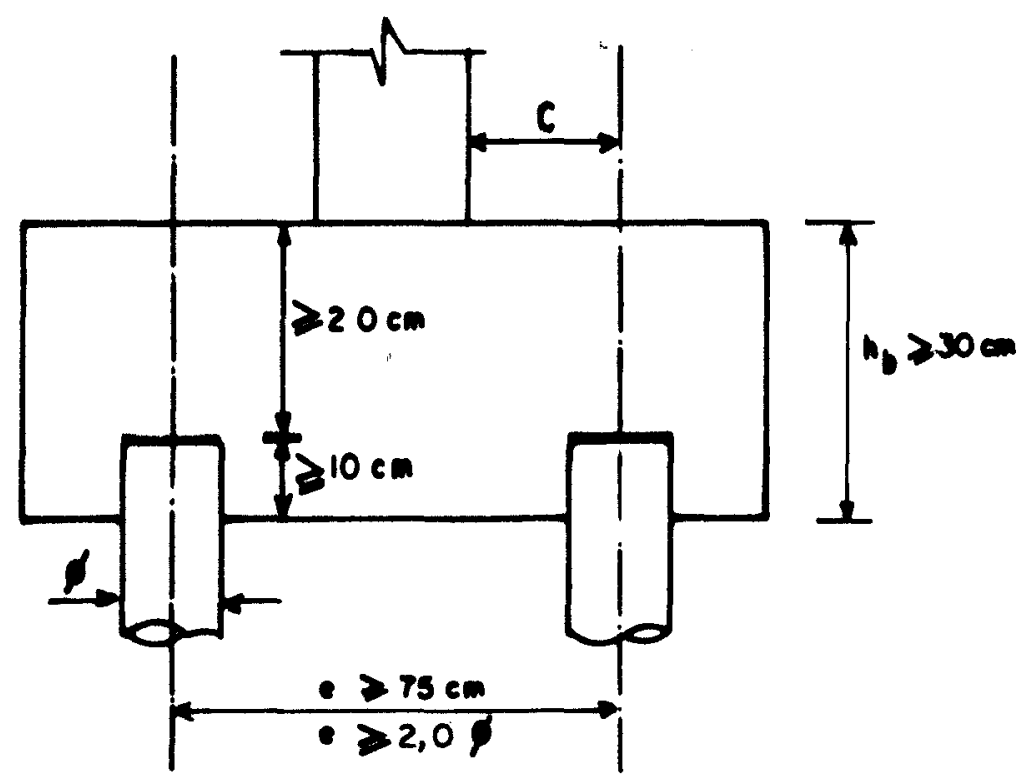

Figura 4.9 - Dimensós mínimas do bloco Fonte: MONTOYA (1973)

Segundo MORAES (1976), as distâncias entre estacas (e) devem ser: e $\geq 2.5 \phi$, para estacas pré-moldadas; e $\geq 3 \phi$, para estacas moldadas no local ou tubulões. O autor recomenda ainda o mesmo cobrimento das estacas adotado por GUERRIN (1955).

Quando não se obtém a resultante das cargas passando pelo centro de gravidade das estacas, convém que se aumente a separação entre estas, de forma a diminuir a carga nas mesmas devidas ao momento produzido pela excentricidade existente.

\subsubsection{4 - CÁLCULO DOS ESFORÇOS NOS BLOCOS}

Os esforços atuantes nos blocos sobre estacas são obtidos a partir das reações das últimas.

Embora as ligações das estacas com os blocos sejam, muitas vezes, feitas com capacidade de absorver momentos fletores, supõem-se, geralmente, que as estacas estejam rotuladas nos blocos. Os estaqueamentos são, em geral, calculados admitindo-se o bloco infinitamente rígido e as 
estacas rotuladas em suas extremidades, supondo ainda todas as estacas com o mesmo comprimento.

Despreza-se também as pressões de apoio do bloco no terreno.

Considerando-se 0 caso de um muro de grande comprimento com carregamento constante ao longo do mesmo, tanto as cargas como os deslocamentos ficarão no plano da seção transversal (estaqueamento plano). Pode-se, desta forma, analisar apenas o trecho do estaqueamento, de extensão arbitrária, considerado como um sistema plano.

Como está sendo assumido estacas cravadas na vertical, o problema se resume à um estaqueamento plano com estacas paralelas.
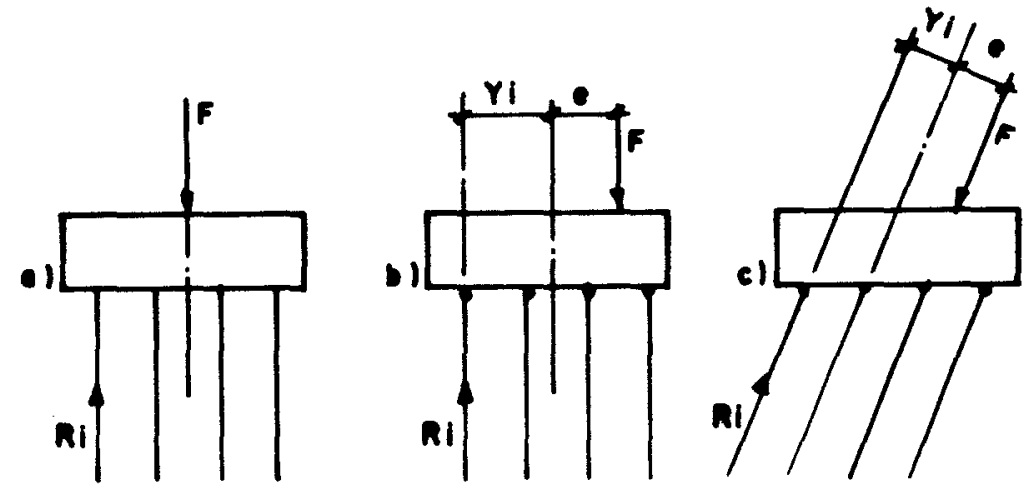

Figura 4.10 - Estaqueamento plano com estacas paralelas:

a) estacas verticais, com esforço vertical centrado:

b) estacas verticais, com esforço vertical excêntrico:

c) estacas inclinadas com esforço excêntrico. Fonte: PFEIL (1990)

Nestes estaqueamentos, para estacas idênticas, quando a carga atuante passa pelo centro de gravidade das estacas, a carga é distribuída igualmente entre as mesmas pelo bloco rígido.

Se a carga atuar com uma excentricidade $e_{x}$, tendo-se em vista a hipótese de rigidez infinita do bloco, as cargas nas estacas são determinadas pela fórmula da flexão 
composta, uma vez que coincidem as hipóteses adotadas na resolução dos dois problemas:

$$
R_{i}=\frac{F}{n} \pm \frac{F e_{x} y_{i}}{\sum y_{j}^{2}}
$$

onde:

$R_{i}=$ carga na estaca $i(k N)$;

$F=$ carga por unidade de comprimento do muro $(\mathrm{kN} / \mathrm{m})$;

$n=$ número de estacas na faixa considerada;

$e_{x}=$ distância entre 0 ponto de aplicação da carga ao centro de gravidade das estacas (m);

$Y_{i}=$ distância da estaca $i$ ao centro de gravidade do estaqueamento (m);

$\sum y_{j}^{2}=$ somatório das distâncias ao quadrado das $j$ estacas contidas no plano do estaqueamento $\left(\mathrm{m}^{2}\right)$.

- cálculo dos esforços nos blocos seguirão um dos dois métodos a seguir:

a) Método das Bielas;

b) Método do CEB (1970).

A escolha do método será feita em função da maior semelhança do bloco obtido no pré-dimensionamento com aquele resultante das imposições de cada método.

\section{a) Método das Bielas}

Os esforços no bloco serão obtidos admitindo-se, em seu interior, uma treliça constituída da barras tracionadas, situadas logo acima do arrasamento das estacas, e barras comprimidas e inclinadas chamadas bielas, com extremidades junto da região de apoio dos pilares e da cabeça das estacas.

A linha de atuação dos esforços de compressão (bielas de compressão) é obtida ligando-se os pontos localizados nos eixos das estacas com aqueles situados à distância $\frac{e_{m}}{4}$ para dentro da face dos encontros, sendo $e_{m} a$ espessura dos muros.

o esforço nas barras tracionadas ( $Z$ ), será: 


$$
z=\frac{R}{\operatorname{tg} \alpha_{1}}
$$

onde:

$R=$ reação da estaca $k(k N)$;

$\alpha_{1}$ = ângulo entre a biela de compressão $e$ as barras tracionadas (graus).

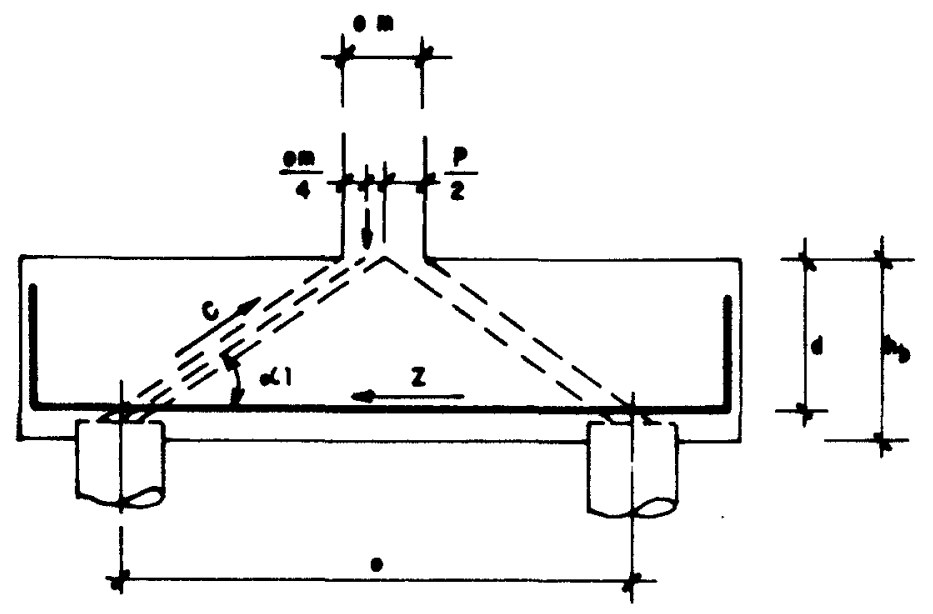

Figura 4.11 - Treliça idealizada no interior do bloco Fonte: MORAES (1976)

A biela comprimida deverá ser verificada para dois casos, segundo MORAES (1976):

a.1) Tensão máxima de compressão no concreto, na biela junto ao pilar

$$
\frac{F}{2 A_{p} \operatorname{sen}^{2} \alpha_{1}} \leq \frac{1.4 f_{c d}}{1.65}=0.85 f_{c d}
$$

a.2) Tensão máxima de compressão no concreto, na biela junto à estaca

$$
\frac{R}{A_{e} \operatorname{sen}^{2} \alpha_{1}} \leq 0.85 \mathrm{f}_{c d}
$$

onde:

$F=$ carga total no bloco (kN);

$R=$ reação na estaca $(k N)$;

$A_{p}=$ área da seção transversal da faixa do muro considerada $\left(\mathrm{cm}^{2}\right)$; 
$A_{e}=$ área da seção transversal da estaca $\left(\mathrm{cm}^{2}\right)$;

$f_{c d}=$ resistência de cálculo à compressão do concreto $\left(\mathrm{kN} / \mathrm{cm}^{2}\right)$.

0 ângulo $\alpha_{1}$ deverá estar situado entre $45^{\circ}$ e $55^{\circ}$. Para 0 caso de bloco sobre duas estacas simetricamente dispostas com relação ao pilar:

$$
\operatorname{tg} \alpha_{1}=\frac{2 d}{e-e_{m} / 2}
$$

de onde obtém-se:

$$
0.5\left(e-\frac{e_{m}}{2}\right) \leq d \leq 0.71\left(e-\frac{e_{m}}{2}\right)
$$

\section{b) Método do CEB}

Este método refere-se a blocos que apresentam as seguintes características geométricas:

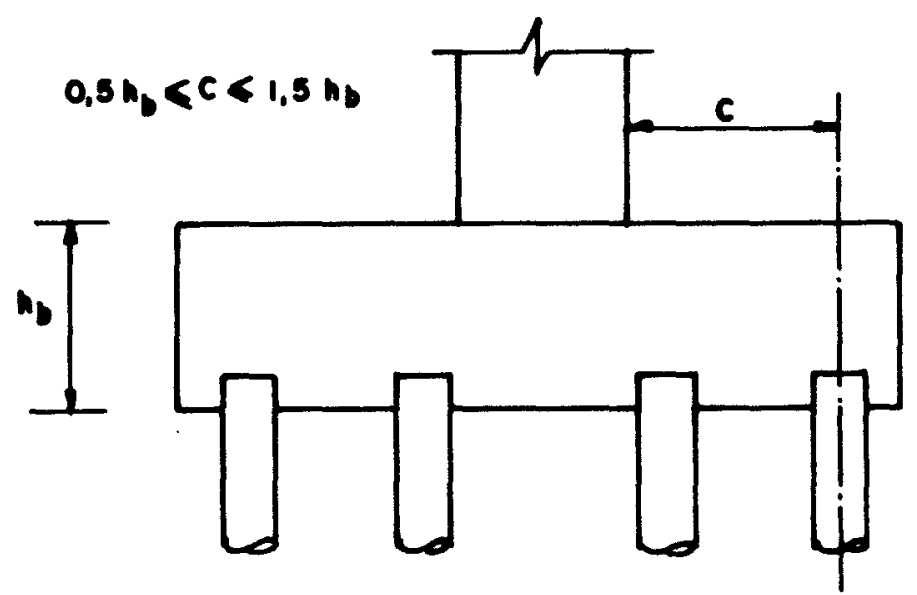

Figura 4.12 - Caracteristicas geométricas necessárias ao cálculo dos blocos segundo O CEB (1970)

Onde deve-se ter: $0.5 \mathrm{~h}_{b} \leq c \leq 1.5 \mathrm{~h}_{b}$. Esta desigualdade deve ser satisfeita em todas as direçes, do contrário não são aplicáveis as recomendações deste método.

No caso de blocos sobre estacas, a aba c é avaliada a partir do eixo da estaca mais afastada da face do pilar ou da parede. 
Quando aparecem tensões de tração, supõem-se que a estabilidade seja assegurada pela resistência das estacas à tração, desde que a força de tração seja equilibrada com segurança, levando-se em conta o peso próprio da estaca, sua resistência ao arrancamento, a seção de sua armadura longitudinal e a eficiência da ancoragem destas armadura na sapata.

o momento fletor que determinará a armadura inferior é calculado em relação à uma seção de referência $\mathrm{S1}$, levando-se em conta a totalidade dos esforços agindo sobre a parte do bloco limitada por essa seção e que não é atravessada pelo eixo do pilar ou pelo plano médio da parede paralelo à $S 1$.

Segundo SANTOS (1984), a seção de referência $S_{1}$ é definida da seguinte maneira: ela é plana, normal à superfície de apoio e afeta a totalidade da sapata; está situada entre as faces do pilar ou da parede, a uma distância da face igual a $0.15 e_{m}$, onde $e_{m}$, para o caso em questão, é a espessura do muro no sentido perpendicular à seção considerada. Esta última recomendação deve-se ao fato de que, no caso de pilares de seção alongada ou paredes espessas, o valor do momento pode crescer sensivelmente além da seção situada na face do pilar ou parede.

- esforço cortante $\mathrm{V}_{d}$ de cálculo, computado por unidade de largura, é verificado em uma seção de referência $\mathrm{S}_{2}$. Esta seção, perpendicular à superfície de apoio, é definida a uma distância $\frac{d}{2}$ da face do pilar ou parede, salvo no caso em que uma ou mais estacas fiquem situadas a uma distância da face do pilar inferior àquela anteriormente estipulada. Neste caso a seção $S_{2}$ fica definida junto à face do pilar.

o esforço $V_{d}$, definido em $S_{2}$, deve ser inferior ou no máximo igual ao esforço cortante limite $v_{d l i m}$ dado, segundo SANTOS (1984):

$$
v_{d 1 i m}=\frac{2.5}{\gamma_{c}}\left(1-\frac{c}{5 d}\right) b_{2} d_{2} \sqrt{f_{c k}}
$$


onde:

$\gamma_{c}=$ coeficiente de minoração da resistência do concreto;

$\alpha=$ altura útil do bloco $(\mathrm{cm})$;

$d_{2}=$ altura útil do bloco medida na seção de referência $s_{1}$ (cm) ;

$\mathrm{b}_{2}=$ unidade de largura do bloco considerada $(\mathrm{cm})$;

$\mathrm{f}_{c k}=$ resistência característica do concreto à compressão $\left(\mathrm{kgf} / \mathrm{cm}^{2}\right)$.

sendo $v_{d l i m}$ obtido em $\mathrm{kgf} / \mathrm{m}$.

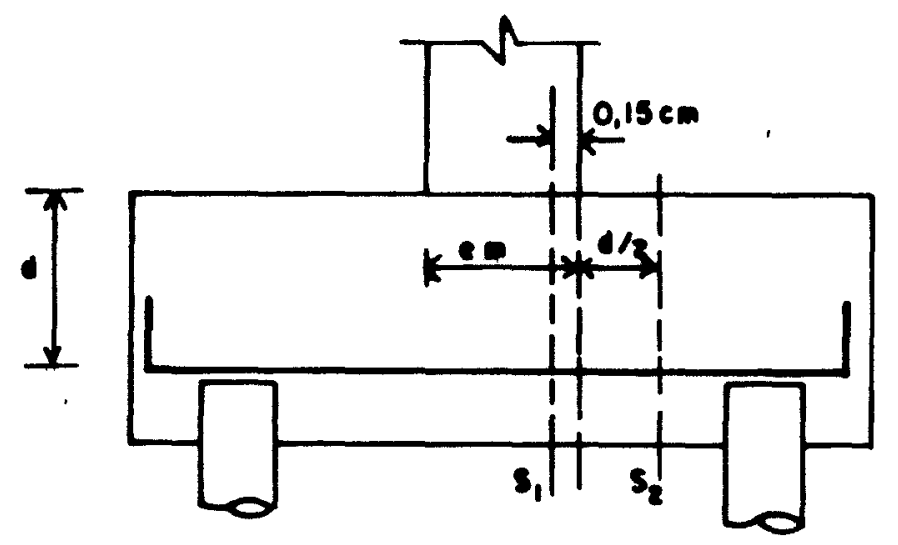

Figura 4.13 - Seções de referência $S_{1}$ e $S_{2}$

A resistência ao esforço cortante deve ser verificada, também, em qualquer seção do bloco onde as características geométricas da seção e a intensidade ou a localização das reações podem provocar circunstâncias mais desfavoráveis que aquelas relativas às seções de referência.

Isto pode ocorrer na vizinhança das estacas de canto. Neste caso, o esforço cortante que solicita a seção é igual à reação $R_{d}$ da estaca de canto.

A seção que deverá ser verificada fica situada a uma distância $\frac{d}{2}$, sendo a altura útil d medida junto a face da estaca considerada. A largura $b_{2}^{\prime}$ é igual a altura útil d acrescida da largura (diâmetro) da estaca. A altura dí é a altura útil da seção $S_{2}^{\prime}$ assim definida.

A reação $R_{d}$ da estaca deve ser no máximo igual à reação limite $R_{d} l_{i m}$ ' definida pela relação: 


$$
R_{d l i m}=\frac{1.2}{\gamma_{c}} b_{2}^{\prime} d_{2}^{\prime} \sqrt{f_{c k}}
$$

com ${ }_{c k}$ em $\mathrm{kgf} / \mathrm{cm}^{2}$ e $R_{d 1 \text { i m }}$ obtido em $\mathrm{kgf}$.

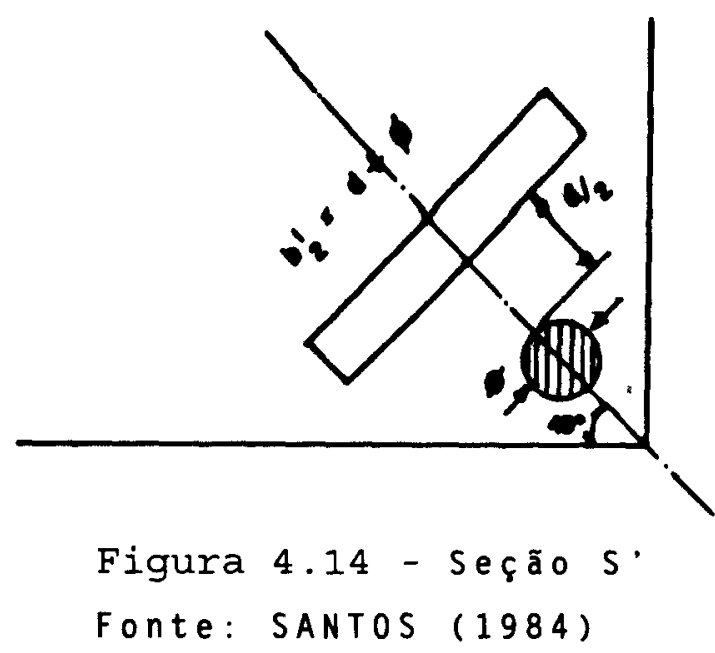

\section{3 - CÁLCULO COM CONTINUIDADE}

- cálculo com continuidade será desenvolvido supondo-se perfeita ligação entre a laje da superestrutura e os encontros.

A estrutura assim definida será analisada como um pórtico. Dessa forma, para efeito de cálculo, não haverá distinção entre superestrutura e encontros.

- pré-dimensionamento da laje será feito analogamente ao da estrutura sem continuidade (ítem 4.2.1.1). Tendo-se fixado a espessura da laje, pode-se, arbitrando-se uma espessura para os encontros, ter uma idéia dos esforços nos engastes e nos nós mediante o emprego do formulário desenvolvido por GREKOW et al (1971). De posse destes, estima-se a viabilidade do dimensionamento do pórtico. Pórticos cujas paredes possuem espessura muito menores que a laje, tem seu funcionamento estrutural semelhante àquele com laje bi-apoiada, pois praticamente não ocorrerá distribuição de esforços da laje para os encontros. 


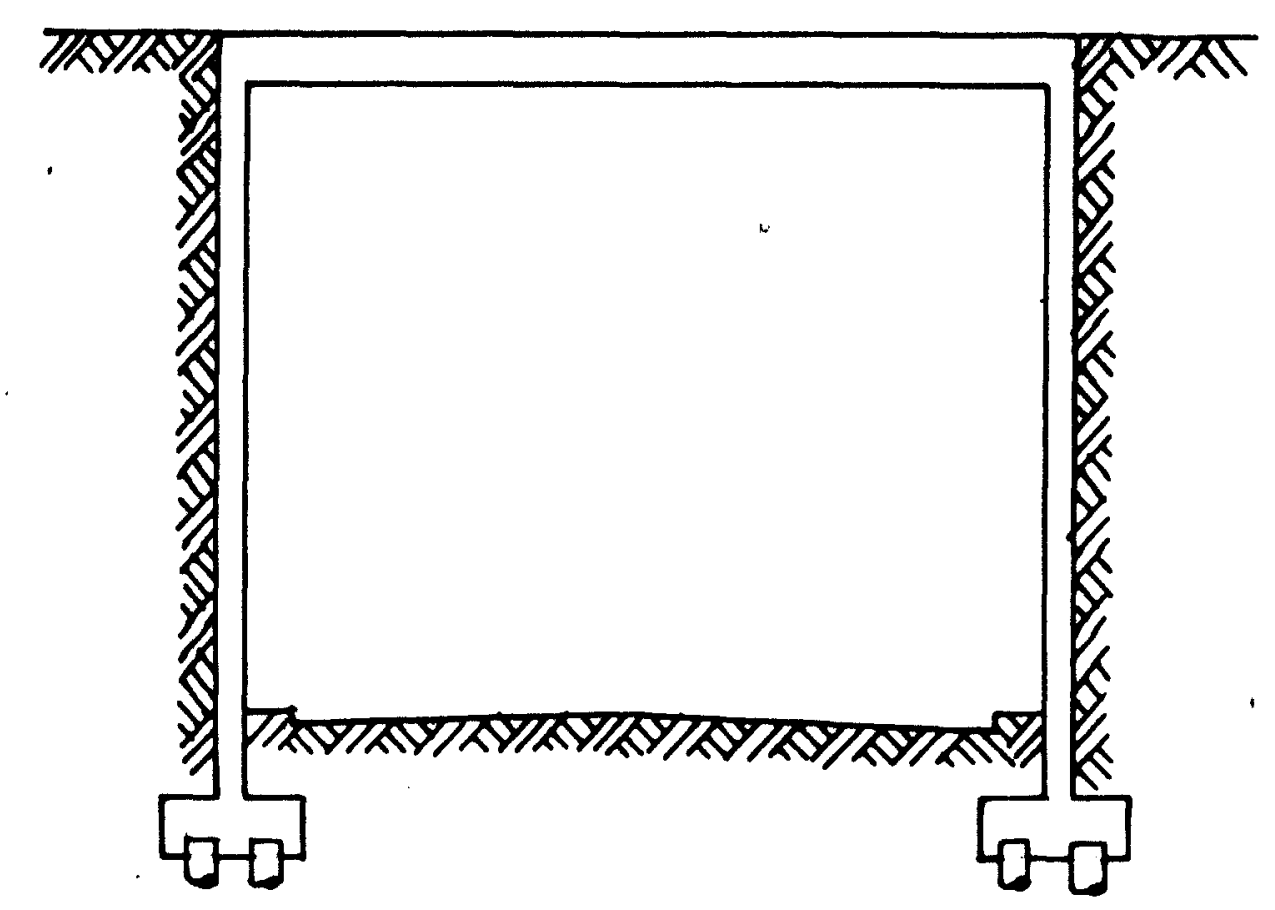

Figura 4.15 - Estrutura idealizada para o cálculo com continuidade

As cargas permanentes uniformementes distribuídas, aplicadas tanto no tabuleiro como nos encontros, terão seus esforcos calculados por metro de largura da ponte. Para isso, lança-se mão de um programa para cálculo de pórticos planos desenvolvido pelo autor, durante a fase de obtenção dos créditos, na disciplina Análise Matricial de Estruturas.

As cargas móveis serão computadas de acordo com o conceito de largura colaborante, elaborado por RÜsCH (1965).

Segundo este, tendo-se em mente que uma placa contínua diferencia-se de uma viga contínua antes de tudo porque, para ela, a seção transversal contribuinte não é constante, variando principalmente conforme $\circ$ lugar e $\circ$ estado de carga, pode-se fazer a seguinte aproximação:
a) Considerar, inicialmente, a ponte de laje como viga contínua com os mesmos vínculos e mesma carga da laje;
b) os momentos obtidos com a consideração anterior serão transformados em momentos de laje, dividindo-os pela largura colaborante respectiva;
c) a largura colaborante é determinada, de maneira aproximada, comparando um caso de carga possível de ser


calculado pela teoria das placas, com 0 caso correspondente calculado como viga.

Fazendo uma analogia para o caso de uma ponte em pórtico', os momentos obtidos através do cálculo como pórtico plano serão transformados em momentos de pórtico em laje (tri-dimensional), dividindo-se os mesmos pela largura colaborante definida acima.

- cálculo da fundação em nada difere daquele apresentado nos ítens 4.2 .2 .3 e 4.2.2.4 para a estrutura sem continuidade, adotando-se as mesmas considerações.

\subsection{1 - CÁLCULO DA PONTE EM PÓRTICO - CARREGAMENTO MÓVEL}

0 cálculo das cargas móveis verticais desenvolve-se, seguindo o conceito definido de largura colaborante (ítem 4.3), conforme se segue:

a) Cálculo da laje isolada segundo RÜSCH (1965);

b) cálculo como viga isolada;

c) cálculo das larguras colaborantes;

d) cálculo dos esforços como pórtico plano;

e) cálculo dos esforços na ponte em pórtico.

Os esforços provenientes da aceleração e frenagem dos veículos, considerados atuando ao longo da largura da laje, são calculados através do programa para pórticos planos, comentado no ítem 4.3. Para isso, obtém-se o valor desse carregamento conforme discutido no ítem 4.2.2.2, dividindo-o em seguida pela largura $\ell_{y}$ da laje $e$ considerando-se esta força horizontal aplicada nos nós do pórtico.

\subsubsection{1 - CÁLCULO DA LAJE ISOLADA}

- cálculo desenvolve-se de maneira análoga ao apresentado no ítem 4.2.1.2, observando-se a vinculação (laje bi-engastada com os bordos livres). 


\subsubsection{2 - CÁLCULO COMO VIGA ISOLADA}

- cálculo como viga faz-se necessário para a obtenção das larguras colaborantes. Conforme observa-se adiante, no ítem 4.3.1.3, essa é obtida apenas nos pontos de esforços máximos. Assim, calcula-se os esforços nos apoios (cortantes e momentos) e no centro do vão (momentos).

Para a obtenção desses esforços, determina-se, primeiramente, a linha de influência da viga. Em seguida calcula-se o trem-tipo atuante, posicionando-o da maneira mais desfavorável, de acordo com a linha de influência encontrada anteriormente, chegando-se aos esforços máximos. Para tanto, não se considera a porção do carregamento que provoque redução das solicitações

Segundo PFEIL (1990), denomina-se linha de influência de uma solicitação $S_{m}$, num ponto $m$, uma linha cujas ordenadas fornecem os valores de $S_{m}$ para diversas posições de uma carga unitária.

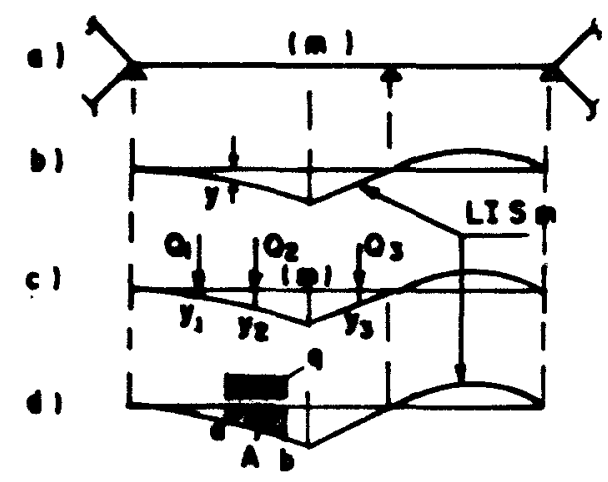

Figura 4.16 - Conceito de linha de influência:
a) esquema de uma estrutura, mostrando a seção ( $m$ ):
b) a linha de influência fornece a solicitação Sm, na seção (m), para qualquer posição de uma carga unitaria:
c) solicitação na seção (m), causada por várias cargas $Q: S m=Q 1 y 1+Q 2 y_{2}+Q_{3} y_{3}$ :
d) solicitação na seção (m). causada por uma carga distribuida uniforme q: $S m=\int_{a}^{b} q y d x=q \int_{a}^{b} y d x=q A$.
Fonte: PFEIL (1990) 
A linha de influência de uma viga bi-engastada pode ser obtida analiticamente. As ações que surgem nos apoios restritó, por ocasião da aplicąção de uma carga unitária $(F=1)$, são:

$$
\begin{aligned}
& M_{A}=\frac{a b^{2}}{\ell_{x}^{2}} \\
& M_{B}=\frac{a^{2} b}{\ell_{x}^{2}} \\
& R_{A}=\frac{b^{2}}{\ell_{x}^{3}}(3 a+b) \\
& R_{B}=\frac{a^{2}}{\ell_{x}^{3}}(a+3 b)
\end{aligned}
$$

sendo $M_{A}, M_{B}, R_{A}, R_{B}, a, b e \ell_{x}$, obtidos conforme a Figura 4.17 .

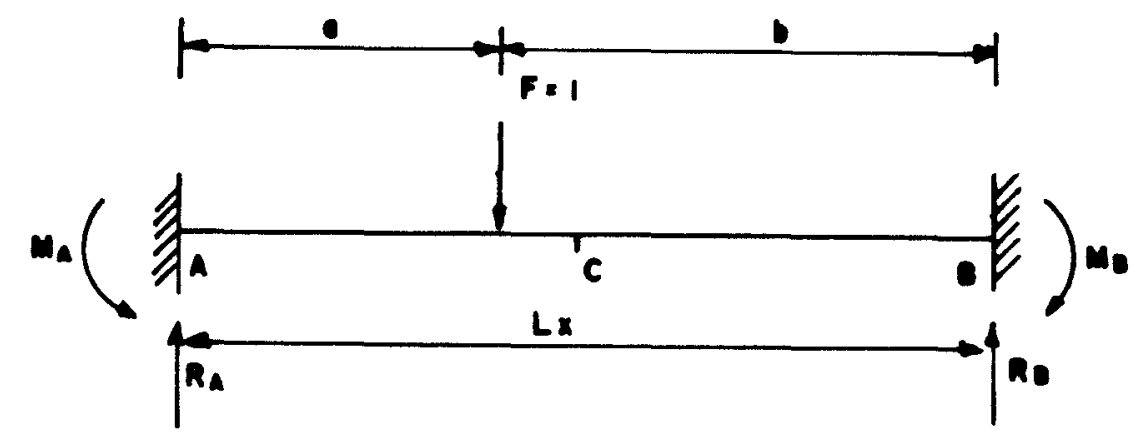

Figura 4.17 - Ações que surgem nos apoios restritos por ocasião da aplicação de uma força unitária

Pode-se, assim, calcular os valores dos momentos no

centro do vão:

$$
M_{v a ̃ o}=\frac{b^{2}}{2 \ell_{x}}-\left(\frac{\ell_{x}}{2}-a\right)
$$

b) para a força $F=1$ aplicada em $a \geq \frac{\ell_{x}}{2}$ 


$$
M_{\text {va o }}=\frac{b^{2}}{2 l_{x}}
$$

o trem-tipo representa as cargas ficticias, as quais supostas atuando diretamente isobre as vigas, produzem nestas os mesmos esforços das cargas reais dispostas sobre o tabuleiro.

Para o caso em questão, supõem-se que a viga seja constituída de uma faixa de laje de um metro de largura. Os valores das cargas serão:

$$
\begin{aligned}
& \mathrm{p}_{1}=\ell_{y} \mathrm{p} \\
& \mathrm{p}_{2}=\left(\ell_{y}-3.00\right) \mathrm{p} \\
& \overline{\mathrm{F}}=2 \mathrm{~F}_{\mathrm{r}}
\end{aligned}
$$

onde:

$p_{1}$ e $p_{2}=$ cargas uniformemente distribuídas atuando sobre a viga à frente e atrás do veículo tipo e juntamente com o mesmo, respectivamente $(\mathrm{kN} / \mathrm{m})$;

$\bar{F}=$ cargas concentradas das 2 rodas de um mesmo eixo do veículo tipo $(\mathrm{kN})$;

$\ell_{y}=$ largura da laje do tabuleiro $(\mathrm{m})$;

$\mathrm{p}$ = carga uniformemente distribuida sobre $\circ$ tabuleiro à exceção da área ocupada pelo veículo tipo $\left(\mathrm{kN} / \mathrm{m}^{2}\right)$;

$F_{r}=$ carga de uma roda do veículo tipo $(\mathrm{kN})$.

As cargas $p$ e $F_{r}$ são dadas conforme a NBR 7188 (1984), cujos valores são mostrados nas tabelas 4.2 e 4.3 .

As cargas $p_{1} p_{2}$ e $\bar{F}$ constituem $\circ$ trem tipo, e são dispostas de acordo com a figura 4.18a.

Pode-se, segundo a NBR 7188, simplificar o cálculo dos arcos ou vigas principais, homogeneizando-se as cargas distribuidas e subtraindo-se das cargas concentradas dos veículos as parcelas correspondentes àquela homogeneização, desde que não haja redução de solicitações. Dessa forma obtém-se o trem-tipo simplificado considerando-se a carga $p_{1}$ aplicada sobre toda a viga (faixa de 1 metro), descontando-se da carga $\bar{F}$ a parcela referente a essa homogeneização. 


$$
\bar{F}^{\prime}=\bar{F}-\frac{\left(p_{1}-p_{2}\right) \times 6}{3}
$$

1
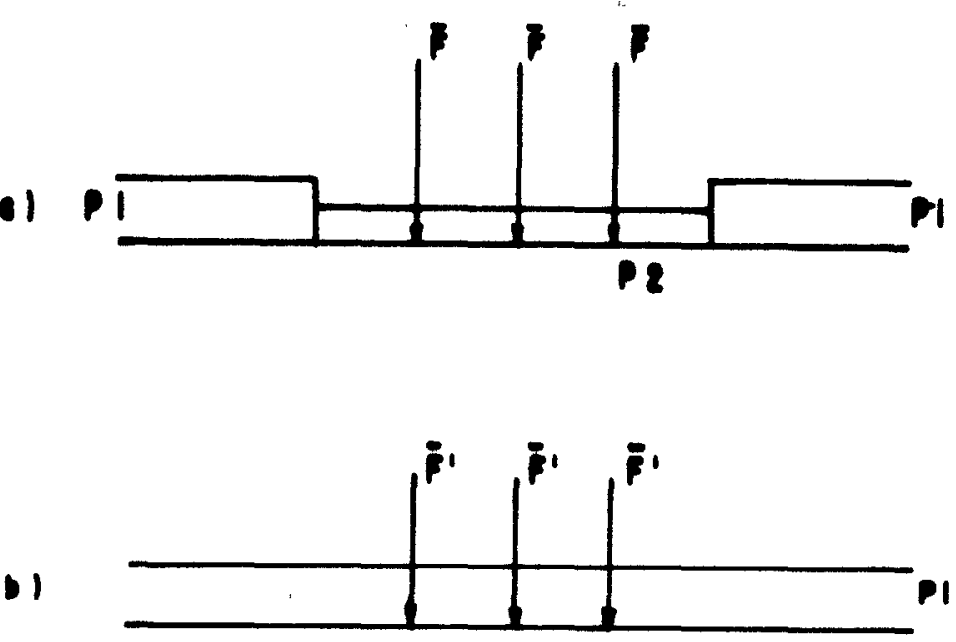

Figura 4.18 - a) Trem-tipo atuante na viga:

b) trem-tipo simplificado.

\subsubsection{3 - CÁLCULO DAS LARGURAS COLABORANTES}

As larguras colaborantes são obtidas através da razão entre os momentos fletores $e$ as forças cortantes obtidos com o cálculo como viga, e os mesmos resultantes do cálculo como laje isolada (RÜSCH).

Uma vez que o cálculo como viga fornece somente momentos fletores nos engastes $e$ no centro do vão, considera-se para a avaliação da largura colaborante no meio dos bordos livres o próprio momento do centro do vão. Para o caso dos bordos dos engastes, utiliza-se a seguinte relação:

onde:

$$
b_{e r}=\frac{b_{e m}}{b_{x m}} b_{x r}
$$

$b_{x m}=$ largura colaborante para o momento fletor no meio do vão (m) ;

$b_{x r}=$ largura colaborante para o momento fletor no meio dos bordos livres (m);

$\mathrm{b}_{\mathrm{em}}=$ largura colaborante para o momento fletor no meio dos 


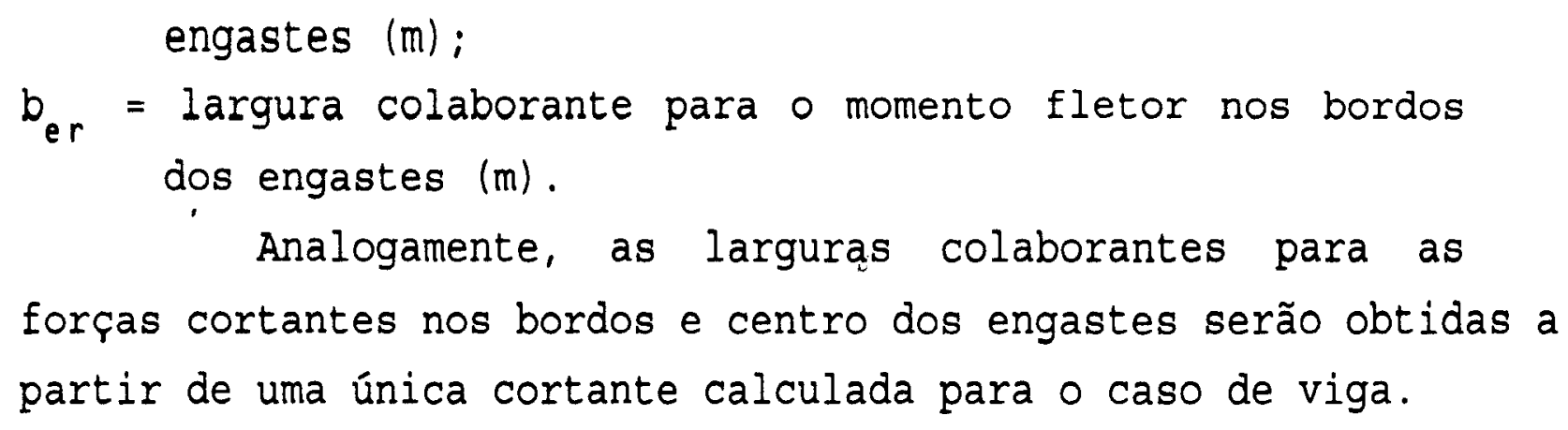

Segundo MONTANARI (1976), a largura colaborante para os momentos mínimos (quando negativos), causados por carregamentos em tramos adjacentes, não poderá ser calculada conforme proposto, pois as tabelas de RÜSCH (1965) tratam apenas de lajes isoladas. Neste caso pode-se calculá-la em função das larguras colaborantes já determinadas para $\circ$ apoio e para 0 meio do vão, utilizando-se a seguinte expressão:

$$
\left.b_{(} \times \mathrm{m}\right)=1.5 b_{x m}-0.5 b_{e m}
$$

sendo $b_{(-x m)}$ a largura colaborante no meio do vão para cargas que provocam momentos negativos neste vão.

\subsubsection{4 - CÁLCULO DOS ESFORÇOS COMO PÓRTICO PLANO \\ Os esforços no pórtico, da mesma forma que na viga} (ítem 4.3.1.2), são obtidos a partir do carregamento mais desfavorável do trem-tipo sobre as linhas de influência do pórtico.

Para que seja possível, posteriormente, o detalhamento das armaduras do pórtico, torna-se necessário o traçado dos diagramas de momentos fletores (DMF) e esforços cortantes (DEC). Assim, é preciso calcular os esforços em várias seções definidas tanto mais próximas quanto maior precisão no traçado desses diagramas se desejar.

Como esses esforços são obtidos a partir do carregamento das respectivas linhas de influência, estas devem ser calculadas para cada seção definida. Contudo, uma vez que as cargas móveis somente atuam no tabuleiro, as linhas de influência só precisam ser calculadas para cargas atuantes no mesmo.

Utiliza-se para obtenção das linhas de influência o 
processo espontâneo. Este processo consiste em obter os diversos diagramas das solicitações desejadas, para diversas posições de uma carga unitária, efetuando-se depois uma troca de ordenadas.

- processo espontâneo só é conveniente para estruturas muito simples, tornando-se muito trabalhoso em estruturas estaticamente indeterminadas. Assim, utiliza-se 0 mesmo programa comentado no item 4.3, obtendo-se, sem muita dificuldade, as linhas de influência desejadas.

\subsubsection{5 - CÁLCULO DOS ESFORÇOS NA PONTE EM PÓRTICO}

Os esforços na ponte em pórtico são calculados dividindo-se os esforços obtidos do cálculo como pórtico plano pelas larguras colaborantes.

Os momentos transversais da ponte em pórtico são considerados como sendo os mesmos calculados para a placa isolada (ítem 4.3.1.1).

Para o cálculo dos esforços nos encontros, utiliza-se as larguras colaborantes obtidas para o vão (centro e bordos).

\subsection{2 - CÁlCULO DA PONTE EM PÓRTICO - CARREGAMENTO PERMANENTE}

As cargas permanentes consideradas no cálculo do ponte em pórtico são as mesmas do cálculo sem continuidade. São elas:
a) Cargas devidas ao peso próprio da estrutura e de outros materiais colocados sobre a mesma;
b) cargas de empuxo devido aos aterros de acesso e sobrecargas de veículos adjacentes aos encontros;
c) carregamento devido à variação de temperatura e retração do concreto.




\subsubsection{1 - ESFORÇOS DEVIDOS AO PESO PRÓPRIO E SOBRECARGAS PERMANENTES}

As cargas devidas ao peso próprio da laje da superestrutura, acrescidas das sobrecargas permanentes que possam ser consideradas como uniformemente distribuidas sobre a mesma (pavimentação, recapeamento), são computadas considerando-se faixas de 1 metro de largura. Assim, para 0 cálculo dos esforços no pórtico provenientes desses carregamentos, utiliza-se o programa para pórticos planos.

os esforços devidos às defensas, dispostas ao longo dos bordos livres, são calculados utilizando-se da tabela 103 de RÜsCH (1965) e posteriormente 'corrigidos' na mesma proporção existente entre os esforços devidos ao carregamento móvel, obtido com a aproximação de RÜSCH (larguras colaborantes), e os mesmos obtidos diretamente das tabelas de RÜSCH (placa bi-engastada).

\subsubsection{2 - ESFORÇOS DEVIDOS AO EMPUXO DE TERRA E SOBRECARGA DOS VEÍCULOS ADJACENTES AOS ENCONTROS}

Os esforços provenientes dos aterros de acesso e sobrecargas dos veículos adjacentes aos encontros devem, no caso do pórtico, ser obtidos para dois casos distintos:

a) Empuxo unilateral (ativo) - calcula-se o pórtico supondo carregamento em apenas um dos encontros. Avalia-se a magnitude das cargas conforme exposto no ítem 4.2.2.2;

b) empuxo equilibrado (repouso) - o pórtico é calculado supondo carregamento em ambos os encontros. As cargas são obtidas de maneira análoga ao empuxo unilateral, substituindo-se apenas o valor do coeficiente de empuxo no cálculo das cargas devidas aos aterros de acesso. Esse coeficiente, para o caso de solos arenosos e argilas normalmente adensadas, foi determinado através de uma correlação empírica com o ângulo de atrito interno $(\varphi)$, 
por JAKY apud GAIOTO (1979):

$K_{0}=1-\operatorname{sen} \varphi$

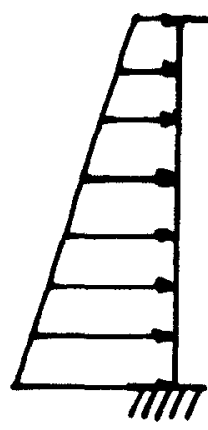

$1 \cdot 1$

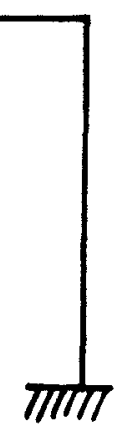

TIII

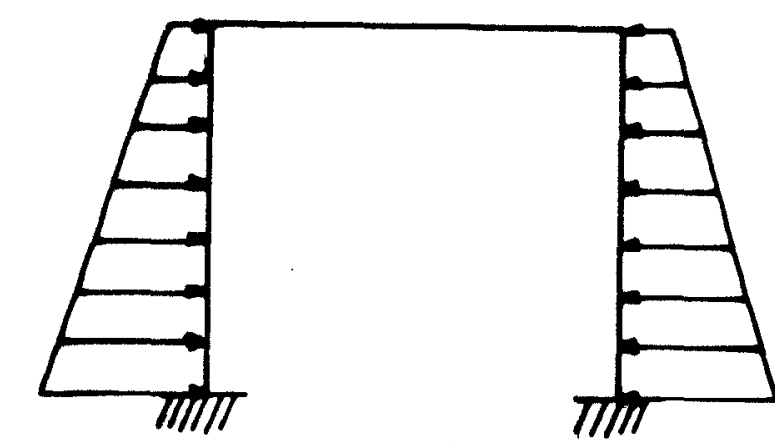

1 1

Figura 4.19 - Carregamento do pórtico:

a) Empuxo unilateral:

b) empuxo equilibrado.

Obtém-se os esforços através da utilização do programa para pórticos planos, considerando-se esses carregamentos atuando em faixas de 1 metro de largura.

\subsubsection{3 - ESFORÇOS DEVIDOS À VARIAÇÃO DA TEMPERATURA E RETRAÇÃO DO CONCRETO}

A variação de temperatura e retração do concreto são consideradas como um único fenômeno representado pela queda de temperatura de $30^{\circ} \mathrm{C}$, conforme exposto no item 4.2 .2 .2 .

- cálculo dos esforços provenientes dessa queda de temperatura é feito utilizando-se do formulário desenvolvido por GREKOW et al (1971), considerando-se faixas de 1 metro de largura. Segundo este, os esforços introduzidos no pórtico através da variação de temperatura $\Delta t$ são:

a) Momentos fletores nos engastes

$$
M_{A}=M_{B}=\frac{k+1}{k} \theta_{t}
$$

b) momentos fletores nos nós

$$
M_{c}=M_{D}=-\theta_{t}
$$


c) reações nos apoios

$$
-H_{A}=H_{B}=\frac{2 k+1}{\kappa} \frac{\theta_{t}}{h}
$$

sendo:

$$
\begin{aligned}
& \theta_{t}=\frac{3}{\mu} \frac{E I_{t r}}{h} \alpha \Delta t \\
& k=\frac{h}{l_{x}} \frac{I_{t r}}{I_{e}} \\
& \mu=2+k
\end{aligned}
$$

onde:

$\mathrm{h}=$ altura teórica do pórtico (m);

$E=$ módulo de elasticidade do concreto $\left(\mathrm{kN} / \mathrm{m}^{2}\right)$;

$I_{t r}=$ momento de inércia do tramo (faixa de 1 metro) em $\mathrm{m}^{4}$; $I_{e}=$ momento de inércia dos pilares (faixa de 1 metro) em $\mathrm{m}^{4}$.

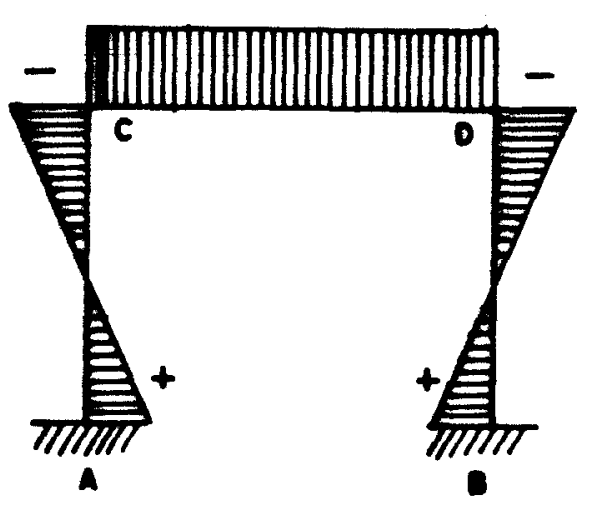

Figura 4.20 - Diagrama de momentos fletores devido à uma variação de temperatura $\Delta t$ (negativa)

Sendo o diagrama de momentos fletores linear (fig. 4.20), os momentos nas diversas seções dos encontros (faixas) são obtidos por semelhança de triângulos. Os esforços cortantes são obtidos diretamente das reações de apoio.

\subsubsection{4 - CÁLCULO DOS BLOCOS DE FUNDAÇÃO}

$\quad$ Os blocos são pré-dimensionados e calculados
conforme exposto nos itens 4.2 .2 .3 e
respectivamente.




\section{4 - DiMENSIONAMENTO DOS ELEMENTOS ESTRUTURAIS}

0 dimensionamento das peças estruturais (laje, encontros e blocos) é feito no estado limite último.

Embora a norma NBR 7187 (1986) forneça critérios para a combinação das ações, julgou-se mais conveniente seguir, no presente trabalho, os critérios da norma NBR 8681 (1984), por entender que esta última se sobrepõem a norma NBR 7187.

As solicitações atuantes de cálculo (Fd) nos estados limites últimos devem ser determinadas com a consideração das ações indicadas no decorrer deste capítulo, multiplicadas pelos coeficientes de segurança definidos a seguir (tabelas 4.4 a 4.7 ).

Deve-se analisar, segundo a NBR 7187, as solicitações variáveis com o tempo que conduzam a situações críticas de dimensionamento, considerando-se todas as fases de construção da estrutura.

Considerando-se que a ponte está sujeita a um carregamento normal (decorrente do uso previsto da construção), restringe-se o dimensionamento à solicitação de cálculo obtida com a combinacão normal. Entretanto, por constituir-se de elementos pré-moldados, é necessário fazer uma verificação na fase construtiva do mesmo, onde utiliza-se a combinação última especial. A combinação última excepcional não é utilizada. Desse modo, tem-se:

a) Para as combinações últimas normais

$$
F_{d}=\sum_{i=1}^{m} \gamma_{g i} F_{G i, k}+\gamma_{q}\left(F_{Q 1, k}+\sum_{j=2}^{n} \psi_{\circ j} F_{Q j, k}\right)
$$

onde:

$F_{G i, k}=$ valores característicos das ações permanentes;

$F_{Q 1, k}=$ valor característico da ação variável principal;

$\begin{aligned} F_{Q j, k}= & \text { valores característicos das outras ações } \\ & \text { variáveis; }\end{aligned}$ 
$\gamma_{g i}=$ coeficientes de ponderação das ações permanentes $i$

$\gamma_{\mathrm{q}}=$ coeficiente de ponderação das ações variáveis;

$\psi_{\circ j}=$ 'fator de combinação.

b) para as combinações últimas especiais ou de construção vale a equação 4.37 tomando-se para $F_{q 1, k} \circ$ valor da ação variável admitida como principal para a situação transitória. 0 fator $\psi_{\circ j}$ é igual ao adotado nas combinações normais, salvo quando a ação principal $F_{Q 1, k}$ tiver um tempo de atuação muito pequeno, caso em que $\psi_{o j}$ pode ser tomado com $\circ$ correspondente $\psi_{2 j}$ (combinação de utilização) .

Segundo a NBR 8681 (1984), os coeficientes de ponderação $\gamma_{g}$ das ações permanentes majoram os valores representativos das ações permanentes que provocam efeitos desfavoráveis e minoram os representativos daquelas que provocam efeitos favoráveis para a segurança da estrutura.

Esses coeficientes devem ser tomados com os valores básicos a seguir:

a) Ações permanentes de grande variabilidade - para as ações constituidas pelo peso próprio das estruturas, dos elementos constrututivos permanentes não estruturais e dos equipamentos fixos, todos considerados globalmente, quando o peso próprio da estrutura não supera $75 \%$ da totalidade destes pesos permanentes e para outras ações permanentes de grande variabilidade, adotam-se os valores indicados na tabela 4.4;

b) ações permanentes de pequena variabilidade - para as ações permanentes, quando o peso próprio da estrutura supera $75 \%$ da totalidade dos pesos permanentes e para outras ações de pequena variabilidade, adotam-se oa valores indicados na tabela 4.5;

c) efeitos de recalques de apoio e de retração dos materiais - neste caso adotam-se os valores indicados na tabela 4.6 . 
Tabela 4.4 - Coeficientes de ponderação para ações

permanentes de grande variabilidade

\begin{tabular}{l|c|c}
\hline \multirow{2}{*}{ Combinações } & \multicolumn{2}{|c}{ Para efeitos } \\
\cline { 2 - 3 } & desfavoráveis & Favoráveis \\
\hline Normais & $\gamma_{g}=1.4$ & $\gamma_{g}=0.9$ \\
Especiais & $\gamma_{g}=1.3$ & $\gamma_{g}=0.9$ \\
\hline
\end{tabular}

Fonte: NBR 8681 (1984)

Tabela 4.5 - Coeficientes de ponderação para ações permanentes de pequena variabilidade

\begin{tabular}{l|c|c}
\hline \multirow{2}{*}{ Combinações } & \multicolumn{2}{|c}{ Para efeitos } \\
\cline { 2 - 3 } & desfavoráveis & Favoráveis \\
\hline Normais & $\gamma_{\mathrm{g}}=1.3$ & $\gamma_{\mathrm{g}}=1.0$ \\
Especiais & $\gamma_{\mathrm{g}}=1.2$ & $\gamma_{\mathrm{g}}=1.0$ \\
\hline
\end{tabular}

Fonte: NBR $8681(1984)$

Os coeficientes de ponderação $\gamma_{q}$ das ações variáveis majoram os valores representativos das mesmas que provocam efeitos desfavoráveis para a segurança da estrutura. As ações variáveis que provocam efeitos favoráveis não são consideradas nas combinações de ações, admitindo-se que sobre a estrutura atuem apenas as parcelas de ações variáveis que produzam efeitos desfavoráveis.

- fator de combinação $\psi$. para a combinação última normal é tomado, para o caso de pontes rodoviárias, com o valor $\psi_{0}=0.6$. Nos casos particulares de combinações últimas excepcionais e especiais ou de construção a norma NBR 8681 fornece outros valores.

Segundo a NBR 6118 (1982), os valores de cálculo da resistência dos materiais à compressão ou à tração são os respectivos valores característicos, adotados no projeto, 
Tabela 4.6 - Coeficientes de ponderaça para efeitos de recalques de apoio e de retraça dos materiais

\begin{tabular}{l|c|c}
\hline \multirow{2}{*}{ Combinações } & \multicolumn{2}{|c}{ Para efeitos } \\
\cline { 2 - 3 } & desfavoráveís & Favoráveis \\
\hline Normais & $\gamma_{\epsilon}=1.2$ & $\gamma_{\epsilon}=1.0$ \\
Especiais & $\gamma_{\epsilon}=1.2$ & $\gamma_{\epsilon}=1.0$ \\
\hline
\end{tabular}

Fonte: NBR $8681(1984)$

Tabela 4.7 - Coeficientes de ponderação para açós variáveis

\begin{tabular}{l|c|c}
\hline Combinações & $\begin{array}{l}\text { Ações variáveis em } \\
\text { geral incluída as } \\
\text { cargas acidentais } \\
\text { móveis }\end{array}$ & $\begin{array}{l}\text { Efeitos de } \\
\text { temperatura }\end{array}$ \\
\hline Normais & $\gamma_{q}=1.4$ & $\gamma_{\epsilon}=1.2$ \\
Especiais & $\gamma_{q}=1.2$ & $\gamma_{\epsilon}=1.0$ \\
\hline
\end{tabular}

Fonte: NBR $8681(1984)$

divididos pelo coeficiente de minoração $\gamma_{c}$ (concreto) ou $\gamma_{s}$ (aço), ou seja:

$$
\begin{aligned}
& f_{c d}=\frac{f_{c k}}{\gamma_{c}} \\
& f_{t d}=\frac{f_{t k}}{\gamma_{c}} \\
& f_{y c d}=\frac{f_{y c k}}{\gamma_{s}} \\
& f_{y d}=\frac{f_{y k}}{\gamma_{s}}
\end{aligned}
$$

onde:

$\mathrm{f}_{c d}=$ resistência de cálculo do concreto à compressão;

$f_{t d}=$ resistência de cálculo do concreto à tração;

$f_{y c d}=$ resistência de cálculo do aço à compressão; 
$f_{y d}=$ resistência de cálculo do aço à tração.

$f_{c k}=$ resistência característica do concreto à compressão;

$f_{t k}=$ resistência característica do concreto à tração;

$f_{y c k}=$ resistência característica do aço à compressão;

$f_{y k}=$ resistência característica do aço à tração.

Os coeficientes de minoração dos materiais, no estado limite último, são:

$\gamma_{c}=1.4$ (em geral);

$\gamma_{s}=1.15$ (desde que sejam obedecidas as prescrições de norma quanto ao controle de qualidade).

- dimensionamento das armaduras segue 0 seguinte critério:

a) Laje da superestrutura - as armaduras são dimensionadas à flexão simples utilizando-se as tabelas desenvolvidas por PINHEIRO (1986);

b) Encontros - os encontros do sistema estrutural isostático são dimensionados à flexo-compressão considerando-se trechos de espessura constante ao longo da altura. Para o sistema estrutural hiperestático faz-se também 0 dimensionamento à flexo-compressão.

c) Blocos da fundação - faz-se o dimensionamento de acordo com ○ método de cálculo adotado (ítem 4.2.2.4). Para o Método das Bielas a armadura principal é dimensionada à tração sendo que no Método do CEB a mesma é dimensionada à flexão.

\section{5 - VERIFICAÇÕES}

\subsection{1 - VERIFICAÇÃO DO ESTADO LIMITE ÚLTIMO DE RESISTENNCIA À FADIGA}

A verificação deste estado limite deve ser procedida através da análise, com base em métodos elásticos, das variações de tensões na armadura, considerando-se os 
efeitos dinâmicos (carga móveis, impactos e força centrífuga), da fluência do concreto e das perdas de protensão, e desprezando-se a resistência do concreto à tração após a fissuração.

Os efeitos do vento, aceleração e frenagem, cargas eventuais nos passeios, retração, temperatura não são incluídos nesse cálculo, face a reduzida frequência de aplicação. Nos pilares e nas vigas de travamento não há necessidade de se considerar fadiga do aço.

0 critério de verificação da resistência à fadiga da norma NBR 7187 (1986) admite que a armadura esteja submetida a uma variação de tensões $\Delta \sigma_{s}=\sigma_{s m a x}{ }^{*} \sigma_{s m i n}$.

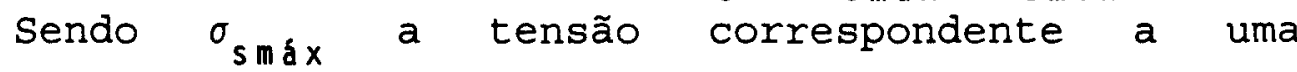
combinação frequente de ações, com seu valor máximo, e $\sigma_{\text {smin }}$ a tensão correspondente, conforme $\circ$ caso, a uma combinação quase permanente ou frequente de ações com seu valor mínimo, a resistência à fadiga estará verificada se $\Delta \sigma_{s}$ for menor ou igual à resistência à fadiga de cálculo, $\Delta \mathrm{f}_{\mathrm{s}^{\prime}}$ ' dada pela expressão: $\quad \Delta f_{s d}=\Delta f_{s k} / \gamma_{f a t}$, sendo $\Delta f_{s k}$ a resistência característica à fadiga e $\gamma_{f a t} \circ$ coeficiente de segurança à fadiga, cujo valor é $\gamma_{f a t}=1.5$. Caso contrário, é necessário aumentar a percentagem de armadura na seção, de modo a reduzir a amplitude da variação de tensões $\Delta \sigma_{s}$, até que seja atendida a condição limite acima estabelecida.

Ainda segundo a NBR 7187, na ausência de resultados de ensaios, devem ser adotados como resistência característica à fadiga os seguintes valores: $250 \mathrm{MPa}$ para barras lisas e $150 \mathrm{MPa}$ para barras de alta aderência. Deve-se, ainda, reduzir esses valores através da aplicação do coeficiente multiplicador $f$ nos casos indicados a seguir:

a) Barras curvas ( $r=$ raio de curvatura) : $f=1-1.5(\phi / r)$;

b) solda pontilhada ou contínua: $f=0.4$;

c) solda de topo: $f=0.7$.

A resistência à fadiga de elementos de ligação deve ser comprovada, quando for $\circ$ caso, por testes realizados pelo fabricante. 
A norma alemã DIN-1045 estabelece que as flutuações das tensões em serviço $\left(\Delta \sigma_{s}^{\prime}\right)$ devem ser limitadas à:

a) na flexão: $\Delta \bar{\sigma}_{s} \leq 180 \mathrm{MPa}$;

b) na flexão utilizando-se barras soldadas: $\Delta \bar{\sigma}_{s} \leq 80 \mathrm{MPa}$;

c) no cisalhamento utilizando-se barras dobradas: $\Delta \bar{\sigma}_{s} \leq 180$ $\mathrm{MPa}$;

d) no cisalhamento utilizando-se estribos: $\Delta \bar{\sigma}_{s} \leq 140 \mathrm{MPa}$.

Quando existirem variações de tensões superiores às descritas anteriormente, a área de aço deve ser majorada por:

$$
C F=\frac{\Delta \bar{\sigma}_{s}^{\prime}}{\Delta \bar{\sigma}_{s}}
$$

onde $\Delta \bar{\sigma}_{s}$ é, conforme o caso, um dos valores limites fornecidos.

Adota-se, no presente trabalho, a verificação sugerida pela norma alemã DIN 1045 por considerar-se as verificações da atual norma de pontes NBR 7187 um tanto conservadoras.

Os valores das tensões em serviço na flexão simples para seções retangulares podem ser obtidas, segundo SÜSSEKIND (1987):

$$
\sigma_{s}=\frac{M}{A_{s}\left(d-\frac{x}{3}\right)}
$$

sendo:

$$
x=\frac{n A_{s}}{b_{w}}\left(-1+\sqrt{1+\frac{2 b_{w} d}{n A_{s}}}\right)
$$

onde:

$M=$ momento fletor atuante na seção $(\mathrm{kNcm} / \mathrm{m})$;

$A_{s}=$ área de aço submetida ao momento $\mathrm{M}\left(\mathrm{cm}^{2}\right)$;

$\mathrm{d}=$ altura útil da seção de concreto $(\mathrm{cm})$;

$\mathrm{x}=$ posição da linha neutra $(\mathrm{cm})$;

$b_{w}=$ largura da seção considerada (faixa de 1 metro);

$n=E_{s} / E_{c} ;$ sendo $E_{s} \circ$ módulo de elasticidade do aço e $E_{c} \circ$ módulo de elasticidade secante do concreto, cujos valores são: 


$$
\begin{aligned}
& E_{s}=2.1 \times 10^{7} \mathrm{MPa} ; \\
& E_{c}=9.5\left(f_{c k}+8\right)^{1 / 3}
\end{aligned}
$$

onde $f_{c k}^{\prime}$ é a resistência característica do concreto à compressão adotada no projeto (MPa) "e $E_{c}$ expresso em GPa.

Para as seções solicitadas à flexo-compressão, SÜSSEKIND (1987) fornece as seguintes expressões para as tensões no concreto e no aço:

$$
\begin{aligned}
& \sigma_{s}=\frac{2 N x}{b_{w} x^{2}-2 n A_{s}(d-x)} \\
& \sigma_{s}=n \sigma_{c} \frac{d-x}{x}
\end{aligned}
$$

A posição da linha neutra $(x)$ é determinada segundo a equação (4.45), mostrada abaixo:

$$
b_{w} x^{3}+3 b_{w}\left(\frac{M_{s}}{N}-d\right) x^{2}+6 \frac{M_{s}}{N} n A_{s} x-6 \frac{M_{s}}{N} n A_{s} d=0
$$

sendo:

$$
M_{s}=\left|M_{\text {max }}\right|+\left|N_{m a x}\right| e_{s}=\underset{\text { armadura }(\mathrm{kNcm} / \mathrm{m}) ;}{\text { momento fletor máximo atuante na }}
$$

onde:

$$
\begin{aligned}
& \left|M_{m a x}\right| \text { e }\left|N_{m a x}\right|=\text { momentos fletores e forças cortantes } \\
& \text { máximas em módulo; } \\
& e_{s}=\text { excentricidade da armadura com relação ao centro de } \\
& \text { gravidade da seção. }
\end{aligned}
$$

\subsection{2 - VERIFICAÇÃO DAS FASES CONSTRUTIVAS}

- processo construtivo proposto obriga a se verificar os elementos pré-moldados (vigas) nas fases construtivas. Durante um certo período de tempo as vigas pré-moldadas deverão suportar, além do peso próprio, o peso do comcreto depositado sobre as mesmas. Neste fase não se pode considerar, no caso do pórtico, a ligação dessas com os encontros.

Deve-se também verificar as vigas às solicitações 
dinâmicas devidas ao transporte e montagem. Segundo a NBR 9062 (1985), quando uma análise dinâmica não puder ser efetuada, a solicitação dinâmica pode ser considerada, aproximadamente, por uma estática equivalente, calculada através do coeficiente de amplificação dinâmica pela expressão:

$$
g_{e}=\beta_{a} g
$$

onde:

$g$ = carga estática permanente no transporte $(\mathrm{kN} / \mathrm{m})$;

$\mathrm{g}_{\mathrm{e}}=$ carga estática equivalente $(\mathrm{kN} / \mathrm{m})$;

$\beta_{\mathrm{a}}=$ coeficiente de ação dinâmica; $\beta_{\mathrm{a}}=1.3$ ou $\beta_{\mathrm{a}}=0.8$ no caso de possível alívio de $g$ devido à ação dinâmica.

\subsection{3 - VERIFICAÇÃO DO FENDILHAMENTO NO NÓ DO PÓRTICO}

o detalhamento do nó do pórtico, constituído da emenda por traspasse de laços em gancho, é possível, segundo LEONHARDT (1978), para o caso de porcentagens moderadas de armadura $\rho \leq 0.5 \%$ e diâmetro da armadura $\phi \leq d / 18$, sendo d a altura útil da laje ou encontro.

No interior dos ganchos ou laços deve-se dispor 4 barras transversais contra o fendilhamento. De acordo com Leonhardt, essa armadura deverá absorver os esforços de fendilhamento supostos aproximadamente iguais a $\frac{z}{5}$, sendo $z$ a força de tração na barra emendada. A norma NBR 6118 (1982) prescreve que quando não houver no trecho de ancoragem compressão do concreto transversalmente à armadura, suficiente para impedir a fissuração do mesmo, deve-se dispor uma armadura transversal com capacidade para resistir a $25 \%$ do esforço ancorado $\left(\frac{z}{4}\right)$.

A norma alemã DIN 1045 exige para emendas por tranpasse na região do nó qualidade do concreto $B_{n} \geq 250$, sendo $B_{n}$ a resistência média do concreto à compressão dada em $\mathrm{kgf} / \mathrm{cm}^{2}{ }^{\mathrm{n}}$, aço nervurado e estribos ou estribos em laço em forma de grampos para a segurança na região do canto. 


\subsection{4 - VERIFICAÇÃO DA LIGAÇ̃̃O DOS CONCRETOS COM IDADES DIFERENTES}

Admite-se, para efeito de cálculo, perfeita ligação entre os elementos pré-moldados (vigas) e o concreto moldado no local de maneira a formarem juntos a laje da superestrutura.

Para garantir que 0 comportamento estrutural conjunto ocorra de fato, é essencial o estudo dos esforços que se desenvolvem na interface dessa união, notadamente os esforços de cisalhamento.

Segundo a FEDERATION INTERNATIONALE DE LA PRECONTRAINTE (FIP) (1982), para simplificar e dinamizar a rotina de cálculo, considera-se, resumidamente, duas categorias de superficie ou interface (categoria 1 e categoria 2) e dois níveis de problemas (situação de baixa e alta solicitação cisalhante), da seguinte maneira:

a) Categorias da superficie (interface)

categoria 1 - são as superfícies obtidas naturalmente durante a produção do pré- moldado;

categoria 2 - superfícies onde a rugosidade foi feita deliberadamente.

b) níveis do problema

baixa solicitação cisalhante - esta situação é encontrada nas estruturas cujos elementos pré-moldados possuem grande superfície de contato com o concreto moldado no local (fig. 4.21). O esforço cortante será normalmente baixo, e se resultar menor que o obtido através das expressões 4.47 ou 4.49, nenhuma armadura transversal será necessária; alta solicitação cisalhante - situação característica de estruturas com seção transversal conforme a figura 4.22. A armadura transversal deve ser verificada utilizando-se a expressão 4.48 .

Segundo a FIP apud BALLARIN (1990), na verificação dos esforços ocorrentes na interface valem algumas observações: 
a) A armadura de cisalhamento é verificada no estado limite último. Embora na maioria das situações seja necessário garantir o trabalho conjunto da estrutura nas solicitações de serviço, o presente método dispensa essas verificações de serviço;

b) pelos procedimentos de cálculo assumidos, em situações de baixa solicitação cisalhante nenhuma fissura pode ocorrer na interface. Se os esforços assim calculados levam a uma condição de fissuração, deve-se prever armadura.

Embora o método seja válido para elementos bi-apoiados, recomendando-se a confirmação experimental para outros tipos de vãos, ele será também utilizado para a verificação dos esforços ocorrentes no sistema estrutural hiperestático (pórtico). Desta forma poder-se-á comparar esses resultados com os obtidos pela proposição da norma NBR 9062, descrita em seguida.

De acordo com a FIP deve-se ter na interface tensões cisalhantes menores ou iguais as descritas a seguir:

a) Para situações de baixa solicitação cisalhante

$$
\tau_{w u}=\beta_{2} f_{t d} \text {, }
$$

b) para situações de alta solicitação cisalhante

$$
\tau_{w u}=\beta_{1} \rho_{w} f_{y d}+\beta_{2} f_{t d} \leq 0.25 f_{c k}
$$

sendo:

$$
\rho_{w}=\frac{A_{s w}}{b_{w} s} \geq 0.001
$$

onde:

$A_{s w}=$ área de armadura transversal que atravessa a interface e se encontra efetivamente ancorada $\left(\mathrm{cm}^{2}\right)$. MATTOCK (1987) sugere espessuras mínimas de capa de $75 \mathrm{~mm}, 90$ $\mathrm{mm}$ e $150 \mathrm{~mm}$, para ancoragem de barras com diâmetros de $9 \mathrm{~mm}\left(3 / 8^{\prime \prime}\right), 12 \mathrm{~mm}\left(1 / \mathrm{2}^{\prime \prime}\right)$ e $15 \mathrm{~mm}$ (5/8"), considerando-se concreto com resistência de $21 \mathrm{MPa}$ e ancoragem em gancho ou laço;

$\mathrm{b}_{\mathrm{w}}=$ largura da seção ou da interface $(\mathrm{cm})$;

$s$ = espaçamento da armadura transversal (cm); 
$f_{y d}=$ resistência de cálculo do aço à tração (MPa);

$f_{t d^{\prime}}=$ resistência de cálculo do concreto à tração obtida através da expressão: $f_{t d}=0.25 \sqrt{f_{c k}}$;

$\mathrm{f}_{c k^{\prime}}=$ resistência característica do concreto à compressão medida em cubos de $15 \mathrm{~cm}$ (MPa);

$\beta_{1}$ e $\beta_{2}=$ fatores multiplicativos do aço e do concreto, respectivamente, cujos valores estão reproduzidos na tabela 4.8 .
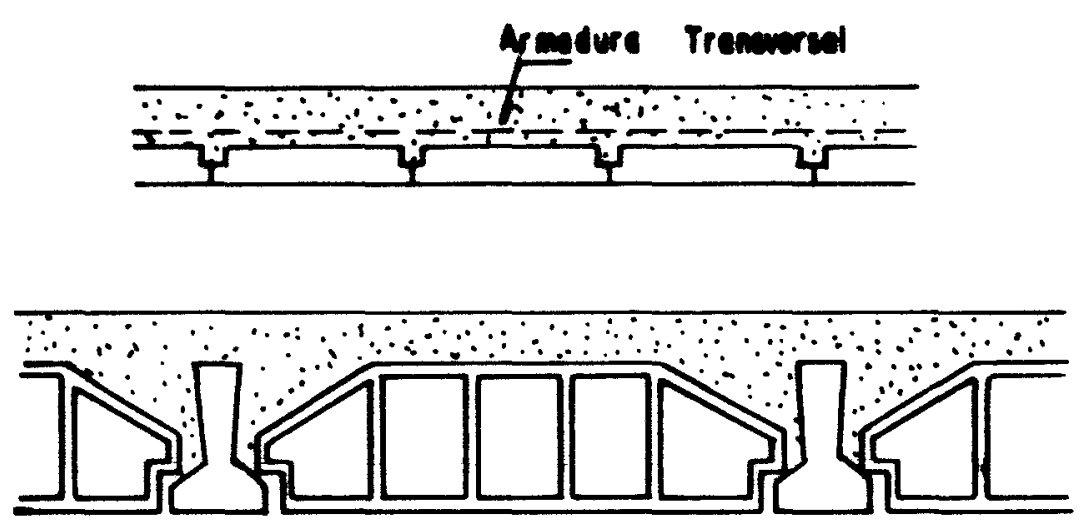

Figura 4.21 - Situaçóes de baixas solicitacōes cisalhantes
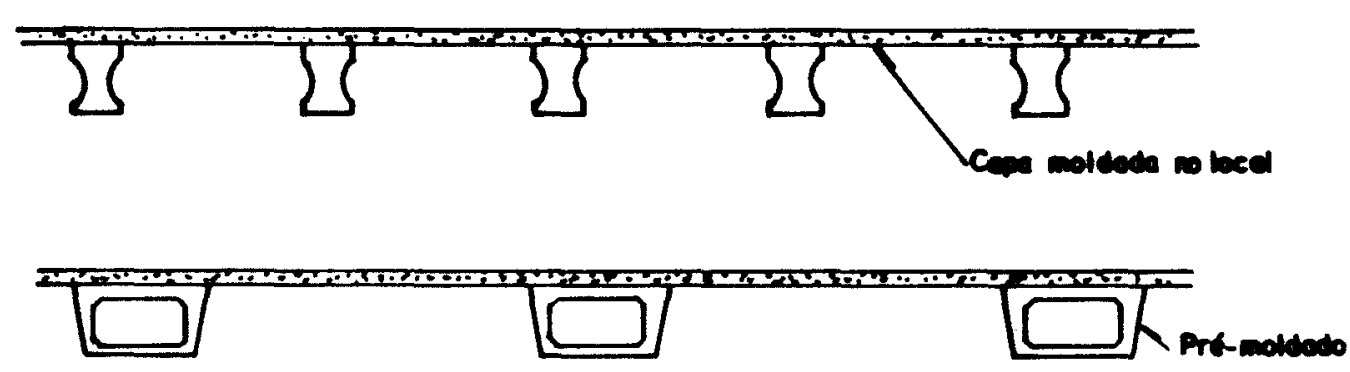

Figura 4.22 - Situações de altas solicitações cisalhantes

Nos casos especiais onde o esforço cortante é crítico, pode-se utilizar a seguinte expressão como alternativa à equação 4.47 :

$$
\tau_{w u}=k_{1} k_{2} k_{3} \beta_{2} f_{t d^{\prime}} \leq 1.5 \beta_{2} f_{t d^{\prime}}
$$


Tabela 4.8 - Fatores $\beta_{1}$ e $\beta_{2}$

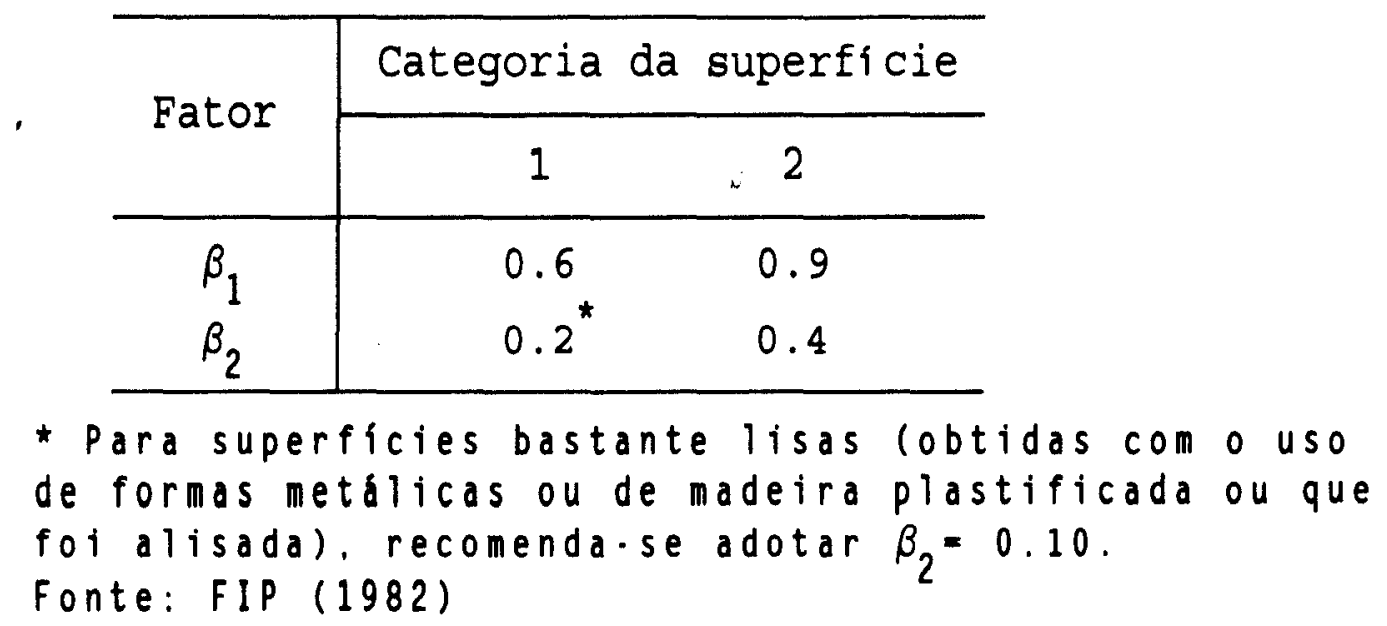

sendo:

$$
\mathrm{k}_{1}=0.7 \frac{\mathrm{x}}{\mathrm{e}}+0.3 \leq 1.0 \text {, onde: }
$$

$x$ = distância da extremidade tracionada até a interface (m);

$e=$ distância do centro de gravidade da seção não fissurada de concreto até a extremidade tracionada (m).

$$
\mathrm{k}_{2}=2.0-0.4 \frac{\mathrm{M}}{\mathrm{V} d} \geq 1.0 \text {, onde: }
$$

$\mathrm{M}=$ momento fletor atuante $(\mathrm{MNm} / \mathrm{m})$;

$\mathrm{V}=$ esforço cortante atuante $(\mathrm{MN} / \mathrm{m})$;

$d$ = altura útil da seção (m).

$$
\begin{aligned}
& \qquad \mathrm{k}_{3}=\frac{0.3}{\mathrm{~b} \mathrm{~d}^{2}}\left(\mathrm{f}_{\mathrm{ctd}} \mathrm{W}_{\mathrm{u}}+0.16 \mathrm{M}_{0}\right)+0.8 \geq 1.0 \text {, onde: } \\
& \mathrm{M}_{0}=\text { momento fletor necessário para produzir tensão nula na } \\
& \text { extremidade tracionada da seção composta }(\mathrm{MNm} / \mathrm{m}) ; \\
& \mathrm{W}_{u}=\frac{\mathrm{I}}{\mathrm{e}}\left(\mathrm{m}^{3}\right) \text {, onde: } \\
& I_{=} \text {momento de inércia da seção de concreto não fissurada } \\
& \left(\mathrm{m}^{4}\right) ; \\
& \mathrm{f}_{\mathrm{ctd}}=\text { resistência de cálculo do concreto à tração na flexão } \\
& \left(\mathrm{MN} / \mathrm{m}^{2}\right) .
\end{aligned}
$$

Para a análise do efeito de cargas repetitivas (fadiga) os valores obtidos com a expressão 4.47 devem ser reduzidos em $50 \%$. 
Segundo a NBR 9062 (1985), permite-se considerar a peça composta como monolítica para duas situações:

a) Colaboração completa para o estado limite último;

b) colaboração parcial para os estados limites de utilização. Neste caso o estado limite último deve ser verificado para a parte pré-moldada da peça composta.

Na falta de cálculo mais rigoroso, permite-se calcular a peça composta como peça monolítica se a tensão de aderência de cálculo $\tau_{\text {sd }}$ satisfizer a condição:

$$
\tau_{s d} \leq \beta_{s} \frac{f_{y d} A_{s}}{b s}+\beta_{c} f_{t d}
$$

onde:

$\mathrm{f}_{\mathrm{yd}}=$ resistência de cálculo à tração do aço $\left(\mathrm{kN} / \mathrm{cm}^{2}\right)$;

$A_{s}=$ área da armadura $\left(\mathrm{cm}^{2}\right)$ atravessando, perpendicularmente, a interface e totalmente ancorada nos elementos componentes [MATTOCK (1987)];

$\mathrm{b}=$ largura da interface $(\mathrm{cm})$;

$s=$ espaçamento da armadura $(\mathrm{cm})$;

$f_{t d}=$ resistência de cálculo à tração do concreto. Segundo a NBR 6118 para $\circ$ menos resistente dos concretos em contato $\left(\mathrm{kN} / \mathrm{cm}^{2}\right)$.

$\beta_{s}$ e $\beta_{c}=$ coeficientes de minoração aplicados à armadura e ao concreto, respectivamente, cujos valores para 0 caso de superfícies intencionalmente ásperas com rugosidade de $0.5 \mathrm{~cm}$ em $3.0 \mathrm{~cm}$ são definidos na tabela 4.9. Para valores intermediários pode-se interpolar linearmente entre os existentes.

Tabela 4.9 - Valores dos coeficientes $\beta_{s}$ e $\beta_{c}$

\begin{tabular}{ccc}
\hline As $/ \mathrm{s} b(\%)$ & $\beta_{\mathrm{s}}$ & $\beta_{\mathrm{c}}$ \\
\hline$\leq 0.2$ & 0 & 0.3 \\
$z 0.5$ & 0.9 & 0.6 \\
\hline
\end{tabular}

Fonte: NBR $9062(1985)$ 
A tensão de aderência de cálculo deve ser obtida da seguinte forma:

$$
\tau_{s d}=\frac{F_{m d}}{a_{v} b}
$$

onde:

$F_{m d}=$ valor médio da força de compressão ou de tração acima da ligação, ao longo do comprimento $a_{v}(k N)$;

$a_{v}=$ distância entre os pontos de momento nulo e máximo na peça $(\mathrm{cm})$;

Admite-se $A_{s}=0$ quando $\tau_{s d} \leq \beta_{c} f_{t d}$ e são satisfeitas simultâneamente as seguintes condições:

a) A interface ocorra em região da peça onde haja predominância da largura sobre as outras dimensões da peça (topo de placas, mesa das vigas T ou TT etc.);

b) a superfície de ligação deve ter rugosidade conforme exposto anteriormente $(0.5 \mathrm{~cm} \mathrm{em} 3.0 \mathrm{~cm})$;

c) o plano de ligação não esteja submetido a esforços normais de tração nem a tensões alternadas provenientes de carregamentos repetidos;

d) a armadura da alma resista a totalidade das forcas de tração provenientes de esforços cortantes, desprezada a contribuição do concreto na zona comprimida;

e) seja escovada a superfície do concreto já endurecido para eliminar a nata de cimento superficial e seja abundantemente molhada e encharcada a superficie que vai receber o novo concreto, pelo menos com 2 horas de antecedência à nova concretagem.

\subsection{5 - VERIFICAÇÃO DO ESTADO DE DEFORMAÇÃO EXCESSIVA}

A norma NBR 6118 (1982) prescreve que no projeto, especial atenção deverá ser dada à verificação da possibilidade de ser atingido o estado de deformação excessiva, a fim de que as deformações não possam ser 
prejudiciais à estrutura ou a outras partes da construção.

Deve-se estudar as possíveis consequências indesejáveis das deformações e previstos os dispositivos necessários para evitá-las, adotando-se contraflechas quando conveniente.

No cálculo das deformações deve-se levar em conta a retração e a deformação lenta.

Segundo PFEIL (1990), os vigamentos apoiados ou contínuos de pontes de concreto armado são, em geral, bastante rígidos, não se produzindo vibrações ou flechas exageradas sob ação de carga móvel.

o cálculo das flechas em pontes de concreto armado é bastante complicado pela redução do momento de inércia decorrente da fissuração e ainda pelos efeitos da fluência do concreto.

A flecha imediata (sem efeito de fluência) pode, segundo a AMERICAN ASSOCIATION OF STATE HIGHWAY AND TRANSPORTATION OFFICIALS (AASHTO) apUd PFEIL (1990), ser calculada com um momento de inércia efetivo le dado pela fórmula empírica:

$$
I_{e}=I_{r}+\left(\frac{M_{r}}{M}\right)^{3}\left(I_{c}-I_{r}\right) \leq I_{c}
$$

onde:

$I_{r}=$ momento de inércia da seção fissurada, multiplicando-se a área da armação por $\mathrm{n}=8\left(\mathrm{~cm}^{4}\right)$;

$I_{c}=$ momento de inércia da seção bruta de concreto $\left(\mathrm{cm}^{4}\right)$;

$\mathrm{M}=$ momento máximo no tramo ( $\mathrm{kNcm})$;

$M_{r}=$ momento de fissuração da seção, dado aproximadamente por

$$
M_{r}=E_{c t} \frac{I_{c}}{Y_{1}}
$$

onde:

$f_{c t}=$ resistência característica do concreto à tração na flexão $\left(\mathrm{kN} / \mathrm{cm}^{2}\right) ; \mathrm{f}_{\mathrm{ct}}=1.2 \mathrm{f}_{\mathrm{tk}}$ para peças de seção $\mathrm{T}$ ou duplo $T$ e $f_{c t}=1.5 f_{t k}$ para peças de seção retangular; $y_{1}=$ distância do centro de gravidade da seção bruta de 
concreto à fibra mais tracionada $(\mathrm{cm})$.

Para seções retangulares, o momento de inércia da seção fissurada pode ser calculado de maneira expedita com os valores da tabela 4.10 .

Tabela 4.10 - Valores de $\frac{I_{r}}{I_{c}}$ para vigas de seça retangular

\begin{tabular}{l|lll|lll}
\hline \multirow{2}{*}{ n } & \multicolumn{2}{|c|}{$A_{s}{ }^{\prime}=0}$, & $d^{\prime} / d=$ & \multicolumn{2}{|c}{$A_{s}{ }^{\prime}=A_{s}}$, & \multicolumn{2}{c}{$d^{\prime} / d=$} \\
\cline { 2 - 7 } & 0.10 & 0.15 & 0.20 & 0.10 & 0.15 & 0.20 \\
\hline 0.05 & 0.30 & 0.23 & 0.20 & 0.32 & 0.25 & 0.21 \\
0.10 & 0.54 & 0.44 & 0.38 & 0.58 & 0.48 & 0.40 \\
0.15 & 0.70 & 0.60 & 0.52 & 0.80 & 0.66 & 0.56 \\
0.20 & 0.82 & 0.72 & 0.64 & 1.00 & 0.82 & 0.70 \\
0.25 & 0.97 & 0.82 & 0.75 & 1.20 & 1.00 & 0.84 \\
0.30 & 1.05 & 0.92 & 0.90 & 1.40 & 1.16 & 0.98 \\
\hline
\end{tabular}

Fonte: PFEIL (1990)

As vigas simplesmente apoiadas, de altura constante, podem ser calculadas com 0 momento de inércia efetivo $I_{e}$, calculado na seção de maior momento, e suposto constante em todo o vão. Para vigas contínuas, o momento de inércia efetivo $I_{e}$, pode ser tomado igual à média aritmética dos valores obtidos com a equação $4.52 \mathrm{a}$ para as seções críticas de momentos positivos e negativos.

O módulo de elasticidade instantâneo $\mathrm{E}_{c}$ do concreto a ser usado com a equação $4.52 \mathrm{a}$ é o módulo secante, obtido através da equação 4.42 .

o cálculo das flechas finais de carga permanente, inclusive efeitos de fluência e retração do concreto, pode ser feito, segundo PFEIL (1990), multiplicando-se a flecha imediata por um dos coeficientes da Tabela 4.11. 
Tabela 4.11 - Coeficientes para obter a flecha final em funça da da flecha inicial

\begin{tabular}{c|c|c|c}
\hline $\begin{array}{c}\text { Umidade do } \\
\text { meio ambiente }\end{array}$ & $A_{s}{ }^{\prime}=0$ & $A_{s}{ }^{\prime}=\frac{1}{2} A_{s}$ & $A_{s}{ }^{\prime}=A_{s}$ \\
\hline alta & 2.5 & 1.8 & 1.5 \\
média & 3.0 & 2.2 & 1.8 \\
baixa & 3.5 & 2.5 & 2.0 \\
\hline
\end{tabular}

Fonte: PFEIL (1990)

\subsection{6 - VERIFICAÇÃO DO ESTADO DE FISSURAÇÃO INACEITÁVEL}

A condição de fissuração da estrutura, avaliada considerando-se a mesma em serviço, é feita segundo o critério da norma NBR 6118 (1982).

Segundo esta, considera-se atingido um estado limite de fissuração quando o valor da abertura $\omega$ das fissuras na superfície do concreto iguala ou ultrapassa os seguintes valores:

a) $0.1 \mathrm{~mm}$, para peças não protegidas, em meio agressivo;

b) $0.2 \mathrm{~mm}$, para peças não protegidas, em meio não agressivo;

c) $0.3 \mathrm{~mm}$, para peças protegidas.

A NBR 6118 admite, apoiada em resultados experimentais, que um estado limite de utilização por fissuração não é atingido caso seja respeitada uma das duas desigualdades seguintes:

$$
\begin{aligned}
& \frac{\phi}{2 \eta_{\mathrm{b}}-0.75} \times \frac{\sigma_{s}}{\mathrm{E}_{\mathrm{s}}}\left(\frac{4}{\rho_{\mathrm{r}}}+45\right) \leq\left\{\begin{array}{l}
1, \text { para } \omega \leq 0.1 \mathrm{~mm} \\
2, \text { para } \omega \leq 0.2 \mathrm{~mm} \\
3, \text { para } \omega \leq 0.3 \mathrm{~mm}
\end{array}\right. \\
& \frac{\phi}{2 \eta_{\mathrm{b}}-0.75} \times \frac{\sigma_{s}}{\mathrm{E}_{\mathrm{s}}} \times \frac{3 \sigma_{s}}{f_{t k}} \leq\left\{\begin{array}{l}
1, \text { para } \omega \leq 0.1 \mathrm{~mm} \\
2, \text { para } \omega \leq 0.2 \mathrm{~mm} \\
3, \text { para } \omega \leq 0.3 \mathrm{~mm}
\end{array}\right.
\end{aligned}
$$

onde:

$\phi=$ diâmetro das barras da armadura (mm);

$\eta_{\mathrm{b}}=$ coeficiente de aderência do aço empregado, não se tomando, em hipótese alguma, $\eta_{b}>1.8$; 
$f_{t k}=$ resistência característica do concreto à tração $\left(\mathrm{kgf} / \mathrm{cm}^{2}\right)$;

$\sigma_{s}=$ tensão em serviço na armadura para a solicitação característica atuante $\left(\mathrm{kgf} / \mathrm{cm}^{2}\right)$, calculada através da equação 4.40;

$E_{s}=$ módulo de elasticidade longitudinal do aço $\left(E_{s}=2.1 \times 10^{6}\right.$ $\left.\mathrm{kgf} / \mathrm{cm}^{2}\right)$;

$\rho_{r}=$ taxa geométrica da armadura na seção transversal de concreto $A_{c r}$ interessada pela fissuração $\left(\rho_{r}=A_{s} / A_{c r}\right)$. 0 valor de $A_{c r}$ é obtido de acordo com a figura 4.23.

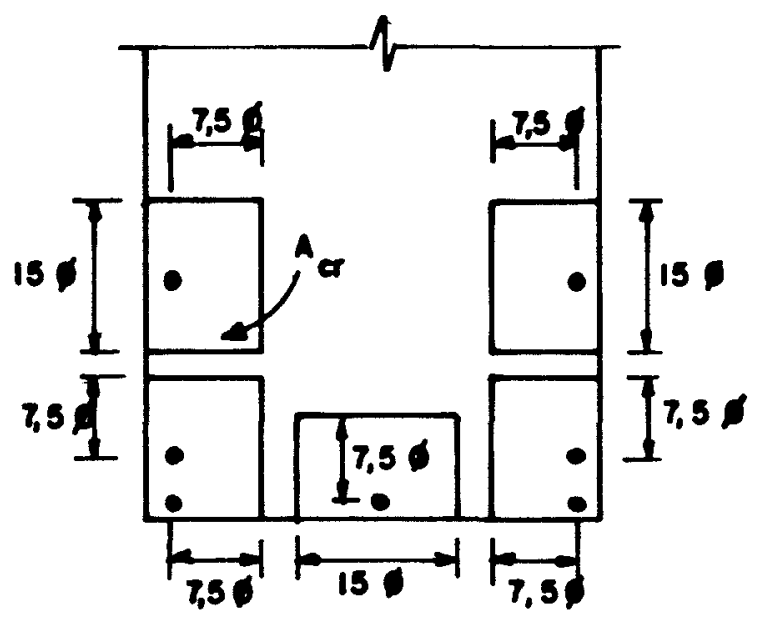

Figura 4.23 - Área de concreto (A $\mathrm{cr}$ )

\section{6 - DETALHAMENTO DA ESTRUTURA}

- detalhamento das armaduras é feito a partir das envoltórias dos esforços (momentos e cortantes).

A envoltória da laje da estrutura sem continuidade é obtida a partir das superfícies de influência de RÜsCH (1965) (fig. 4.3a). As demais envoltórias (muro em balanço, laje e encontros do pórticol são obtidas a partir dos esforços calculados em seções pré-definidas.

Essas envoltórias sofrem um processo de deslocamento horizontal, para atender à ancoragem das bielas comprimidas utilizadas nas treliças ideais de dimensionamento da armadura transversal. 
0 deslocamento horizontal $a_{1}$, no caso de estribos verticais, é dado pela equação:

$$
\frac{a_{1}}{d}=1.5-1.2 \eta \geq 0.5
$$

onde:

$\mathrm{d}$ = altura útil da peça $(\mathrm{cm})$;

sendo:

$$
\eta=\frac{{ }_{d}}{1.15 \tau_{w d}}
$$

onde:

$\tau_{w d}=$ valor de cálculo da tensão convencional de cisalhamento no concreto, na alma das peças (tensão de referência) em $\mathrm{MPa} ; \tau_{\mathrm{wd}}=\mathrm{V}_{\mathrm{d}} / \mathrm{b}_{\mathrm{w}} \mathrm{d}$;

$\tau_{d}=1.15 \tau_{w d}-\tau_{c}(e m M P a)$

sendo $\tau_{c}=\psi_{1} \sqrt{f_{c k}}$, com valor de $\psi_{1}$ obtido segundo 0 item A-2.2 do anexo da NBR 7197 (1989).

Não há, entretanto, necessidade de calcular um valor de $a_{1}$ para cada seção, podendo-se tomar um valor constante para cada tramo ou trecho da viga.

A escolha da relação $a_{1} / d$, para cada trecho, pode ser feita com os valores da Tabela 4.12 .

Tabela 4.12 - Valores simplificados da relação a /d

\begin{tabular}{l|ccc}
\hline \multirow{2}{*}{ Tipo de armadura transversal } & \multicolumn{3}{|c}{ Valor de $\eta$} \\
\cline { 2 - 4 } & $\leq 0.6$ & 0.6 a 0.8 & 5.8 \\
\hline Estribos verticais com ou sem & 1.00 & 0.75 & 0.50 \\
ferros dobrados & 0.75 & 0.50 & 0.25 \\
Estribos inclinados a $45^{\circ}$ & & & 0.50 \\
\hline
\end{tabular}

Fonte: NBR $6118(1982)$

Para lajes sem armadura transversal calculada (caso em que $\tau_{w d}<\tau_{w u 1}$ ) toma-se $a_{1}=1.5 \mathrm{~d}$.

- cálculo das ancoragens e emendas das barras de armação segue as recomendações da NBR 6118. 


\section{5 - EXEMPLO ILUSTRATIVO}

\section{1 - INTRODUÇÃO}

Com o objetivo de verificar o comportamento estrutural e realizar uma estimativa dos custos diretos da estrutura proposta, apresenta-se no presente capítulo um exemplo de cálculo de uma ponte com 8 metros de vão.

Para efeito de comparação serão considerados os dois sistemas estruturais discutidos no capítulo, 4 ou seja, sistema sem continuidade (laje bi-apoiada) e sistema com continuidade (laje engastada nos encontros).

\section{2 - CARACTERÍSTICAS GEOMÉTRICAS DA PONTE}

o cálculo é desenvolvido para uma ponte destinado à integrar rodovias.

Segundo PFEIL (1990), as normas do Departamento

Nacional de Estradas de Rodagem (DNER) adotam as seguintes larguras de pista: Classe I - $7.20 \mathrm{~m}$, Classe II e III - 6.00 à $7.20 \mathrm{~m}$. Nas estradas com duas pistas independentes com duas faixas de tráfego cada uma, a largura utilizada é $7.00 \mathrm{~m}$. Os acostamentos tem largura mínima variável, conforme a classe da estrada e a região atravessada. Nas estradas Classe I, normalmente adotam-se acostamentos de 2.50 metros de largura. Admitindo-se que a ponte será destinada a uma estrada Classe I de pista simples, sua largura total mínima 


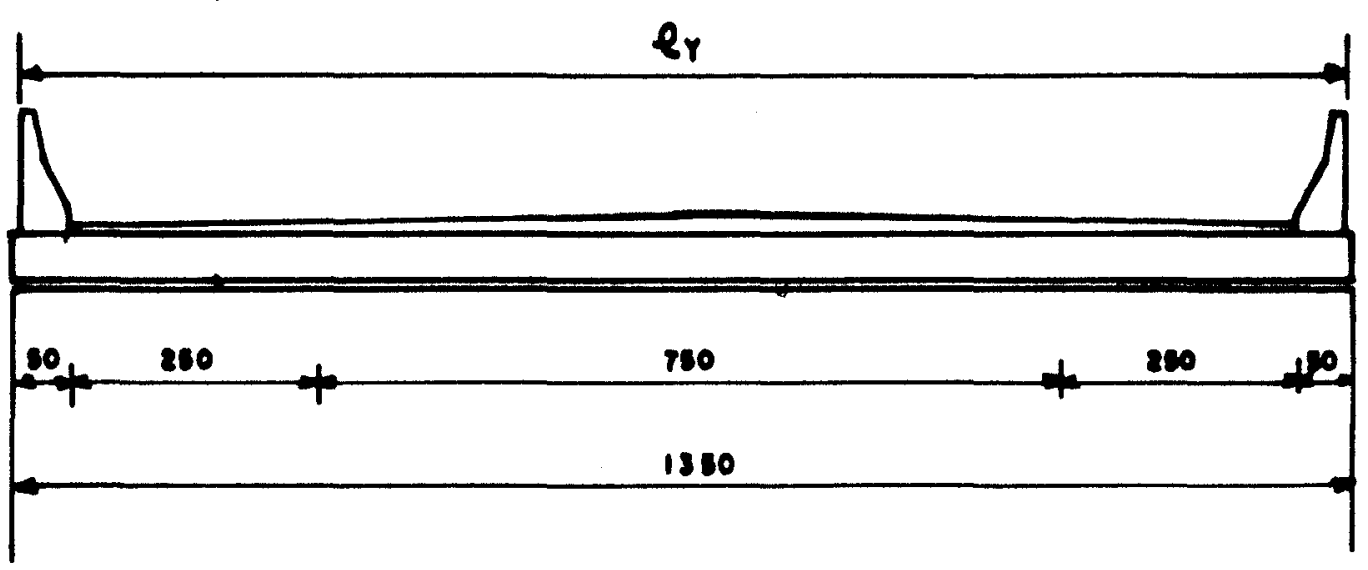

Figura 5.1 - Seção transversal do tabuleiro da ponte dimensões em cm.

deve ser de 13.20 metros, considerando-se 0.50 metros em cada borda destinados às defensas. Adota-se para efeito de cálculo a largura de 13.50 metros.

Considerando-se que a ponte poderá ser utilizada para fins de retorno ou mesmo como travessia de estradas vicinais, este deve ter espaço livre mínimo sob a superestrutura de 5.50 metros de altura (DNER).

\section{3 - CÁLCULO SEM CONTINUIDADE}

Tem-se a estrutura conforme exposto no item 4.2.

\subsection{1 - CÁLCULO DA SUPERESTRUTURA}

Admite-se a utilização de concreto com resistência característica à compressão $f_{c k}=21 \mathrm{MPa}$ tanto na fabricação das vigas pré-moldadas como no concreto moldado no local.

\subsubsection{1 - PRÉ - DIMENSIONAMENTO DA LAJE}

Considerando-se $\circ$ valor da relação $\ell_{j} / e_{1}=18 \mathrm{e} \mathrm{um}$ vão teórico de 8.20 metros, chega-se a uma laje de espessura igual a 45 centímetros (utilizando-se a Tabela 4.1). Toma-se este valor da relação $\ell_{j} / e_{1}$ lembrando-se de que as pontes em lajes maciças são apropriadas, segundo LEONHARDT (1979), para vãos de até 20 metros, aproximadamente (para as quais se teria o maior valor de $\left.\ell_{i} / e_{1}\right)$. 


\subsubsection{2 - CÁLCULO DA LAJE SEGUNDO RÜSCH}

- o cálculo é desenvolvido admitindo-se que a ponte seja da Classe 45.

Tendo-se fixadas as dimensões da laje, toma-se por lx o vão da ponte (direção do tráfego). Dessa forma, chega-se aos seguintes dados da estrutura:
a) Vão teórico: $\ell_{x}=8.20 \mathrm{~m}$;
b) largura da laje: $\ell_{y}=13.50 \mathrm{~m}$;
c) espessura da laje: $e_{1}=45 \mathrm{~cm}$;
d) condições de apoio: bi-apoiada;
e) relação $\ell_{y} / \ell_{x}=1.65 \cong 1.60$.

Segundo RÜSCH (1965), para essas condições de apoio e relação $\ell_{y} / \ell_{x}$ utiliza-se no cálculo dos momentos fletores a tabela 6. Os coeficientes para o cálculo dos esforços cortantes no meio e no canto do apoio são obtidos das tabelas 99 e 101 (RÜSCH), respectivamente.

\section{Esforços devidos ao carregamento permanente}

No cálculo dos esforços devidos ao carregamento permanente deve-se considerar, além do peso próprio e da sobrecarga de pavimentação $(10 \mathrm{~cm})$, uma carga uniformemente distribuida de $2.00 \mathrm{kN} / \mathrm{m}^{2}$ proveniente de um futuro recapeamento (NBR 7187).

Chega-se assim a uma carga uniformemente distribuida sobre a laje $\mathrm{g}=15.65 \mathrm{kN} / \mathrm{m}^{2}$, para a qual obtém-se, através das equações 4.3 e 4.4 , os seguintes esforços:

$M_{x m},=131.54 \mathrm{kNm} / \mathrm{m}$;

$\mathrm{M}_{\mathrm{ym}}{ }^{\prime}=21.89 \mathrm{kNm} / \mathrm{m}$;

$\mathrm{M}_{x r^{\prime}}=131.54 \mathrm{kNm} / \mathrm{m}$;

$\mathrm{V}_{\text {em }}{ }^{\prime}=64.17 \mathrm{kN} / \mathrm{m}$;

$\mathrm{V}_{\text {er }}{ }^{\prime}=64.17 \mathrm{kN} / \mathrm{m}$;

onde:

$M_{x m}=$ momento fletor no meio da placa na direção $x$;

$\mathrm{M}_{y \mathrm{~m}}=$ momento fletor no meio da placa na direção $y$;

$M_{x r}=$ momento fletor no meio dos bordos livres na direção $x_{i}$ 
$\mathrm{V}_{\text {em }}=$ força cortante no meio dos apoios;

$v_{\text {er }}=$ força cortante no canto dos apoios;

sendo utilizado $\circ$ apóstrofe para identificar os esforços provenientes de carregamento permanente uniformemente distribuído sobre a placa.

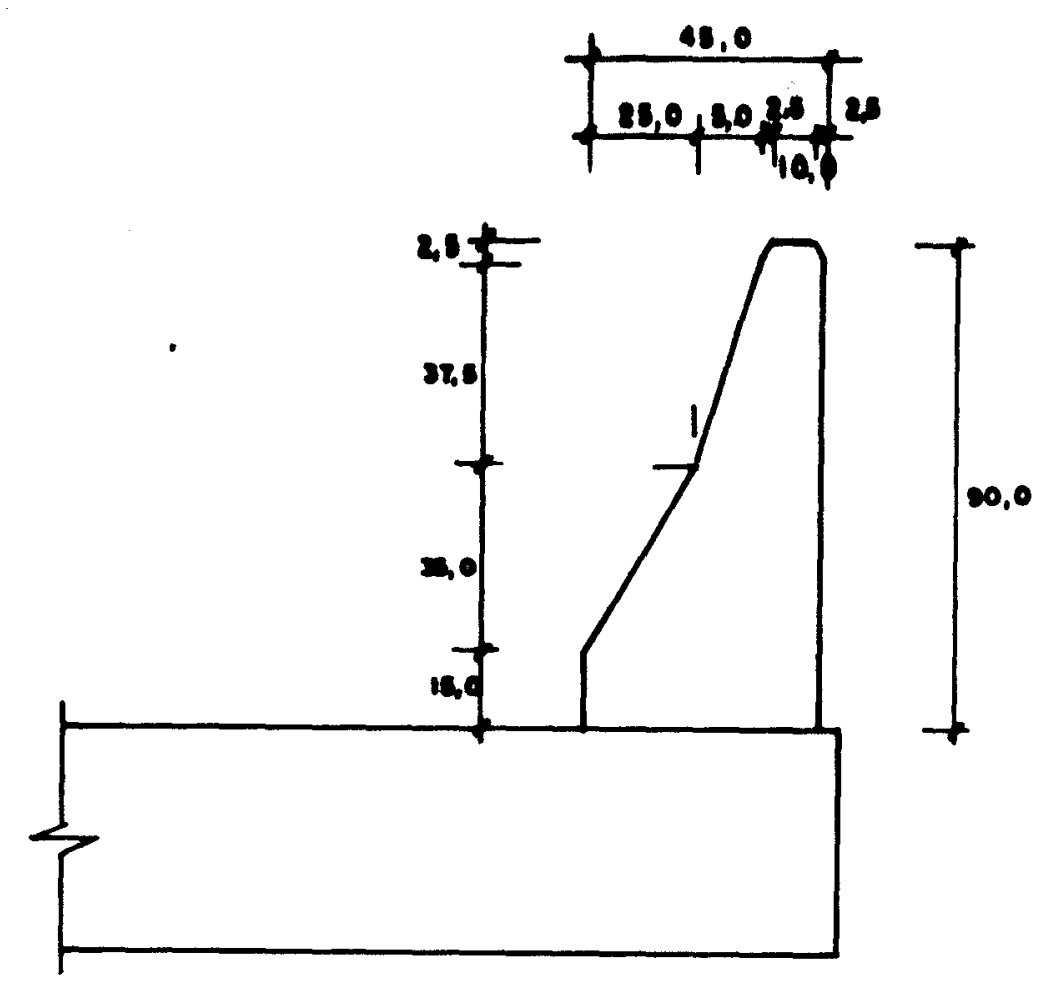

Figura 5.2 - Dimensões do guarda-corpo ( $\mathrm{cm}$ )

Os esforços devidos ao peso das defensas são quantificados através da Tabela 103 (RÜSCH), considerando-se uma carga por unidade de comprimento ao longo dos bordos livres. Sendo a seção transversal dos guarda-corpos dada conforme a Figura 5.2, chega-se a uma carga uniformemente distribuída igual à $6.25 \mathrm{kN} / \mathrm{m}$. Portanto:

$\mathrm{M}_{\mathrm{xm}}{ }^{\prime}=5.13 \mathrm{kNm} / \mathrm{m}$;

$\mathrm{M}_{y \mathrm{~m} \text { " }}=2.05 \mathrm{kNm} / \mathrm{m}$;

$M_{x r^{\prime \prime}}=13.33 \mathrm{kNm} / \mathrm{m}$;

onde os dois apóstrofes indicam esforços provenientes de carregamento permanente aplicado ao longo dos bordos livres.

Vê-se que o cálculo segundo RÜSCH fornece apenas os 
valores dos esforços máximos (centro do vão). Assim, para que se possa realizar posteriormente um melhor detalhamento da armadura, calcula-se os momentos fletores atuantes em seções definidąs a cada décima parte do vão $(0.82 \mathrm{~m})$. Para o caso dos momentos devidos às defensas, considera-se o valor do mesmo nos bordos livres.

Esses momentos são obtidos calculando-se, primeiramente, uma carga distribuída equivalente, a partir do momento máximo $M_{x r}=M_{x r}{ }^{\prime}+M_{x r}=144.87 \mathrm{kNm} / \mathrm{m}$. Entrando com este momento na equação 4.3, obtém-se a carga equivalente $g_{e q}=17.24 \mathrm{kN} / \mathrm{m}^{2}$, com a qual pode-se, na equação 4.4 , obter o valor da força cortante máxima (apoios) correspondente, $v_{a}=70.67 \mathrm{kN} / \mathrm{m}$.

Desse modo pode-se ter os valores dos momentos fletores nas seções definidas através da seguinte equação:

$$
M_{s}=70.67 x-17.24 \frac{x^{2}}{2}
$$

sendo $\mathrm{x}$ a distância em metros da seção considerada ao apoio da laje.

As forças cortantes são determinadas diretamente por semelhança de triângulos, uma vez que o diagrama de esforços cortantes é linear variando de \pm 64.17 de um extremo ao outro do vão. Esses esforços são mostrados na Tabela 5.4.

\section{Esforços devidos ao carregamento móvel}

Para a obtenção dos coeficientes nas tabelas, torna-se necessário a avaliação da largura de distribuição (t). Sendo o veículo tipo Classe 45 tem-se, segundo a Tabela 4.3 , para as larguras de contato de todas as rodas: $b_{1}=b_{2}=$ $b_{3}=0.50$ metros. Com o comprimento de contato igual a 0.20 metros, obtém-se a largura de contato do quadrado equivalente $b=0.32$ metros. Observando-se a Figura 4.2, calcula-se $t=$ 0.97 metros. A distância entre rodas de um mesmo eixo é a = 2.00 metros (Tabela 4.3).

$\mathrm{Na}$ Tabela 6 de RÜsCH para $\frac{t}{a}=0.49 \cong 0.50 \mathrm{e}$ $\ell_{x} / a=4.10$, interpolando-se entre os valores fornecidos, obtém-se os coeficientes apresentados nas Tabelas 5.1 e 5.2 
para o cálculo dos momentos fletores.

No cálculo da força cortante, tem-se (Tabelas $99 \mathrm{e}$ 101 de RÜSCH) os valores dos coeficientes apresentados na Tabela 5.3.

Calculando-se o valor do coeficiente de impacto segundo a equação 4.2 e obtendo-se as cargas $F$ e $p$ das Tabelas 4.2 e 4.3 , calcula-se os momentos fletores e esforços

Tabela 5.1 - Coeficientes para o cálculo dos momentos fletores devidos à carga $P$

\begin{tabular}{c|ccc}
\hline \multirow{2}{*}{$\frac{\ell_{x}}{a}$} & \multicolumn{3}{|c}{$t / a=0.50$} \\
\cline { 2 - 4 } & $M_{x \text { m }}$ & $M_{y ~ m}$ & $M_{x r}$ \\
\hline 4.00 & 0.84 & 0.47 & 1.82 \\
4.10 & 0.85 & 0.48 & 1.85 \\
5.00 & 0.96 & 0.58 & 2.12 \\
\hline
\end{tabular}

Tabela 5.2 - Coeficientes para o cálculo dos momentos fletores devidos às cargas $p$ e $p$ '

\begin{tabular}{c|cccccc}
\hline \multirow{2}{*}{$\frac{\ell_{x}}{\mathrm{a}}$} & \multicolumn{2}{|c}{$\mathrm{M}_{\mathrm{x} \mathrm{m}}$} & \multicolumn{2}{c}{$\mathrm{M}_{\mathrm{ym}}$} & \multicolumn{2}{c}{$\mathrm{M}_{\mathrm{xr}}$} \\
\cline { 2 - 7 } & $\mathrm{p}$ & $\mathrm{p}^{\prime}$ & $\mathrm{p}$ & $\mathrm{p}^{\prime}$ & $\mathrm{p}$ & $\mathrm{p}^{\prime}$ \\
\hline 4.00 & 0.15 & 5.80 & 0.11 & 1.33 & 0.30 & 3.80 \\
$\mathbf{4} .10$ & 0.17 & 6.20 & 0.12 & 1.42 & 0.34 & 4.14 \\
5.00 & 0.35 & 9.82 & 0.24 & 2.25 & 0.66 & 7.24 \\
\hline
\end{tabular}

cortantes com a equação 4.1a. Assim:

$\varphi=1.34 ;$

$F=75 \mathrm{kN}$;

$\mathrm{p}=5 \mathrm{kN} / \mathrm{m}^{2}$;

$M_{x m \prime \prime}=128.10 \mathrm{kNm} / \mathrm{m}$;

$M_{y m \prime \prime}=58.56 \mathrm{kNm} / \mathrm{m}$;

$\mathrm{M}_{\mathrm{Xr} \prime \prime}=215.94 \mathrm{kNm} / \mathrm{m}$;

$\mathrm{V}_{\mathrm{am} \mathrm{m}^{\prime \prime}}=104.45 \mathrm{kN} / \mathrm{m}$;

$\mathrm{V}_{\mathrm{ar} \prime \prime}=249.17 \mathrm{kN} / \mathrm{m}$;

sendo os três apóstrofes indicativos de esforços provenientes do carregamento móvel. 
Tabela 5.3 - Coeficientes para o cáculo das forças cortantes devidos as cargas $P$, $p$ e $P^{\text {. }}$

\begin{tabular}{c|cc|cccc}
\hline \multirow{2}{*}{$\frac{\ell_{x}}{\mathrm{a}}$} & \multicolumn{2}{|c|}{$\mathrm{t} / \mathrm{a}$} & 0.50 & \multicolumn{2}{|c}{$\mathrm{V}_{\mathrm{am}}$} & \multicolumn{2}{c}{$\mathrm{V}_{\mathrm{ar}}$} \\
\cline { 2 - 8 } & $\mathrm{V}_{\mathrm{am}}$ & $\mathrm{V}_{\mathrm{ar}}$ & $\mathrm{p}$ & $\mathrm{p}^{\prime}$ & $\mathrm{p}$ & $\mathrm{p}^{\prime}$ \\
\hline 4.00 & 0.90 & 2.35 & 0.26 & 1.60 & 0.28 & 1.57 \\
4.10 & 0.91 & 2.35 & 0.27 & 1.67 & 0.30 & 1.64 \\
5.00 & 0.96 & 2.38 & 0.37 & 2.26 & 0.44 & 2.29 \\
\hline
\end{tabular}

Os casos tabelados em RÜSCH (1965) consideram a carga móvel ocupando toda a largura da placa. Entretanto as defensas não permitem que estas cargas sejam dispostas exatamente nos bordos livres da placa. Assim, para efeito de dimensionamento da armadura, considera-se os momentos atuantes à distância de 0.75 metros dos bordos livres (Figura 5.3). Este momento é calculado por interpolação linear entre os calculados no meio $e$ bordos da laje $\left(M_{x m}\right.$ e $\left.M_{x r}\right)$. Desse modo:

$$
M_{x \eta}=M_{x r}-\left(\frac{M_{x r}-M_{x m}}{6.75} 0.75\right)
$$

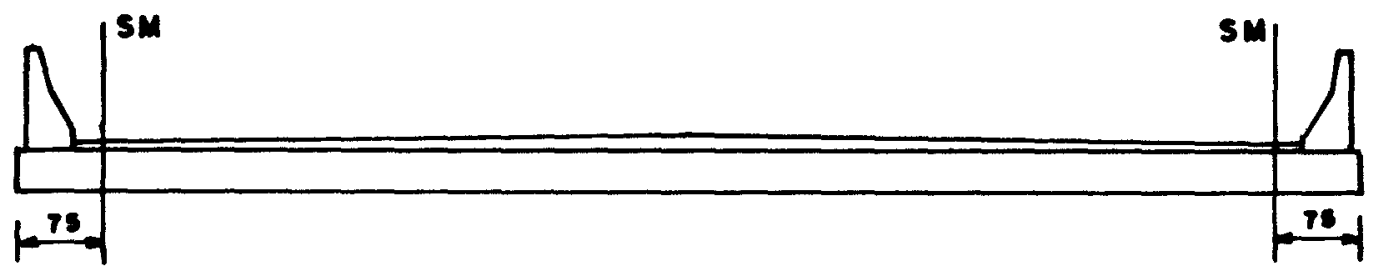

Figura 5.3 - Seção considerada para o cálculo dos esforços provenientes das cargas móveis (SM).

Com base nas superfícies de influência elaboradas por RÜSCH (Figura 4.3), pode-se obter os momentos atuantes nas demais seções estabelecidas na laje.

As forças cortantes nas seções estabelecidas são calculadas analogamente àquelas provenientes do carregamento permanente, fazendo-se, entretanto, a mesma redução considerada para os momentos fletores (seção à $0.75 \mathrm{~m}$ dos 
bordos livres). Dessa forma chega-se aos resultados apresentados na Tabela 5.4.

Tabela 5.4 - Esforços nas seções definidas na laje

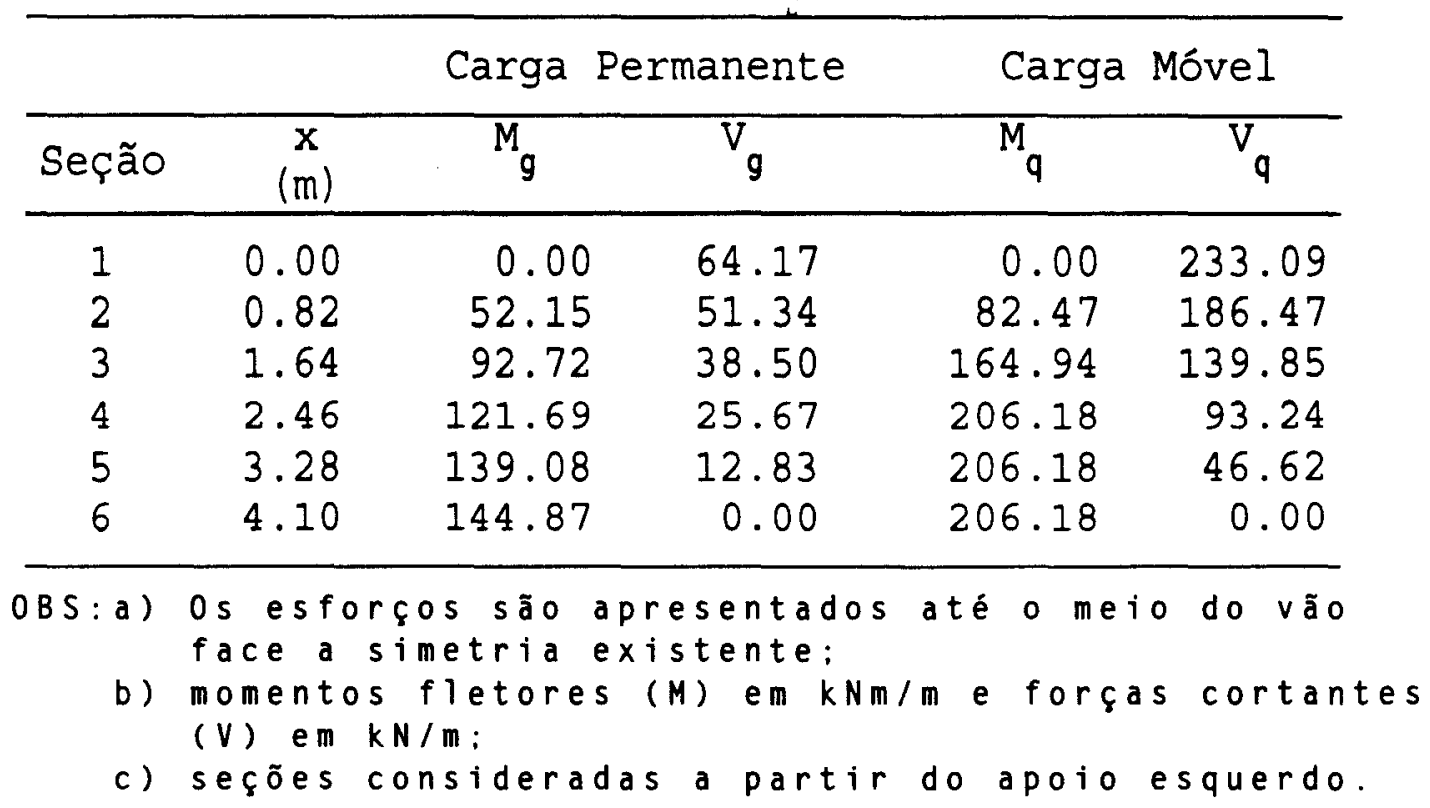

\subsection{2 - CÁLCULO DA INFRAESTRUTURA}

A infraestrutura é calculada com base nas hipóteses assumidas no item 4.2.2.

\subsubsection{1 - PRÉ-DIMENSIONAMENTO DOS ENCONTROS}

Para efeito de cálculo, adota-se para a altura teórica dos encontros o valor $\mathrm{h}=7.00 \mathrm{~m}$, considerando-se a necessidade de um vão livre de 5.50 metros de altura sob a ponte (ítem 5.2).

Admite-se a utilização de concreto com resistência característica à compressão $f_{c k}=21 \mathrm{MPa}$.

Os encontros são calculados com base nas hipóteses assumidas no ítem 4.2.2.

Seguindo o exposto no ítem 4.2.2.1, tem-se segundo a equação $4.7, \mathrm{~K}=\frac{1}{3}$, para um ângulo de atrito interno igual a $30^{\circ}$.

Obtendo-se a resultante do empuxo atuante sobre 0 muro com a equação 4.5, pode-se, com a equação 4.8, avaliar a espessura útil $\left(d_{m}\right)$ necessária ao muro na sua base. Assim: 
$E=147.00 \mathrm{kN} / \mathrm{m}$, para $\gamma_{\mathrm{t}}=18.00 \mathrm{kN} / \mathrm{m}^{3}$;

$d_{m}=58.57 \mathrm{~cm}$.

Lembrando-se da existência de outras cargas não consideradas nesta etapa do cálculo, adota-se para a espessura do muro na sua base 0 valor $e_{m}=70 \mathrm{~cm}$. Para 0 topo, admitindo-se agregado do tipo brita $n \cdot 2$, adota-se a espessura de $20 \mathrm{~cm}$, que atende no tocante aos esforços provenientes da superestrutura.

\subsubsection{2 - CÁLCULO DOS ENCONTROS}

Para a obtenção das envoltórias de esforços, define-se seções a cada metro a partir da base do muro.

A rigidez do encontro é obtida com a equação 4.13 a partir das flexibilidades do pilar e do aparelho de apoio.

Cálcula-se a flexibilidade do pilar com a equação 4.12 onde $y$ é medido com relação ao ponto médio entre as seções, e o momento de inércia calculado adotando-se a espessura do muro neste mesmo ponto. o valor do módulo de elasticidade do concreto $\left(E_{c}\right)$ é calculado, de acordo com a NBR 6118, da seguinte forma:

$$
E_{c}=6600 \sqrt{f_{c k}+3.5}, \text { com } E_{c k} \text { e } E_{c} \text { em MPa }
$$

donde, para $\mathrm{f}_{\mathrm{ck}}=15 \mathrm{MPa}$, obtém-se $E_{c}=2856.31 \mathrm{kN} / \mathrm{cm}^{2}$.

Desse modo, obtém-se o valor da flexibilidade do pilar, $\delta_{p}=3.27 \times 10^{-4} \mathrm{~m} / \mathrm{kN}$.

Para se calcular a flexibilidade do neoprene torna-se necessário o seu dimensionamento. Seguindo as indicações do SERVICE CENTRAL D'ETUDES TECHINIQUES (Anexo A) chega-se a uma almofada de $1.00 \mathrm{~cm}$ de espessura de dimensão 10x30, a qual é disposta sob cada elemento pré-moldado (viga). Portanto, para uma dureza shore igual a 50, tem-se, através da Tabela A.4 e da equação 4.14, ○ valor da flexibilidade do neoprene $\delta_{n}=4.17 \times 10^{-4} \mathrm{~m} / \mathrm{kN}$.

As verificações da rotação imposta ao aparelho de apoio e da segurança contra o deslizamento são realizadas após o cálculo da flecha no centro do vão e da obtenção das forças horizontais atuantes no apoio, respectivamente. 


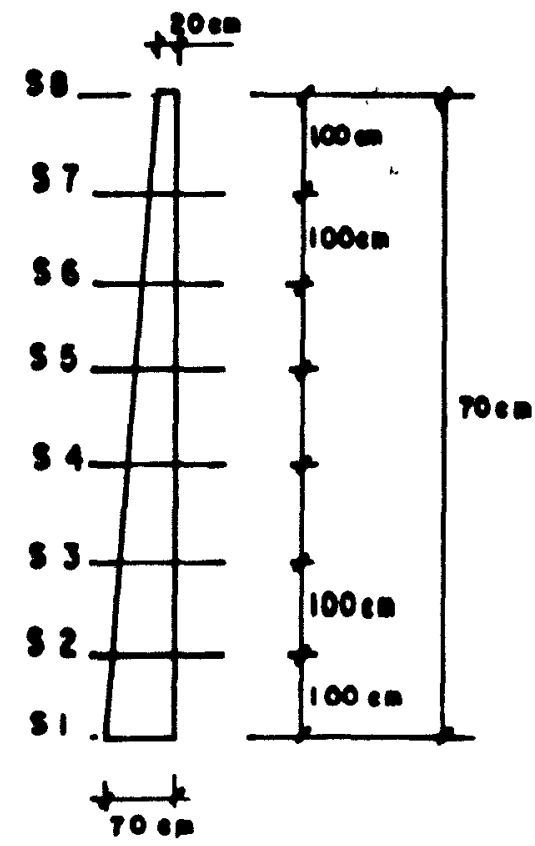

Figura 5.4 - Dimensões e secões definidas nos encontros

Tabela 5.5 - Cálculo da flexibilidade do pilar $\left(\delta_{p}\right)$

\begin{tabular}{rcccrr}
\hline Trecho & $\begin{array}{c}\Delta y \\
(\mathrm{~m})\end{array}$ & $\begin{array}{c}\mathrm{y} \\
(\mathrm{m})\end{array}$ & $\begin{array}{c}\mathrm{em} \\
(\mathrm{cm})\end{array}$ & \multicolumn{1}{c}{$\begin{array}{c}\mathrm{I} \\
\left(\mathrm{cm}^{4}\right)\end{array}$} & \multicolumn{1}{c}{$\underline{y}^{2} \Delta y$} \\
\hline $7-8$ & 1.00 & 0.5 & 23.57 & 1091.18 & 2.29 \\
$6-7$ & 1.00 & 1.5 & 30.71 & 2413.56 & 9.32 \\
$5-6$ & 1.00 & 2.5 & 37.85 & 4518.73 & 13.83 \\
$4-5$ & 1.00 & 3.5 & 44.99 & 7588.69 & 16.14 \\
$3-4$ & 1.00 & 4.5 & 52.13 & 11805.43 & 17.15 \\
$2-3$ & 1.00 & 5.5 & 59.27 & 17350.96 & 17.43 \\
$1-2$ & 1.00 & 6.5 & 66.42 & 24418.30 & 17.30 \\
\hline
\end{tabular}

Calcula-se então a rigidez do conjunto com a equação $4.13: \mathrm{k}_{n+p}=1344.10 \mathrm{kN} / \mathrm{m}$.

Esforços provenientes dos aterros de acesso e sobrecarga dos veículos adjacentes ao muro

Transformando-se o carregamento do veículo tipo em carga uniformemente distribuída e compondo-a com a carga distribuida $p$, que considera o efeito dos demais veículos, através das equações 4.15, obtém-se, pela equação 4.16, uma 
altura de terra equivalente $h_{0}$. Assim:

$p_{v}=25.00 \mathrm{kN} ;$

$\bar{p}=9.44 \mathrm{kN} / \mathrm{m}^{2}$;

$h_{0}=0.52 \mathrm{~m}$, para $\gamma_{t}=18.00 \mathrm{kN} / \mathrm{m}^{3}$.

Para a altura teórica ido muro, $h=7.00 \mathrm{~m}$, calcula-se, com as equações 4.17 o carregamento atuante no mesmo. Pode-se, então, obter os esforços nas seções definidas (Figura 5.4), desse modo:

$\mathrm{P}_{\mathrm{q}}=3.15 \mathrm{kN} / \mathrm{m}$;

$P_{a}=42.00 \mathrm{kN} / \mathrm{m}_{i}$

$P_{y}=3.15+6.00 y$

$v_{s}=\frac{y}{2}(6.30+6.00 y)$

$M_{s}=\frac{y^{2}}{6}(10.45+6.00 y)$

sendo $V_{s}$ e $M_{s}$ a força cortante e o momento fletor na seção $s$, respectivamente, e y a distância em metros do nível do terreno à seção considerada.

Os valores desses esforços são apresentados na Tabela 5.6 .

\section{Esforços provenientes da variação de temperatura e retração} do concreto

Conforme considerado no ítem 4.2.2.2, os esforcos provenientes da ocorrência destes fenômenos são avaliados conjuntamente através de uma queda de temperatura de $30^{\circ} \mathrm{C}$.

A deformação específica é, para essa variação de temperatura e coeficiente de dilatação térmica do concreto $\alpha=10^{-5}$, através da equação 4.19 , igual a $\epsilon_{c t}=-30 \times 10^{.5}$.

Sendo a ponte simétrica e os encontros com iguais rigezas, o ponto de deslocamento nulo localiza-se no meio do vão.

Calcula-se, então, pela equação 4.20, a força introduzida no muro em consequência da deformação do tabuleiro: $F_{t}=1.67 \mathrm{kN} / \mathrm{m}$.

Os esforços são obtidos diretamente, sendo a força cortante constante, de valor igual à $F_{t}$, $e$ momento fletor 
nas seções igual à $M_{s}=1.67 \mathrm{y}$. Estes valores são apresentados na Tabela 5.6 .

\section{Esforços provenientes da aceleração e frenagem dos veículos}

Seguindo a recomendação da NBR 7187 (1986), tem-se as seguintes forças atuantes no tabuleiro:

a) Aceleração: $25.63 \mathrm{kN}_{\text {; }}$

b) frenagem: $135.00 \mathrm{kN}$.

Adota-se, portanto, a força $F_{f}=135 \mathrm{kN}$. Sabendo-se que esta força é absorvida pelos dois encontros, pode-se calcular o momento fletor por unidade de largura atuante nas seções definidas: $M_{s}=5 y$, sendo $y$ a distância em metros do nível do terreno à seção considerada.

A força cortante é constante ao longo de toda altura, de valor $\mathrm{V}_{\mathrm{f}}=5.00 \mathrm{kN} / \mathrm{m}$.

Os valores desses esforços nos encontros são apresentados na Tabela 5.6 .

Tabela 5.6 - Esforcos nas seções definidas nos encontros

\begin{tabular}{|c|c|c|c|c|c|c|c|}
\hline \multirow[b]{2}{*}{ Seção } & \multirow[b]{2}{*}{$\begin{array}{c}Y \\
(m)\end{array}$} & \multirow{2}{*}{$\frac{\text { Empuxo de }}{\mathrm{M}_{\mathrm{a}}}$} & \multirow{2}{*}{$\frac{\text { terra }}{v_{a}}$} & \multirow{2}{*}{$\frac{\begin{array}{l}\text { Variação } \\
\text { retração }\end{array}}{M_{t}}$} & \multirow{2}{*}{$\begin{array}{l}\text { de temp. } \\
\text { do concr. } \\
v_{t}\end{array}$} & \multicolumn{2}{|c|}{$\begin{array}{c}\text { Aceleração } \\
\text { frenagem }\end{array}$} \\
\hline & & & & & & $M_{f}$ & $V_{f}$ \\
\hline 8 & 0.0 & 0.00 & 0.00 & 0.00 & 1.67 & 0.00 & 5.00 \\
\hline 7 & 1.0 & 2.74 & 6.15 & 1.67 & 1.67 & 5.00 & 5.00 \\
\hline 6 & 2.0 & 14.97 & 18.30 & 3.34 & 1.67 & 10.00 & 5.00 \\
\hline 5 & 3.0 & 42.68 & 36.45 & 5.01 & 1.67 & 15.00 & 5.00 \\
\hline 4 & 4.0 & 91.87 & 60.60 & 6.68 & 1.67 & 20.00 & 5.00 \\
\hline 3 & 5.0 & 168.54 & 90.75 & 8.35 & 1.67 & 25.00 & 5.00 \\
\hline 2 & 6.0 & 278.70 & 126.90 & 10.02 & 1.67 & 30.00 & 5.00 \\
\hline 1 & 7.0 & 428.34 & 169.05 & 11.69 & 1.67 & 35.00 & 5.00 \\
\hline
\end{tabular}

5.3.2.3 - PRÉ-DIMENSIONAMENTO DOS BLOCOS

Observando-se as recomendações do ítem 4.2.2.3, chega-se a um bloco cujas dimensões são apresentadas na Figura 5.5 . 


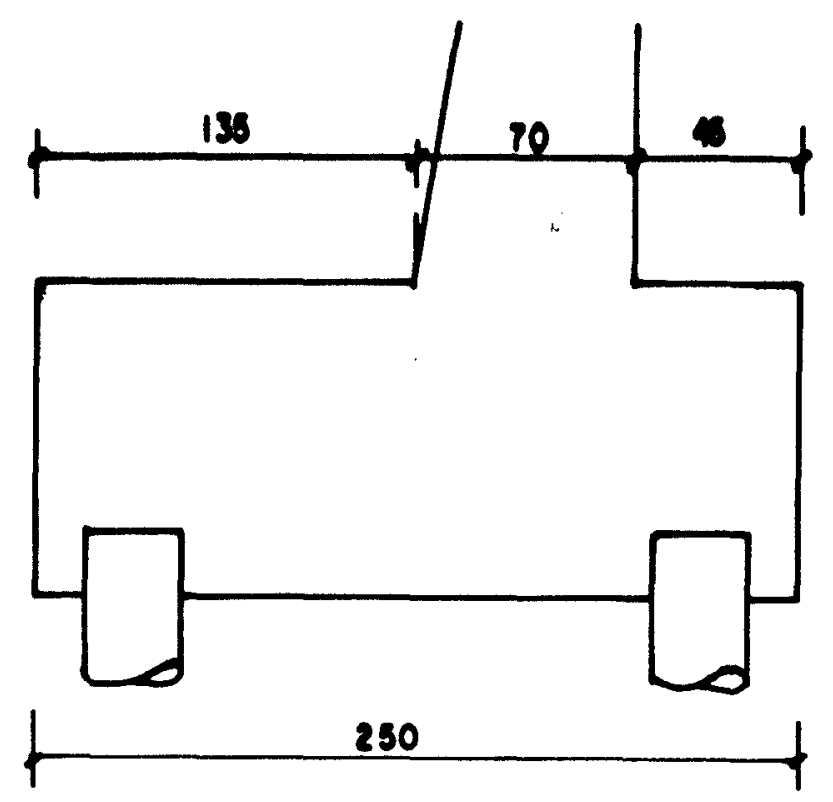

Figura 5.5 - Pré-dimensionamento dos blocos

\subsubsection{4 - CÁLCULO DOS ESFORÇOS NOS BLOCOS}

Primeiramente deve-se adequar o bloco obtido no pré-dimensionamento a um dos métodos propostos no ítem 4.2.2.4. Vê-se, assim, que o mesmo assemelha-se mais a um bloco cujas características são necessárias ao cálculo através do método do CEB (1970). Atendendo às exigências do método, modificam-se as características geométricas dos blocos, que passam a se apresentar conforme a Figura 5.6.

Adotam-se estacas pré-moldadas de concreto vibrado de diâmetro $\phi_{\mathrm{e}}=30 \mathrm{~cm}$ (capacidade nominal de resistência à compressão igual a $400 \mathrm{kN}$ ) a cada metro.

Calculando-se as cargas permanentes atuantes no bloco (peso-próprio, peso da terra sobre o mesmo, peso do muro) e compondo-as com os esforços decorrentes do carregamento na superestrutura e encontros, obtém-se 0 carregamento total no bloco. A reação devida às cargas móveis é determinada calculando-se a mesma para o caso de uma viga bi-apoiada $(570.90 \mathrm{kN})$ e dividindo-se este resultado pela largura do encontro $(13.50 \mathrm{~m})$. Admite-se, desta forma, que este esforço ao ser aplicado aos blocos, distribuiu-se por toda a extensão dos encontros. Desconsidera-se o efeito do 
impacto.

O carregamento total no bloco pode ser convertido em forças horizontais $(H)$ e verticais $(F)$, conforme a Figura 5.6 .

A força horizontal $(\mathrm{H})$ i é suposta equilibrada através das vigas de travamento. Ocorrendo 0 aterro dos acessos separadamente, deve-se verificar a influência desta força no carregamento das estacas. O momento provocado pela força $\mathrm{H}$ atenuará a carga na estaca mais solicitada (estaca 2), conforme observa-se na Figura 5.6.

Considerando-se vigas de travamento a cada 3.5 metros, a força horizontal aplicada em cada estaca é igual a: $\mathrm{H}^{\prime}=\frac{3.5}{12} \mathrm{H}=49.31 \mathrm{kN}$.

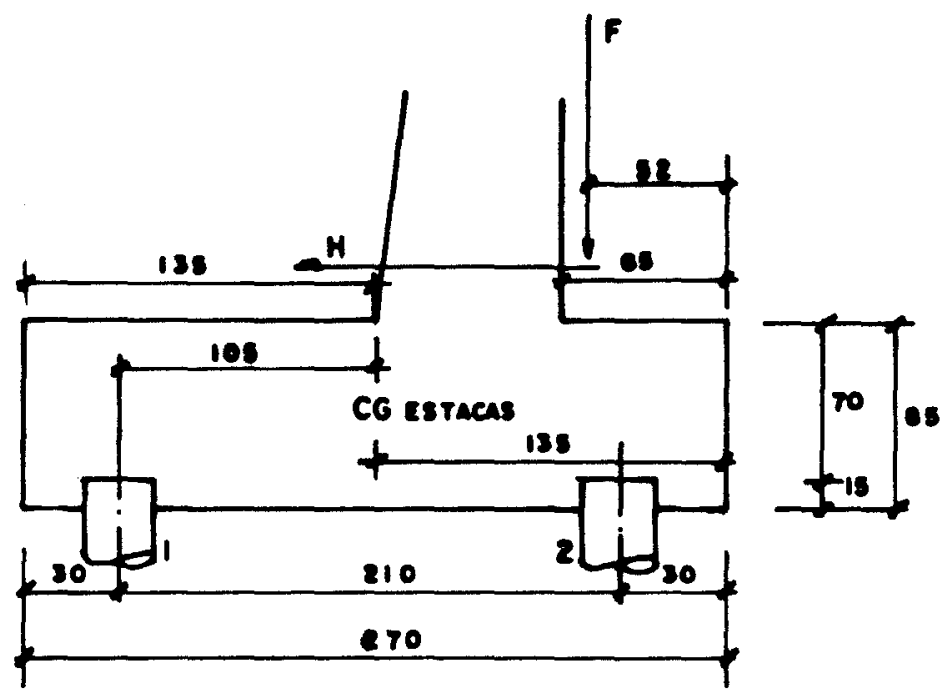

Figura 5.6 - Caracteristicas geométricas e carregamento nos blocos:

$F=432.85 \mathrm{kN} / \mathrm{m}$;

$H=169.05 \mathrm{kN} / \mathrm{m}$.

MOLITERNO (1980) apresenta uma marcha de cálculo para se determinar a resistência de grupos de estacas à forças horizontais. Admite-se neste trabalho que uma estaca suporte cargas horizontais da ordem de $10 \%$ de sua resistência à compressão.

Dessa forma, entrando com a força vertical (F) e o momento desta com relação ao centro de gravidade das estacas (CG) na equação 4.22, calcula-se as cargas correspondentes à 
cada estaca: .

$\mathrm{R}_{1}=44.92 \mathrm{kN}$;

$R_{2}=387.50 \mathrm{kN}$;

onde $R_{1}$ e $R_{2}$ são, conforme a Figura 5.6, as cargas correspondentes às estacas 1 e 2 , respectivamente.

o momento fletor, utilizado no cálculo da armadura inferior, é o maior momento obtido com relação à seção de referência $S_{1}$, definida no ítem 4.2.2.4. Portanto:

$M=176.31 \mathrm{kNm} / \mathrm{m}$.

- esforço cortante de cálculo $\left(V_{d}\right)$ deve ser verificado na seção de referência $S_{2}$, não devendo ser maior que o obtido com a equação 4.34. Desse modo:

$\mathrm{v}_{\mathrm{d}}=542.50 \mathrm{kN} / \mathrm{m}<\mathrm{v}_{\mathrm{dlim}}=1159.13 \mathrm{kN} / \mathrm{m}$.

- esforço cortante também deve ser verificado na vizinhança das estacas de canto, onde a reação da estaca $\left(R_{d}\right)$ deve ser no máximo igual àquela obtida com a equação 4.27. Assim:

$R_{d}=387.50 \mathrm{kN}<R_{d i \mathrm{~m}}=566.88 \mathrm{kN}$.

\section{4 - CÁLCULO COM CONTINUIDADE}

Tem-se a estrutura conforme a Figura 4.15.

o pré-dimensionamento da laje da superestrutura é feito analogamente àquele desenvolvido para a laje do cálculo sem continuidade. Chega-se, portanto, a uma espessura igual a $45 \mathrm{~cm}$.

Os encontros, considerados inicialmente com espessura igual a $30 \mathrm{~cm}$, apresentaram no detalhamento altas taxas de armadura. Adota-se assim a espessura de $45 \mathrm{~cm}$, que proporcionará uma melhor distribuição dos esforços além de facilitar a comparação entre os sistemas estruturais considerados (isostático e hiperestático) fazendo com que ambos possuam o mesmo consumo de concreto tanto na superestrutura quanto na infraestrutura (encontros).

Para a obtenção dos diagramas de momentos fletores (DMF) e esforços cortantes (DEC), são definidas as seções mostradas na Figura 5.7. 


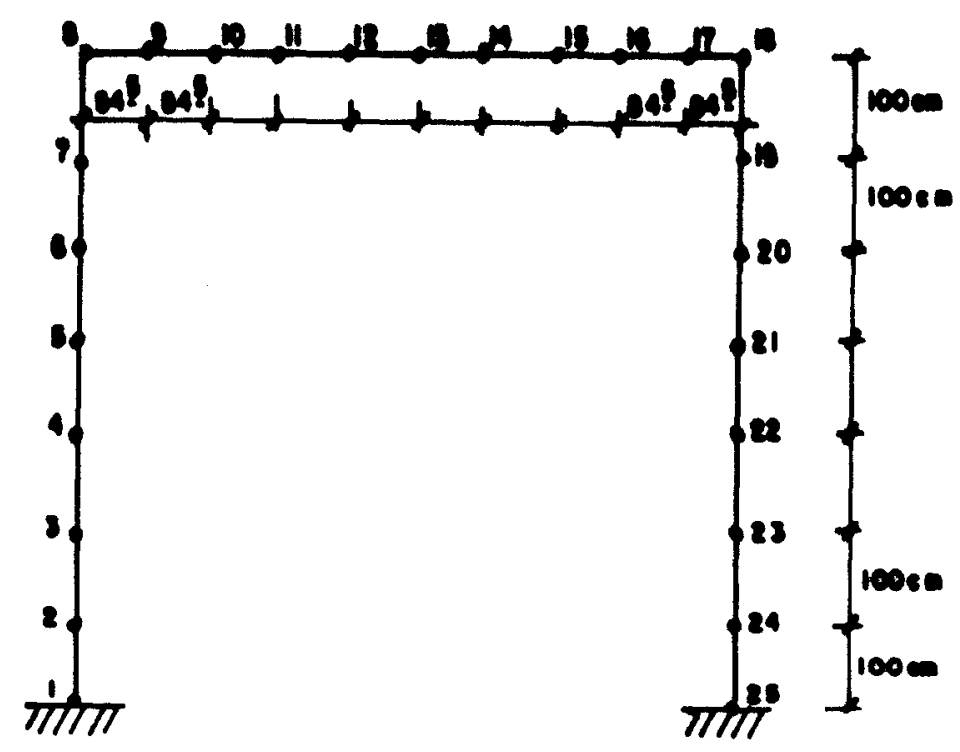

Figura 5.7 - Seções definidas no pórtico para o traçado dos diagramas de momento fletor e esforço cortante

\subsection{1 - CÁlCULO DA PONTE EM PÓRTICO - CARREGAMENTO MÓVEL}

- cálculo dos esforços devidos às cargas verticais é desenvolvido seguindo o conceito de largura colaborante, definido no ítem 4.3 .

Os esforços provenientes da aceleração e frenagem dos veículos são obtidos com a utilização do programa para pórticos planos (desenvolvido pelo autor). O carregamento considerado é o mesmo calculado no ítem 5.3.2.2. Os valores dos esforços nas seções definidas (Figura 5.7) são apresentados na Tabela 5.13 .

\subsubsection{1 - CÁLCULO DA LAJE ISOLADA}

- cálculo é desenvolvido analogamente àquele apresentado no ítem 5.3.1.2.

Com exceção do momento transversal no meio da laje $\left(\mathrm{M}_{\mathrm{ym}},\right)$, não é necessário o cálculo dos esforços devidos ao carregamento permanente, pois os mesmos são obtidos, de maneira imediata, com a utilização do programa para pórticos 
planos.

Tem-se os seguintes dados da estrutura:

a) Vão teórico: $l_{x}=8.45 \mathrm{~m}$;

b) largura da laje: $\ell_{y}=13.50 \mathrm{~m}$;

c) espessura da laje: $e_{1}=45 \mathrm{~cm}$;

d) condições de apoio: bi-engastada;

e) relação $\ell_{y} / \ell_{x}=1.60$.

- momento transversal no meio da laje devido às cargas permanentes é calculado com a equação 4.3 , sendo igual a $M_{y m^{\prime}}=6.59 \mathrm{kNm} / \mathrm{m}$. A este valor deve ser acrescentado a influência do peso das defensas, calculada no ítem 5.4.2.1.

os parâmetros necessários ao cálculo dos esforços decorrentes do carregamento móvel são, para o veículo tipo Classe 45, iguais a: $\ell_{x} / a=4.23$ e $\frac{t}{a}=0.50$.

$$
\text { Assim, na tabela } 36 \text { de RÜsCH (1965), }
$$

interpolando-se entre os valores existentes, encontram-se os coeficientes para o cálculo dos momentos fletores. Estes valores são apresentados nas Tabela 5.7 e 5.8 .

Tabela 5.7 - Coeficientes para o cálculo dos momentos fletores devidos à carga $P$.

\begin{tabular}{|c|c|c|c|c|}
\hline$\ell_{x}$ & \multicolumn{4}{|c|}{$t / a=0.50$} \\
\hline $\bar{a}$ & $\overline{M_{x m}}$ & $\mathrm{M}_{\mathrm{ym}}$ & $M_{x r}$ & $-{ }^{-M} \times$ e \\
\hline $\begin{array}{l}4.00 \\
4.23 \\
5.00\end{array}$ & $\begin{array}{l}0.47 \\
0.49 \\
0.56\end{array}$ & $\begin{array}{l}0.30 \\
0.31 \\
0.36\end{array}$ & $\begin{array}{l}1.08 \\
1.14 \\
1.34\end{array}$ & $\begin{array}{l}1.08 \\
1.11 \\
1.22\end{array}$ \\
\hline
\end{tabular}

Para $\varphi=1.34$, tem-se segundo a equação 4.1a:

$M_{x m \prime \prime}=60.36 \mathrm{kNm} / \mathrm{m}$;

$M_{y m ",}=34.64 \mathrm{kNm} / \mathrm{m}$;

$\mathrm{M}_{\mathrm{Xr}}{ }^{\prime \prime}=120.06 \mathrm{kNm} / \mathrm{m}$;

$M_{x \in m} " 1=-132.53 \mathrm{kNm} / \mathrm{m}$;

onde $M_{x m}, M_{y m}, M_{x r}$ são os mesmos momentos definidos no ítem 5.3 .1 .2 e $M_{x e m}$ é o momento fletor no meio do engaste na direção $x$. Os apóstrofes identificam os esforços provenientes de carregamento móvel. 
Tabela 5.8 - Coeficientes para o calculo dos momentos fletores devidos as cargas $p$ e $p^{\prime}$.

\begin{tabular}{|c|c|c|c|c|c|c|c|c|}
\hline \multirow{2}{*}{$\frac{\ell_{x}}{a}$} & \multicolumn{2}{|c|}{$M_{x m}$} & \multicolumn{2}{|c|}{$M_{y m}$} & \multicolumn{2}{|c|}{$M_{x r}$} & \multicolumn{2}{|c|}{$-M_{x \in m}$} \\
\hline & $\mathrm{p}$ & $p^{\prime}$ & $p$ & $p^{\prime}$ & $p$ & $p^{\prime}$ & $p$ & $p^{\prime}$ \\
\hline $\begin{array}{l}4.00 \\
4.23\end{array}$ & $\begin{array}{l}0.03 \\
0.04\end{array}$ & $\begin{array}{l}1.30 \\
1.62\end{array}$ & $\begin{array}{l}0.04 \\
0.05\end{array}$ & $\begin{array}{l}0.38 \\
0.47\end{array}$ & $\begin{array}{l}0.10 \\
0.13\end{array}$ & $\begin{array}{l}0.50 \\
0.69\end{array}$ & $\begin{array}{l}0.25 \\
0.32\end{array}$ & $\begin{array}{l}2.40 \\
2.81\end{array}$ \\
\hline 5.00 & 0.06 & 2.69 & 0.10 & 0.77 & 0.22 & 1.32 & 0.54 & 4.19 \\
\hline
\end{tabular}

Para as forças cortantes, os coeficientes obtidos são os apresentados na Tabela 5.9. Com estes valores na equação $4.1 a$, chega-se às seguintes cortantes:

$\mathrm{V}_{\text {em }}$ ' $=105.12 \mathrm{kN} / \mathrm{m}$;

$V_{\text {er" }}=250.98 \mathrm{kN} / \mathrm{m}$.

onde $v_{\text {em }}$ e $v_{\text {er }}$ são definidos no item 5.3.1.2.

Tabela 5.9 - Coeficientes para o cálculo das forças cortantes devidos às cargas $P, p$ e $p^{\text {. }}$

\begin{tabular}{c|cc|cccc}
\hline \multirow{2}{*}{$\frac{\ell_{x}}{\mathrm{a}}$} & \multicolumn{2}{|c|}{$\mathrm{t} / \mathrm{a}$} & 0.50 & \multicolumn{2}{|c}{$\mathrm{V}_{\text {e m }}$} & \multicolumn{2}{c}{$\mathrm{V}_{\text {er }}$} \\
\cline { 2 - 7 } & $\mathrm{V}_{\mathrm{a} \mathrm{m}}$ & $\mathrm{V}_{\mathrm{ar}}$ & $\mathrm{p}$ & $\mathrm{p}^{\prime}$ & $\mathrm{p}$ & $\mathrm{p}^{\prime}$ \\
\hline 4.00 & 0.90 & 2.35 & 0.26 & 1.60 & 0.28 & 1.57 \\
$\mathbf{4 . 2 3}$ & 0.91 & $\mathbf{2 . 3 6}$ & 0.29 & 1.75 & 0.32 & 1.74 \\
5.00 & 0.96 & 2.38 & 0.37 & 2.26 & 0.44 & 2.29 \\
\hline
\end{tabular}

\subsubsection{2 - CÁLCULO DOS ESFORCOS COMO VIGA ISOLADA}

\section{a) Cálculo das linhas de influência}

Através das equações 4.28 e 4.29, determina-se as linhas de influência necessárias ao cálculo dos esforços no engaste (cortante e momento) e no centro do vão (momento). Estas são apresentadas na Tabela 5.10, para uma carga

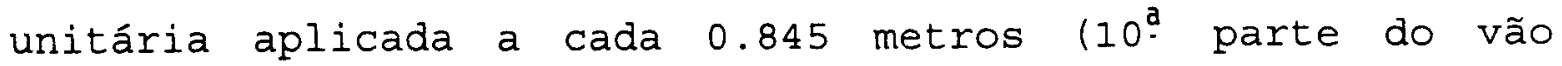
teórico). 


\section{b) Cálculo do trem-tipo}

Utilizando-se as Tabelas 4.2 e 4.3 calcula-se, com as equações 4.30, o trem-tipo atuante nas vigas (faixas de 1 metro). Com a equação 4.31 obtém-se ro trem-tipo simplificado.
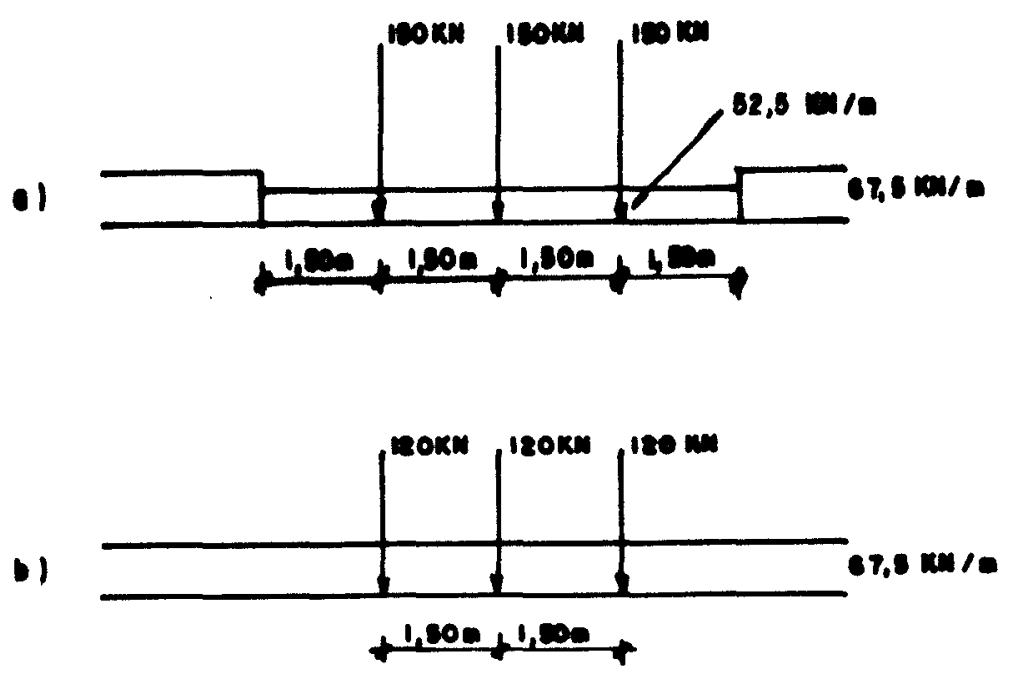

Figura 5.8 - a) Trem-tipo atuante na viga:

b) trem-tipo simplificado.

\section{c) Cálculo dos esforços}

Posicionando o trem-tipo simplificado, da maneira mais desfavorável, sobre as linhas de influência calculadas (Tabela 5.10), obtém-se os seguintes esforços:

$M_{e}=-1042.53 \mathrm{kNm}$;

$\mathrm{M}_{\mathrm{v}}=587.94 \mathrm{kNm}$;

$\mathrm{V}_{\mathrm{e}}=803.77 \mathrm{kN}$;

onde:

$\mathrm{M}_{\mathrm{e}}$ = momento fletor no engaste;

$\mathrm{M}_{\mathrm{v}}=$ momento fletor no centro do vão;

$\mathrm{V}_{\mathrm{e}}=$ força cortante no engaste. 
Tabela 5.10 - Ordenadas das linhas de influência da viga

\begin{tabular}{cccc}
\hline$X(m)$ & $M$ engaste & $M$ vão & $V$ engaste \\
\hline 0.000 & 0.000 & 0.000 & 1.000 \\
0.845 & -0.685 & 0.042 & 0.972 \\
1.690 & -1.082 & 0.169 & 0.896 \\
2.535 & -1.242 & 0.380 & 0.784 \\
3.380 & -1.217 & 0.676 & 0.648 \\
4.225 & -1.056 & 1.056 & 0.500 \\
5.070 & -0.811 & 0.676 & 0.352 \\
5.915 & -0.532 & 0.380 & 0.216 \\
6.760 & -0.270 & 0.169 & 0.104 \\
7.605 & -0.076 & 0.042 & 0.028 \\
8.450 & 0.000 & 0.000 & 0.000 \\
\hline
\end{tabular}

\subsubsection{3 - CÁLCULO DAS LARGURAS COLABORANTES}

Com os esforços encontrados como laje e viga isoladas, calcula-se, conforme o item 4.3.1.3, as seguintes larguras colaborantes:

\section{Para o momento fletor}
a) no meio do vão: $b_{x m}=9.74 \mathrm{~m}$;
b) no meio dos bordos livres: $b_{x r}=4.90 \mathrm{~m}$;
c) no meio do engaste: $b_{e m}=7.87 \mathrm{~m}$;

\section{Para a forca cortante}

a) no meio do engaste: $b_{a m}=7.65 \mathrm{~m}$;

b) no canto do engaste: $b_{a r}=3.20 \mathrm{~m}$.

As larguras colaborantes para o momento fletor no canto do engaste $\left(b_{e r}\right)$ e no meio e bordos do vão para cargas que provocam momentos negativos neste vão $\left(b_{(-x m)} e b_{(-x r)}\right)$, são obtidas através das equações 4.32 e 4.33, respectivamente. Assim:

$\mathrm{b}_{\mathrm{er}}=3.96 \mathrm{~m}$;

$b_{(-x m)}=10.68 \mathrm{~m}$ i

$b_{(\cdot x r)}=5.37 \mathrm{~m}$. 


\subsubsection{4 - CÁLCULO DOS ESFORÇOS COMO PÓRTICO PLANO}

Os esforços são calculados na seções definidas no item 5.4 (Figura 5.7).

\section{a) Cálculo das linhas de influência}

As linhas de influência são determinadas para cargas unitárias atuantes no vão do ponte a cada 0.845 metros (10 parte do vão teórico), através do programa para pórticos planos (processo espontâneo). Chega-se aos resultados apresentados nas Tabelas $5.11 \mathrm{a}$ e $5.11 \mathrm{~b}$.

\section{b) Cálculo dos esforços}

Posicionando o trem-tipo simplificado (Figura 5.8) sobre as linhas de influência, pode-se obter os esforços no pórtico plano, os quais são apresentados na Tabela 5.12 .

Tabela $5.11 a$ - Linhas de influência dos momentos fletores

\begin{tabular}{|c|c|c|c|c|c|c|c|c|c|c|c|c|c|}
\hline$x(m)$ & $M 1$ & M2 & $M 3$ & M4 & M5 & MG & $M 7$ & m8 & $M 9$ & M1O & MII & $M 12$ & M13 \\
\hline 0.000 & 0.000 & 0.000 & 0.000 & 0.000 & 0.000 & 0.000 & 0.000 & 0.000 & 0.000 & 0.000 & 0.000 & 0.000 & 0.000 \\
\hline 0.845 & 0.085 & 0.027 & -0.031 & -0.008 & -0.146 & -0.203 & -0.261 & -0.310 & 0.452 & 0.377 & 0.303 & 0.220 & 0.154 \\
\hline 1.690 & 0.172 & 0.069 & -0.033 & -0.135 & -0.238 & -0.340 & -0.442 & -0.545 & 0.145 & 0.034 & 0.678 & 0.523 & 0.367 \\
\hline 2.535 & 0.254 & 0.120 & -0.014 & -0.149 & -0.283 & -0.417 & -0.552 & -0.680 & -0.083 & 0.521 & 1.124 & 0.882 & 0.640 \\
\hline 3.380 & 0.324 & 0.171 & 0.017 & -0.136 & -0.290 & -0.443 & -0.597 & -0.750 & -0.237 & 0.277 & 0.791 & 1.305 & 0.973 \\
\hline 4.225 & 0.373 & 0.213 & 0.053 & -0.107 & -0.267 & -0.427 & -0.587 & -0.746 & -0.324 & 0.099 & 0.521 & 0.944 & 1.366 \\
\hline 5.070 & 0.391 & 0.238 & 0.084 & -0.069 & -0.223 & $3-0.376$ & -0.530 & -0.683 & -0.352 & -0.020 & 0.311 & 0.642 & 0.973 \\
\hline 5.915 & 0.372 & 0.237 & 0.103 & -0.031 & -0.165 & -0.300 & -0.434 & -0.568 & -0.327 & -0.085 & 0.157 & 0.399 & 0.640 \\
\hline 6.760 & 0.305 & 0.203 & 0.101 & -0.002 & -0.104 & -0.206 & -0.309 & -0.411 & -0.255 & -0.100 & 0.056 & 0.212 & 0.367 \\
\hline 7.605 & 0.184 & 0.126 & 0.069 & 0.011 & -0.047 & -0.104 & -0.162 & -0.219 & -0.145 & -0.070 & 0.005 & 0.079 & 0.154 \\
\hline 8.450 & 0.000 & 0.000 & 0.000 & 0.000 & 0.000 & 0.000 & 0.000 & 0.000 & 0.000 & 0.000 & 0.000 & 0.000 & 0.000 \\
\hline
\end{tabular}


Tabela $5.11 b$. Linhas de influência das forças cortantes

\begin{tabular}{|c|c|c|c|c|c|c|c|}
\hline$x(m)$ & $V_{1} \wedge V 7$ & vo & ve & 10 & 11 & 112 & Vi3 \\
\hline 0.000 & 0.000 & 1.000 & 0.000 & 0.000 & 0.000 & 0.000 & 0.000 \\
\hline 0.845 & -0.058 & 0.912 & $\begin{array}{r}-0.008 \\
0.912\end{array}$ & -0 & & & \\
\hline 1.690 & 0.102 & 0.016 & 0.016 & $\begin{array}{r}-0.184 \\
0.016\end{array}$ & -0 & & -0 \\
\hline 2.535 & & 0.714 & 0.714 & 0.714 & $\begin{array}{r}-0.286 \\
0.714\end{array}$ & & \\
\hline 3.360 & -0.153 & 0.600 & 0.600 & 0.800 & 0.608 & $\begin{array}{r}-0.392 \\
0.608\end{array}$ & -0.392 \\
\hline 4.225 & -0.160 & 0.500 & 0.500 & 0.500 & 0.500 & 0.500 & $\begin{array}{r}-0.500 \\
0.500\end{array}$ \\
\hline 5.070 & -0.153 & 0.392 & 0.392 & 0.392 & 0.392 & 0.392 & 0.392 \\
\hline 5.915 & -0.134 & 0.286 & 0.286 & 0.286 & 0.288 & 0.206 & 0.286 \\
\hline 6.760 & -0.102 & 0.184 & 0.184 & 0.104 & 0.104 & 0.184 & 0.184 \\
\hline 7.605 & -0.050 & 0.000 & 0.080 & 0.086 & 0.006 & 0.088 & 0.008 \\
\hline 0.450 & 0.000 & 0.000 & 0.000 & 0.000 & 0.000 & 0.000 & 0.000 \\
\hline
\end{tabular}

Tabela 5.12 - Esforços nas seções do pórtico plano

\begin{tabular}{ccccc}
\hline Seção & \multicolumn{1}{c}{$M(\mathrm{kNm} / \mathrm{m})$} & \multicolumn{2}{c}{$\mathrm{V}(\mathrm{kN} / \mathrm{m})$} \\
\hline & Positivo & Negativo & Positivo & Negativo \\
\hline 1 & 356.22 & & & -150.67 \\
2 & 208.45 & & & -150.67 \\
3 & 70.77 & -12.90 & & -150.67 \\
4 & 2.61 & -112.93 & & -150.67 \\
5 & & -258.72 & & -150.67 \\
6 & & -406.26 & & -150.67 \\
7 & & -554.17 & & -150.67 \\
8 & & -705.49 & 778.92 & \\
9 & 116.29 & -271.18 & 666.83 & -17.51 \\
10 & 361.64 & -44.66 & 555.76 & -46.98 \\
11 & 638.15 & & 448.08 & -97.56 \\
12 & 819.64 & & 345.92 & -165.10 \\
13 & 880.20 & & 251.11 & -251.11 \\
\hline
\end{tabular}

OBS: Os esforços são apresentados somente até a seção 13 devido à simetria existente.

\subsubsection{5 - CÁLCULO DOS ESFORÇOS DA PONTE EM PÓRTICO}

Seguindo o exposto no ítem 4.3.1.5 calcula-se, com os esforços obtidos como pórtico plano e as larguras 
colaborantes,. os esforços na ponte em pórtico.

Para o dimensionamento da armadura considera-se, conforme exposto anteriormente (ítem 5.3.1.2), os esforços à distâncja de 0.75 metros dos bordos livres, interpolando-se linearmente entre os encontrados para o meio e bordos dos encontros e da laje da superestrutura. Estes esforços são apresentados na Tabela 5.13 .

\section{4 .2 - CÁlCULO DA PONTE EM PÓRTICO - CARREGAMENTO PERMANENTE}

\subsubsection{1 - ESFORÇOS DEVIDOS AO PESO PRÓPRIO E SOBRECARGAS PERMANENTES}

Conforme exposto no ítem 4.3.2.1, os esforços devidos ao peso próprio e sobrecarga de pavimentação $(0.10 \mathrm{~m})$ e recapeamento $\left(2 \mathrm{kN} / \mathrm{m}^{2}\right)$ são obtidos através do programa para pórticos planos. A carga considerada é a mesma do cálculo sem continuidade, $g=15.65 \mathrm{kN} / \mathrm{m}^{2}$.

Os acréscimos de momento devido à carga introduzida ao longo dos bordos livres pelas defensas $(6.25 \mathrm{kN} / \mathrm{m})$ são, de acordo com a Tabela 103 de RÜSCH (1965):

$M_{x m "}=1.06 \mathrm{kNm} / \mathrm{m}$;

$\mathrm{M}_{\mathrm{ym} \text { " }}=-1.06 \mathrm{kNm} / \mathrm{m}$;

$M_{x r "}=7.39 \mathrm{kNm} / \mathrm{m}$;

$\mathrm{M}_{x \in \mathrm{m}} "=-1.06 \mathrm{kNm} / \mathrm{m}$;

$M_{x e r "}=-15.32 \mathrm{kNm} / \mathrm{m}$;

sendo $M_{x m}, M_{y m}, M_{x r}, M_{x e m}$ definidos em 5.4.1.1 e $M_{x e r} \circ$ momento no canto do engaste na direção $x$. Os dois apóstrofes indicam que os esforços são provenientes de carregamento fixo ao longo dos bordos livres.

Estes momentos, obtidos para o caso de engastamento perfeito, 'corrigidos' para o caso do pórtico, são iguais a:

$M_{x m "}=1.59 \mathrm{kNm} / \mathrm{m}$;

$\mathrm{M}_{x \mathrm{r}}{ }^{\prime}=11.09 \mathrm{kNm} / \mathrm{m}$;

$M_{x \in m "}=-0.72 \mathrm{kNm} / \mathrm{m}$;

$\mathrm{M}_{\text {xer }}=-10.42 \mathrm{kNm} / \mathrm{m}$.

O momento transversal $\mathrm{M}_{y m}$ " é considerado como sendo 
o próprio obtido para a placa bi-engastada.

No dimensionamento da armadura é considerado o momento atuante ao longo dos bordos livres. Para a determiṇação dos mesmos nas diversas seções, procede-se de maneira análoga àquela desenvolvida para o carregamento fixo do cálculo sem continuidade (ítem 5.3.1.2). Assim:

$g_{e q}=2.41 \mathrm{kN} / \mathrm{m}^{2}$;

$\mathrm{V}_{\mathrm{e}}=10.18 \mathrm{kN} / \mathrm{m}$;

e portanto:

$$
M_{s}=10.18 x-2.41 \frac{x^{2}}{2}-10.42
$$

Os esforços provenientes desses carregamentos, já considerando-se a parcela de acréscimo de momento nas seções ao longo do vão devido às defensas, são apresentados na Tabela 5.13.

\subsubsection{2 - ESFORÇOS DEVIDOS AO EMPUXO DE TERRA E SOBRECARGA DOS VEÍCULOS ADJACENTES AOS ENCONTROS}

Os esforços são determinados com o auxílio do programa para pórticos planos, considerando-se as cargas atuantes em uma faixa de 1 metro de largura.

a) Empuxo unilateral (ativo)

As cargas consideradas são as mesmas obtidas no ítem 5.3 .2 .2 .

\section{b) empuxo equilibrado (repouso)}

As cargas são determinadas analogamente às anteriores substituindo-se nas equações $4.17 \circ$ valor do coeficiente de empuxo, que passa a valer, de acordo com a equação $4.34, \mathrm{~K}_{0}=\frac{1}{2}\left(\right.$ para $\left.\varphi=30^{\circ}\right)$.

Dessa forma, obtém-se o carregamento trapezoidal ao longo da altura dos encontros (Figura 4.19b):

$P_{q}^{\prime}=4.72 \mathrm{kN} / \mathrm{m}$;

$P_{0}=63.00 \mathrm{kN} / \mathrm{m}$; 


$$
P_{T}^{\prime}=67.72 \mathrm{kN} / \mathrm{m} \text {. }
$$

Os esforços calculados a partir desses carregamentos são apresentados na Tabela 5.13 .

\subsubsection{3 - ESFORÇOS DEVIDOS À VARIAÇÃO DE TEMPERATURA E RETRAÇÃO DO CONCRETO}

- cálculo dos esforços devidos à variação de temperatura e retração do concreto procede-se conforme exposto no ítem 4.3.2.3.

Desse modo, para uma faixa de 1 metro de largura da ponte, tem-se:

$I_{t r}=I e=7593.75 \times 10^{-6} \mathrm{~m}^{4} ;$

$\kappa=0.8284 ;$

$\mu=2.8284$;

$\theta_{t}-11.3465 \mathrm{kNm}$;

calculados para a altura teórica da ponte $\mathrm{h}=7.00 \mathrm{~m}$ e vão teórico $\ell_{x}=8.45 \mathrm{~m}$.

Pode-se então, com as equações 4.35 , calcular os esforços:

$M_{1}=M_{25}=-25.04 \mathrm{kNm} / \mathrm{m}$;

$\mathrm{M}_{8}=\mathrm{M}_{18}=11.35 \mathrm{kNm} / \mathrm{m}$;

$-\mathrm{H}_{1}=\mathrm{H}_{25}=-5.20 \mathrm{kN} / \mathrm{m}$.

Observando-se a Figura 4.20 pode-se, por semelhança de triângulos, determinar os momentos nas demais seções do pórtico. A força cortante tem valor constante nos encontros e é nula ao longo da laje.

Os valores desses esforços são apresentados nas Tabelas $5.13 \mathrm{a}$ e $5.13 \mathrm{~b}$. 
Tabelas $5.13 a$ - Momentos fletores na seça SM da ponte (kNm/m)

\begin{tabular}{|c|c|c|c|c|c|c|c|}
\hline 80000 & P.Proprlo & E.Alivo & E.Ropouso & Acol/Fron & C. Movellor & involtoria) & Tomp/rotr \\
\hline 1 & 32.84 & -235.30 & -217.07 & -20.44 & 66.64 & & -25.04 \\
\hline 2 & 18.75 & -109.51 & -60.05 & -15.44 & 39.00 & & -19.86 \\
\hline 3 & 4.66 & -22.81 & 38.28 & -10.44 & 13.24 & -2.41 & -14.66 \\
\hline 4 & -9.44 & 30.78 & 86.90 & -5.44 & 0.49 & -21.13 & -9.46 \\
\hline 5 & -23.53 & 57.27 & 92.83 & -0.44 & & -48.40 & -4.26 \\
\hline 6 & -37.62 & 62.67 & 71.06 & 4.56 & & -75.01 & 0.94 \\
\hline 7 & -51.72 & 52.96 & 24.58 & 9.55 & & -103.68 & 6.13 \\
\hline 8 & -76.23 & 34.21 & -35.60 & 14.55 & & -163.36 & 11.35 \\
\hline 9 & -18.21 & 25.00 & -35.60 & 11.64 & 21.76 & -46.25 & 11.35 \\
\hline 10 & 26.93 & 15.79 & -35.60 & 8.73 & 67.66 & -7.62 & 11.35 \\
\hline 11 & 59.17 & 6.58 & -35.60 & 5.82 & 119.39 & & 11.35 \\
\hline 12 & 78.51 & -2.63 & -35.60 & 2.91 & 153.34 & & 11.35 \\
\hline 13 & 84.96 & -11.84 & -35.60 & 0.00 & 154.67 & & 11.35 \\
\hline 14 & 78.51 & -21.05 & -35.60 & -2.91 & 153.34 & & 11.35 \\
\hline 15 & 59.17 & -30.26 & -35.60 & -5.82 & 119.39 & & 11.35 \\
\hline 16 & 26.93 & -39.47 & -35.60 & -8.73 & 67.66 & -7.62 & 11.35 \\
\hline 17 & -18.21 & -48.68 & -35.60 & -11.64 & 21.76 & -46.25 & 11.35 \\
\hline 18 & -76.23 & -57.89 & -35.60 & -14.55 & & -163.36 & 11.35 \\
\hline 19 & -51.72 & -36.65 & 24.58 & -9.55 & & -103.68 & 6.13 \\
\hline 20 & -37.62 & -15.41 & 71.06 & -4.55 & & -76.01 & $0.94^{\circ}$ \\
\hline 21 & -23.53 & 5.83 & 94.83 & 0.44 & & -48.40 & -4.26 \\
\hline 22 & -9.44 & 27.07 & 86.90 & 5.44 & 0.49 & -21.13 & -9.45 \\
\hline 23 & 4.66 & 48.31 & 38.28 & 10.44 & 13.24 & -2.41 & -14.66 \\
\hline 24 & 18.75 & 69.55 & -60.05 & 15.44 & 39.00 & & -19.86 \\
\hline 25 & 32.84 & 90.79 & -217.07 & 20.44 & 66.64 & & -25.04 \\
\hline
\end{tabular}


Tabelas $5.13 b$ - Forcas cortantes na usega $S M$ da ponte ( $\mathrm{kNm} / \mathrm{m}$ )

\begin{tabular}{|c|c|c|c|c|c|c|c|}
\hline 80000. & P.Proprio & E.Atiro & E.Ropouso & col/Fron & C.Movellonvo & oltorio) & Tomp/roler \\
\hline 1 & -14.09 & 147.34 & 189.38 & 5.00 & -44.04 & & 5.20 \\
\hline 2 & -14.09 & 105.24 & 126.18 & 5.00 & -44.04 & & 5.20 \\
\hline 3 & -14.09 & 69.14 & 71.98 & 5.00 & -44.04 & & 5.20 \\
\hline 4 & -14.09 & 39.04 & 26.78 & 5.00 & -44.04 & & 5.20 \\
\hline 5 & -14.09 & 14.94 & -9.42 & 5.00 & -44.04 & & 5.20 \\
\hline 6 & -14.09 & -31.60 & -36.62 & 5.00 & -44.04 & & 5.20 \\
\hline 7 & -14.09 & -21.26 & -54.83 & 5.00 & -44.04 & & 5.20 \\
\hline \multirow[t]{2}{*}{ - 8} & -14.09 & -15.26 & -64.03 & 5.00 & -44.04 & & 5.20 \\
\hline & 66.12 & -10.90 & 0.00 & -3.44 & 227.68 & & 0.00 \\
\hline 9 & 52.90 & -10.90 & 0.00 & -3.44 & 194.91 & -5.12 & 0.00 \\
\hline 10 & 39.67 & -10.90 & 0.00 & -3.44 & 162.45 & -13.73 & 0.00 \\
\hline 11 & 26.45 & -10.90 & 0.00 & -3.44 & 130.98 & -28.52 & 0.00 \\
\hline 12 & 13.22 & -10.90 & 0.00 & -3.44 & 101.11 & -48.26 & 0.00 \\
\hline 13 & 0.00 & -10.90 & 0.00 & -3.44 & 73.39 & -73.39 & 0.00 \\
\hline 14 & -13.22 & -10.90 & 0.00 & -3.44 & -101.11 & 48.26 & 0.00 \\
\hline 15 & -26.45 & -10.90 & 0.00 & -3.44 & -130.98 & 28.52 & 0.00 \\
\hline 16 & -39.67 & -10.90 & 0.00 & -3.44 & -152.45 & 13.73 & 0.00 \\
\hline 17 & -52.90 & -10.90 & 0.00 & -3.44 & -194.91 & 5.12 & 0.00 \\
\hline \multirow[t]{2}{*}{ - 18} & -66.12 & -10.90 & 0.00 & -3.44 & -227.68 & & 0.00 \\
\hline & 14.09 & 21.24 & 64.03 & 5.00 & 44.04 & & -5.20 \\
\hline 19 & 14.09 & 21.24 & 54.83 & 5.00 & 44.04 & & -5.20 \\
\hline 20 & 14.09 & 21.24 & 36.62 & 5.00 & 44.04 & & -5.20 \\
\hline 21 & 14.09 & 21.24 & 9.42 & 5.00 & 44.04 & & -5.20 \\
\hline 22 & 14.09 & 21.24 & -26.78 & 5.00 & 44.04 & & -5.20 \\
\hline 23 & 14.09 & 21.24 & -71.98 & 5.00 & 44.04 & & -5.20 \\
\hline 24 & 14.09 & 21.24 & -126.18 & 5.00 & 44.04 & & -5.20 \\
\hline 25 & 14.09 & 21.24 & -189.38 & 5.00 & 44.04 & & -5.20 \\
\hline
\end{tabular}

- O numero superior refere-se o cortante a esquarda do secoo

- o inferior o direita da mesma. 


\subsection{3. - CÁLCULO DA INFRAESTRUTURA}

\subsubsection{1 - PRÉ-DIMENSIONAMENTO DOS BLOCOS}

De maneira análoga ao cálculo sem continuidade, procura-se atender as recomendações do ítem 4.2.2.3, obtendo-se $\circ$ bloco com as seguintes características:

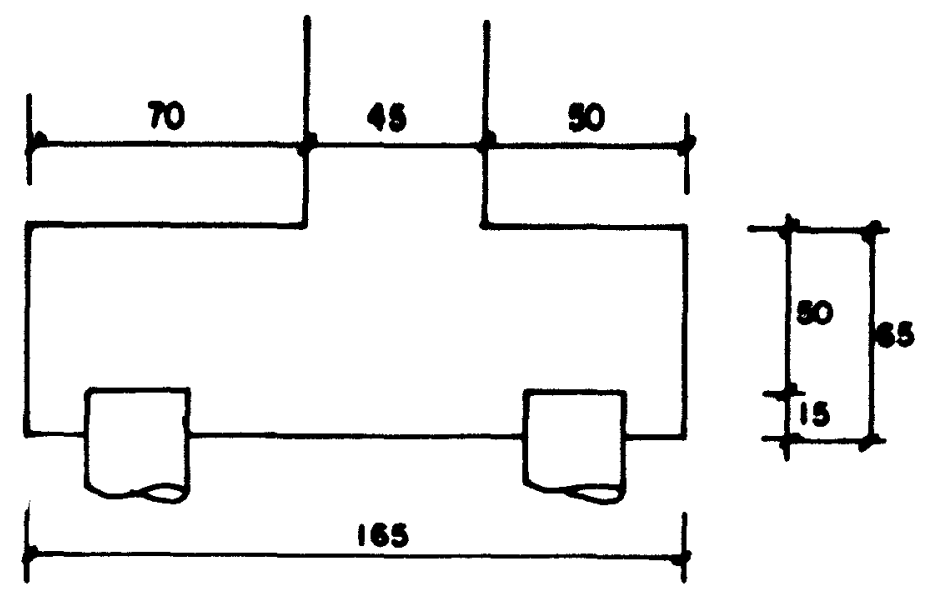

Figura 5.9 - Pré-dimensionamento dos blocos

\subsubsection{2 - CÁLCULO DOS ESFORÇOS NOS BLOCOS}

Adapta-se 0 bloco da Figura 5.8 às dimensões necessárias ao cálculo pelo método do CEB (1970), adotando-se estacas de diâmetro $\phi_{e}=25 \mathrm{~cm}$ (capacidade nominal de resistência à compressão igual a $300 \mathrm{kN}$ ) a cada metro.

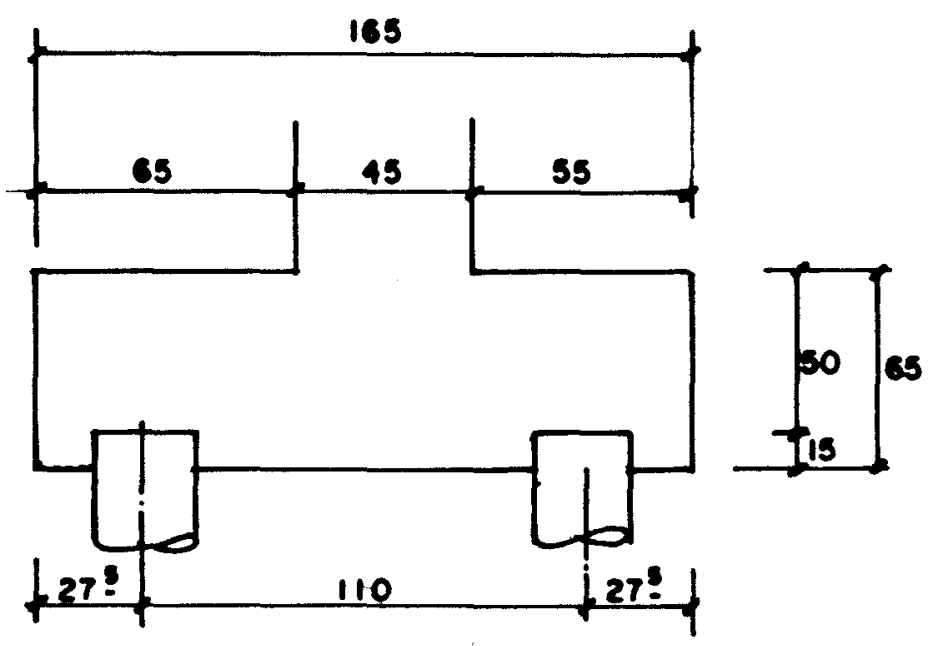

Figura 5.10 - Caracteristicas geometricas dos blocos 
Os esforços provenientes do carregamento móvel sobre a superestrutura são considerados absorvidos por toda a extensão dos encontros $(13.50 \mathrm{~m})$, sem o efeito do impacto.

Para o cálculo das cargas nas estacas, considera-se três combinações de carregamento nos blocos:

a) Reação máxima com momento correspondente - combina-se os esforços provocados pelas cargas permanentes com a reação máxima provocada pelas cargas móveis. A posição do trem-tipo para se obter esta reação provoca 0 'momento correspondente';

b) momento máximo com reação correspondente - combina-se os esforços provocados pelas cargas permanentes com o momento máximo provocado pelas cargas móveis. A posição do trem-tipo para se obter este momento provoca a 'reação correspondente';

c) momento mínimo e reação mínima - verifica-se os esforços resultantes da execução dos aterros de acesso individualmente combinando-se as cargas permanentes com 0 empuxo unilateral.

Convertendo-se $\circ$ carregamento proveniente destas combinações em forças horizontais (H) e verticais (F) tem-se os carregamentos apresentados na Figura 5.11.

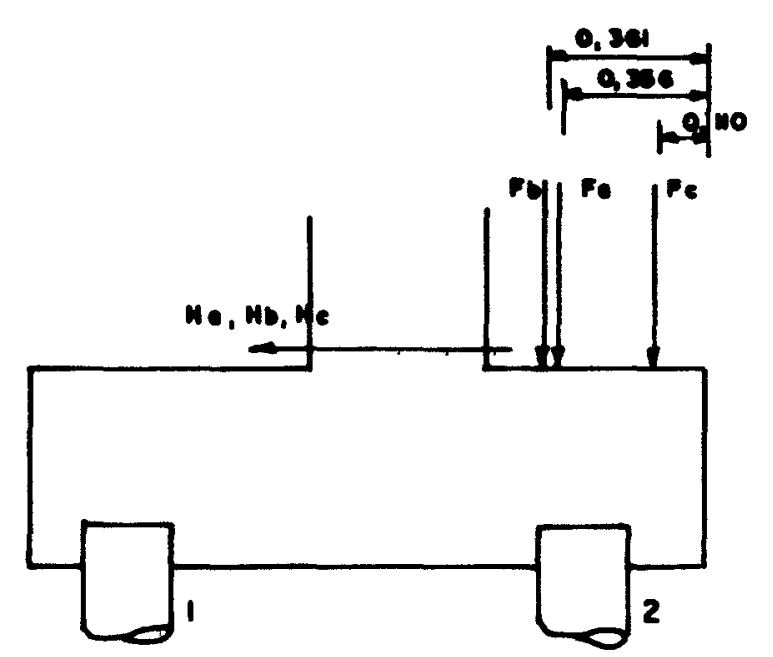

Figura 5.11 - Carregamento nos blocos:

$\mathrm{F}=289.21 \mathrm{kN} / \mathrm{m} ; \quad H=168.74 \mathrm{kN} / \mathrm{m}$

$F_{a}^{a}=280.61 \mathrm{kN} / \mathrm{m} ; H_{b}^{a}=166.96 \mathrm{kN} / \mathrm{m}$

$\mathrm{F}_{\mathrm{c}}^{\mathrm{b}}=235.25 \mathrm{kN} / \mathrm{m}: \mathrm{H}_{\mathrm{c}}^{\mathrm{b}}=133.25 \mathrm{kN} / \mathrm{m}$ 
Para as forcas horizontais valem as mesmas observações do cálculo sem continuidade (ítem 5.3.2.4), observando-se que a força horizontal máxima aplicada a uma estaca é, neste caso, igual a He $=49.22 \mathrm{kN}$.

Utilizando-se a equação 4.22 , calcula-se com as forças verticais e os momentos provocados pelas mesmas as cargas aplicadas em cada estaca:

$R_{1 \mathrm{a}}=21.30 \mathrm{kN} ; \mathrm{R}_{2 \mathrm{a}}=267.91 \mathrm{kN}$;

$R_{1 b}=21.94 \mathrm{kN} ; R_{2 b}=258.67 \mathrm{kN}$;

$R_{1 c}=-35.29 \mathrm{kN} ; R_{2 c}=270.54 \mathrm{kN}$.

onde (Figura 5.11):

$R_{1}=$ carga correspondente à estaca 1 ;

$\mathrm{R}_{2}=$ carga correspondente à estaca 2 ;

sendo os índices $\mathbf{a}, \mathbf{b}$ e $\mathbf{c}$ indicativos do tipo de combinação utilizada.

Nota-se que as reações provocadas nas estacas pela 3- combinação (momento mínimo e reação mínima) são as críticas. Essas reações causam os seguintes momentos nas seções de referência $S_{1}$ :

$M_{+}=92.66 \mathrm{kNm} / \mathrm{m}$;

$M_{\text {. }}=-17.38 \mathrm{kNm} / \mathrm{m}$.

Verificado-se o esforço cortante de cálculo $\left(V_{d}\right)$ na seção de referência $S_{2}$ :

$v_{d}=378.76 \mathrm{kN} / \mathrm{m}<\mathrm{v}_{\mathrm{d} \text { l i m }}=754.53 \mathrm{kN} / \mathrm{m}$

Verificando-se o esforço cortante na vizinhança das estacas de canto:

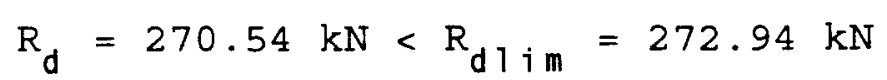

\section{5 - AVALIAÇÃO dOS ESFORÇOS ATRAVÉS DA TÉCNICA DOS} ELEMENTOS FINITOS

Com a finalidade de se verificar os valores dos esforços obtidos através do procedimento descrito no capítulo 4, uma análise mais refinada, utilizando-se a técnica dos elementos finitos é desenvolvida. Esta análise visa somente a 
avaliação dos. momentos fletores provenientes do carregamento móvel, uma vez que os momentos devidos às cargas permanentes já foram avaliados, com boa aproximação, considerando-se faixas de um metro de largura.

Os dois sistemas estruturais estudados, ponte em pórtico e com laje bi-apoiada, são aqui calculados, muito embora para o caso da laje bi-apoiada as tabelas de RÜSCH (1965) forneçam diretamente os momentos na laje da superestrutura, não tendo sido utilizado para este caso o conceito de largura colaborante.

- elemento utilizado no cálculo consiste no elemento de casca tridimensional com quatro nós. Os elementos de membrana e placa são, dessa forma, casos particulares desse elemento geral.

Para o presente cálculo discretiza-se a laje da superestrutura com cento e oitenta elementos retangulares, sendo dezoito elementos na direção da largura e dez na direção do vão. Para o cálculo da ponte em pórtico discretiza-se também os encontros com cento e vinte e seis elementos retangulares cada, dezoito na direção da largura e sete na direção da altura (Figura 5.12).

A aplicação das cargas móveis é feita utilizando-se - trem-tipo simplificado (Figura 5.8b), onde todo o tabuleiro fica submetido a cargas a de multidão, descontando-se das cargas provenientes do veículo tipo a parcela da carga distribuída acrescentada sob o mesmo.

Considera-se este carregamento atuante no plano médio da laje. Dessa forma, as cargas provenientes das rodas do veículo tipo é aplicada sobre a projeção da mesma à $45^{\circ}$ no plano médio da laje (largura de distribuição - Figura 4.2).

A transferência desta carga para os nós da estrutura discretizada é feita através do conceito de área de influência, onde cada nó recebe o carregamento contido na área delimitada pelas retas que unem os pontos médios entre os mesmos (Figura 5.13). 

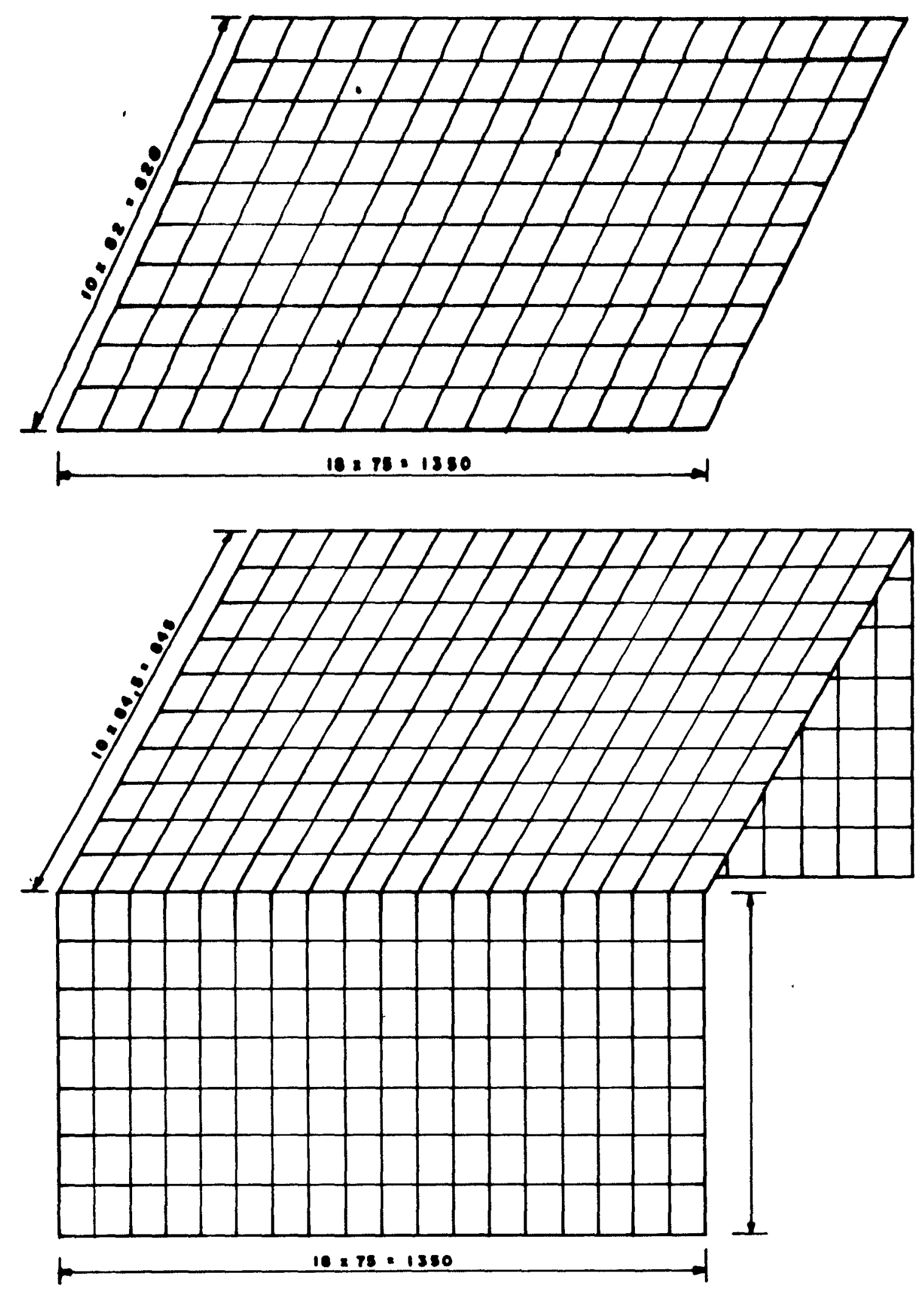

Figura 5.12 - Discretização dos sistemas estruturais:

a) Laje do sistema estrutural isostático Malna: $0.750 \times 0.82 \mathrm{~m}$;

b) Ponte em pórtico

Malha da laje: $0.750 \times 0.845 \mathrm{~m}$;

malha do muro: $0.750 \times 1.000 \mathrm{~m}$. 
De acordo com a Figura 4.2, determina-se as larguras de distribuição:

$t_{x}=0.85 \mathrm{mi}$

$t_{y}=1.15 \mathrm{~m}$;

onde:

$t_{x}=$ largura de distribuição na direção $x$ (vão);

$t_{y}=$ largura de distribuição na direção y (largura).

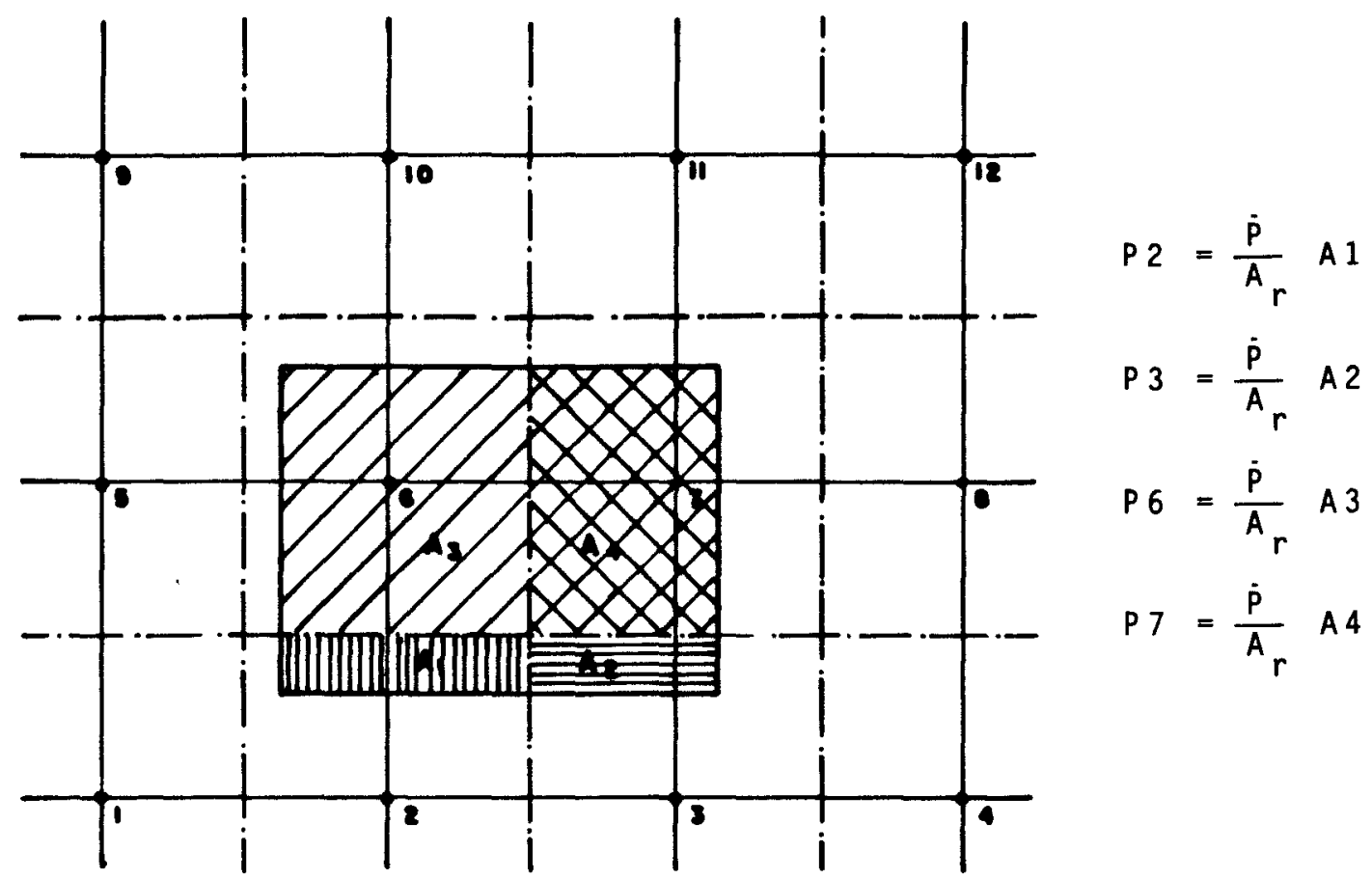

Figura 5.13 - Distribuição das cargas provenientes

das rodas do veiculo tipo pelos nós

da estrutura discretizada.

P2, P3, P6, P7 cargas nos nós respectivos:

$A_{r}=a$ rea da roda projetada no plano médio da 1 a je:

$\dot{\mathbf{p}}=$ carga da roda do veículo tipo.

Legenda: discretização da estrutura: inha que liga o ponto médio entre os nós

As posições ocupadas pelo trem-tipo para a avaliação dos momentos máximos são as seguintes:

a) Para 0 sistema estrutural sem continuidade:

a.1) Veículo tipo no centro do vão e no meio da laje; 
a.2) veículo tipo no centro do vão e nos bordos da laje;

\section{b) Para o sistema estrutural com continuidade:}

b.1). Veículo tipo no centro do vão e no meio da laje;

b.2) veículo tipo a $1 / 3$ do vão e no meio da laje;

b.3) veículo tipo no centro do vão e nos bordos da laje;

b.4) veículo tipo a $1 / 3$ do vão e nos bordos da laje.

A listagem dos resultados fornece momentos fletores nas direções $\mathbf{x}, \mathbf{y}, \mathbf{x y}$ e principais e 0 ângulo dos momentos principais com relação aos eixos globais $x$ e $y$. Para se evitar deformações excessivas, não é aconselhável tolerar desvios maiores que $25^{\circ}$ das direções das armaduras com relação as tensões principais. Assim, quando $\circ$ ângulo fornecido pelo programa for inferior à $25^{\circ}$, utiliza-se os próprios momentos fletores nas direções $\mathrm{x}$ e $\mathrm{y}$, desprezando-se a influência do momento volvente xy. Se o ângulo encontrado for maior, propõem-se a utilização das seguintes expressões:

$M_{x},=M_{1} \cos ^{2} \theta+M_{2} \operatorname{sen}^{2} \theta+\left|\left(M_{1}-M_{2}\right) \operatorname{sen} \theta \cos \theta\right|$

$M_{y} \cdot=M_{1} \operatorname{sen}^{2} \theta+M_{2} \cos ^{2} \theta+\left|\left(M_{1}-M_{2}\right) \operatorname{sen} \theta \cos \theta\right|$

onde:

$M_{1}$ e $M_{2}=$ momentos fletores nas direções principais;

$M_{x}$, e $M_{y},=$ momentos fletores utilizados no dimensionamento;

$\theta=$ ângulo entre as direções dos momentos principais e as direções dos momentos utilizados no dimensionamento

Os momentos fletores máximos obtidos através da técnica dos elementos finitos são mostrados nas Tabelas 5.14 e 5.15 onde também estão, para efeito de comparação, os momentos fletores calculados com $\circ$ método aproximado (conceito de largura colaborante).

No anexo B são apresentados gráficos em forma de iso-valores com os resultados obtidos para os dois casos calculados:

a) Sistema estrutural sem continuidade - iso-momentos na laje nas direções $x, y$ e $x y$ para os dois casos enunciados; 
b) sistema estrutural com continuidade - iso-momentos na laje e nos encontros nas direções $x, y$ e $x y$ para os quatro casos enunciados.

Tabela 5.14 - Envoltória dos momentios fletores
Cálculo sem continuidade

\begin{tabular}{crrrr}
\hline & \multicolumn{2}{c}{ Elementos } & Finitos & \multicolumn{2}{c}{ Calculo Aproximado } \\
\hline seção & $\begin{array}{l}\text { centro } \\
\text { do vão }\end{array}$ & $\begin{array}{l}\text { bordo } \\
\text { livre }\end{array}$ & $\begin{array}{l}\text { centro } \\
\text { do vão }\end{array}$ & \multicolumn{1}{l}{$\begin{array}{l}\text { bordo } \\
\text { livre }\end{array}$} \\
\hline 1 & 0.00 & -42.86 & 0.00 & 0.00 \\
2 & 37.94 & 60.63 & 51.24 & 86.38 \\
3 & 74.62 & 113.70 & 102.48 & 172.75 \\
4 & 106.80 & 166.00 & 128.10 & 215.94 \\
5 & 124.90 & 189.30 & 128.10 & 215.94 \\
6 & 136.40 & 205.60 & 128.10 & 215.94 \\
\hline
\end{tabular}

Tabela 5.15 - Envoltória de momentos fletores Cálculo com continuidade

\begin{tabular}{|c|c|c|c|c|}
\hline & Elemento & Finitos & Calculo & Aproximado \\
\hline seção & $\begin{array}{l}\text { centro } \\
\text { do vão }\end{array}$ & $\begin{array}{l}\text { bordo } \\
\text { livre }\end{array}$ & $\begin{array}{l}\text { centro } \\
\text { do vão }\end{array}$ & $\begin{array}{l}\text { bordo } \\
\text { livre }\end{array}$ \\
\hline 1 & 28.27 & 44.61 & 36.57 & 72.70 \\
\hline 2 & 15.82 & 25.63 & 24.40 & 42.54 \\
\hline 3 & 3.99 & 6.18 & $\begin{array}{ll}7.27 & -1.32\end{array}$ & $14.44 \quad-2.63$ \\
\hline 4 & -7.78 & -17.98 & $0.27-11.59$ & $0.53-23.05$ \\
\hline 5 & -20.03 & -38.56 & -26.56 & -52.80 \\
\hline 6 & -33.51 & -61.25 & -41.71 & -82.91 \\
\hline 7 & -49.56 & -89.11 & -56.90 & -113.10 \\
\hline 8 & -70.64 & -117.80 & -89.64 & $-178 \cdot 15$ \\
\hline 9 & -22.08 & -50.23 & $11.94-25.39$ & $23.73-50.50$ \\
\hline 10 & 20.85 & 60.54 & $37.13-4.18$ & $\begin{array}{ll}73.80 & -8.32\end{array}$ \\
\hline 11 & 57.20 & 106.90 & 65.51 & 130.23 \\
\hline 12 & 77.93 & 122.30 & 84.15 & 167.27 \\
\hline 13 & 90.80 & 131.70 & 90.37 & 179.63 \\
\hline
\end{tabular}

\section{6 - DIMENSIONAMENTO DOS ELEMENTOS ESTRUTURAIS}

Os esforços calculados nos ítens anteriores para cada elemento estrutural (laje, encontros e blocos) são combinados, utilizando-se a equação 4.37 , de forma a obter-se 
as solicitações atuantes de cálculo $\left(F_{d}\right)$ no estado limite último.

Os coeficientes de ponderação $\gamma_{g}$ utilizados (ações permanentes) são aqueles correspondentes às ações permanentes de grande variabilidade (Tabela $4.4 \%$, pois o peso próprio da estrutura não supera $75 \%$ da totalidade dos pesos permanentes.

0 dimensionamento das armaduras é feito seguindo o critério comentado no 1 tem 4.4, utilizando-se os esforços (carregamento móvel) obtidos a partir do cálculo aproximado.

\subsection{1 - DIMENSIONAMENTO DA ESTRUTURA CALCULADA SEM CONTINUIDADE}

\subsubsection{1 - SUPERESTRUTURA}

Os esforços atuantes nas seções da laje (Tabela 5.4) são combinados fornecendo as seguintes solicitações de cálculo:

Tabela 5.16 - Solicitações de cálculo ( $F_{d}$ ) na laje

\begin{tabular}{ccc}
\hline Seção & Momento $(\mathrm{kNm} / \mathrm{m})$ & Cortante $(\mathrm{kN} / \mathrm{m})$ \\
\hline 1 & 0.00 & 416.16 \\
2 & 188.47 & 332.93 \\
3 & 360.72 & 249.69 \\
4 & 459.97 & 166.47 \\
5 & 483.36 & 83.23 \\
6 & 491.47 & 0.00 \\
\hline OBS: solicitaçóes calculadas até o meio devido à \\
simetria existente
\end{tabular}

Cálculo das armaduras:

a) Combate aos momentos fletores - a área de aço necessária à seção 6 é de $33.17 \mathrm{~cm}^{2}$. As áreas de aço nas demais seções são obtidas no detalhamento, a partir do diagrama de momentos fletores;

b) combate às cortantes - verifica-se a necessidade de armadura de cisalhamento mínima $\left(14.00 \mathrm{~cm}^{2}\right)$ até a seção 3 (1.64 $\mathrm{m}$ do apoio). 


\subsubsection{2 - INFRAESTRUTURA}

- Combinando-se os esforços calculados (Tabela 5.6), determina-se as solicitaçães de cálculo nos encontros.

Sendo a força normal atuante nos encontros igual à cortante no apoio da laje $(416.16 \mathrm{kN} / \mathrm{m})$, calcula-se as áreas de aço necessárias em cada seção definida (flexo-compressão) .

Verifica-se que não há necessidade de armadura de combate ao cisalhamento, sendo as tensões de referência $\tau_{w d}$ menores que as tensões últimas $\tau$ wul em todas as seções.

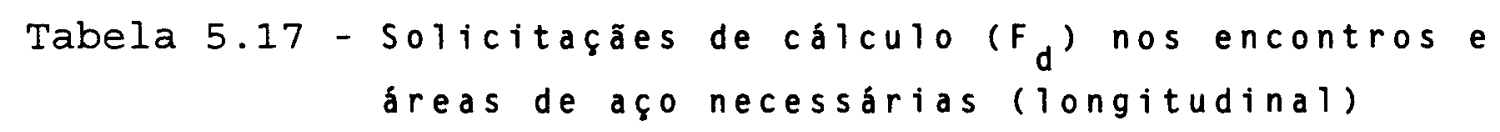

\begin{tabular}{ccccr}
\hline Seção & $\begin{array}{c}\text { espessura do } \\
\text { muro (cm) }\end{array}$ & $\begin{array}{c}\text { Momento } \\
(\mathrm{kNm} / \mathrm{m})\end{array}$ & $\begin{array}{r}\text { Área de } \\
\text { aço }\left(\mathrm{cm}^{2}\right)\end{array}$ & $\begin{array}{r}\text { Cortante } \\
(\mathrm{kN} / \mathrm{m})\end{array}$ \\
\hline 8 & 20.00 & 0.00 & 3.00 & 9.00 \\
7 & 27.14 & 12.84 & 4.07 & 17.61 \\
6 & 34.28 & 38.97 & 5.14 & 34.62 \\
5 & 41.42 & 86.76 & 6.21 & 60.03 \\
4 & 48.56 & 164.63 & 7.28 & 93.84 \\
3 & 55.70 & 280.98 & 8.36 & 136.05 \\
2 & 62.84 & 444.20 & 12.96 & 186.66 \\
1 & 70.00 & 662.70 & 20.02 & 245.67 \\
\hline
\end{tabular}

Com o momento fletor calculado no item 5.3.2.4 $(176.31 \mathrm{kNm} / \mathrm{m})$ determina-se a área de aço principal dos blocos (flexão simples): As $=9.87 \mathrm{~cm}^{2} / \mathrm{m}$. Esta é, entretanto menor que a mínima: As $_{\mathrm{min}}=10.50 \mathrm{~cm}^{2} / \mathrm{m}$.

\subsection{2 - DIMENSIONAMENTO DA ESTRUTURA CALCULADA COM CONTINUIDADE}

\subsubsection{1 - SUPERESTRUTURA E INFRAESTRUTURA}

Para se determinar as solicitações de cálculo ( $\left.F_{d}\right)$ nos encontros e na laje da superestrutura são realizadas duas combinações dos esforços calculados nas seções da ponte 
(Tabela 5.13). São estas:

a) Combinação última normal - combina-se os esforços devidos ao peso próprio, empuxo de terra equilibrado, retração e temperatura, cargas móveis e aceleração e frenagem dos veículos;

b) Combinação última especial - combina-se os esforços devidos ao peso próprio, empuxo de terra unilateral e retração e temperatura.

Calcula-se as áreas de aço longitudinais necessárias nas seções dos encontros (flexo-compressão) e da laje (flexão simples) e determina-se a armadura transversal nos mesmos. Verifica-se não ser preciso dispor armadura transversal nos encontros, sendo necessária apenas armadura mínima $\left(14.00 \mathrm{~cm}^{2} / \mathrm{m}\right.$ ) da seção 8 a 10 na laje (até $1.69 \mathrm{~m}$ dos nós do pórtico).

Tabela 5.18 - Solicitações de cálculo nas seções do pórtico e áreas de aço necessárias (longitudinal)

\begin{tabular}{|c|c|c|c|c|c|}
\hline Seção & \multicolumn{2}{|c|}{$\begin{array}{c}\text { M (envoltória) } \\
(\mathrm{kNm} / \mathrm{m})\end{array}$} & $\begin{array}{l}\text { Área de } \\
\text { Pos. }\end{array}$ & $\begin{array}{l}\text { aço }\left(\mathrm{cm}^{2}\right) \\
\text { Neg. }\end{array}$ & $\underset{(\mathrm{kN} / \mathrm{m})}{\operatorname{Vmax}}$ \\
\hline 1 & 160.72 & -321.56 & 6.75 & 16.75 & 262.89 \\
\hline 2 & 114.79 & -160.27 & 6.75 & 6.75 & 174.41 \\
\hline 3 & 88.00 & -43.05 & 6.75 & 6.75 & 98.53 \\
\hline 4 & 118.43 & & 6.75 & & 61.48 \\
\hline 5 & 111.95 & -30.45 & 6.75 & 6.75 & 98.77 \\
\hline 6 & 70.58 & -102.21 & 6.75 & 6.75 & 136.85 \\
\hline 7 & 29.66 & -207.91 & 6.75 & 8.29 & 162.34 \\
\hline * 8 & & -404.43 & & 16.74 & $171.03 \quad 411.32$ \\
\hline 9 & 29.85 & -151.90 & 6.75 & 8.99 & 346.93 \\
\hline 10 & 123.57 & -44.61 & 6.75 & 6.75 & 282.97 \\
\hline 11 & 241.56 & -1.47 & 14.50 & 6.75 & 220.40 \\
\hline 12 & 315.19 & & 19.70 & & 162.95 \\
\hline 13 & 338.12 & & 21.13 & & 105.64 \\
\hline
\end{tabular}

OBS:a) * forças cortantes à esquerda e a direita da seção. respectivamente;

b) Área de aço minima $=6.75 \mathrm{~cm}^{2}$

As áreas de aço necessárias ao combate dos momentos na fundação calculados no ítem 5.4 .3 .2 são:

$A_{s+}=7.78 \mathrm{~cm}^{2}$;

$A_{s}=1.60 \mathrm{~cm}^{2}<A_{s m i n}=7.50 \mathrm{~cm}^{2}$ 


\section{7 - VERIFICAÇÕES}

\subsection{1 - VERIFICAÇÃO DO ESTADO LIMITE ÚLTIMO DE RESISTENCIA À FADIGA}

De acordo com 0 exposto no ítem 4.5.1, considera-se as cargas efetivamente atuantes permanentes e móveis, desprezando-se os efeitos da retração e temperatura e da aceleração e frenagem dos veículos.

\subsubsection{1 - SISTEMA ESTRUTURAL ISOSTÁTICO}

Não há necessidade de se verificar os encontros, pois as ações variáveis que provocam esforços nestes não precisam ser consideradas.

A laje da superestrutura é verificada a flexão simples na sua seção central (seção 6) e ao cisalhamento na seção do apoio (seção 1). Portanto:

Momentos fletores em servico: $\mathrm{M}_{\mathrm{min}}=144.87 \mathrm{kNm} / \mathrm{m}$;

$M_{\max }=359.73 \mathrm{kNm} / \mathrm{m}$.

Com a área de aço calculada no ítem 5.6.1.1 $\left(A_{s}=33.99 \mathrm{~cm}^{2}\right)$ e 0 módulo de elasticidade do concreto $\left(E_{c}\right)$, obtido com a equação 4.42 , pode-se determinar, com a equação 4.41, a posição da linha neutra e assim, com a equação 4.40, calcular-se as tensões máximas e mínimas na armadura devidas aos momentos. Portanto para:

$\mathrm{d}=40 \mathrm{~cm}$;

$\mathrm{b}_{\mathrm{w}}=100 \mathrm{~cm}$;

$\mathrm{n}=7.195(\mathrm{fck}=21 \mathrm{MPa})$;

$\mathrm{x}=11.75 \mathrm{~cm}$;

tem-se:

$\sigma_{\text {sm in }}=11.812 \mathrm{kN} / \mathrm{cm}^{2}$;

$\sigma_{\text {smax }}=29.330 \mathrm{kN} / \mathrm{cm}^{2}$;

$\Delta \sigma_{s}=17.518 \mathrm{kN} / \mathrm{cm}^{2}=175.18 \mathrm{MPa}<180 \mathrm{MPa}$. 
Forças cortantes em. serviço: $V_{m i n}=64.17 \mathrm{kN} / \mathrm{m}$;

$V_{\text {max }}=297.26 \mathrm{kN} / \mathrm{m}$.

Sendo a área de aço transversal (item 5.4.1.1) igual á $\frac{\text { Asw }}{\mathrm{s}}=14 \mathrm{~cm}^{2} / \mathrm{m}$, calcula-se as tensões devidas ao cisalhamento de seguinte forma:

$$
\sigma_{s}=\frac{1.15 \tau_{w d}-\tau_{c}}{\rho_{w}}
$$

onde:
$\tau_{w d}=\frac{v_{d}}{b_{w} d}=$ tensão de referência (MPa);

$\tau_{c}=0.15 \sqrt{f_{c k}}=$ tensão resistida pelo concreto a tração (MPa);

$\rho_{w}=\frac{A_{S W} / s}{b_{w}}=$ taxa geométrica de armadura;

Assim:

$\sigma_{\text {smin }}=0.00$

$\sigma_{\text {smax }}=119.54 \mathrm{MPa}$;

$\Delta \sigma_{s}=119.54 \mathrm{MPa}<140 \mathrm{MPa}$.

\subsubsection{2 - SISTEMA ESTRUTURAL HIPERESTÁTICO}

As seções verificadas são as seguintes:

a) Encontros - verifica-se a seção 1 à flexo-compressão;

b) laje - verifica-se a seção 8 à flexão simples e ao cisalhamento e a seção 13 à flexão simples.

Na seção 1 tem-se:

Momentos em serviço: $\mathrm{M}_{\mathrm{min}}=-184.23 \mathrm{kNm} / \mathrm{m}$;

$M_{\text {max }}=-117.59 \mathrm{kNm} / \mathrm{m}$.

Forças normais em serviço: $N_{m i n}=-293.80 \mathrm{kN} / \mathrm{m}$;

$\mathrm{N}_{\mathrm{max}}=-66.12 \mathrm{kN} / \mathrm{m}$.

Pode-se, então, calcular o valor do momento fletor máximo atuante na seção da armadura (ítem 4.5.1):

$M_{s}=238.58 \mathrm{kNm} / \mathrm{m}$ para $e_{s}=0.185 \mathrm{~m}$.

Utilizando-se a equação 4.45 calcula-se a posição da linha neutra e, posteriormente, obtém-se as tensões de compressão no concreto $\left(\sigma_{c}\right)$ e de tração no aço $\left(\sigma_{s}\right)$ com as 
equações 4.43 .e 4.44, respectivamente. Assim, para:

$\mathrm{d}=41 \mathrm{~cm}$;

$\mathrm{b}_{w}=100 \mathrm{~cm}$;

$\mathrm{n}=7.77\left(\mathrm{f}_{\mathrm{ck}}=21 \mathrm{MPa}\right)$;

$A_{s}=16.75 \mathrm{~cm}^{2}$ (ítem 5.6.2.1);

tem-se:

$\mathrm{x}=11.82 \mathrm{~cm}$;

$\sigma_{c \max }=-1.089 \mathrm{kN} / \mathrm{cm}^{2} ; \sigma_{s \max }=20.889 \mathrm{kN} / \mathrm{cm}^{2}$;

$\sigma_{c m i n}=-0.245 \mathrm{kN} / \mathrm{cm}^{2} ; \sigma_{s m i n}=4.700 \mathrm{kN} / \mathrm{cm}^{2}$;

e, portanto: $\Delta \sigma_{s}=16.189 \mathrm{kN} / \mathrm{cm}^{2}=161.89 \mathrm{MPa}<180 \mathrm{MPa}$.

Na seção 8, tem-se:

Momentos em serviço: $\begin{aligned} M_{m i n} & =-275.19 \mathrm{kNm} / \mathrm{m} ; \\ M_{m a x} & =-111.83 \mathrm{kNm} / \mathrm{m} .\end{aligned}$

Sendo:

$$
M_{\text {max }}^{\text {min }}=-111.83 \mathrm{kNm} / \mathrm{m} \text {. }
$$

$\mathrm{d}=58 \mathrm{~cm}$;

$\mathrm{b}_{\mathrm{w}}=100 \mathrm{~cm}$;

$\mathrm{n}=7.195\left(\mathrm{f}_{\mathrm{ck}}=21 \mathrm{MPa}\right)$;

$A_{s}=16.45 \mathrm{~cm}^{2}$ (ítem 5.6.2.1);

calcula-se com a equação 4.41 a posição da linha neutra:

$\mathrm{x}=10.59 \mathrm{~cm}$;

com a qual, na equação 4.40 , calcula-se:

$\sigma_{\text {smin }}=12.481 \mathrm{kN} / \mathrm{cm}^{2}$;

$\sigma_{\text {smax }}=30.712 \mathrm{kN} / \mathrm{cm}^{2}$;

$\Delta \sigma_{s}=18.231 \mathrm{kN} / \mathrm{cm}^{2}=182.31 \mathrm{MPa}>180 \mathrm{MPa} ;$

assim: $C F=\frac{182.31}{180}=1.013$;

$A_{S}=C F A_{S}=16.66 \mathrm{~cm}^{2}$.

Forças cortantes em serviço: $V_{m i n}=66.12 \mathrm{kN} / \mathrm{m}$;

$\mathrm{V}_{\max }=293.80 \mathrm{kN} / \mathrm{m}$.

Para $\frac{A_{s w}}{s}=14 \mathrm{~cm}^{2} / \mathrm{m}$, tem-se pela equação 5.5 :

$\sigma_{\text {smin }}=0.00$;

$\sigma_{\text {smax }}=11.235 \mathrm{kN} / \mathrm{cm}^{2}$; 
$\Delta \sigma_{\mathrm{s}}=11.235 \mathrm{kN} / \mathrm{cm}^{2}=112.35 \mathrm{MPa}<140 \mathrm{MPa}$.

Na seção 13 tem-se:

Momentos em serviço: $M_{m i n}=49.36 \mathrm{kNm} / \mathrm{m}$;

$M_{\text {max }}=214.03 \mathrm{kNm} / \mathrm{m}$;

sendo:

$d=40 \mathrm{~cm} ;$

$\mathrm{b}_{\mathrm{w}}=100 \mathrm{~cm}$;

$\mathrm{n}=7.195\left(\mathrm{f}_{\mathrm{ck}}=21 \mathrm{MPa}\right) ;$

$A_{s}=20.69 \mathrm{~cm}^{2}$ (ítem 5.6.2.1);

calcula-se com a equação 4.41 a posição da linha neutra:

$\mathrm{x}=9.53 \mathrm{~cm}$;

com a qual, na equação 4.40 , calcula-se:

$\sigma_{\text {smin }}=6.479 \mathrm{kN} / \mathrm{cm}^{2}$;

$\sigma_{\text {smax }}=28.093 \mathrm{kN} / \mathrm{cm}^{2}$;

$\Delta \sigma_{s}=21.614 \mathrm{kN} / \mathrm{cm}^{2}=216.14 \mathrm{MPa}>180 \mathrm{MPa} ;$

assim: $C F=\frac{216.14}{180}=1.201 ;$

$A_{S}=C F A_{s}=24.84 \mathrm{~cm}^{2}$.

\subsection{2 - VERIFICAÇÃO DAS FASES CONSTRUTIVAS}

Verifica-se, primeiramente, se a vigas pré-moldadas suportarão, com as armaduras calculadas, os esforços provenientes do peso de concreto depositado sobre as mesmas, além de seus pesos próprios.

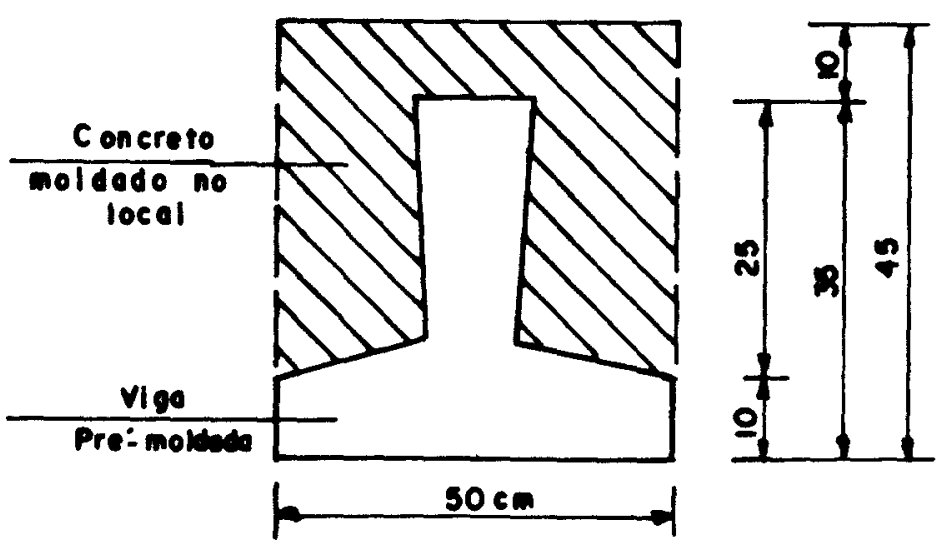

Figura 5.14 - Seção transversal da viga pré-moldada 
Com a Figura 5.14, calcula-se:

$\begin{aligned} & A_{v i g a}= 926.80 \mathrm{~cm}^{2} ; \\ & A_{\text {concreto }}=1323.20 \mathrm{~cm}^{2} . \\ & \text { Obtém-se então: }\end{aligned}$

Peso próprio de uma viga: $P P=2.317 \mathrm{kN} / \mathrm{m}$;

Peso do concreto moldado no local: $P C=3.308 \mathrm{kN} / \mathrm{m}$.

De posse deste carregamento, calcula-se, para a viga bi-apoiada, os seguintes esforços máximos:

a) Momento fletor: $M_{\text {máx }}=50.20 \mathrm{kNm}$;

b) força cortante: $V_{m a ́ x}=23.77 \mathrm{kN}$.

Para a resistência característica do concreto $f_{c k}=21 \mathrm{MPa}$, e considerando-se como seção resistente da viga um retângúlo de $15 \times 35 \mathrm{cms}$, tem-se:

Área longitudinal de aço necessária: $A_{s}=6.81 \mathrm{~cm}^{2}$; Área transversal de aço necessária: $A_{S w}=1.71 \mathrm{~cm}^{2} / \mathrm{m}_{\mathrm{S}}<\mathrm{A}_{S \mathrm{~min}}$.

Verifica-se desta forma que as áreas de aço necessárias ao tabuleiro (ítens 5.6.1.1 e 5.6 .2 .1 ) são suficientes.

Para a análise das solicitações dinâmicas tem-se segundo a equação $4.46: \mathrm{g}_{e}=3.012 \mathrm{kN} / \mathrm{m}$.

Observa-se ser a carga estática equivalente menor que a carga devida ao peso próprio mais o concreto moldado no local, estando, dessa forma, já verificada.

\subsection{3 - VERIFICAÇÃO DO FENDILHAMENTO NO NÓ DO PÓRTICO}

Para que se possa realizar o detalhamento proposto (emenda por traspasse de laços em gancho), deve-se verificar a taxa de armadura $(\rho)$ no nó do pórtico. Para a área de aço calculada na seção 8 (ítem 5.6.2.1), já majorada pelo efeito da fadiga (ítem 5.7.1.2), obtém-se na emenda $\rho=0.57 \%$. Embora, segundo LEONHARDT (1978), essa taxa não deva ser superior à $0.5 \%$, mantém-se o detalhamento, por considerar-se a diferença existente pequena do ponto de vista prático. 
Ainda segundo LEONHARDT (1978), o diâmetro da armadura adotada não deve ser superior à $30 \mathrm{~mm}$, o que não constitui problema, tendo em vista os diâmetros normalmente utilizados.

A armadura necessária aoicombate do fendilhamento deve combater os esforços supostos iguais a $25 \%$ da força de tração na barra emendada. Assim, para:

$\mathrm{M}_{\mathrm{d}}=-397.49 \mathrm{kNm} / \mathrm{m}$;

$z=55.22 \mathrm{~cm}=$ braço de alavanca;

obtém-se:

$F_{d}=719.83 \mathrm{kN} / \mathrm{m}$;

$A_{s}=4.14 \mathrm{~cm}^{2}$.

\subsection{4 - VERIFICAÇ̃̃O DA LIGAÇ̃̃O DOS CONCRETOS COM IDADES DIFERENTES}

Cálculo das tensões limites:

a) Segundo a FIP - para a categoria da superfície 1 e nível do problema igual a baixa solicitação cisalhante tem-se:

$\beta_{2}=0.20$ (Tabela 4.8);

$f_{t d}=1.281 \mathrm{MPa}\left(f_{c k}=21 \mathrm{MPa}\right)$;

pela equação 4.47 calcula-se $\tau_{w u}=0.256 \mathrm{MPa}$.

Considerando-se a área da armadura no cálculo da tensão limite (alta solicitação cisalhante):

$\beta_{1}=0.60$ (Tabela 4.8);

$\rho_{w}=0.7 \times 10^{-3}$ (admitindo metade da armadura transversal - cisalhamento -atravessando a interface);

$\mathrm{f}_{\mathrm{yd}}=435 \mathrm{MPa}$;

pela equação 4.48 , tem-se $\tau_{w u}=0.439 \mathrm{MPa}$.

b) Segundo a NBR 9062 - sendo $A_{s w} / s b=0.14 \%$, encontra-se na Tabela $4.9 \beta_{s}=0$ e $\beta_{c}=0.3$. Para $f_{c k}=21 \mathrm{MPa}$ (menos resistente dos concretos em contato), tem-se na equação $4.50: \tau_{\text {sd }} \leq 0.32$.

Cálculo das tensões atuantes na laje do sistema

isostático:
a) Tensão de referência: $\tau_{w d}=\frac{v_{d}}{b_{w} d}=1.04 \mathrm{MPa}$. 
b) Tensão segụndo a NBR 9062 - aplica-se a equação 4.50:

$F_{m d}=\frac{M_{m a x}}{2 z}=740.62 \mathrm{kN}$;

sendo $z$ a distância $(m)$ do ponto de aplicação da força $F_{m d}$ ao CG da armadura $(z=0.34 \mathrm{~m})$.

Calcula-se assim, através da equação 4.51, a tensão: $\tau_{s d}=0.181 \mathrm{MPa}$.

Cálculo das tensões atuantes na laje do sistema hiperestático:

a) Tensão de referência: $\tau_{w d}=\frac{V_{d}}{b_{w} d}=1.03 \mathrm{MPa}$.

b) Tensão segundo a NBR 9062 - deve-se calcular as tensões atuantes nos nós e no centro do vão.

b.1) Apoios - considera-se o ponto de momento nulo situado a 1.27 metros do apoio, de acordo com a envoltória de momentos (Tabela 5.18). Portanto:

$F_{m d}=361.35 \mathrm{kN}$ sendo $z=0.55 \mathrm{~m}$;

$\tau_{\text {sd }}=0.285 \mathrm{MPa}$.

b.2) Centro do vão:

$F_{m d}=459.81 \mathrm{kN}$ sendo $\mathrm{z}=0.36 \mathrm{~m}$;

$\tau_{s d}=0.156 \mathrm{MPa}$.

Vê-se assim que pelo método da FIP as tensões cisalhantes na interface superam o valor limite estabelecido, sendo que pela NBR 9062 não há problema. Admite-se neste trabalho que a laje esteja comportando-se como peça monolítica, prevendo-se no detalhamento a armadura considerada no cálculo da tensão limite pela FIP $\left(7 \mathrm{~cm}^{2} / \mathrm{m}\right)$.

A avaliação das tensões decorrentes dos efeitos da retração diferencial, deformação e variação de temperatura na interface não é feita, pois sendo tensões localizadas (bordos e final do vão) seus efeitos serão considerados combatidos através de uma armadura de reforço nestes locais. 


\subsection{5. - VERIFICAÇÃO DO ESTADO DE DEFORMAÇÃO EXCESSIVA}

Os momentos são obtidos a partir da combinação quase permanente, nas quais todasi as ações variáveis são consideradas com seus valores quase permanentes $\psi_{2} F_{c k}$, sendo $\psi_{2}=0.2$ (NBR 8681).

0 momento de inércia considerado é o obtido com a equação 4.52a, conforme exposto no ítem 4.5.5.

A verificação é realizada somente para a seção localizada no centro da laje da superestrutura, tanto para 0 sistema isostático quanto para o hiperestático. Desse modo:

a) Cálculo sem continuidade

$\mathrm{M}=187.84 \mathrm{kNm} / \mathrm{m}$;

$I_{c}=759375 \mathrm{~cm}^{4}$.

Na Tabela $4.10 \mathrm{com} \mathrm{n}=8, \rho=7.55 \times 10^{-3}, \mathrm{~d}^{\prime}=3.5 \mathrm{~cm}$ e $d=40 \mathrm{~cm}$, tem-se:

$I_{r} / I_{c}=0.35$ (interpolando);

e portanto $I_{r}=265781.25 \mathrm{~cm}^{4}$.

Calculando-se o valor do momento de fissuração $M_{r}$ através da equação $4.52 \mathrm{a}$, determina-se $\circ$ valor do momento de inércia efetivo $\left(I_{e}\right)$ :

$M_{r}=99.23 \mathrm{kNm} / \mathrm{m}$, para $f_{c t}=2.94 \mathrm{MPa}$ e $\mathrm{y}_{1}=22.5 \mathrm{~cm}$;

$I_{e}=338537.24 \mathrm{~cm}^{4}$.

A flecha imediata devido ao carregamento permanente e a flecha devida às cargas móveis são determinadas através da fórmula clássica da resistência dos materiais:

sendo:

$$
f=\frac{5 \mathrm{p}_{\mathrm{x}}{ }^{4}}{384 \mathrm{E}_{\mathrm{c}} \mathrm{I}_{\mathrm{e}}}
$$

$\mathrm{p}=$ carga uniformemente distribuída;

$\ell_{\mathrm{x}}=$ vão teórico da ponte $\left(\ell_{\mathrm{x}}=8.20 \mathrm{~m}\right)$;

$E_{c}=$ módulo de elasticidade do concreto, calculado através da equação $4.42\left(E_{c}=2918.7 \mathrm{kN} / \mathrm{cm}^{2}\right)$;

Para o carregamento permanente $p=g=15.65 \mathrm{kN} / \mathrm{m}$ (ítem 5.3.1.2), obtendo-se $f=0.93 \mathrm{~cm}$. 
A flecha. final é determinada com o auxílio da Tabela 4.11, com a qual obtém-se, admitindo a umidade do meio ambiente como média e $A_{s^{\prime}}=0$ a flecha $f=2.80 \mathrm{~cm}$.

Para as cargas móveis a carga $p$ é estimada considerando-se as cargas das: rodas do veículo tipo uniformemente distribuídas: $p=48.90 \mathrm{kN} / \mathrm{m}$, obtendo-se a flecha $E=2.91 \mathrm{~cm}$.

b) Cálculo com continuidade - o momento de inércia efetivo $\left(\mathrm{I}_{\mathrm{e}}\right)$ utilizado no cálculo das flechas é o obtido através da média aritmética entre os calculados para o apoio e o meio do vão. Desse modo:

b. 1) Apoio

$\mathrm{M}=145.14 \mathrm{kNm} / \mathrm{m}$;

$I_{c}=759375 \mathrm{~cm}^{4}$;

na Tabela 4.10, com $\mathrm{n}=8, \rho=2.89 \times 10^{-3}, \mathrm{~d}^{\prime}=5 \mathrm{~cm} \mathrm{e}$

$d=58 \mathrm{~cm}$, tem-se:

$I f_{c}=0.17$ (extrapolando);

e portanto $I_{r}=129093.75 \mathrm{~cm}^{4}$.

Sendo o momento de fissuração $M_{r}=76.98 \mathrm{kNm} / \mathrm{m}$ (para $\left.f_{c t}=2.94 \mathrm{MPa} e \mathrm{y}_{1}=29 \mathrm{~cm}\right)$, calcula-se $\circ$ valor do momento de inércia efetivo: $\mathrm{I}_{\mathrm{e}}=224401.77 \mathrm{~cm}^{4}$.

b.2) Meio do vão

$\mathrm{M}=84.56 \mathrm{kNm} / \mathrm{m}$;

$I_{c}=759375 \mathrm{~cm}^{4}$;

com $\mathrm{n}=8, \rho=5.52 \times 10^{-3}$ (já considerando o aumento da área de aço devido a fadiga), $d^{\prime}=3.5 \mathrm{~cm}$ e $d=40$

Cm, tem-se na Tabela 4.10:

$I f_{c}=0.27$ (extrapolando);

e portanto $I_{r}=205790.63 \mathrm{~cm}^{4}$.

Sendo o momento de fissuração $M_{r}=99.23 \mathrm{kNm} / \mathrm{m}$ (para $f_{c t}=2.94 \mathrm{MPa}$ e $\left.Y_{1}=22.5 \mathrm{~cm}\right)$, calcula-se 0 valor do momento de inércia efetivo: $I_{e}=759375 \mathrm{~cm}^{4}$.

Efetuando-se a média entre os valores encontrados, determina-se 0 momento de inércia efetivo $I_{e}=491888.39 \mathrm{~cm}^{4}$.

A flecha no ponte é calculada a partir das flechas obtidas para os casos extremos de viga simplesmente apoiada 
(equação 5.6). e viga engastada (equação 5.7). Determina-se o grau de engastamento do nó da ponte com os momentos já calculados para ambos os casos, obtendo-se sua flecha por interpoḷação linear entre aquelas calculadas para os casos extremos. Tabela 5.19 - Cálculo do grau de engastamento do nó da
ponte

\begin{tabular}{lcc} 
& \multicolumn{2}{c}{ Momento no nó (engaste) } \\
\cline { 2 - 3 } & Peso próprio & Carga móvel \\
\hline Placa bi-engastada & -93.08 & -128.55 \\
Ponte em pórtico & -76.23 & -86.99 \\
\hline Grau de engastamento & $81.90 \%$ & $67.66 \%$ \\
\hline
\end{tabular}

OBS: 0 momento $.86 .99 \mathrm{kNm} / \mathrm{m}$ atua no centro do apoio

Para a viga engastada, tem-se:

$f=\frac{p \ell_{x}{ }^{4}}{384 \mathrm{E}_{\mathrm{c}} \mathrm{I}_{\mathrm{e}}}$

Procedendo conforme exposto,

calcula-se a flecha imediata devida as cargas permanentes: $f=0.24 \mathrm{~cm}$. A flecha final é igual a $f=0.72 \mathrm{~cm}$.

Analogamente ao cálculo sem continuidade, considera-se as cargas móveis como uniformemente distribuídas $(\mathrm{p}=47.60 \mathrm{kN} / \mathrm{m})$, obtendo-se a flecha $f=1.01 \mathrm{~cm}$.

\subsection{6 - VERIFICAÇÃO DO ESTADO DE FISSURAÇÃO INACEITÁVEL}

Analogamente ao ítem anterior, os momentos são obtidos a partir da combinação quase permanente das ações.

- valor limite das aberturas de fissuras $(\omega)$ considerado é de $0.2 \mathrm{~mm}$ (peças não protegidas em meio não agressivo).

A verificação é realizada nas seções mais solicitadas dos encontros e da laje da superestrutura. Assim: a) Para o sistema estrutural isostático - são verificadas a 
seção 1 do muro (engaste) e a seção 6 da laje da superestrutura (meio do vão);

b) para o sistema estrutural hiperestático - são, analogamente ao caso anterior, verificadas as secões $1 \mathrm{e}$ 13 do pórtico (Figura 5.7).

\section{a) Sistema estrutural isostático}

a.1) seção 1 do muro

o momento fletor máximo atuante na seção da armadura é igual a $\mathrm{M}_{\mathrm{sl}}=472.02 \mathrm{kNm} / \mathrm{m}$. Através da equação $4.45 \mathrm{com}$ :

$\mathrm{d}=64.50 \mathrm{~cm}$;

$\mathrm{b}_{\mathrm{w}}=100.00 \mathrm{~cm}$;

$\mathrm{n}=7.77$ (para $\left.\mathrm{f}_{\mathrm{ck}}=21 \mathrm{MPa}\right)$;

$A_{s}=20.02 \mathrm{~cm}^{2}$;

obtém-se a posição da linha neutra $x=13.60 \mathrm{~cm}$. Com as equações 4.43 e 4.44 chega-se à tensão na armadura $\sigma_{s}=32.94 \mathrm{kN} / \mathrm{cm}^{2}$. Calculando-se a taxa geométrica da armadura na seção transversal de concreto interessada pela fissuração (Figura 4.23), pode-se, tomando-se para o coeficiente de aderência do aço $\eta_{b}=1.5$, calcular $\circ$ valor das desigualdades fornecidas pelas equações $4.53 \mathrm{a}$ e $4.53 \mathrm{~b}$ :

$\rho_{r}=0.0178$, para $A_{c r}=1125 \mathrm{~cm}^{2}$;

Através da equação 4.53a: 3.01

Através da equação $4.53 \mathrm{~b}: 7.35$

a.2) seção 6 da laje

Procedendo-se da mesma forma, tem-se:

$M_{6}=187.84 \mathrm{kNm} / \mathrm{m}$;

$\mathrm{d}=40.00 \mathrm{~cm}$;

$\mathrm{b}_{\mathrm{w}}=100.00 \mathrm{~cm}$;

$\mathrm{n}=7.195$ (fck $=21 \mathrm{MPa}) ;$

$A_{s}=33.99 \mathrm{~cm}^{2}$;

Calcula-se pela equação 4.41 a posição da linha neutra $x=11.75 \mathrm{~cm}$, com a qual através da equação 4.40 chega-se a tensão na armadura $\sigma_{s}=15.32$ $\mathrm{kN} / \mathrm{cm}^{2}$. Analogamente ao ítem anterior:

$\rho_{r}=0.0134$, para $A_{c r}=2531 \mathrm{~cm}^{2}$; 
Pela equação 4.53a: 2.23

Pela equação 4.53b: 1.52

b) Sistema estrutural hiperestático

b.1) seção 1 (engaste do muro) i

Analogamente ao ítem a.1 tem-se:

$M_{s 1}=200.53 \mathrm{kNm} / \mathrm{m}_{i}$

$\mathrm{d}=41.00 \mathrm{~cm}$;

$b_{w}=100.00 \mathrm{~cm}$;

$\mathrm{n}=7.77$

$A_{s}=16.75 \mathrm{~cm}^{2}$;

$\mathrm{x}=10.10 \mathrm{~cm}$;

$\sigma_{\mathrm{s}}=24.69 \mathrm{kN} / \mathrm{cm}^{2}$;

$\rho_{\mathrm{r}}=0.0138$, para $\mathrm{A}_{\mathrm{cr}}=1216 \mathrm{~cm}^{2}$;

Pela equação 4.53a: 2.80

Pela equação $4.53 \mathrm{~b}: 4.13$

b.2) seção 13 (meio do vão)

Analogamente ao ítem a.2 tem-se:

$M_{s 1}=84.56 \mathrm{kNm} / \mathrm{m}$;

$\mathrm{d}=40.00 \mathrm{~cm}$;

$b_{w}=100.00 \mathrm{~cm}$;

$\mathrm{n}=7.195$

$A_{s}=24.84 \mathrm{~cm}^{2}$;

$\mathrm{x}=10.30 \mathrm{~cm}$;

$\sigma_{s}=9.31 \mathrm{kN} / \mathrm{cm}^{2}$;

$\rho_{r}=0.0138$, para $A_{c r}=1800 \mathrm{~cm}^{2}$;

Pela equação 4.53a: 1.32

Pela equação $4.53 \mathrm{~b}: 0.56$

Nota-se que as secões localizadas na base do muro, para ambos os sistemas estruturais, não verificam as desigualdades $4.53 \mathrm{a}$ e 4.53b. Deve-se então realizar alguma proteção para as armaduras aí localizadas.

\section{8 - DETALHAMENTO DA ESTRUTURA}

- detalhamento das armaduras é feito de acordo com - exposto no ítem 4.6, utilizando-se os esforços obtidos a 
partir do cálculo aproximado. Este detalhamento pode ser observado no Anexo $C$.

\section{9 ; ANÁLISE DOS RESULTADOS}

A análise do detalhamento de ambos os sistemas estruturais levou aos seguintes resultados:

Tabela 5.20 - Consumos para o sistema com continuidade

\begin{tabular}{lccc}
\hline & $\begin{array}{c}\text { Área Forma } \\
\left(\mathrm{m}^{2}\right)\end{array}$ & $\begin{array}{c}\text { Volume Concreto } \\
\left(\mathrm{m}^{3}\right)\end{array}$ & $\begin{array}{c}\text { Peso Aço } \\
(\mathrm{kg})\end{array}$ \\
\hline Superestrutura & 8.0 & 54.1 & 5922 \\
Encontros & 756.0 & 42.5 & 5788 \\
Fundação & 39.4 & 29.0 & 908 \\
\hline Total & 803.4 & 125.6 & 12618 \\
\hline
\end{tabular}

Tabela 5.21 - Consumos para o sistema sem continuidade

\begin{tabular}{lccc}
\hline & $\begin{array}{c}\text { Área Forma } \\
\left(\mathrm{m}^{2}\right)\end{array}$ & $\begin{array}{c}\text { Volume Concreto } \\
\left(\mathrm{m}^{3}\right)\end{array}$ & $\begin{array}{c}\text { Peso Aço } \\
(\mathrm{kg})\end{array}$ \\
\hline Superestrutura & 7.6 & 51.1 & 5139 \\
Muros & 757.0 & 42.5 & 4713 \\
Fundação & 55.1 & 62.0 & 1523 \\
\hline Total & 819.7 & 155.6 & 11375 \\
\hline
\end{tabular}

Com estes valores pode-se chegar aos seguintes índices de consumo:

$$
\begin{aligned}
& I_{1}=\frac{\text { Peso de aço }}{\text { Volume de concreto }}\left(\mathrm{kg} / \mathrm{m}^{3}\right) \\
& I_{2}=\frac{\text { Área de Forma }}{\text { Volume de concreto }}\left(\mathrm{m}^{2} / \mathrm{m}^{3}\right) \\
& \text { Os valores de } I_{1} \text { e } I_{2} \text { são mostrados na Tabela } 5.22 \text { e } 5.23 .
\end{aligned}
$$


Tabela 5.22 - Indices de consumo para o sistema com continuidade

\begin{tabular}{lrr}
\hline & $I_{1}$ & \multicolumn{1}{c}{$I_{2}$} \\
\hline Superestrutura & 109.5 & 0.15 \\
Encontros & 136.2 & 17.79 \\
Fundação & 31.3 & 1.36 \\
\hline Total & 100.5 & 6.40 \\
\hline
\end{tabular}

Tabela 5.23 - Indices de consumo para o sistema sem continuidade

\begin{tabular}{lrr}
\hline & $I_{1}$ & \multicolumn{1}{c}{$I_{2}$} \\
\hline Superestrutura & 100.6 & 0.15 \\
Muros & 110.9 & 17.81 \\
Fundação & 24.6 & 0.90 \\
\hline Total & 73.10 & 5.27 \\
\hline
\end{tabular}

Observa-se que o consumo com a forma é praticamente igual concentrando-se nos encontros. A área de forma obtida na superestrutura foi somente devido aos bordos da laje, daí valores tão baixos.

o volume de concreto foi maior para o sistema sem continuidade $\left(30 \mathrm{~m}^{3}\right)$ devido unicamente à fundação.

o consumo de aço foi maior para a ponte em pórtico. observando-se os indices $I_{1}$ e $I_{2}$ verifica-se que os encontros mostraram-se bem mais onerosos que os muros do sistema sem continuidade, gastando-se $1075 \mathrm{~kg}$ de aço a mais sendo que o consumo de concreto foi o mesmo. O peso de aço necessário para a formação da união rígida na ponte em pórtico elevou o consumo da superestrutura em $783 \mathrm{~kg}$ com relação ao sistema sem continuidade, pois as vigas responsáveis por todo o aço gasto no tabuleiro para esta alternativa consumiram $4599 \mathrm{~kg}$ (com excessão de $540 \mathrm{~kg}$ nescessários para a armação transversal - combate ao $\mathrm{M}_{\mathrm{y}}$ ).

No geral o sistema com continuidade elevou 0 consumo de aço em relação a opção sem continuidade em $1243 \mathrm{~kg}$.

Analisando os resultados obtidos através da técnica 
dos elementos. finitos (ver item 5.5, tabelas 5.14 e 5.15), pode-se fazer os seguintes comentários:

a) Para o sistema sem continuidade as diferenças encontradas nos yalores dos momentos nas seções entre o apoio e centro do vão $(\simeq 50 \%)$ foram causadas pelo fato de só terem sido processados carregamentos com o veículo tipo no centro do vão (bordos e meio da laje). Observa-se que o desvio percentual para o caso crítico, momento no centro do vão, foi de $+5 \%$ para os bordos e $-6 \frac{\%}{6}$ para o meio da laje do cálculo através das tabelas de $\mathrm{RU} S \mathrm{SCH}$ (1965) em relação ao feito com a utilização da técnica dos elementos finitos.

b) Para o sistema com continuidade, da mesma forma que 0 sistema sem continuidade, o carregamento considerado no processamento do pórtico só leva a esforços máximos nas seções críticas, isto é, no engaste, na ligação entre superestrutura e encontros e no meio do vão. Nestes pontos - desvio percentual do cálculo aproximado em relação ao processo dos elementos finitos foi de $+29 \%$ e $+63 \%$ no engaste (seção 1) para o centro do vão e bordos, respectivamente; de $+27 \%$ e $+51 \%$ na ligação entre encontro e superestrutura (seção 8 ) e de $-0.5 \%$ e $+36 \%$ no meio do vão (seção 13). Vale observar que de acordo com as linhas de influência do pórtico (Tabela 5.11a), o carregamento ideal para a avaliação dos momentos tanto nos engastes quanto na ligação entre encontro e superestrutura seria 0 trem tipo posicionado a distância de $40 \%$ do vão e não a $1 / 3(\simeq 33 \%)$.

Como pode-se observar, os valores dos esforços provenientes do carregamento móvel obtidos com a utilização do Método dos Elementos Finitos mostraram uma redução significativa para o caso do sistema estrutural hiperestático. Desta forma, um novo detalhamento é feito utilizando-se estes esforços e os quantitativos e índices de consumo apresentados a seguir (Tabelas 5.24 e 5.25).

A partir deste novo consumo de aço chega-se à valores praticamente iguais para os dois sistemas estruturais observando-se um gasto superior de $106 \mathrm{~kg}$ de ferro para a ponte em pórtico $(+0.9 \%)$. 
Tabela 5.24 - Consumos para o sistema com continuidade calculo utilizando os esforços obtidos através da Técnica dos Elementos Finitos

\begin{tabular}{lccc}
\hline & $\begin{array}{c}\text { Área Forma } \\
\left(\mathrm{m}^{2}\right)\end{array}$ & $\begin{array}{c}\text { Volume Concreto } \\
\left(\mathrm{m}^{3}\right)\end{array}$ & $\begin{array}{c}\text { Peso Aço } \\
(\mathrm{kg})\end{array}$ \\
\hline Superestrutura & 8.0 & 54.1 & 5063 \\
Encontros & 756.0 & 42.5 & 5510 \\
Fundação & 39.4 & 29.0 & 908 \\
\hline Total & 803.4 & 125.6 & 11481 \\
\hline
\end{tabular}

Tabela 5.25 - Indices de consumo para o sistema com conti. nuidade. Cálculo utilizando os esforços obtidos através da Técnica dos Elementos Finitos

\begin{tabular}{lrr}
\hline & \multicolumn{1}{c}{ I1 } & \multicolumn{1}{c}{ I2 } \\
\hline Superestrutura & 93.6 & 0.15 \\
Encontros & 129.6 & 17.79 \\
Fundação & 31.3 & 1.36 \\
\hline Total & 91.4 & 6.40 \\
\hline
\end{tabular}




\title{
$6 \cdot$ CONSIDERAÇ̃̃ES FINAIS
}

\section{$6.1 \cdot$ CONCLUSÕES}

\begin{abstract}
Com o detalhamento feito a partir dos resultados obtidos com 0 método aproximado (conceito de largura colaborante), faz-se uma análise dos custos diretos donde observa-se que os gastos com material são basicamente iguais entre o tipo construtivo escolhido e a alternativa em viga. Houve um consumo maior de aço na ponte em pórtico, compensado pelo menor volume de concreto (devido à fundação), sendo que os dois sistemas estruturais necessitam da mesma área de
\end{abstract} forma.

- cálculo dos momentos fletores máximos, pela técnica dos elementos finitos, foi oportuno pois serviu para mostrar que, ao contrário do cálculo para o sistema isostático, onde os valores ficaram bem próximos, houve para - sistema estrutural escolhido, uma variação significativa com relação aos valores obtidos através do processo apresentado. Observa-se que, com o detalhamento da ponte em pórtico a partir destes esforços, o consumo de aço fica basicamente igual para as duas alternativas. Deste modo a economia de concreto na fundação faz com que o sistema com continuidade ofereça alguma vantagem em relação ao sistema sem continuidade.

Deve-se lembrar que a continuidade conseguida, 
através da ligação entre a superestrutura e a infraestrutura, aumentará os custos de execução, pois, para a sua realização, será necessário maior gasto com mão-de-obra provocando um aumento' do tempo de obra.

Como se pode observar no ítem 5.7.1, a verificação à fadiga fez com que o sistema estrutural hiperestático perca vantagens sobre o isostático. Isto certamente deve-se ao fato de que os esforcos provenientes dos aterros de acesso, sendo contrários aos decorrentes do peso próprio, diminuiram a influência das cargas permanentes face às móveis. Assim existe uma maior flutuação de esforços no sistema com continuidade fazendo com que a área de aço da superestrutura tenha aumentado significativamente $(20 \%)$.

Outro fato relevante é que o melhor aproveitamento das seções de concreto otimiza o dimensionamento do muro de arrimo no sistema isostático.

Uma alternativa ao detalhamento proposto seria reduzir-se a área de aço nos nós do pórtico (15\%) com consequente aumento da área de aço do vão (7.5\%). Isto traria benefícios: primeiro porque $\circ$ aumento da área de aço no centro do vão diminuiria as tensões na mesma, podendo-se obter melhores resultados no ítem relativo à verificação da fadiga; segundo porque diminuiria a porcentagem de armadura no nó do pórtico o que, segundo Leonhardt (1978), é melhor para o detalhamento adotado.

- detalhamento das vigas pré-moldadas poderia ser feito de modo a se reduzir a área de aço ao caminhar para o centro da laje face aos menores momentos fletores. No entanto, este procedimento poderia causar problemas em obra pois trabalhar-se-ia com vigas diferentes.

\section{2 - CONTINUIDADE DE PESQUISA}

Sugere-se, como continuidade do trabalho, a avaliação de outras situações para o tipo estrutural escolhido, conseguidas através da variação das dimensões da laje do tabuleiro, da altura e espessura dos encontros. 
Podería-se, deste modo, tentar generalizar algumas tendências com relação ao consumo e comportamento estrutural entre os sistemas estruturais normalmente utilizados em pontes de pequeno's vãos.

As grandes variações encontradas nos resultados dos momentos fletores decorrentes do carregamento móvel para 0 tipo construtivo escolhido (ponte em pórtico) com os dois métodos de cálculo utilizados, método aproximado (conceito de largura colaborante) e Método dos Elementos Finitos torna necessária a verificação dos esforços para outras situações. Esta avaliação poderia ser feita também para o carregamento permanente.

A introdução da protensão no tabuleiro da ponte, assim como a variação do sistema estrutural, poderia ser estudada.

Pode-se também estudar a deformabilidade da ligação do tabuleiro com os encontros (emendas por traspasse de laços em gancho), que neste trabalho foi considerada como rígida. 


\section{ANEXO A \\ DIMENSIONAMENTO DE APARELHOS DE APOIO ELASTOMÉRICOS SEGUNDO 0 SERVICE CENTRAL D'ETUDES TECHNIQUES}




\section{A.1 - DIMENSIONAMENTO $\AA$ À COMPRESSÃO}

\section{A.1.1 - TENSÃO DE COMPRESSÃO MÉdIA ATUANTE $\left(\sigma_{c}\right)$ SOBRE A ALMOFADA DE NEOPRENE}

$$
\sigma_{c}=\frac{\mathrm{N}}{\mathrm{ab}} \leq 1.5 \mathrm{kN} / \mathrm{cm}^{2}
$$

onde:

$\mathrm{N}=$ força normal à seção do apoio;

$a, b=$ dimensões em planta do neoprene.

Em geral, adota-se para $\sigma_{c}$ valores da ordem de $1 \mathrm{kN} / \mathrm{cm}^{2}$. A NBR 9062 [4] recomenda os limites $0.7 \mathrm{kN} / \mathrm{cm}^{2}$ e $1.1 \mathrm{kN} / \mathrm{cm}^{2}$ para as pressões de contato das almofadas simples e fretadas, respectivamente.

\section{A.1.2 - TENSÃo DE CISALHAMENTO $\left(\tau_{c}\right)$ ENTRE O NEOPRENE E A PLACA METÁLICA (APOIOS FRETADOS)$$
\tau_{c}=1.5 \frac{\sigma_{c}}{\text { fator de forma }} \leq 3 \mathrm{G}_{\mathrm{n}}
$$

onde :

fator de forma $=\frac{a b}{2(a+b) h_{n}}$

$h_{n}=$ espessura de neoprene entre as placas metálicas;

$\mathrm{G}_{\mathrm{n}}=$ módulo de cisalhamento do neoprene.

- módulo de cisalhamento do neoprene mede a deformabilidade do material sob tensões de cisalhamento. Este depende da dureza shore e da temperatura do material. A $20^{\circ} \mathrm{C}$, obtém-se os seguintes valores:

A dureza shore do neoprene é medida pela profundidade da penetração de uma agulha no material numa escala de 0 a 90 (escala shore. A dureza 0 shore corresponde a um material completamente mole, não oferecendo nenhuma resistência à penetração da agulha. A dureza 90 corresponde ao material muito duro. 
Tabela A.1 - Módulo de cisalhamento do neoprene à $20^{\circ} \mathrm{C}$, em função da dureza Shore

\begin{tabular}{c|rrr}
\hline Dureza Shore & 50 & 60 & 70 \\
\hline$G_{n}(\mathrm{MPa})$ & 0.8 & 1.0 & 1.2 \\
\hline
\end{tabular}

\section{A.2 - ESFORÇOS TRANSVERSAIS}

Tensão de cisalhamento $(\tau)$ no elastômero

$$
\tau=\frac{H}{a b}=G_{n} \frac{\Delta}{\sum h_{n}}
$$

onde:

$\mathrm{H}=$ força horizontal atuante no topo do apoio de neoprene;

$\Delta=$ deslocamento no neoprene provocado pela ação de $\mathrm{H}$.

Para esforços de ação muito rápida (vento, frenagem), 0 módulo de cisalhamento do neoprene é aproximadamente igual ao dobro do valor obtido em ensaios normais. Devido a isso, considera-se para análise, apenas a metade da tensão de cisalhamento provocada por esses esforços.
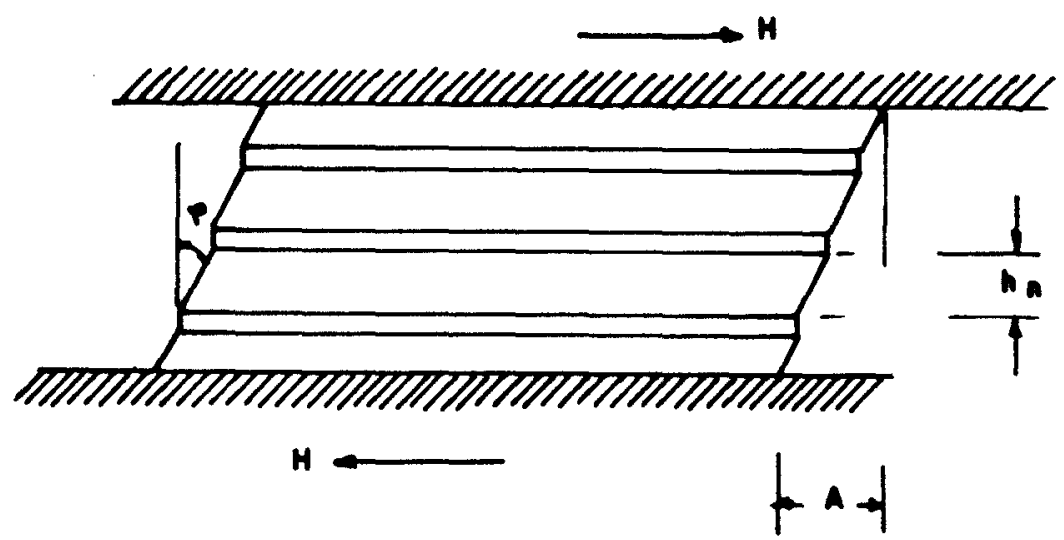

Figura A.1 - Deformação de uma almofada de neoprene fretado. sob ação de um esforço horizontal (H) 
No caso de deformações de longa duração, tais como provocadas por temperatura, retração ou fluência, calcula-se - esforço transversal correspondente, entrando-se com esse valor na fórmula (A.3).

A tensão de cisalhamento $\tau$ no neoprene deve ficar limitada aos valores $0.5 G_{n}$ e $0.7 G_{n}$ ' para ações de longa duração e ações de longa duração juntamente com ações dinâmicas, respectivamente.

\section{A.3 - ROTAÇÃO IMPOSTA}

$$
\tau_{\alpha}=\frac{G_{n}}{2}\left(\frac{b}{h_{n}}\right)^{2} \operatorname{tg} \alpha_{1}<1.5 G_{n}
$$

onde:

$\alpha_{1}$ = ângulo de rotação da lâmina de neoprene;

No caso de uma almofada de apoio com n lâminas, sendo $\alpha$ a rotação imposta ao apoio, a condição (A.4) modifica-se para:

$$
\tau_{\alpha}=\frac{G_{n}}{2}\left(\frac{b}{h_{n}}\right)^{2} \frac{\operatorname{tg} \alpha}{n}<1.5 G_{n}
$$

\section{A.4 - FLAMBagem DO APARELHO DE APOIO}

$$
\frac{b}{\sum h_{n}} \geq 5
$$

\section{A.5 - SEGURANÇA CONTRA DESLIZAMENTO}

Para evitar-se o deslizamento da almofada de apoio, sob carga mínima, deve-se ter as seguintes pressões sobre 0 apoio:

apoio em concreto

$$
\sigma_{c} \text { in } \geq 2 \mathrm{MPa}
$$

apoio em aço

$\sigma_{c}$ in $\geq 3 \mathrm{MPa}$.

A segurança contra o deslizamento pode ser verificada com a equação: 


$$
H<\mu \sigma_{c} m i n a b
$$

onde $\mu$ é o coeficiente de atrito, que pode ser estimado a partir da seguinte relação empírica:

$$
\mu=0.12+\frac{2}{\sigma_{c}^{m i n}}
$$

Quando a segurança ao deslizamento não for satisfeita, o apoio deverá ser fixado, por meio de batentes metálicos ou parafusos. 


\section{ANEXO B}

GRÁFICOS DE ISO-MOMENTOS OBTIDOS ATRAVÉS DA TÉCNICA DOS ELEMENTOS FINITOS 
SISTEMA ESTRUTURAL SEM CONTINUIDADE

ISO-MOMENTOS NA LAJE NAS DIRECOES $X, Y E X Y$ 


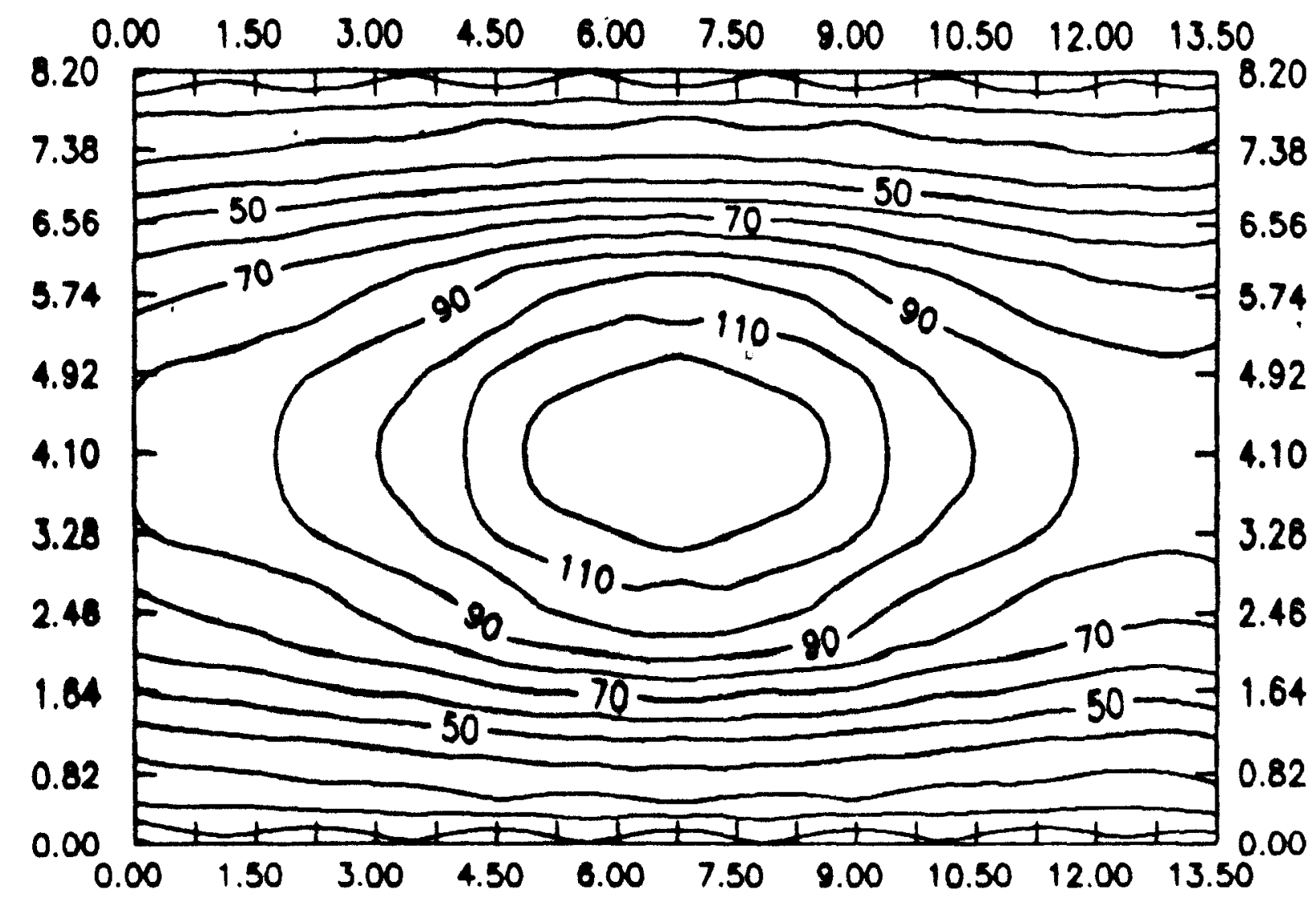

ISO-MOMENTOS NA DIRECAO X - VEICULO NO CENTRO DO VAO E MEIO DA LANE

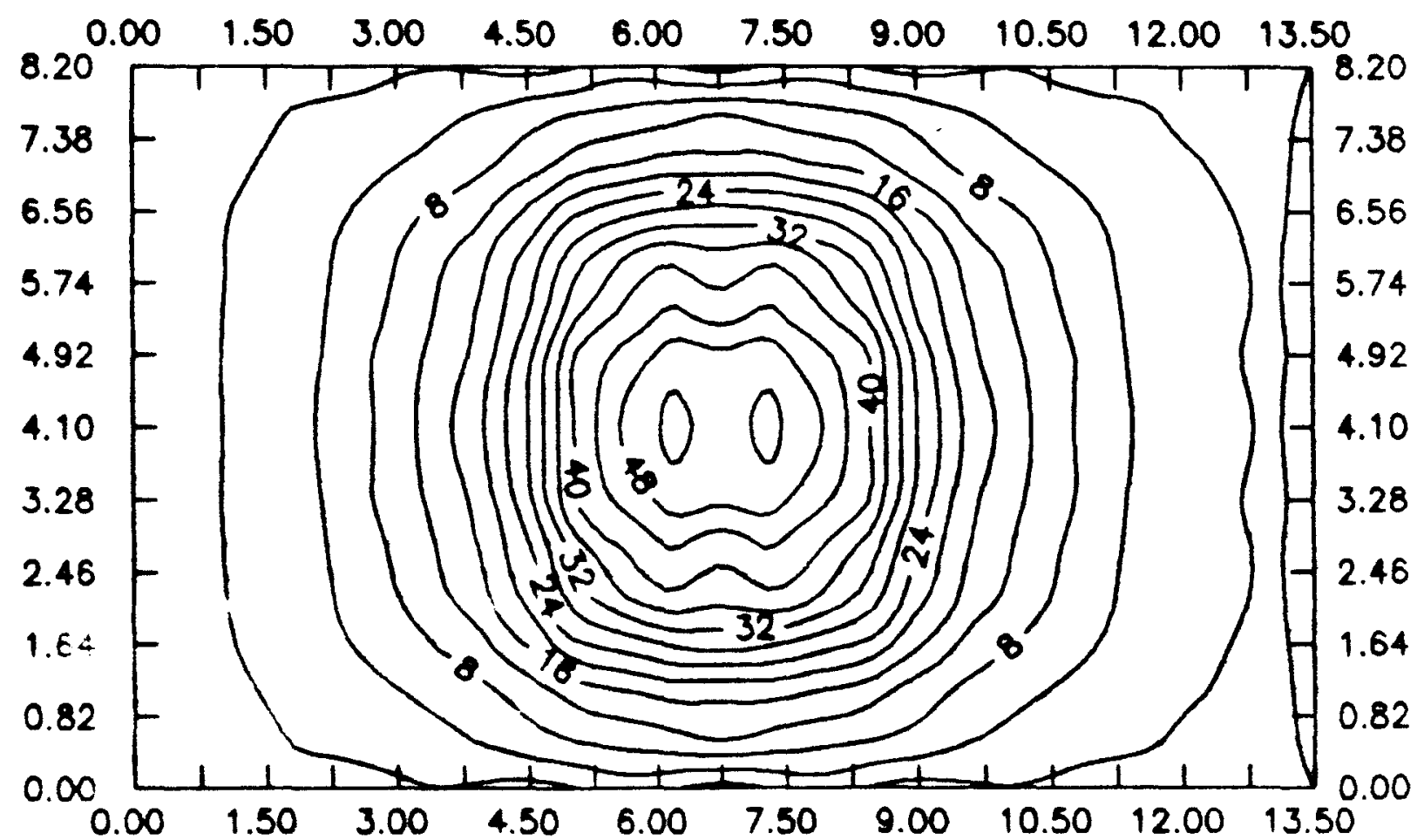

ISO-MOMENTOS NA DIRECAO Y - VEICULO NO CENTRO DO VAO E MEIO DA LAJE 


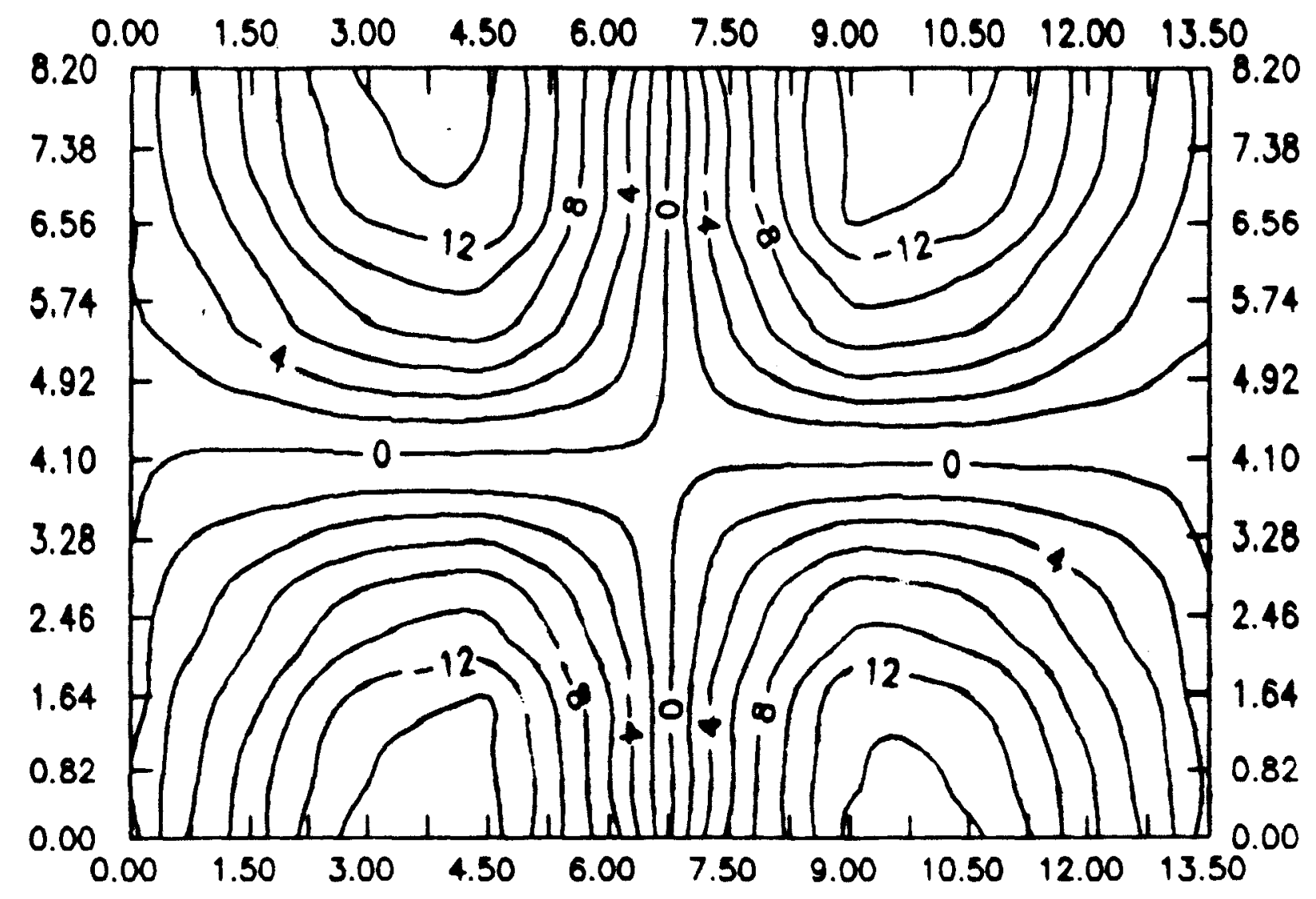

ISO-MOMENTOS NA DIRECAO XY - VEICULO NO CENTRO DO VAO E MEIO DA LAJE

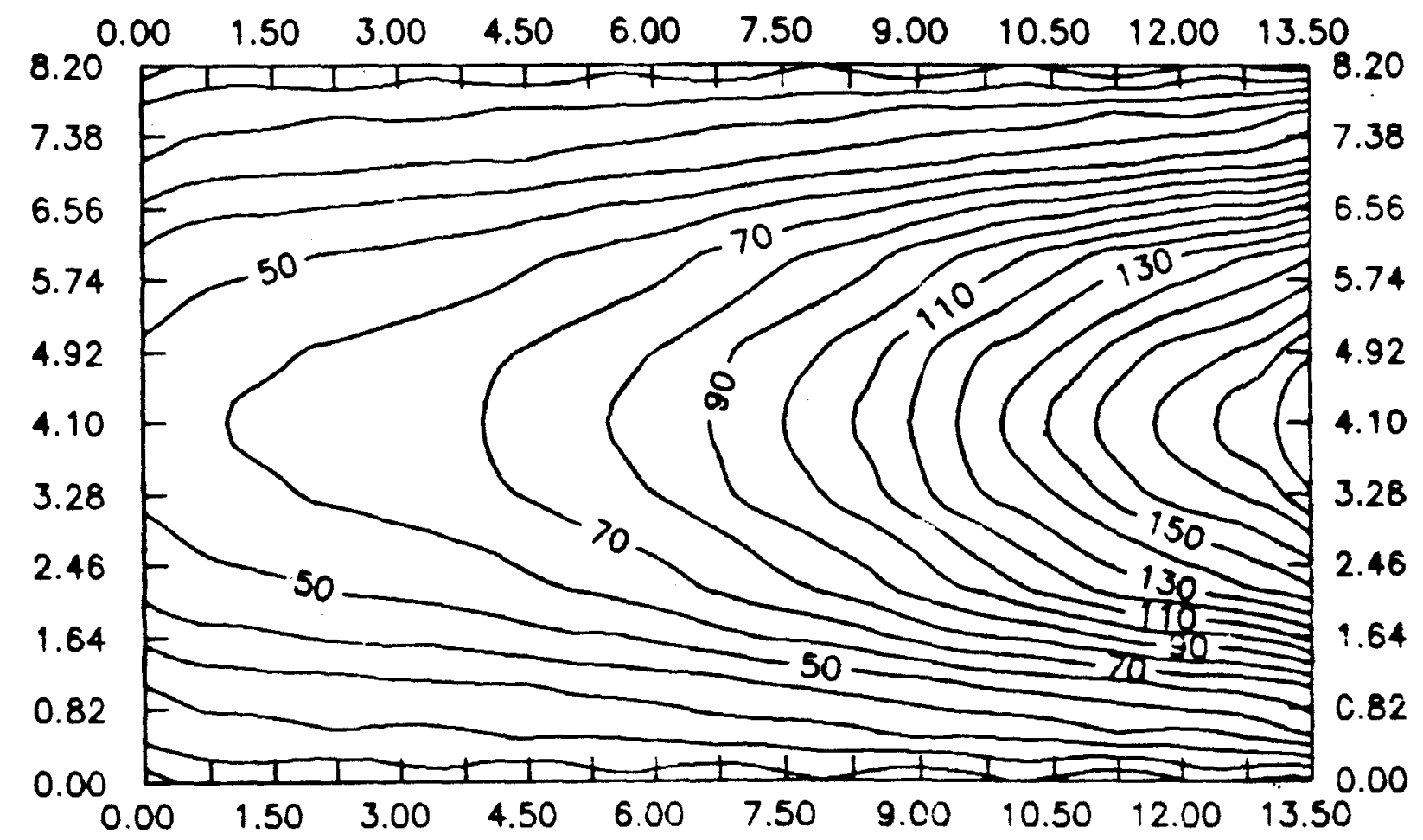

ISO-MOMENTOS NA DIRECAO X - VEICULO NO CENTRO DO VAO E BORDO DA LAJE 


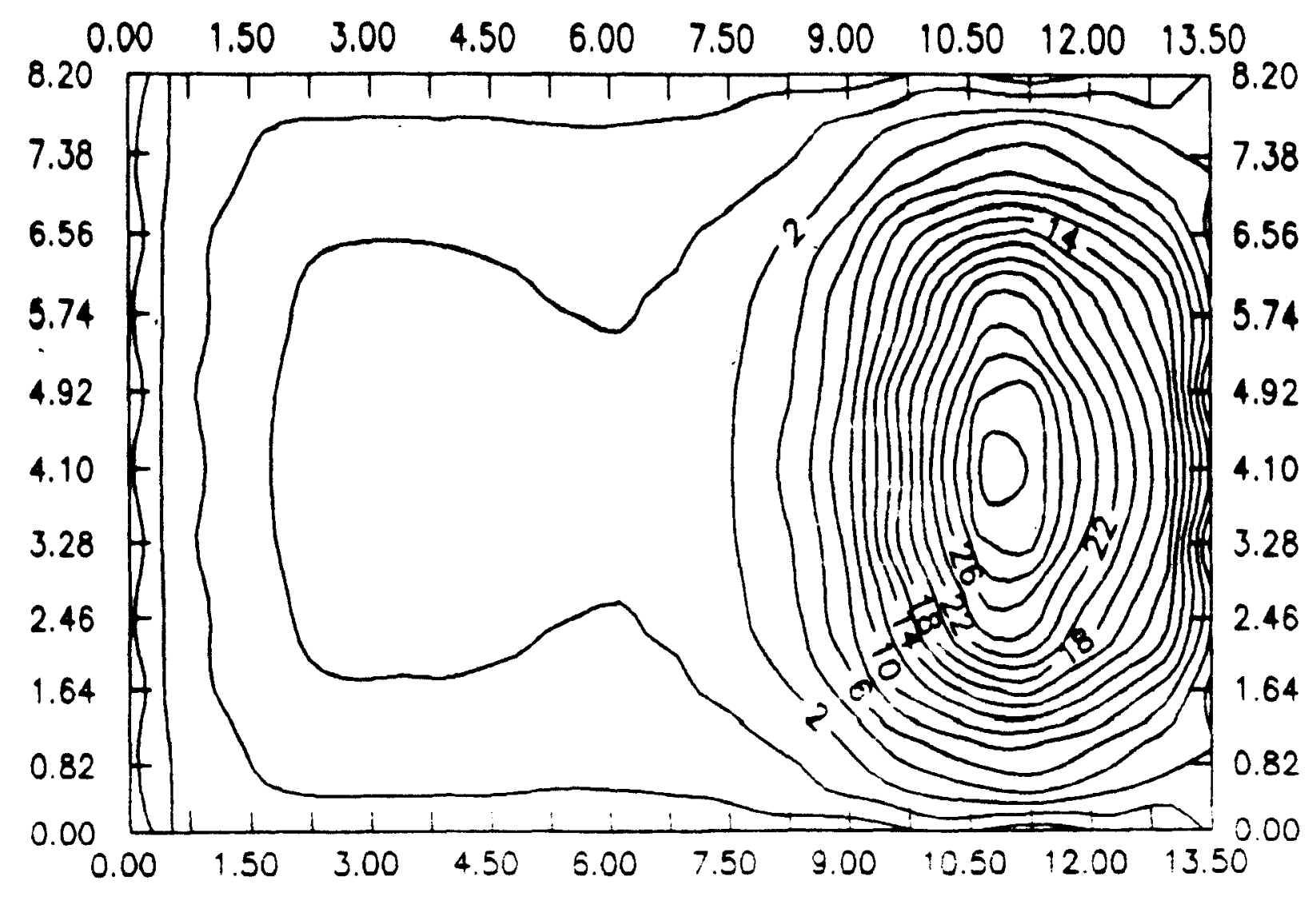

ISO-MOMENTOS NA DIRECAO Y - VEICULO NO CENTRO DO VAO E BORDO DA LAE

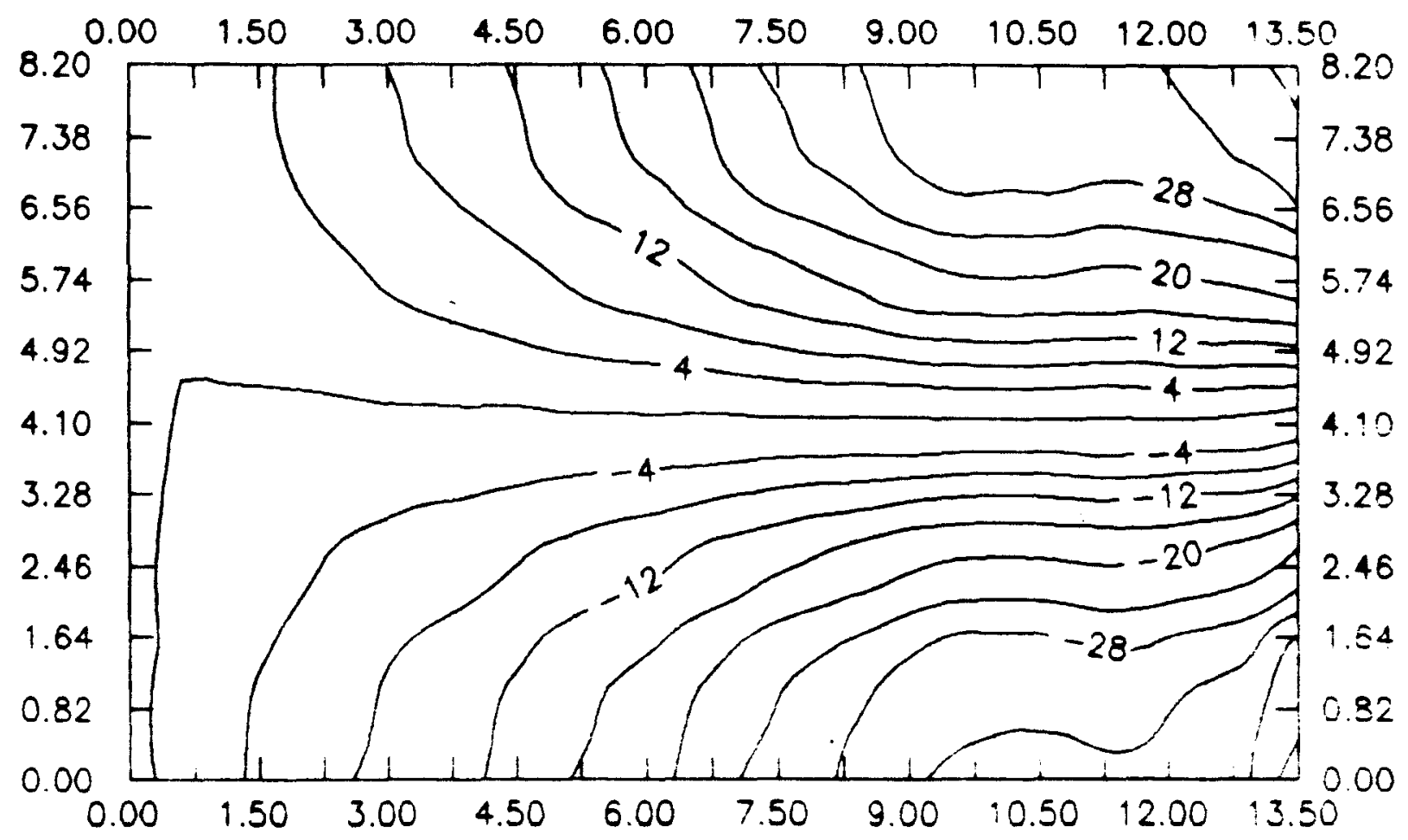

ISO-MOMENTOS NA DIRECAO XY - VEICULO NO CENTRO DO VAO E BORDO DA LAUE 
SISTEMA ESTRUTURAL COM CONTINUIDADE ISO-MOMENTOS NA LAJE E NOS ENCONTROS NAS DIRECOES $X, Y E X Y$ 


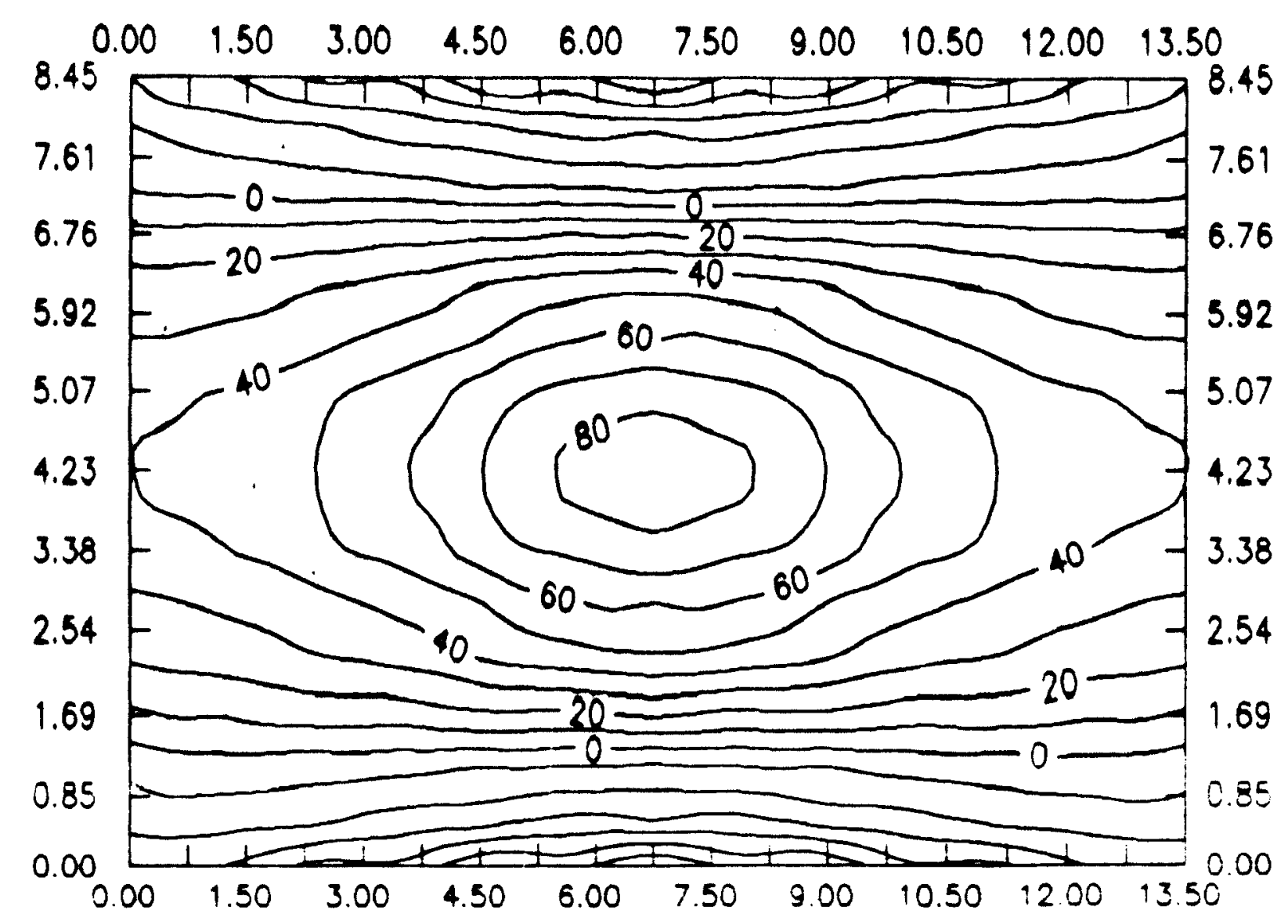

ISO-MOMENTOS NA DIRECAO X - VEICULO NO CENTRO dO VAO E MEIO DA LAJE

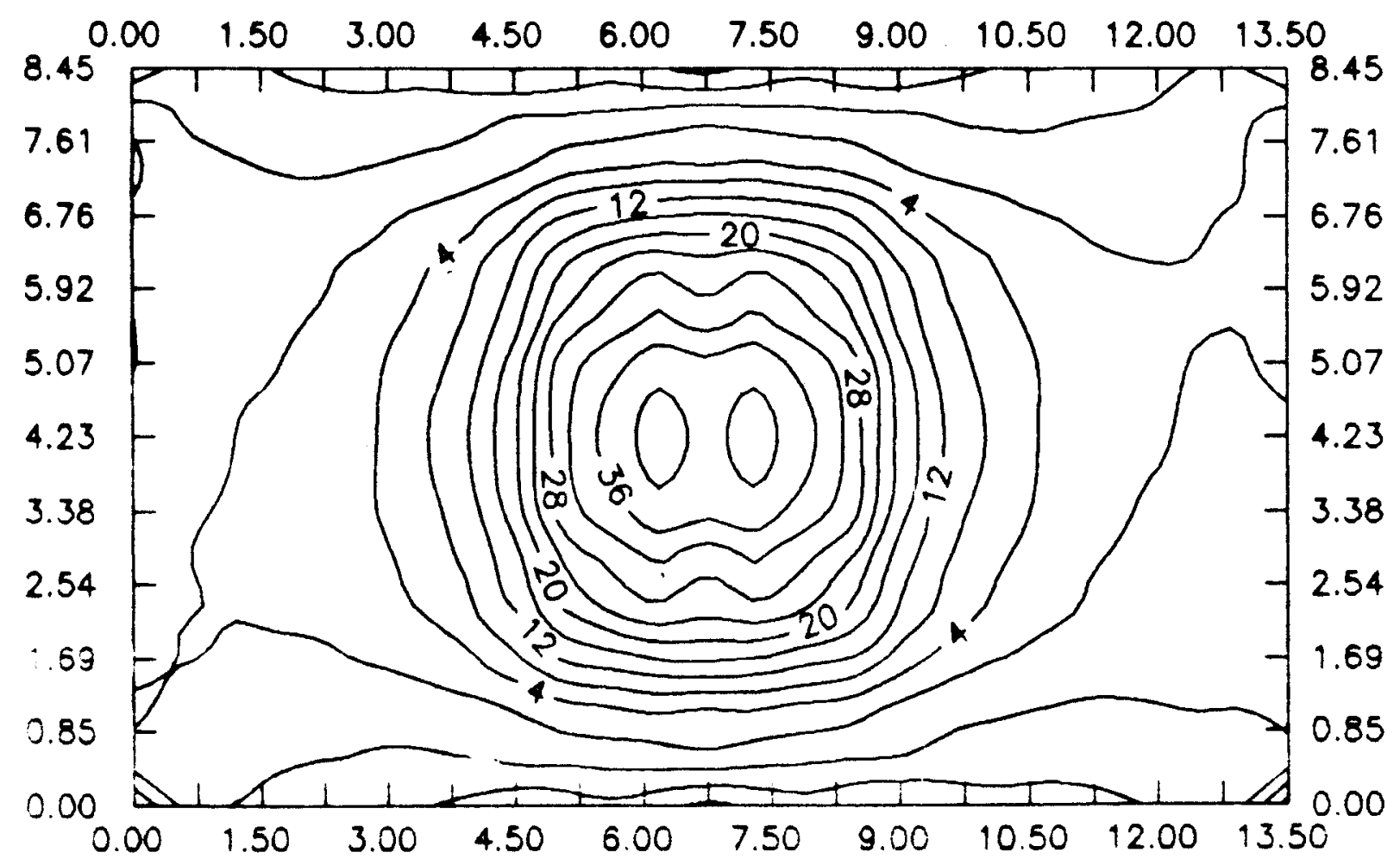

ISO-MOMENTOS NA DIRECAO Y - VEICULO NO CENTRO DO VAO E MEIO DA LAJE 


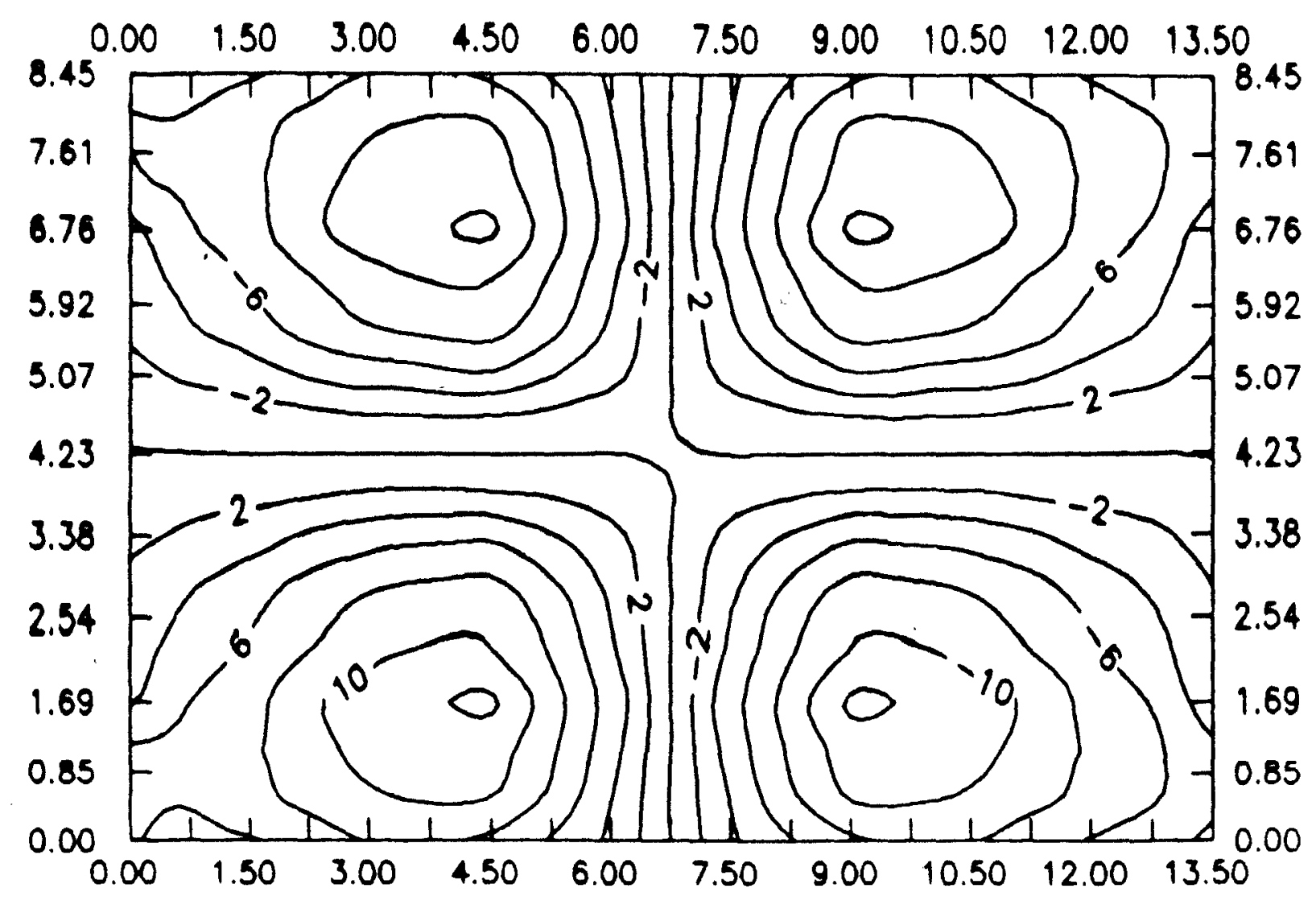

ISO-MOMENTOS NA DIRECAO XY - VEICULO NO CENTRO DO VAO E MEIO DA LAJE

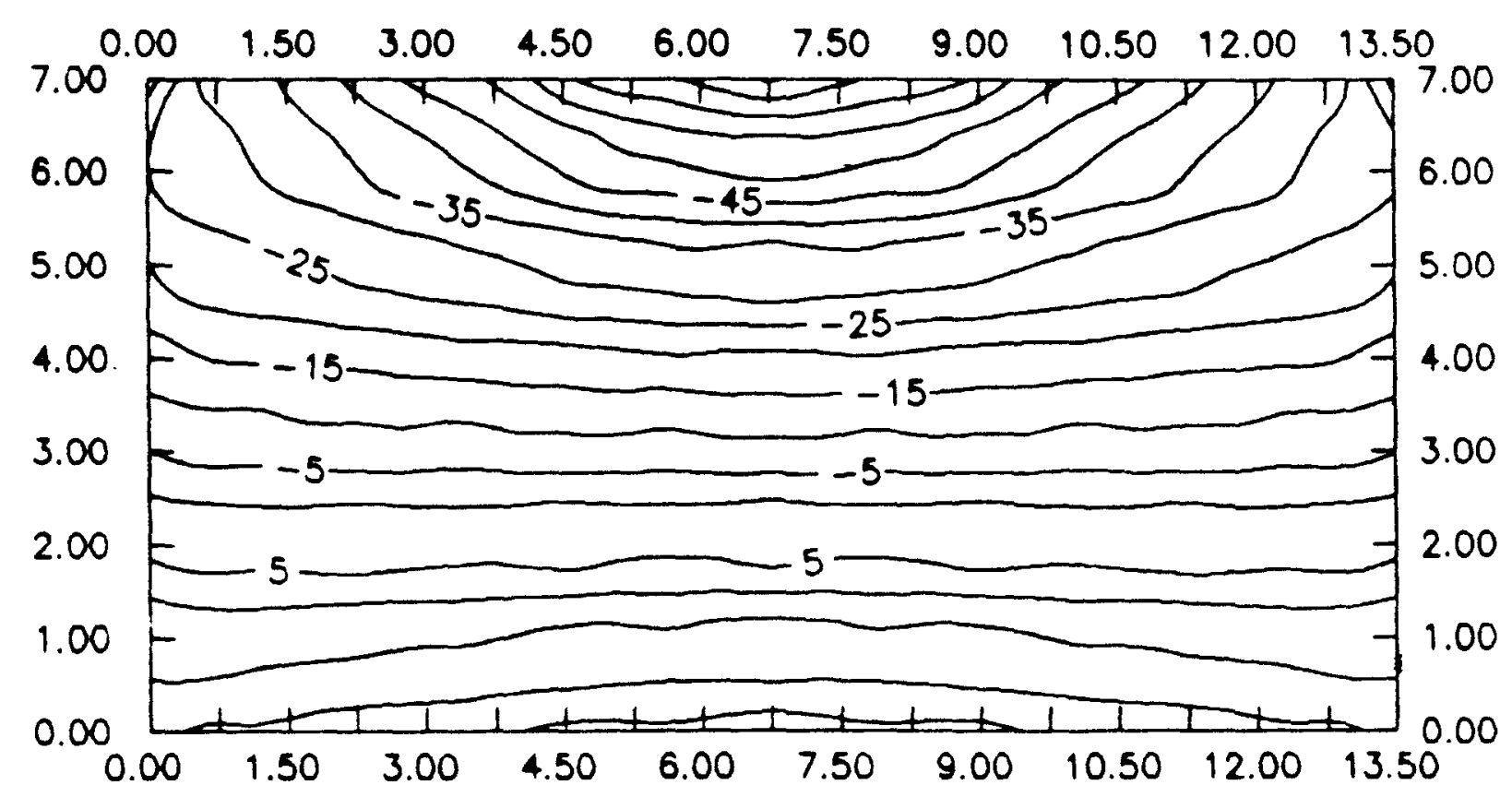

ISO-MOMENTOS NA DIRECAO X - VEICULO NO CENTRO dO VAO E MEIO DA LAJE 


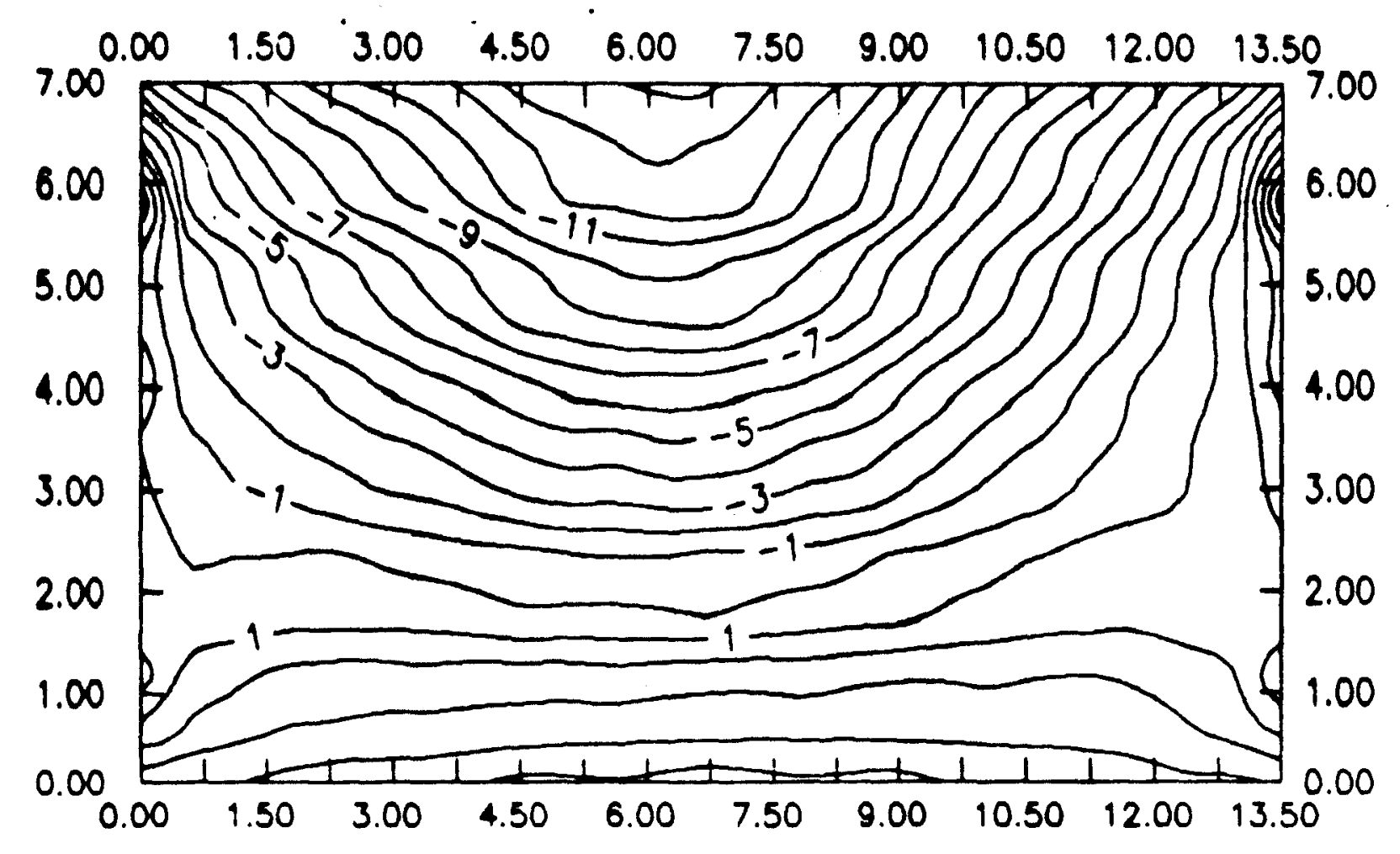

ISO-MOMENTOS NA DIRECAO Y - VEICULO NO CENTRO DO VAO E MEIO DA LAJE

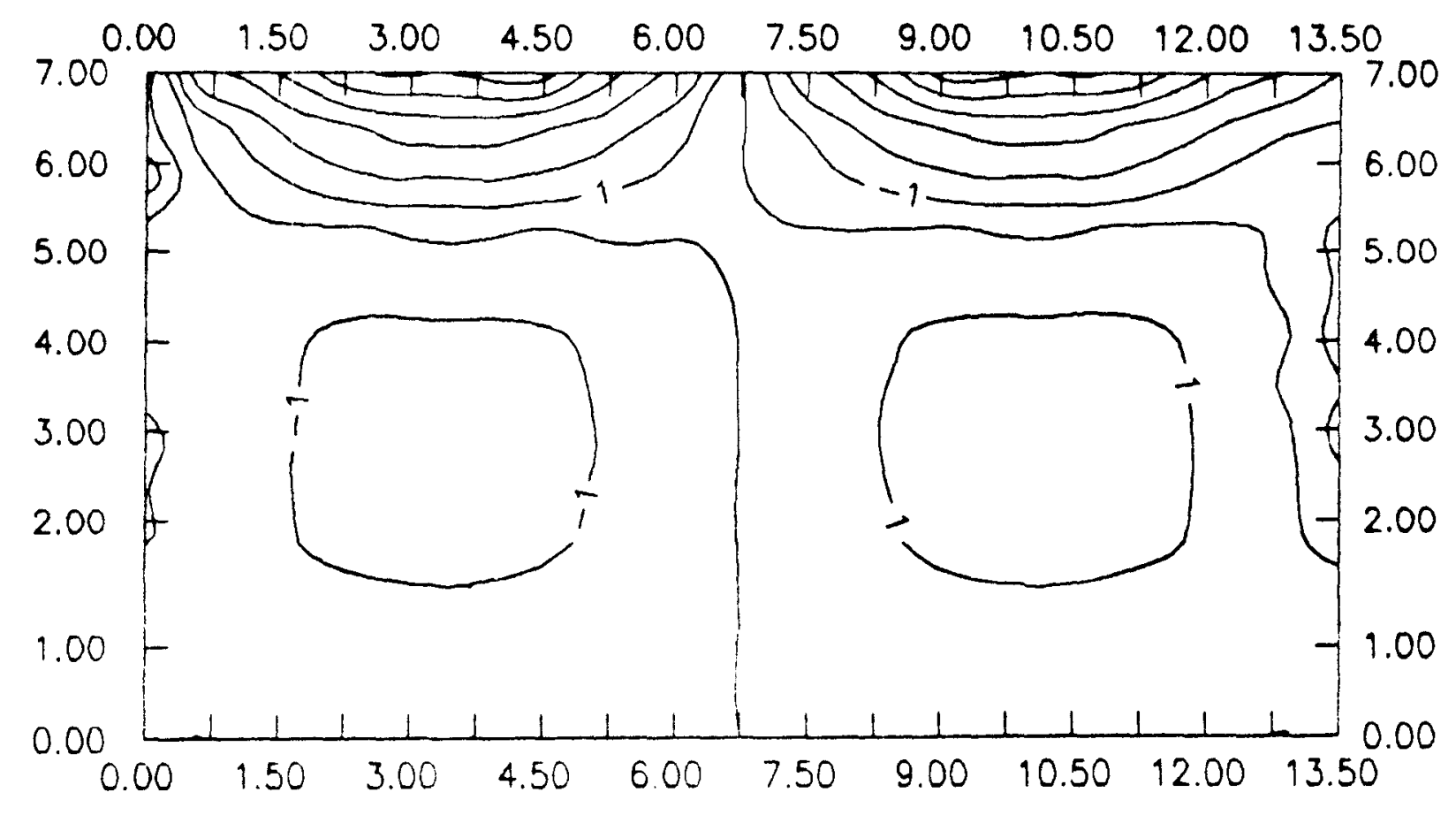

ISO-MOMENTOS NA DIRECAO XY - VEICULO NO CENTRO DO VAO E MEIO DA LAJE 


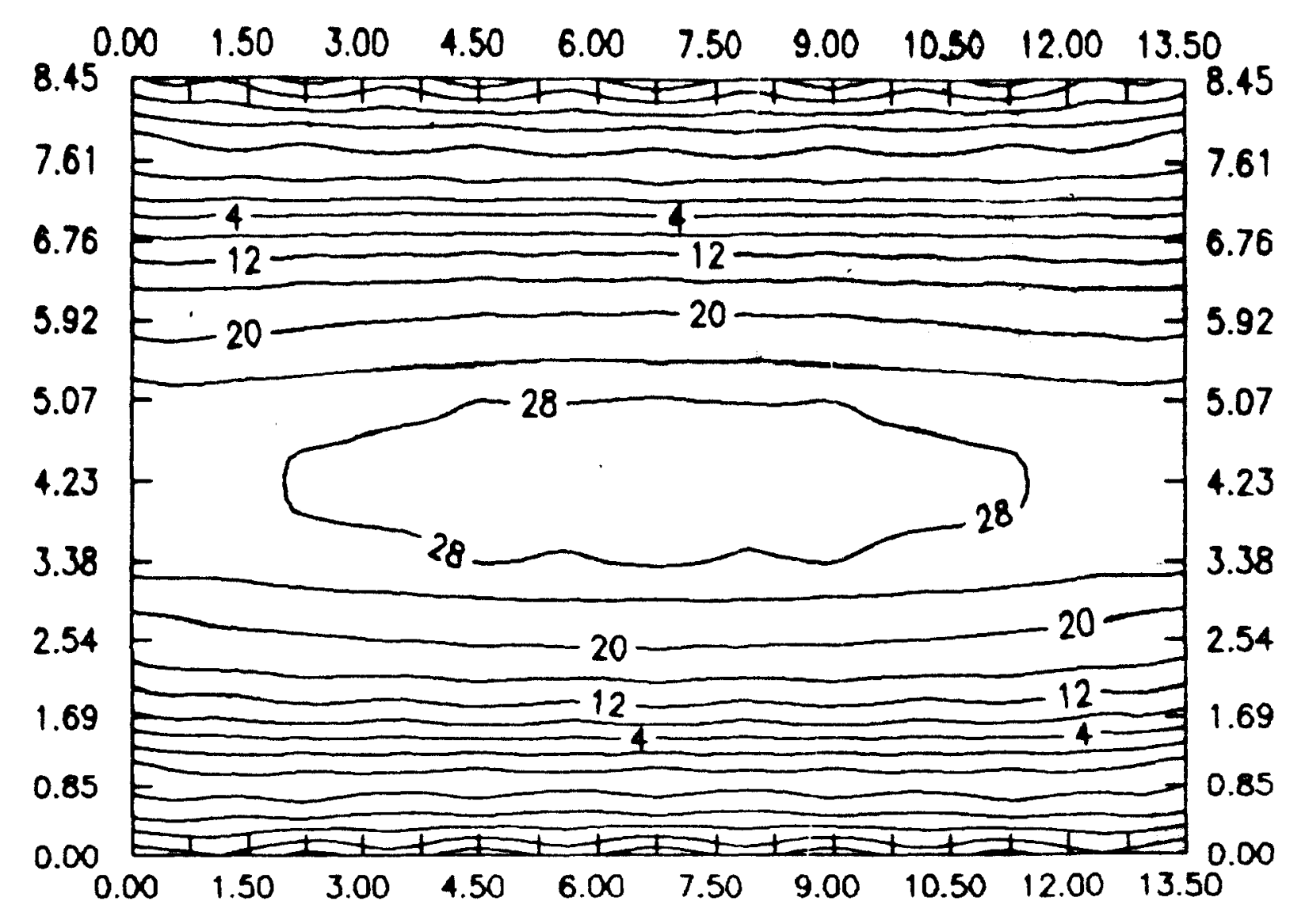

ISO-MOMENTOS NA DIRECAO X - VEICULO A 1/3 DO VAO E NO MEIO DA LAJE

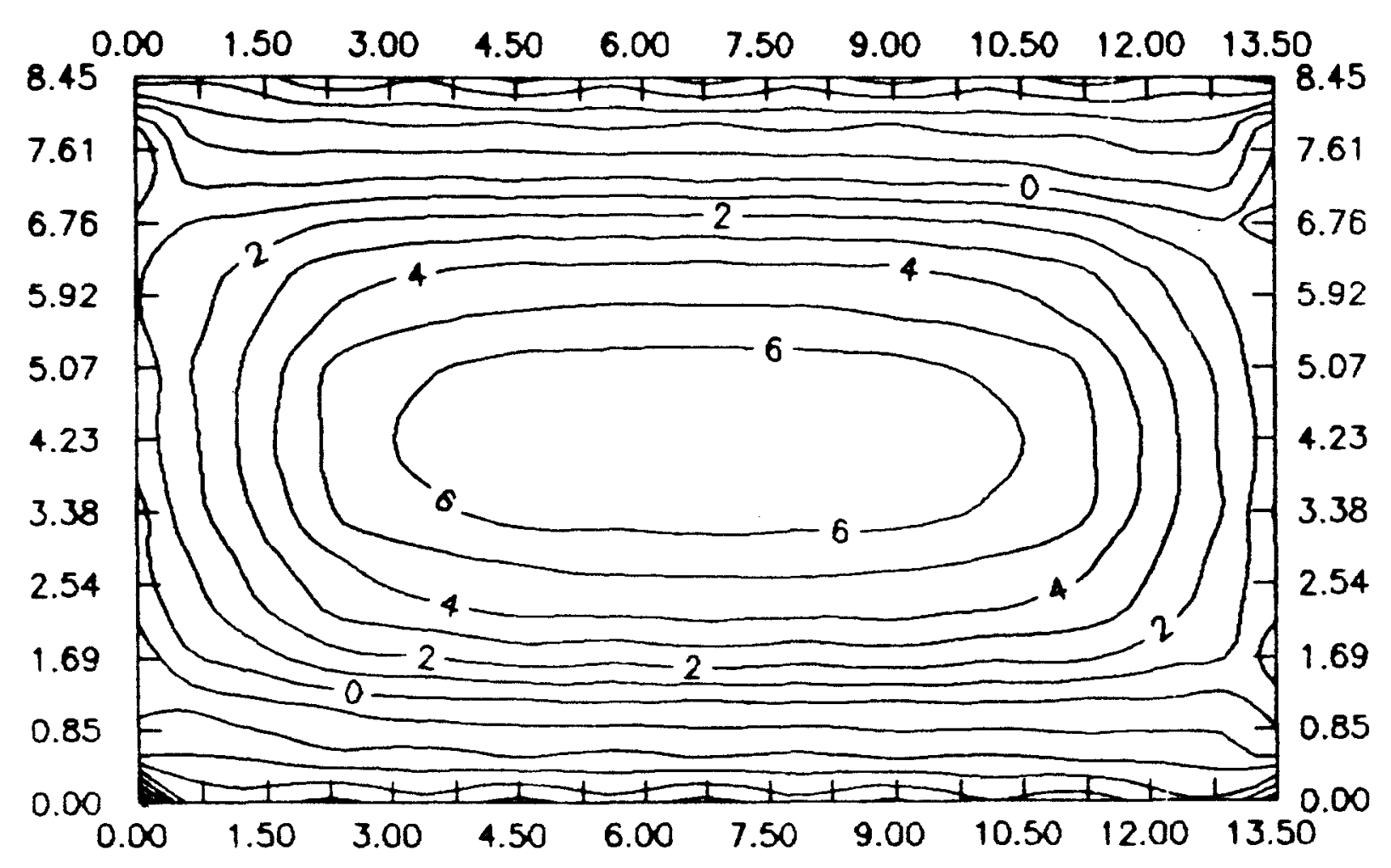

ISO-MOMENTOS NA DIRECAO Y - VEICULO A 1/3 DO VAO E NO MEIO DA LUNE 


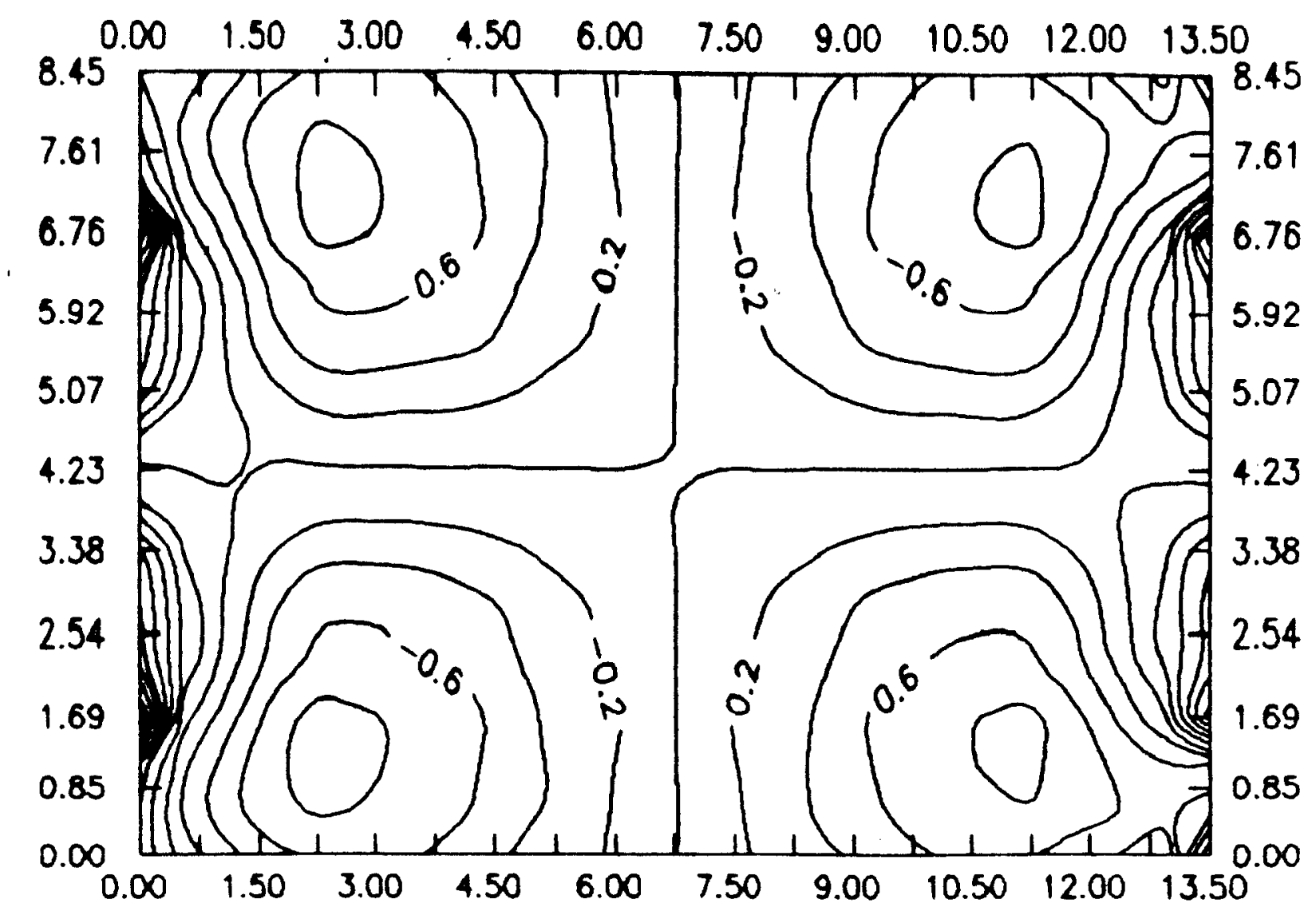

ISO-MOMENTOS NA DIRECAO XY - VEICULO A 1/3 DO VAO E NO MEIO DA LANE

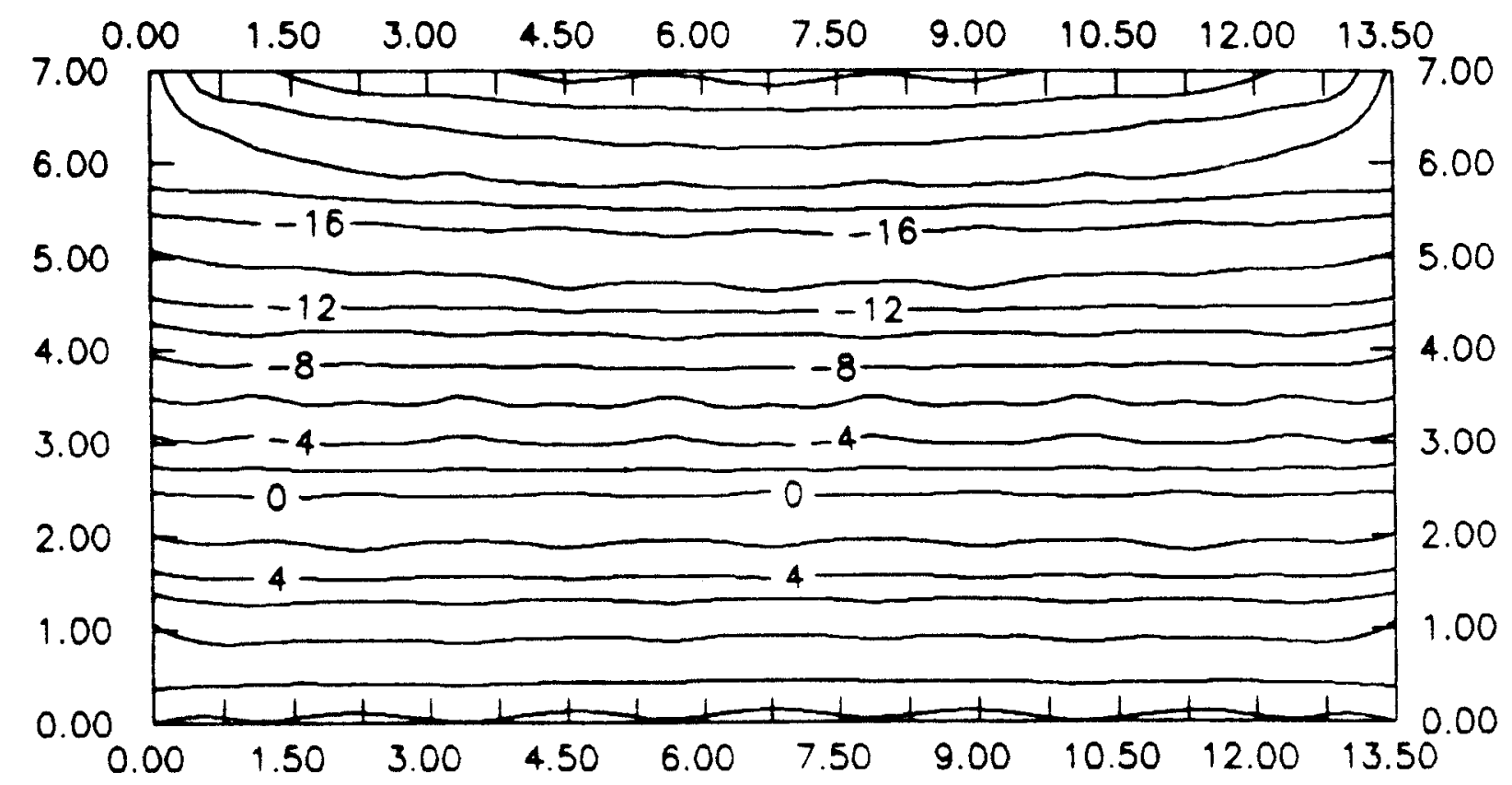

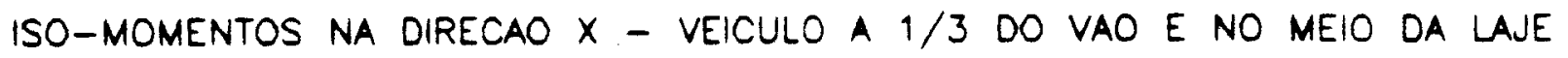




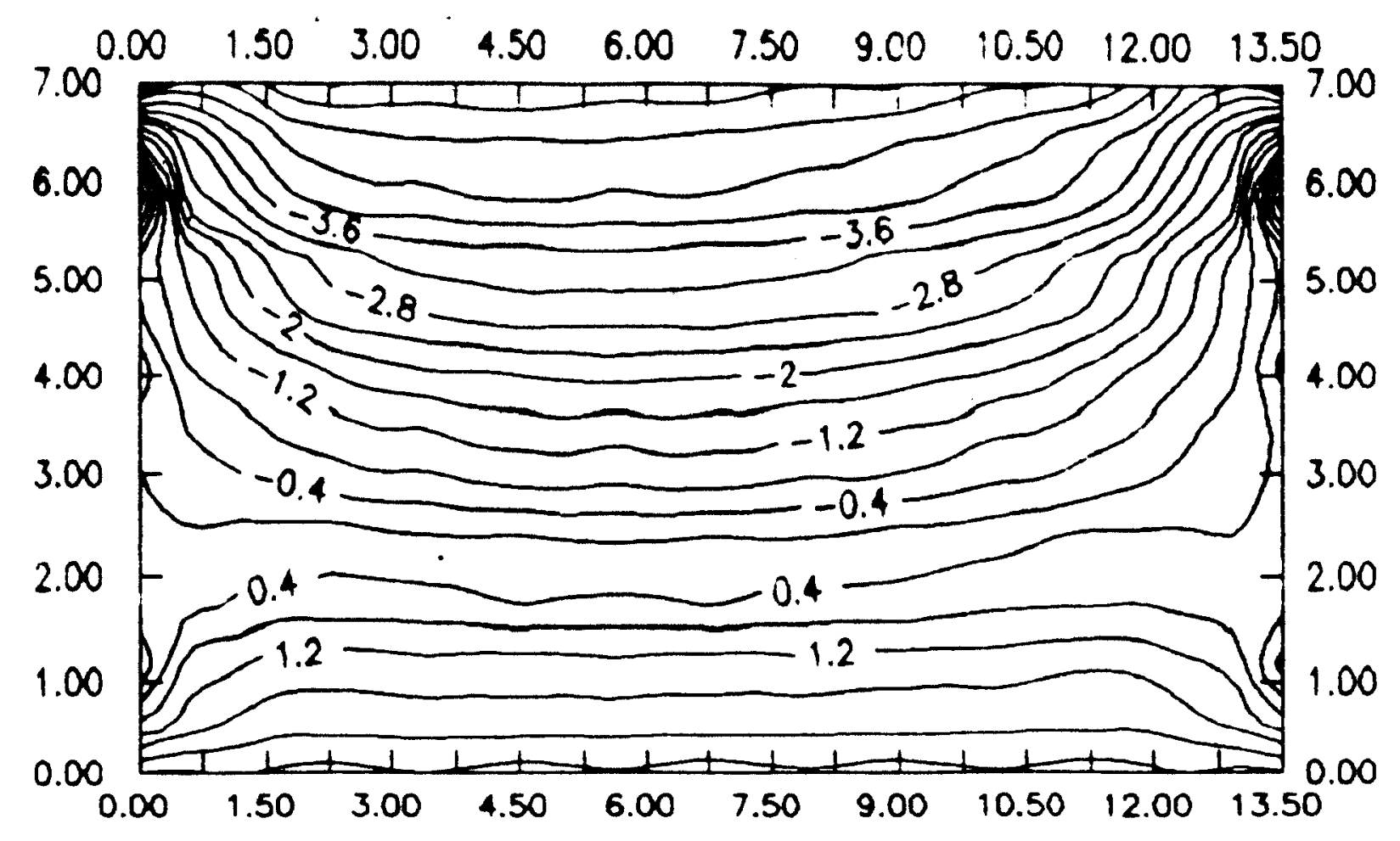

ISO-MOMENTOS NA DIRECAO Y - VEICULO A 1/3 DO VAO E NO MEIO DA LAJE

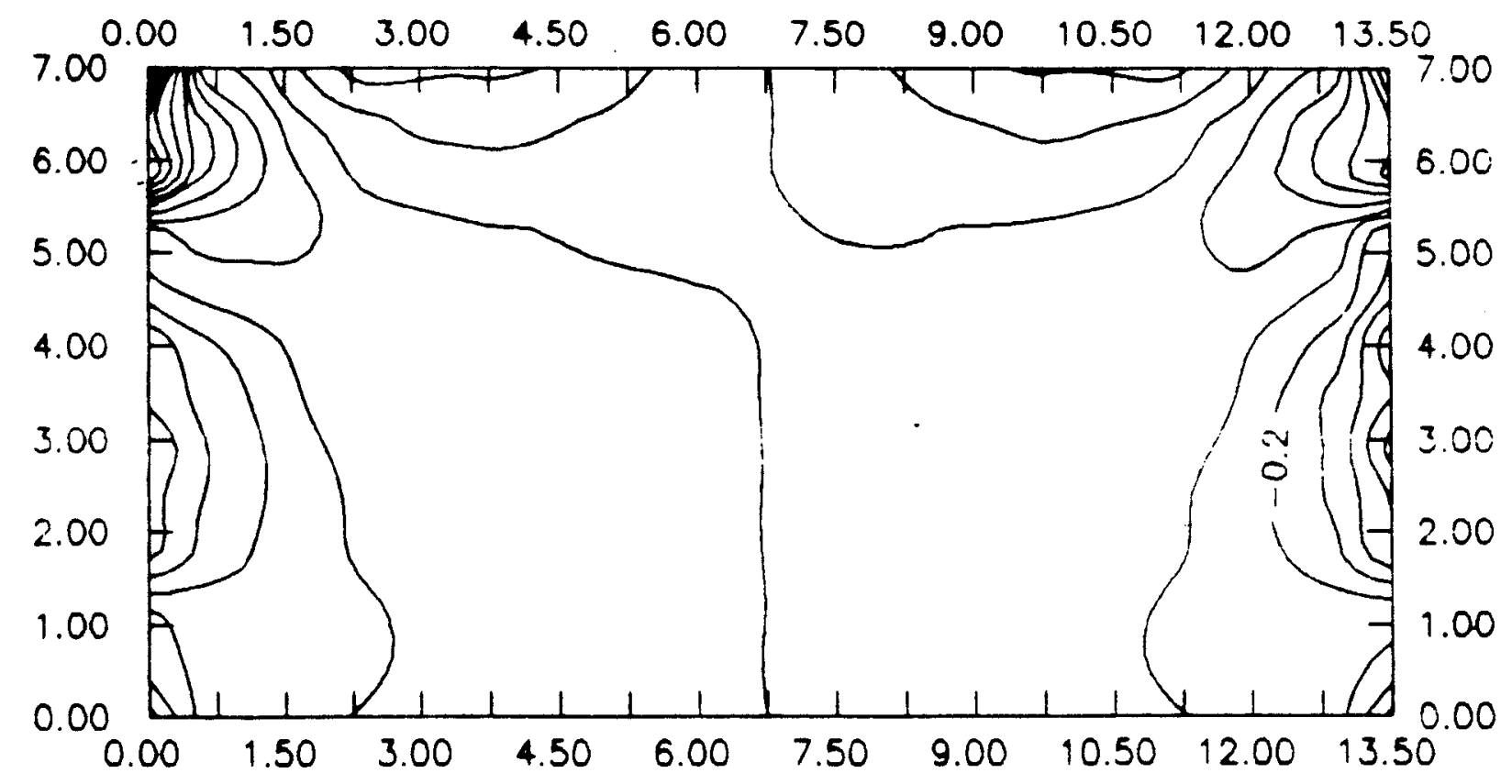

ISO-MOMENTOS NA DIRECAO XY - VEICULO A $1 / 3$ DO VAO E NO MEIO DA LAJE 


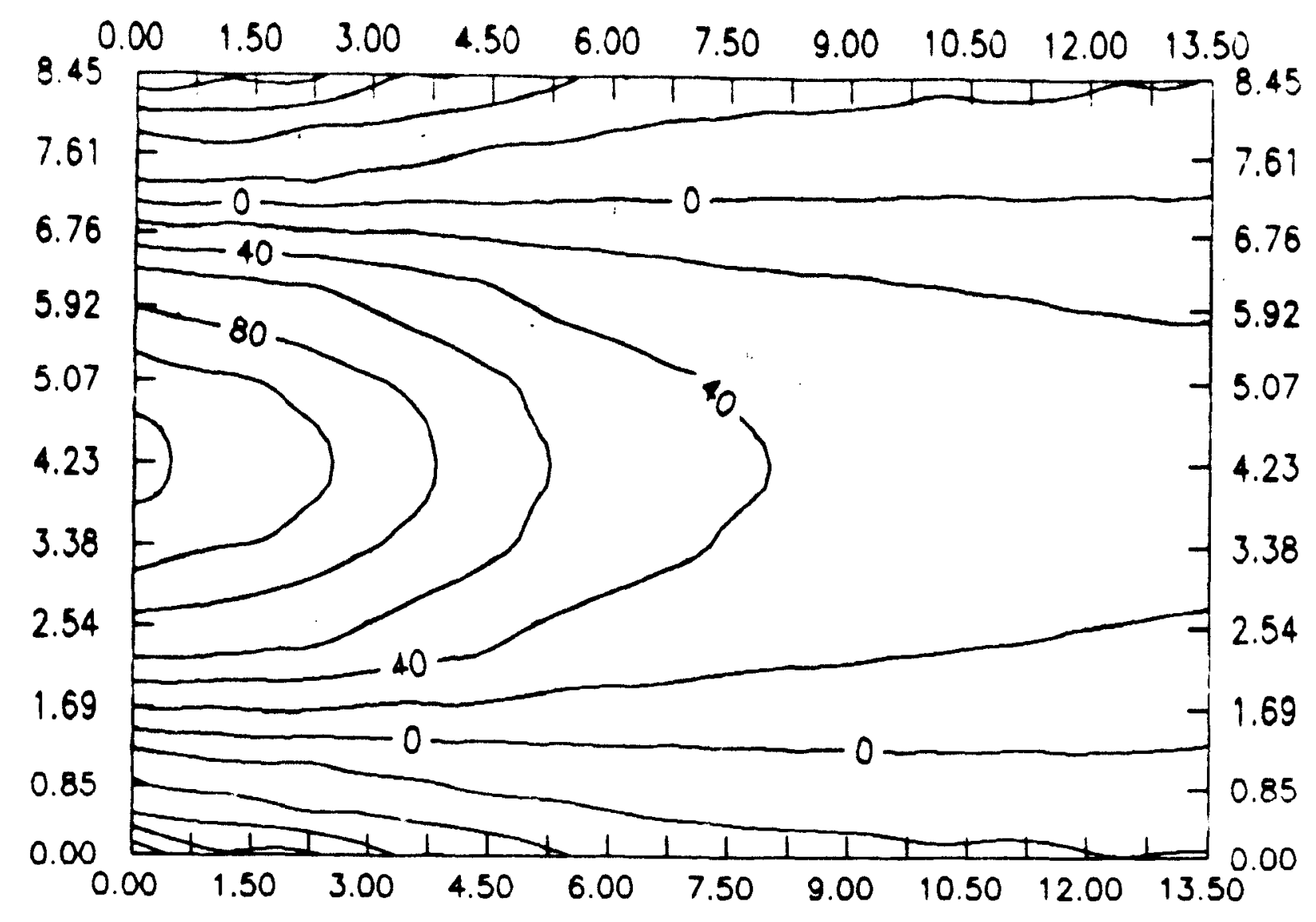

ISO-MOMENTOS NA DIRECAO X - VEICULO NO CENTRO DO VAO E BORDO DA LAJE

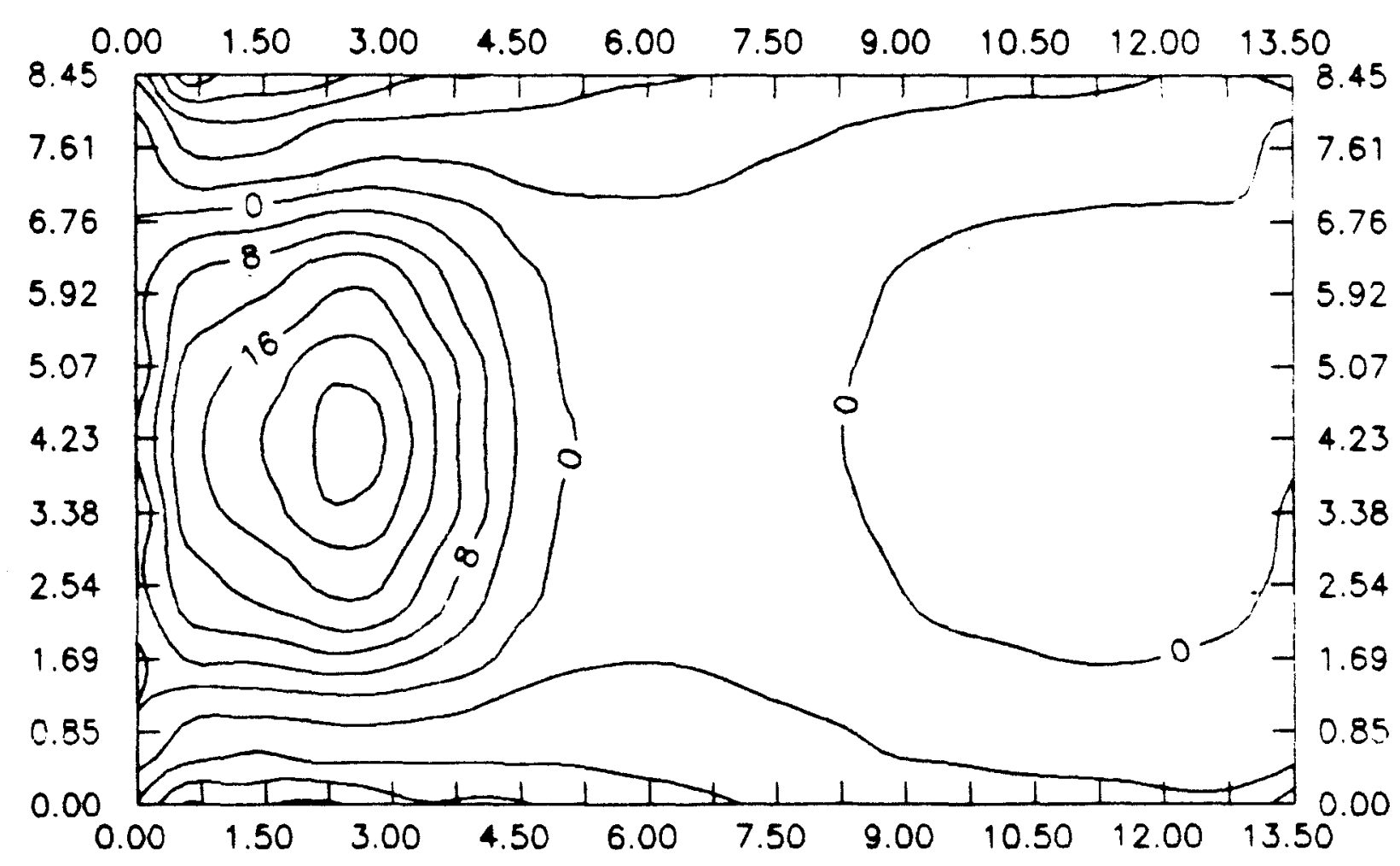

ISO-MOMENTOS NA DIRECAO Y - VEICULO NO CENTRO DO VAO E BORDO DA LAJE 


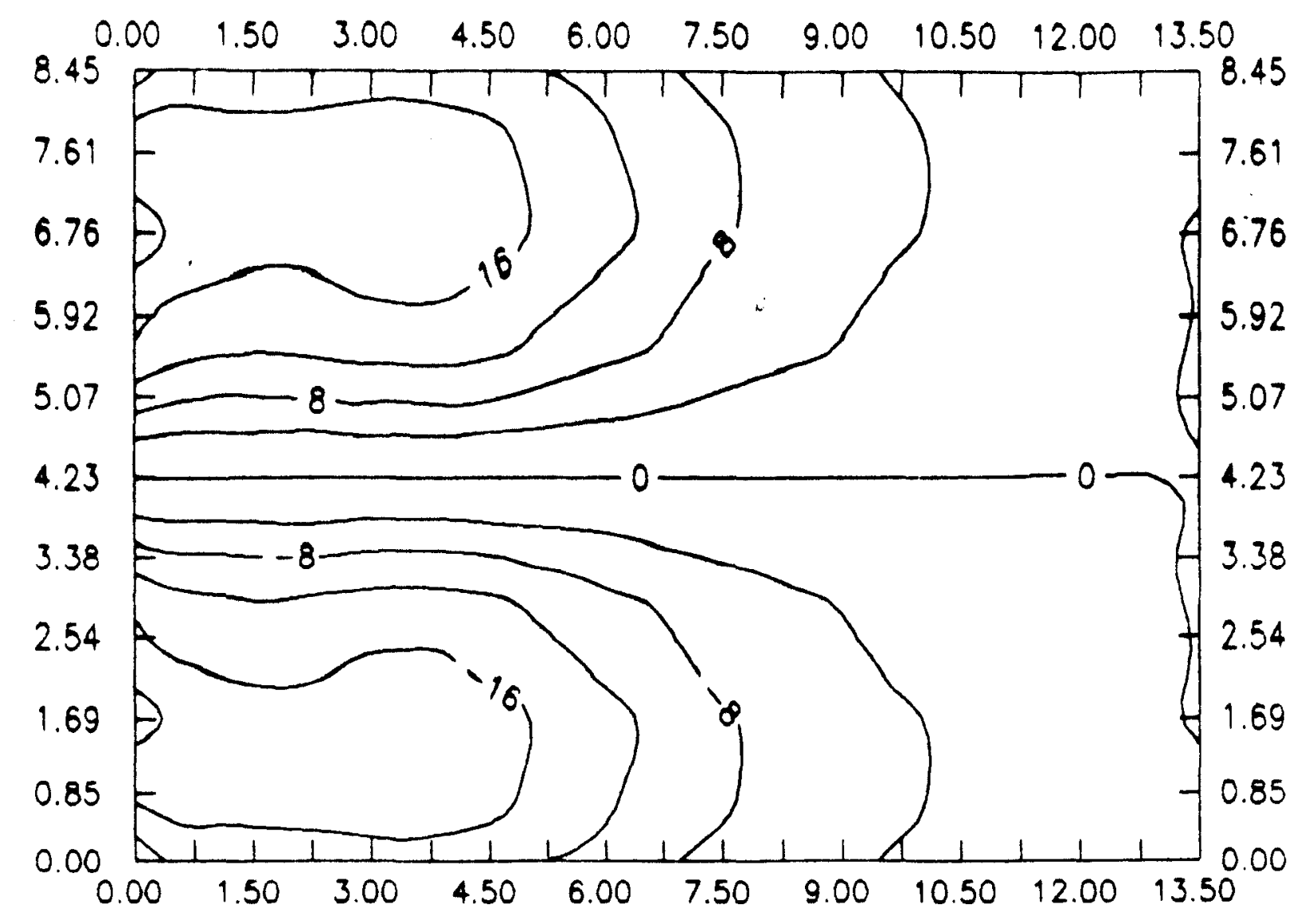

ISO-MOMENTOS NA DIRECAO XY - VEICULO NO CENTRO DO VAO E BORDO DA LAJE

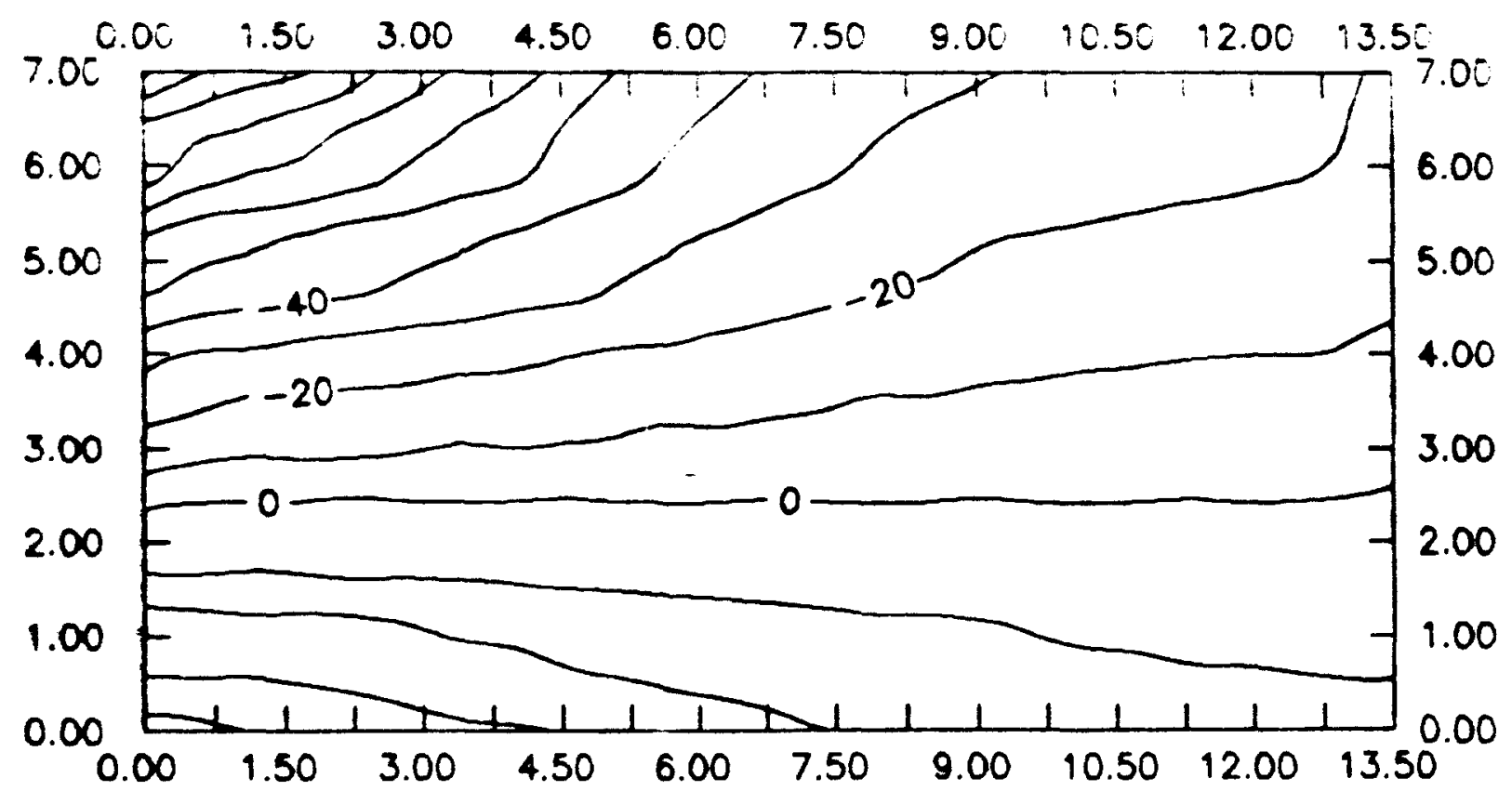

ISO-MOMENTOS NA DIRECAO X - VEICULO NO CENTRO DO VAO E BORDO DA LAJE 


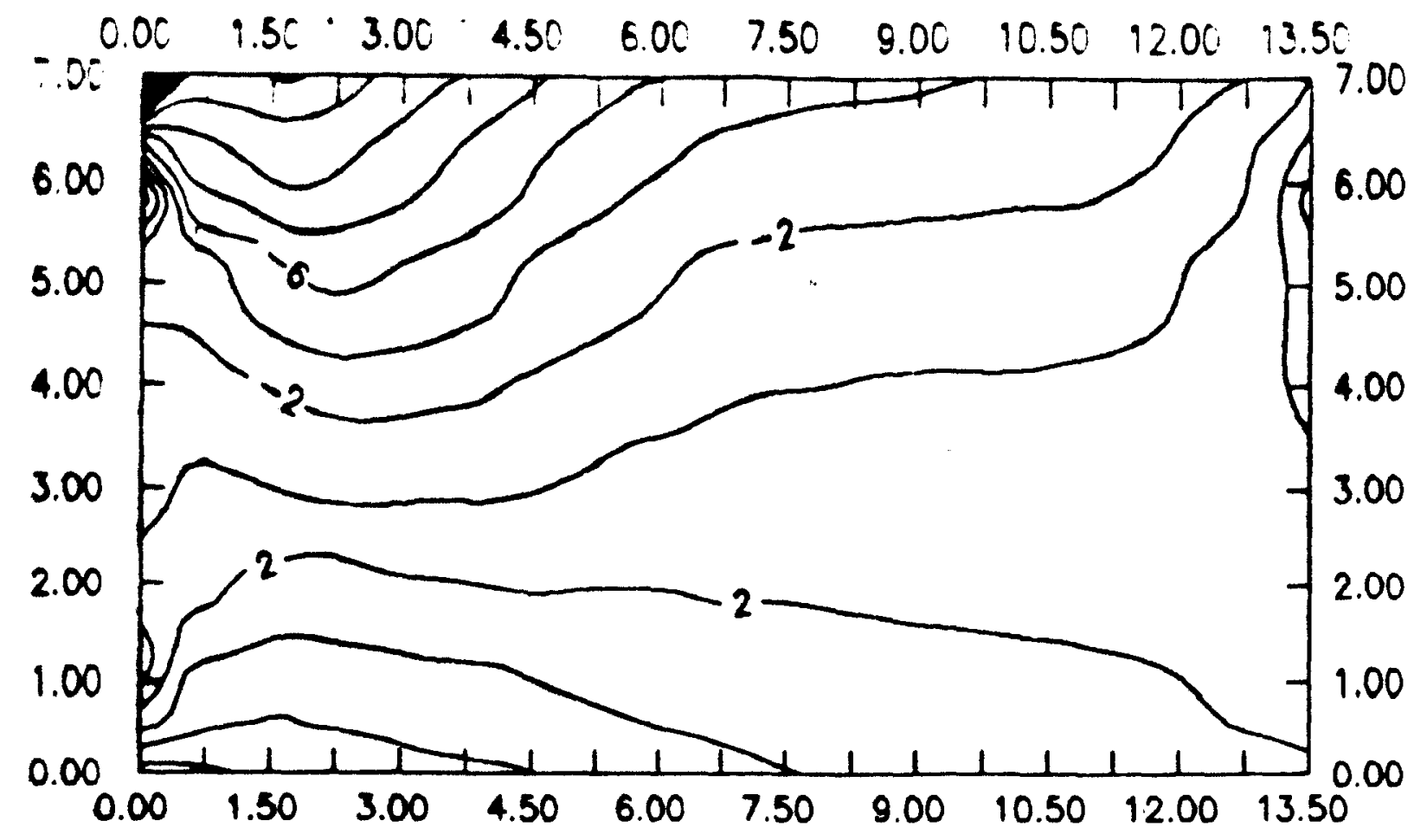

ISO-MOMENTOS NA DIRECAO Y - VEICULO NO CENTRO DO VAO E BORDO DA LANE

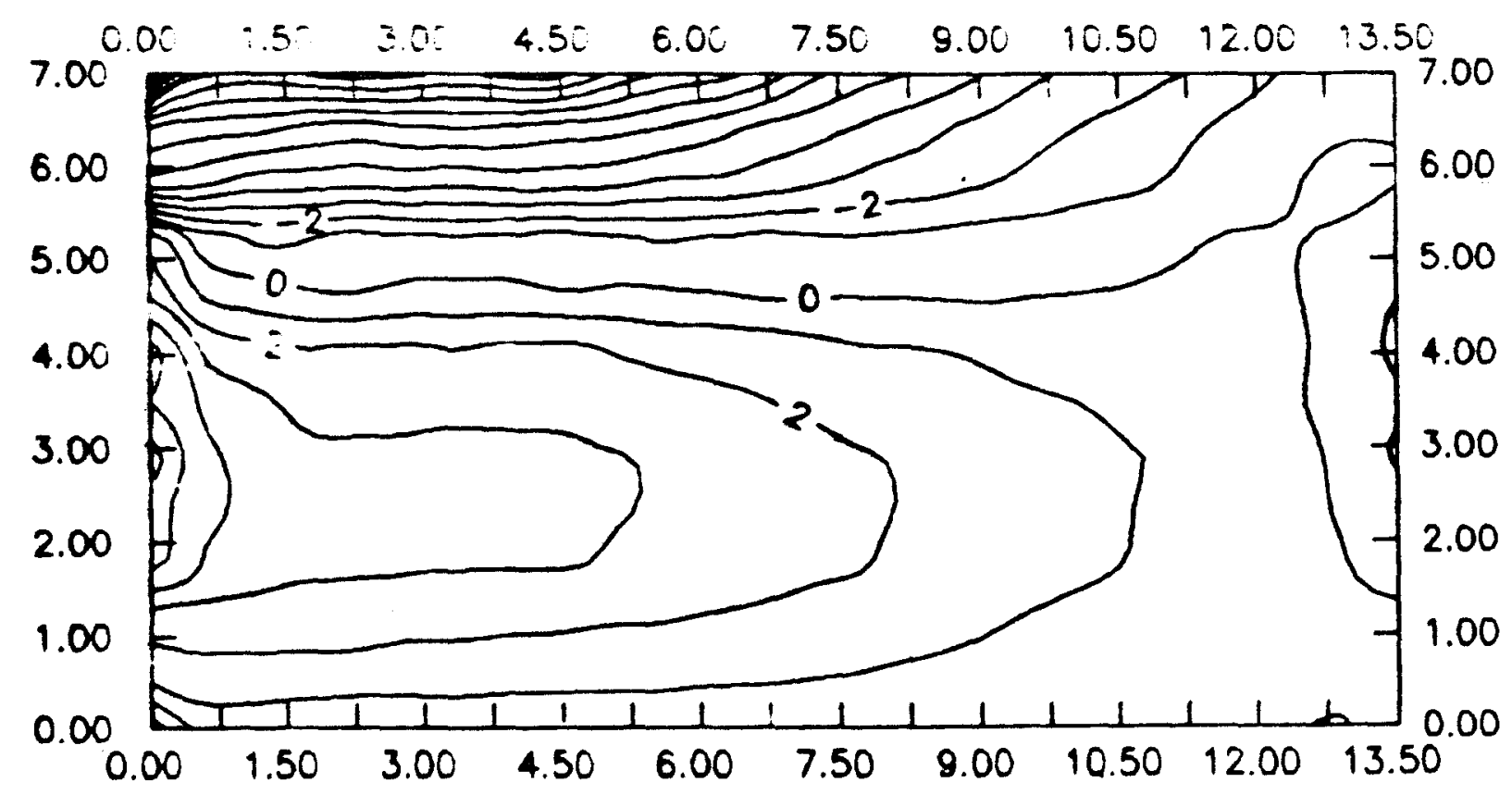

ISO-MOMENTOS NA DIRECAO XY - VEICULO NO CENTRO DO VAO E BORDO DA LAJE 


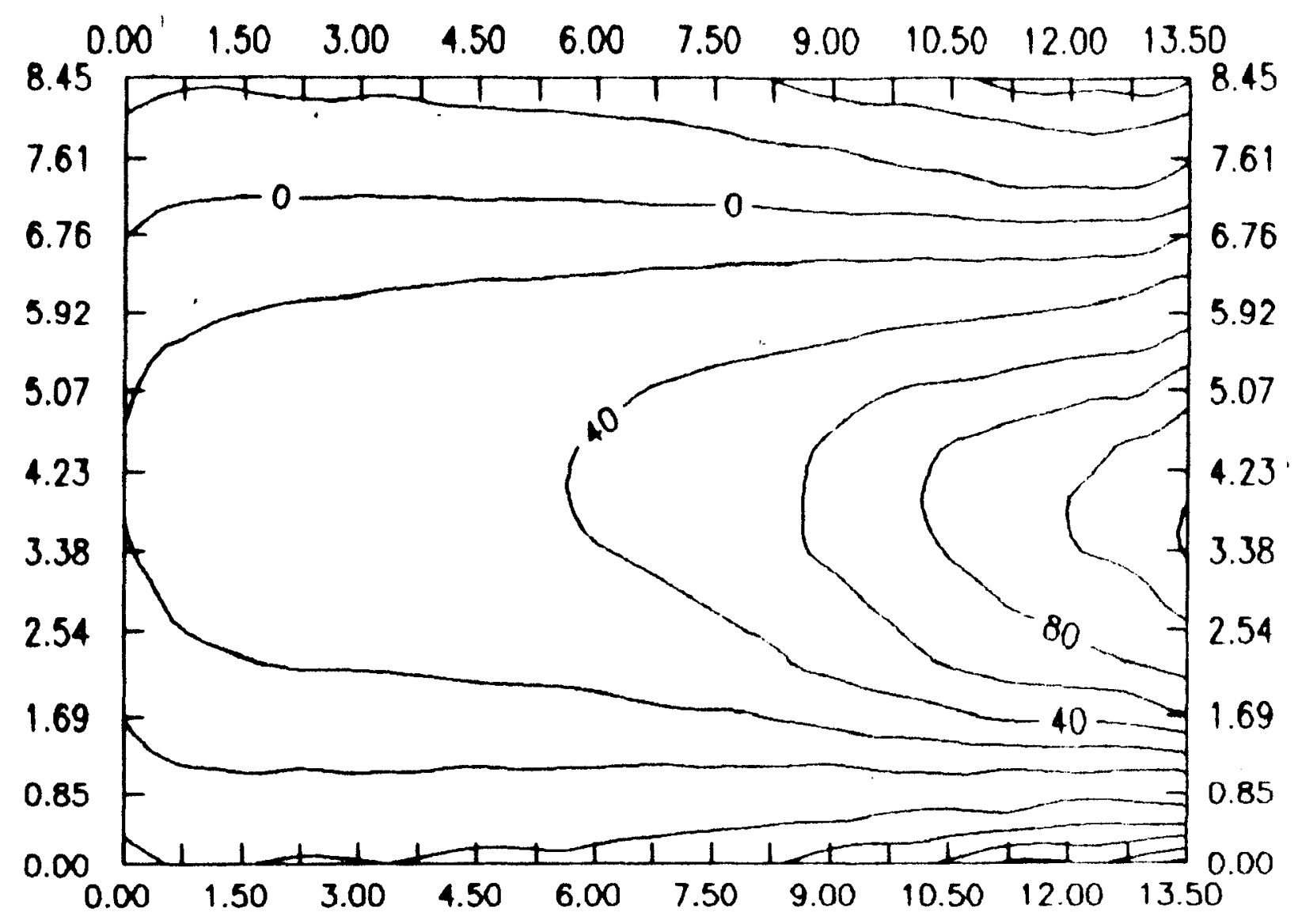

ISO-MOMENTOS NA DIRECAO $X$ - VEICULO A 1/3 DO VAO E BORDO DA LANE

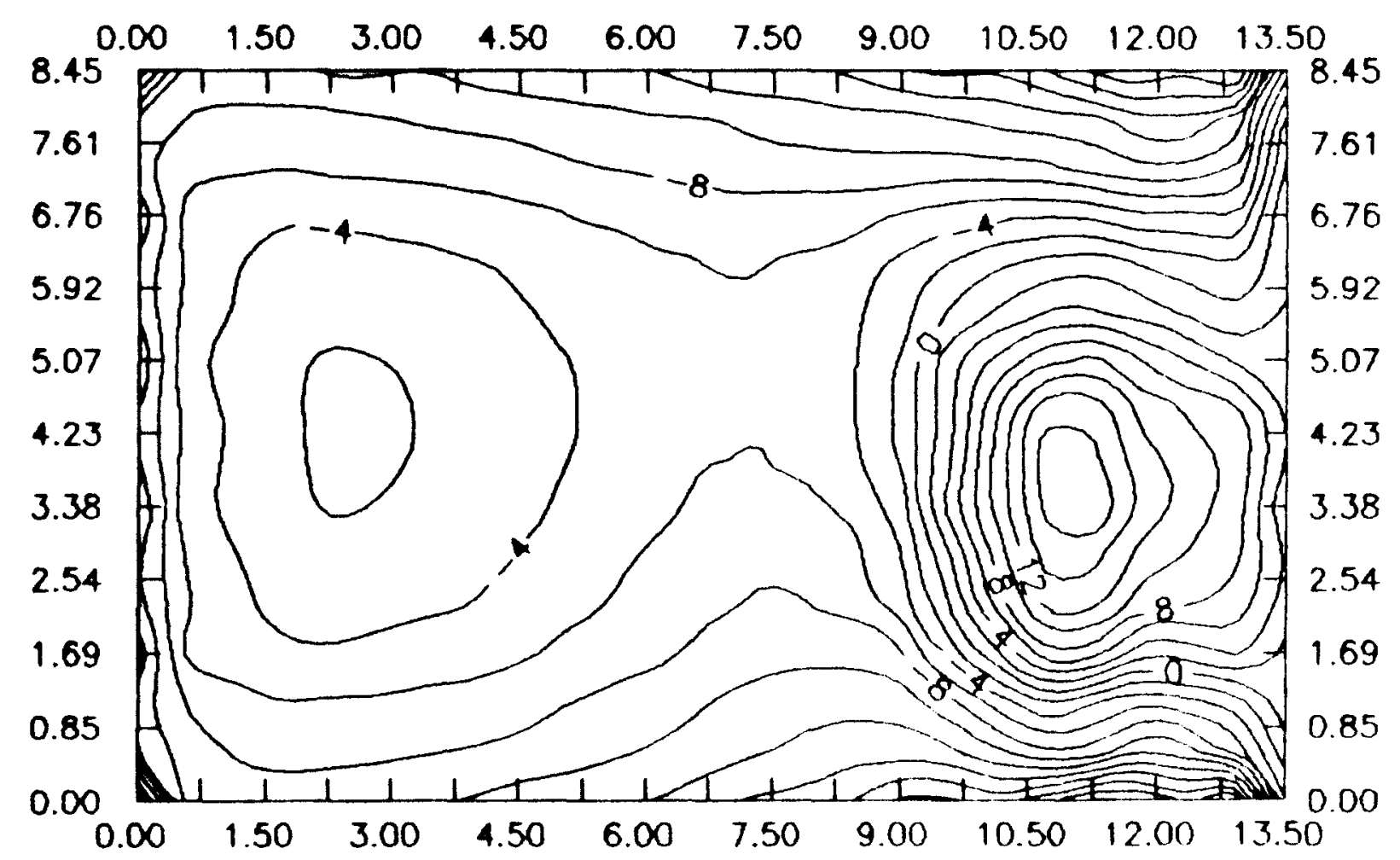

ISO-MOMENTOS NA DIRECAO Y - VEICULO A 1/3 DO VAO E BORDO DA LAJE 


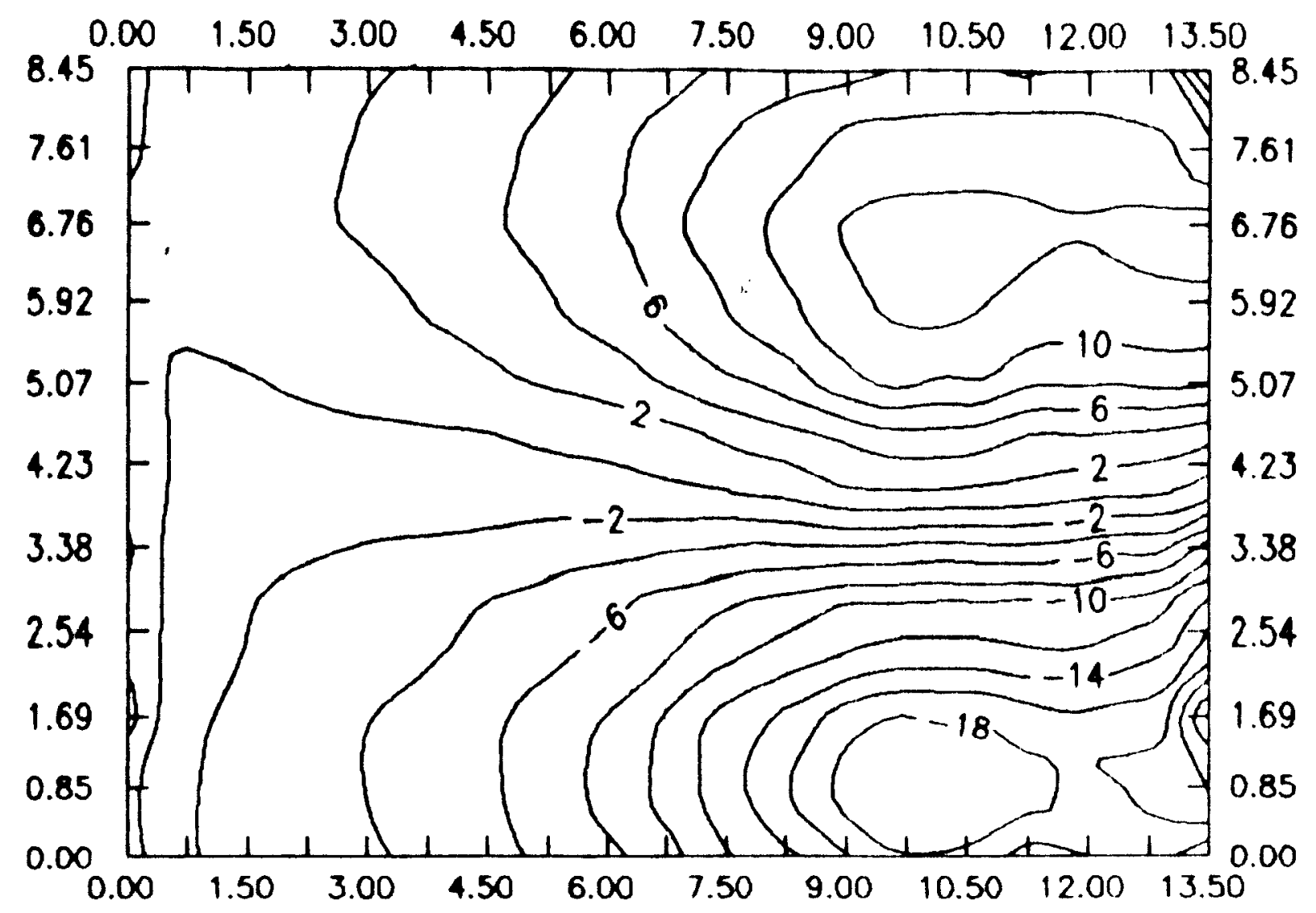

ISO-MOMENTOS NA DIRECAO XY - VEICULO A $1 / 3$ DO VAO E BORDO DA LAJE

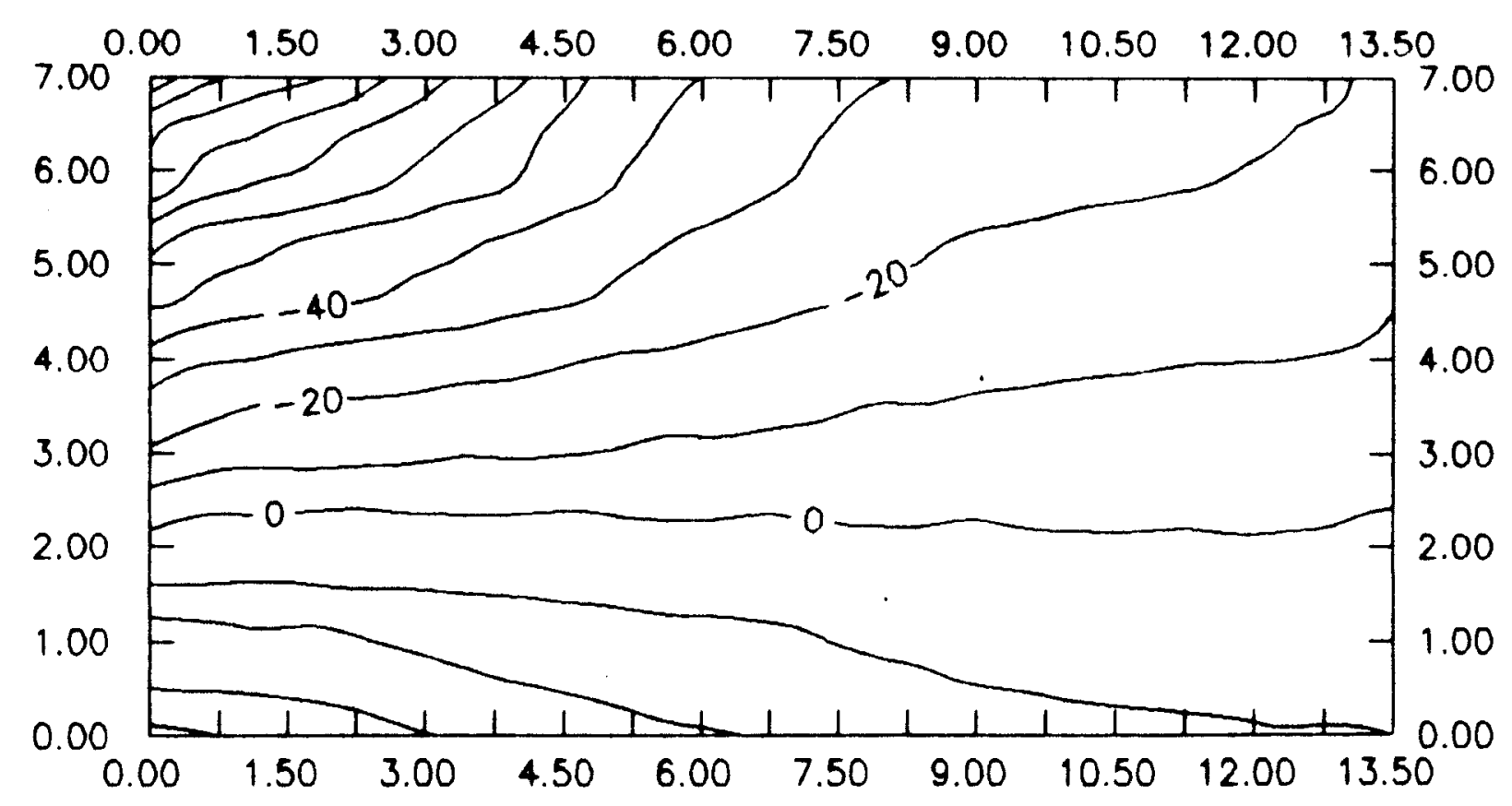

ISO-MOMENTOS NA DIRECAO X - VEICULO A $1 / 3$ DO VAO E BORDO DA LAJE 


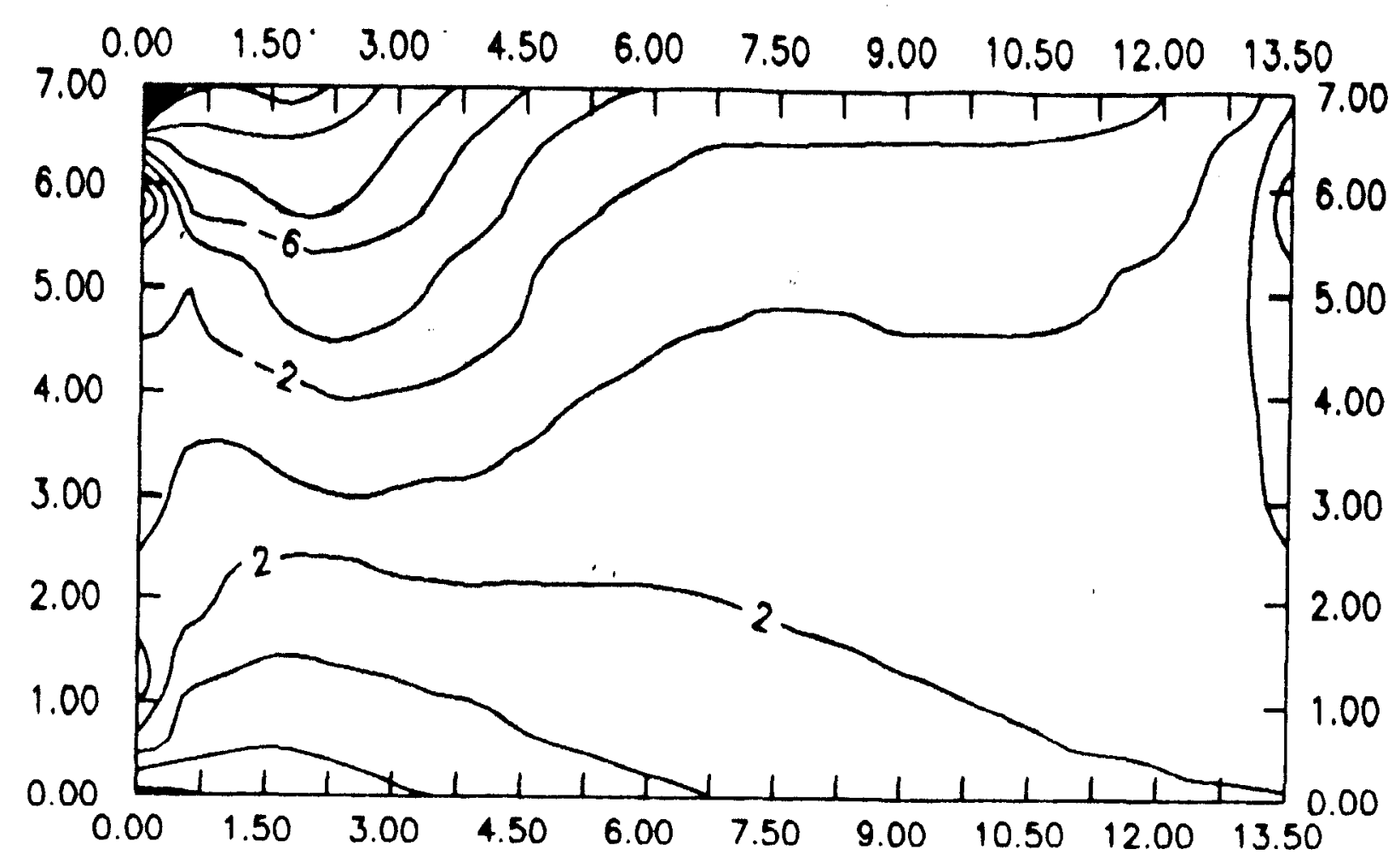

ISO-MOMENTOS NA DIRECAO Y - VEICULO A 1/3 DO VAO E SORDO DA LANE

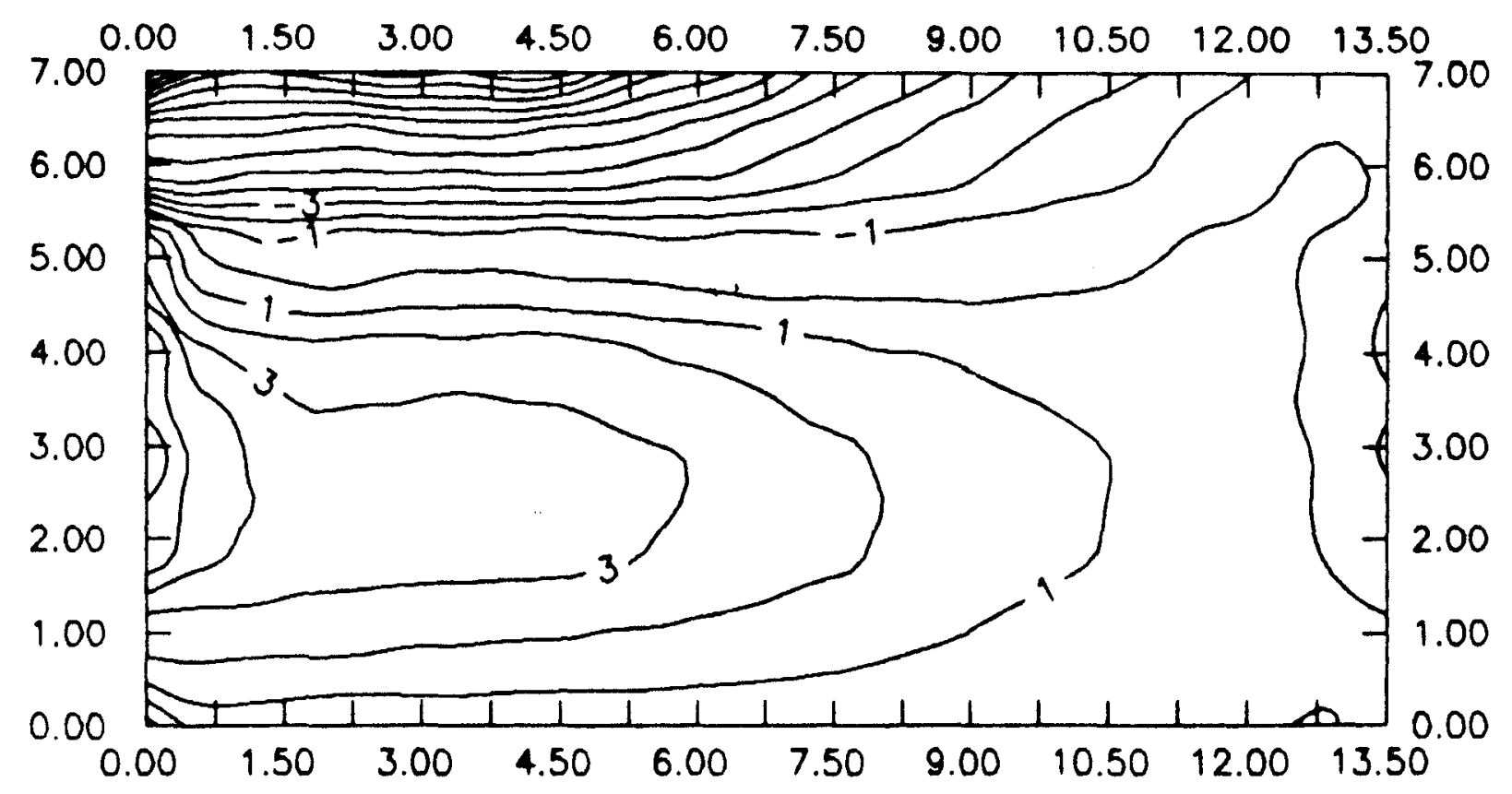

ISO-MOMENTOS NA DIRECAO XY - VEICULO A $1 / 3$ DO VAO E BORDO DA LAJE 


\begin{abstract}
ANEXO C
DETALHAMENTO DAS ESTRUTURAS UTILIZANDO-SE OS ESFORÇOS OBTIDOS COM O MÉTODO APROXIMADO
\end{abstract}




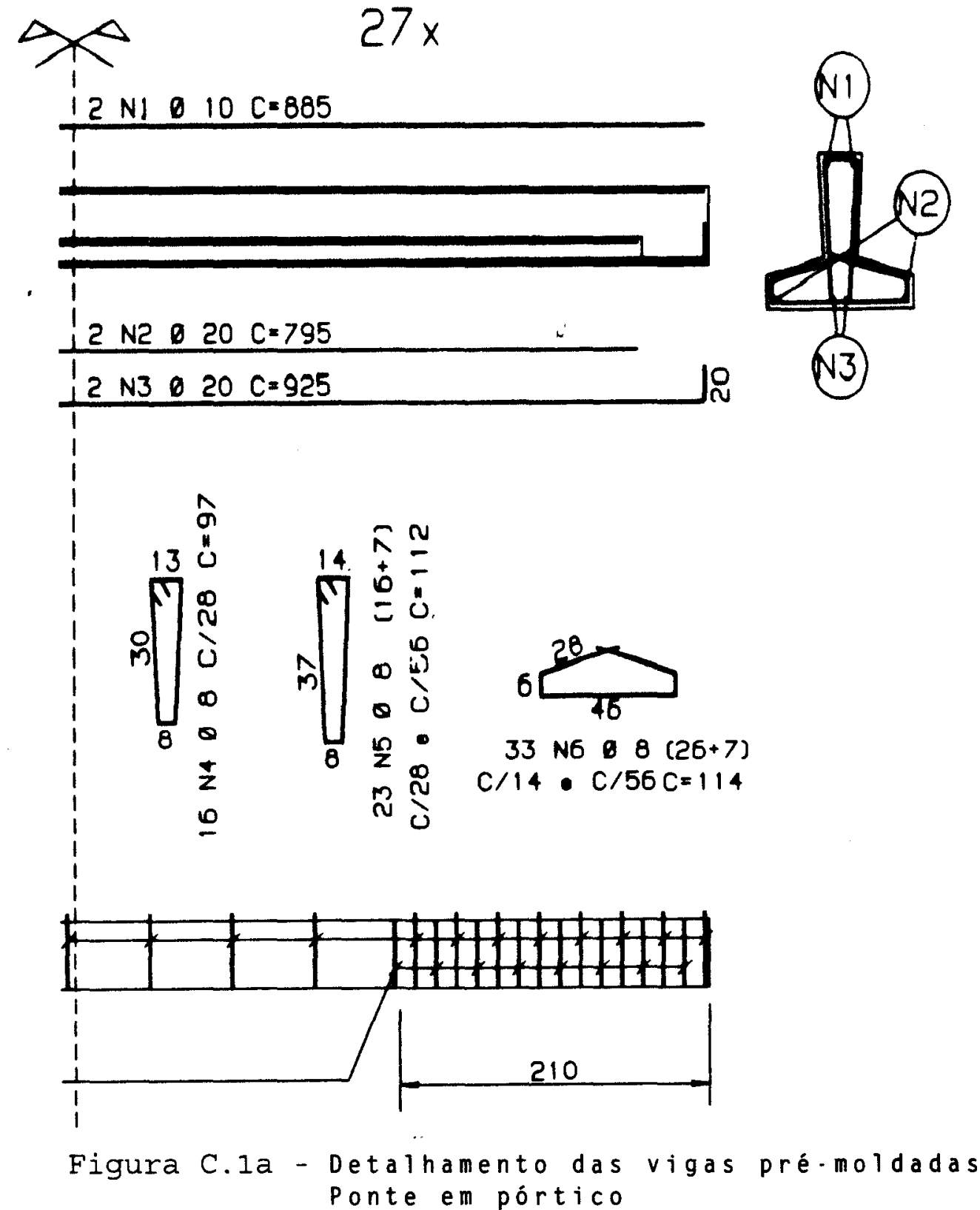

\begin{tabular}{|l|r|r|r|r|r|}
\hline ELEM & \multicolumn{3}{c|}{ POS. } \\
\hline & 1 & 10 & 54 & 885 & 47790 \\
& 2 & 20 & 54 & 795 & 42930 \\
& 3 & 20 & 54 & 925 & 49950 \\
& 4 & 8 & 432 & 97 & 41904 \\
& 5 & 8 & 621 & 112 & 69552 \\
& 6 & 8 & 691 & 114 & 101574 \\
\hline
\end{tabular}

\begin{tabular}{|c|c|c|c|}
\hline $\mathrm{ACO}$ & $\begin{array}{l}\text { RESL } \\
\text { BIT. } \\
(\mathrm{mm})\end{array}$ & $\begin{array}{c}O A C O C A \\
\text { COMPR. } \\
(\mathrm{m})\end{array}$ & $\begin{array}{r}50-60 \\
\text { PESO } \\
(\mathrm{kg})\end{array}$ \\
\hline $\begin{array}{l}50 \mathrm{~A} \\
50 \mathrm{~A} \\
50 \mathrm{~A}\end{array}$ & $\begin{array}{r}8 \\
10 \\
20\end{array}$ & $\begin{array}{r}2130 \\
478 \\
929\end{array}$ & $\begin{array}{r}852 \\
301 \\
2322\end{array}$ \\
\hline \multicolumn{4}{|c|}{ Poso Totol $(C A 50 A)=$} \\
\hline
\end{tabular}

Figura C.1b - Tabela de ferros das vigas pré-moldadas da ponte em pórtico $(27 x)$ 


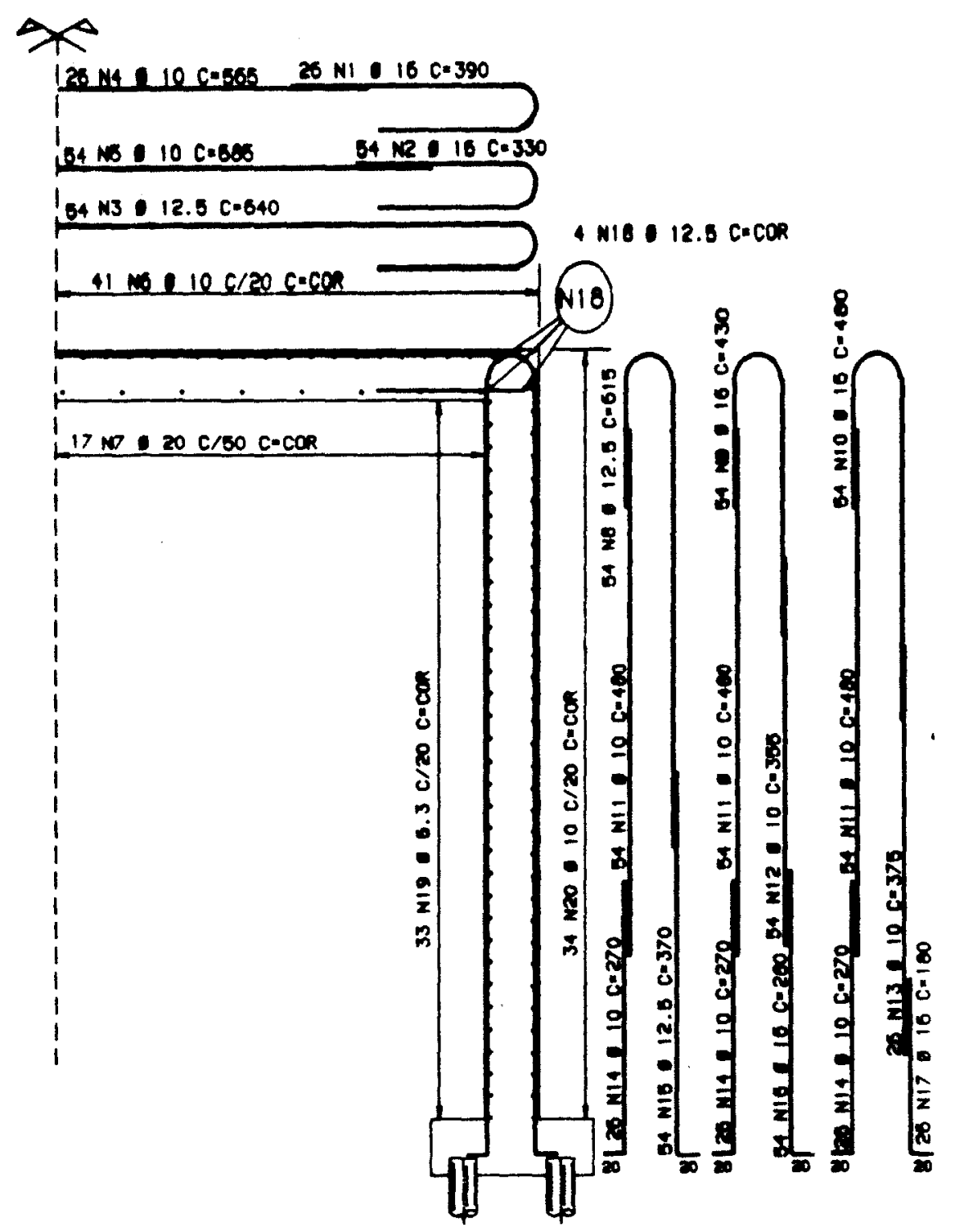

Figura C.2a - Detalhamento da ponte:

Encontros e nós do pórtico 


\begin{tabular}{|c|c|c|c|c|c|}
\hline ELEM & POS & हाT. & OUAN & $\begin{array}{l}\text { COAPP } \\
\text { UNIT }\end{array}$ & $\begin{array}{l}\text { PENTO } \\
\text { TOTAL }\end{array}$ \\
\hline & $\begin{array}{r}1 \\
2 \\
3 \\
4 \\
5 \\
6 \\
7 \\
8 \\
9 \\
10 \\
11 \\
12 \\
13 \\
14 \\
15 \\
16 \\
17 \\
18 \\
19 \\
20\end{array}$ & $\begin{array}{l}16 \\
10 \\
12.5 \\
10 \\
10 \\
10 \\
20 \\
12.5 \\
16 \\
16 \\
10 \\
10 \\
10 \\
10 \\
12.5 \\
16 \\
16 \\
12.5 \\
6.3 \\
10\end{array}$ & $\begin{array}{r}52 \\
100 \\
54 \\
26 \\
54 \\
40 \\
16 \\
100 \\
100 \\
100 \\
324 \\
100 \\
52 \\
156 \\
108 \\
100 \\
52 \\
0 \\
66 \\
68\end{array}$ & $\begin{array}{r}390 \\
330 \\
640 \\
565 \\
685 \\
- \text { CORR- } \\
- \text { CORR- } \\
515 \\
430 \\
480 \\
480 \\
355 \\
375 \\
270 \\
370 \\
280 \\
180 \\
\text { - CORR- } \\
\text { - CORR- } \\
- \text { CORR- }\end{array}$ & $\begin{array}{r}20200 \\
35640 \\
34560 \\
14690 \\
36990 \\
54000 \\
21600 \\
65420 \\
46440 \\
51840 \\
155520 \\
38340 \\
19500 \\
42120 \\
39960 \\
30240 \\
9360 \\
10800 \\
89100 \\
91000\end{array}$ \\
\hline
\end{tabular}

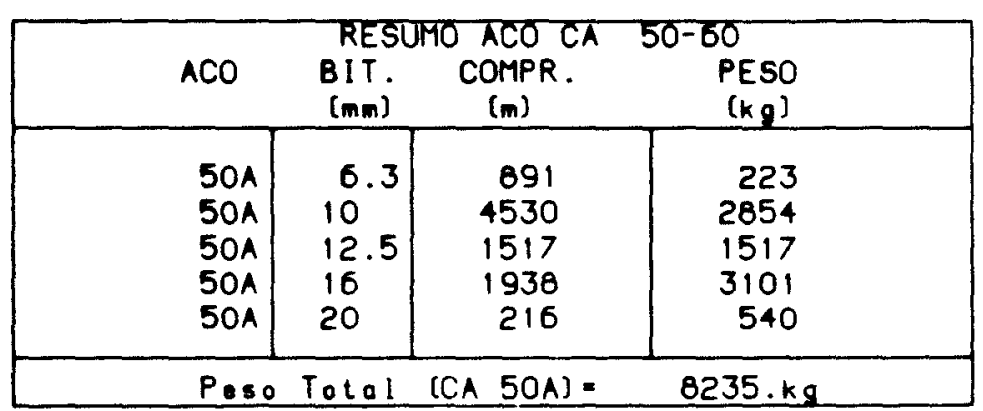

Figura C.2b - Tabela de ferros da ponte em pórtico - relativa a o detalhamento dos encontros e do nó do pórtico. 

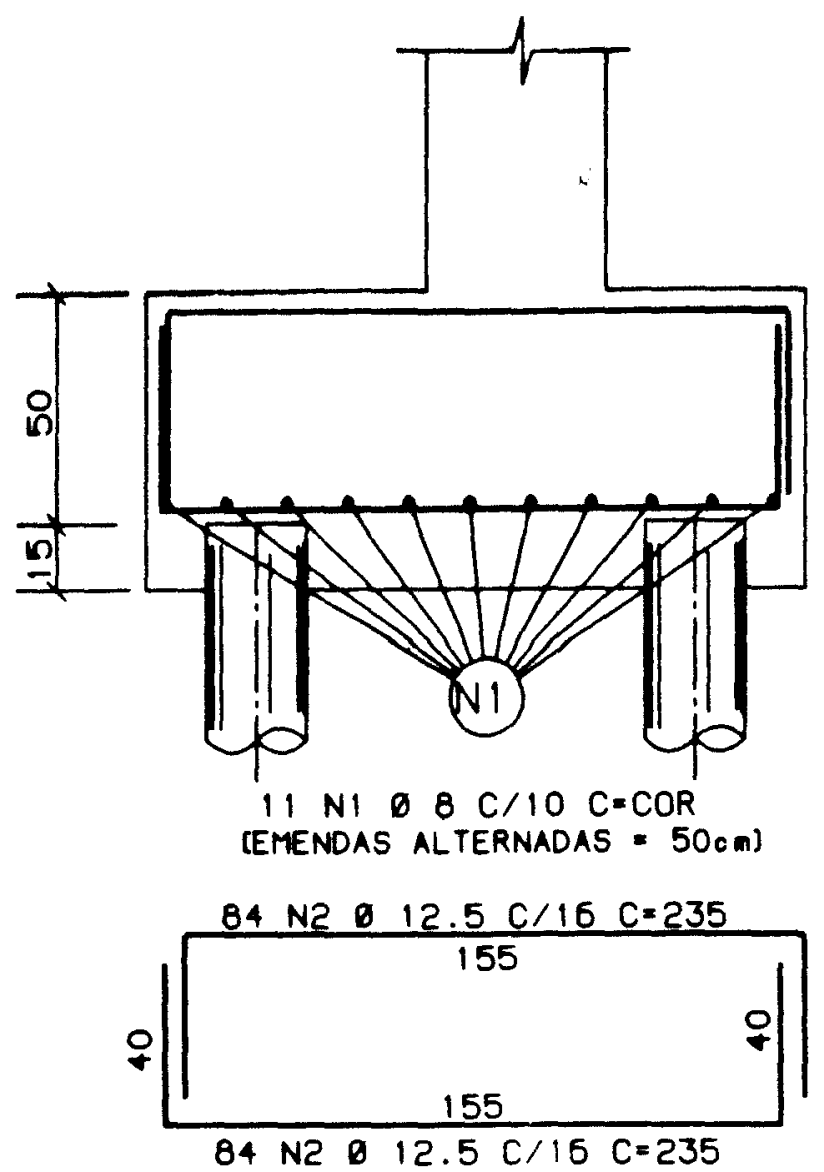

Figura C.3a - Detalhamento da fundação da ponte em pórtico

\begin{tabular}{|c|c|c|c|c|c|}
\hline \multirow[t]{3}{*}{ ELEM } & \multirow[t]{2}{*}{ POS. } & \multirow[t]{2}{*}{ BIT. } & \multirow[t]{2}{*}{ OUANT } & \multicolumn{2}{|c|}{ COMPR IMENTO } \\
\hline & & & & UNIT & TOTAL \\
\hline & $\begin{array}{l}1 \\
2\end{array}$ & $\begin{array}{c}8 \\
12.5\end{array}$ & $\begin{array}{r}22 \\
336\end{array}$ & $\begin{array}{r}- \text { CORR- } \\
235\end{array}$ & $\begin{array}{l}29590 \\
78960\end{array}$ \\
\hline
\end{tabular}

\begin{tabular}{|c|c|c|c|}
\hline \multirow{2}{*}{ ACO } & \multicolumn{2}{c|}{ RESUMO ACO CA } \\
BIT. & $\begin{array}{c}50-60 \\
\text { COMPR. } \\
(\mathrm{mm})\end{array}$ & $\begin{array}{c}\text { PESO } \\
\text { (kg) }\end{array}$ \\
\hline $50 A$ & 8 & 296 & $\begin{array}{l}118 \\
790\end{array}$ \\
\hline $50 A$ & 12.5 & 790 & $900 . \mathrm{kg}$ \\
\hline
\end{tabular}

Figura C.3b - Tabela de ferros da fundação da ponte em pórtico 


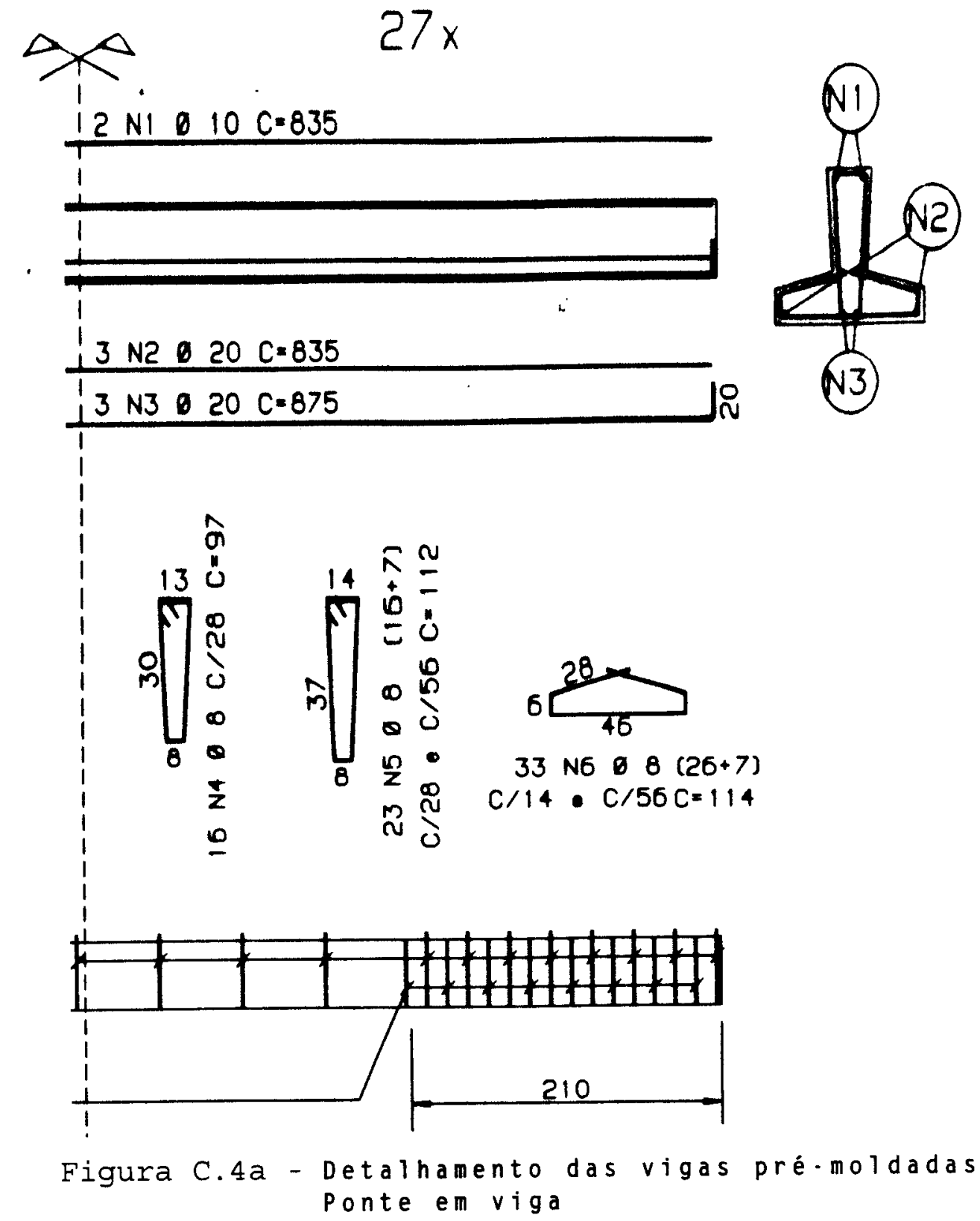

\begin{tabular}{|l|r|r|r|r|r|}
\hline ELEM & \multicolumn{3}{c|}{ POS. BIT. } & OUANT & \multicolumn{3}{c|}{ COMPRIMENTO } \\
\hline & 1 & 10 & 54 & 835 & 45090 \\
& 2 & 20 & 81 & 835 & 67635 \\
& 3 & 20 & 81 & 875 & 70875 \\
& 4 & 8 & 432 & 97 & 41904 \\
& 5 & 6 & 621 & 112 & 69552 \\
& 6 & 8 & 891 & 114 & 101574 \\
\hline
\end{tabular}

\begin{tabular}{|l|c|c|c|}
\hline \multicolumn{4}{c}{ RESUMO ACO CA } \\
ACO & $\begin{array}{c}50-\text { BIT. } \\
\text { (mm) }\end{array}$ & $\begin{array}{c}\text { COMPR. } \\
\text { (m) }\end{array}$ & $\begin{array}{c}\text { PESO } \\
(\mathrm{kg})\end{array}$ \\
\hline $50 A$ & 8 & 2130 & 852 \\
$50 A$ & 10 & 451 & 284 \\
$50 A$ & 20 & 1385 & 3463 \\
\hline
\end{tabular}

Figura C.4b - Tabela de ferros das vigas pré-moldadas da ponte em viga $(27 x)$ 


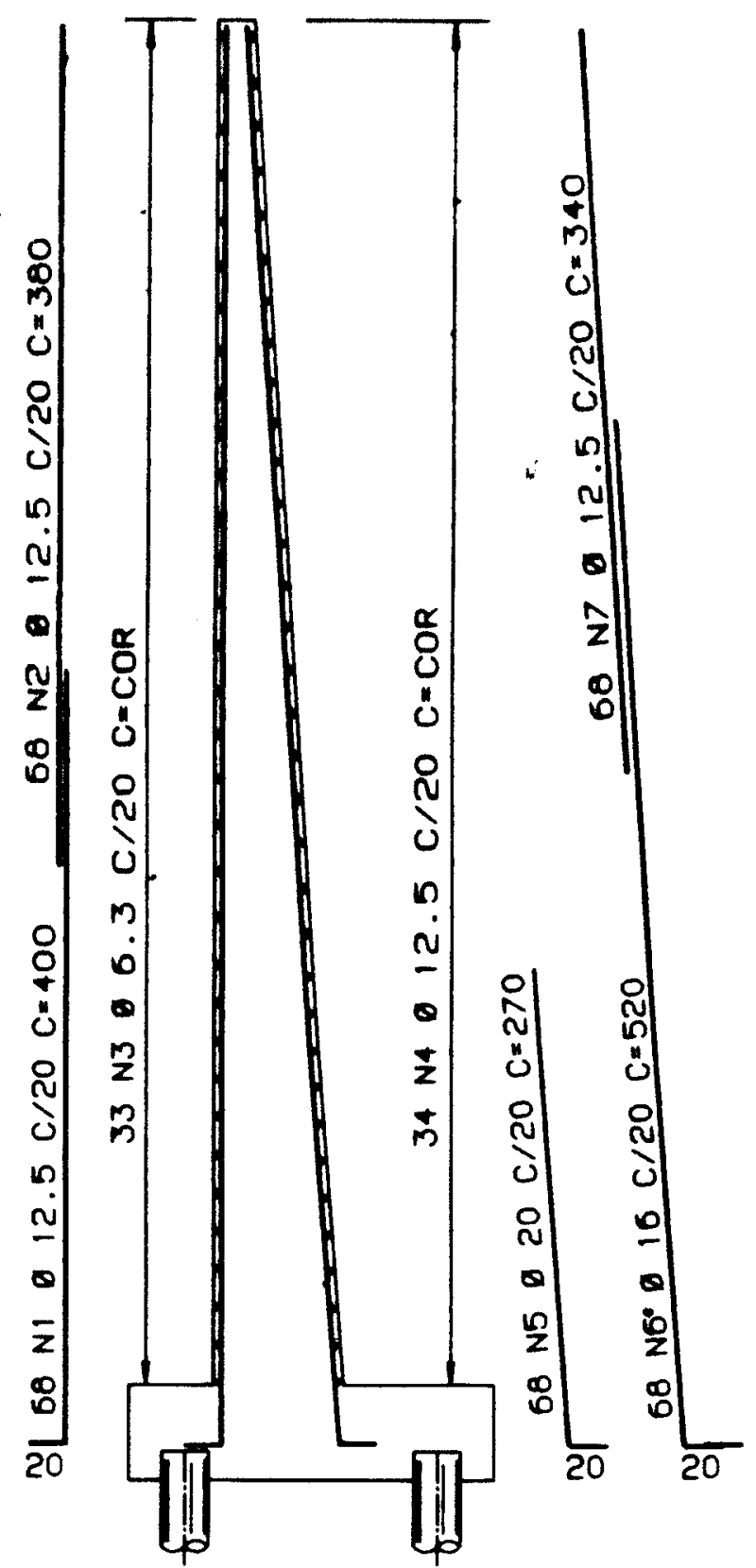

Figura C.5a - Detalhamento dos muros da ponte em viga

\begin{tabular}{|l|r|r|r|r|r|}
\hline ELEM & \multicolumn{1}{c|}{ POS. } \\
\hline & 1 & 12.5 & 136 & 400 & 54400 \\
& 2 & 12.5 & 136 & 380 & 51600 \\
& 3 & 6.3 & 66 & - CORR- & 89100 \\
& 4 & 12.5 & 68 & - CORR & 91800 \\
& 5 & 20 & 136 & 270 & 36720 \\
& 6 & 16 & 136 & 520 & 70720 \\
& 7 & 12.5 & 136 & 340 & 46240 \\
& & & & & \multicolumn{1}{c|}{ COMPRIMENTO } \\
& &
\end{tabular}

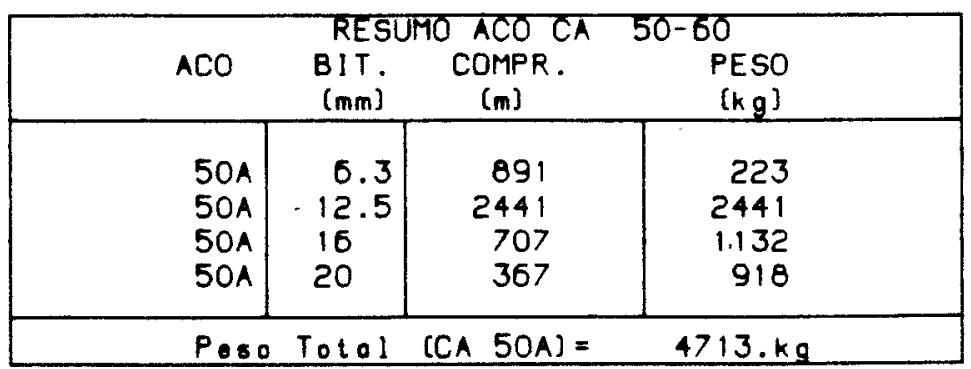

Figura C.5b - Tabela de ferros dos muros da ponte em viga 


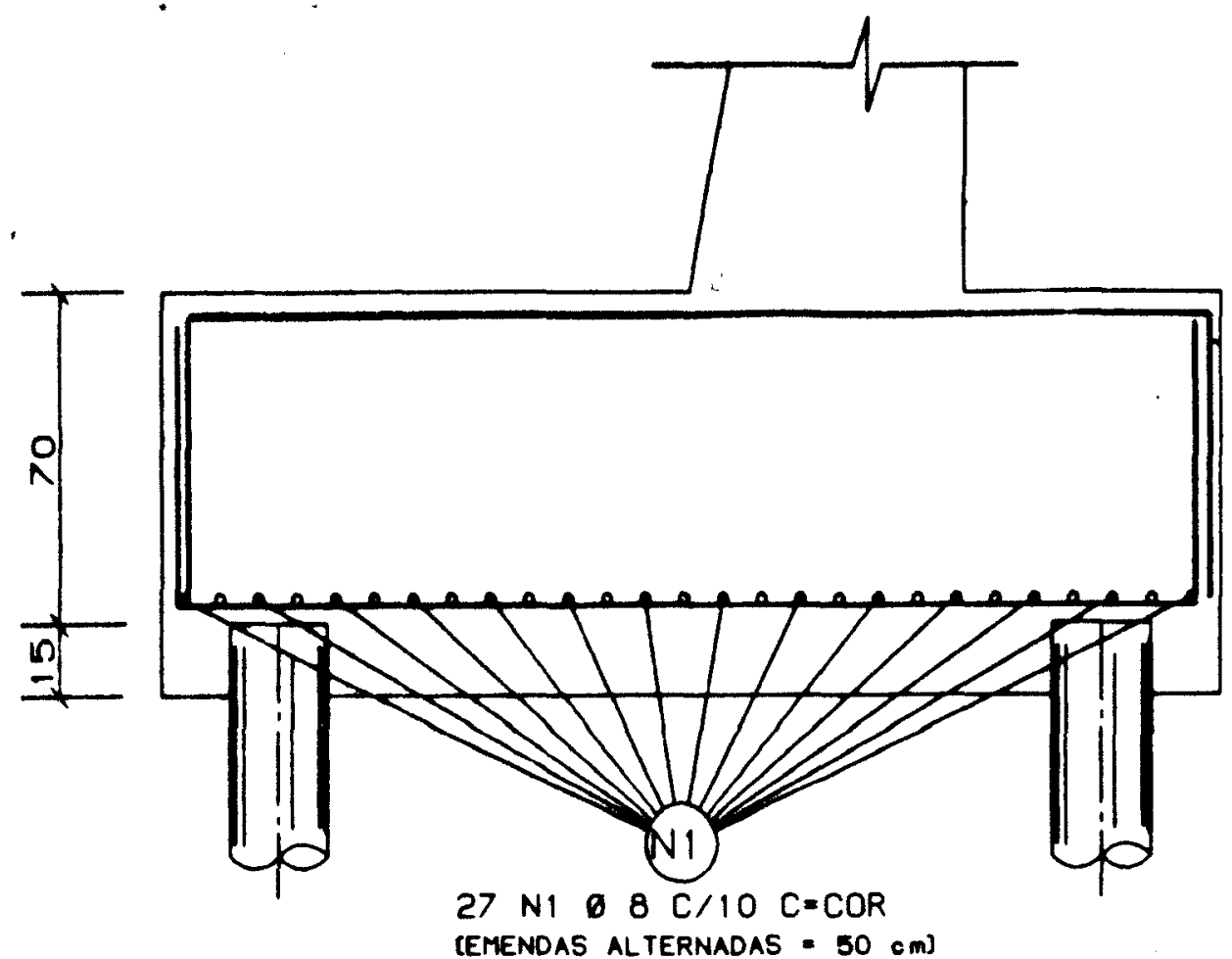

68 N2 $98 C / 20 \quad C=380$

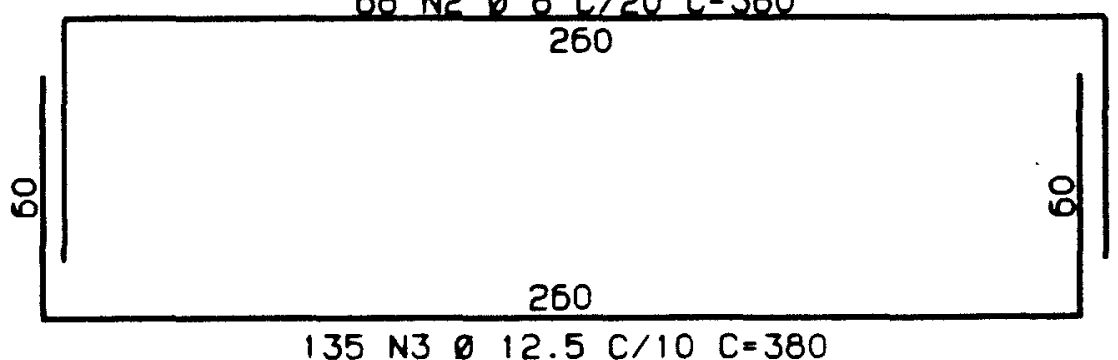

Figura C.6a - Detalhamento da fundação da ponte em viga

\begin{tabular}{|l|r|r|r|r|r|}
\hline ELEM & \multicolumn{3}{c|}{ POS. BIT. } \\
\hline & 1 & 0 & 54 & - CORR- & 72630 \\
& 2 & 0 & 136 & 380 & 51580 \\
& 3 & 12.5 & 270 & 380 & 102600 \\
\hline
\end{tabular}

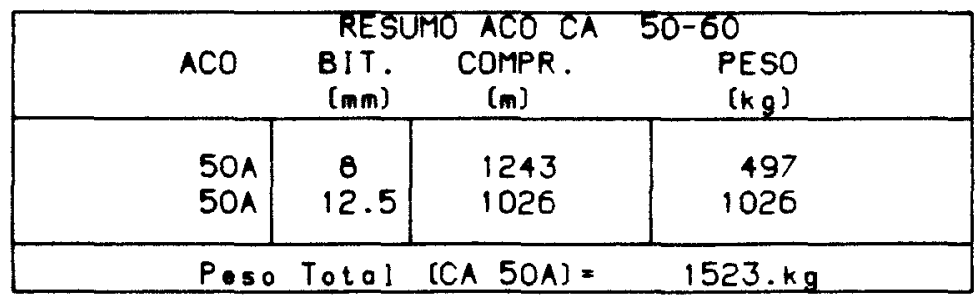

Figura C.6b - Tabela de ferros da fundaça da ponte em viga 


\section{ANEXO D}

GRÁFICOS DE MOMENTOS FLETORES E FORÇAS

CORTANTES - MÉTODO APROXIMADO 


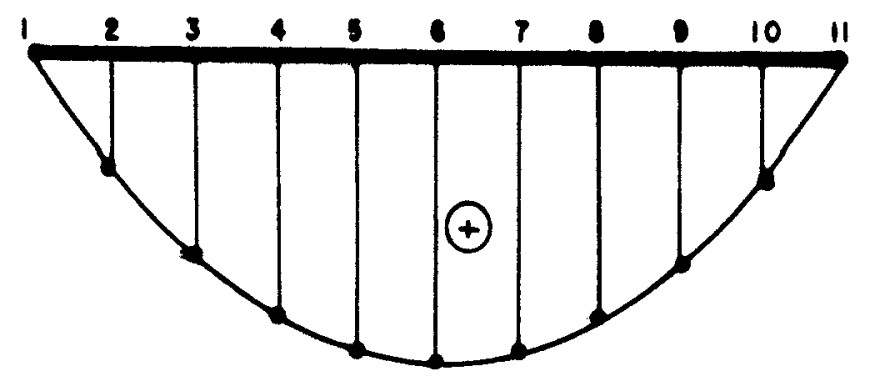

Figura D.1- Diagrama de Momento Fletor - Carga Permanente

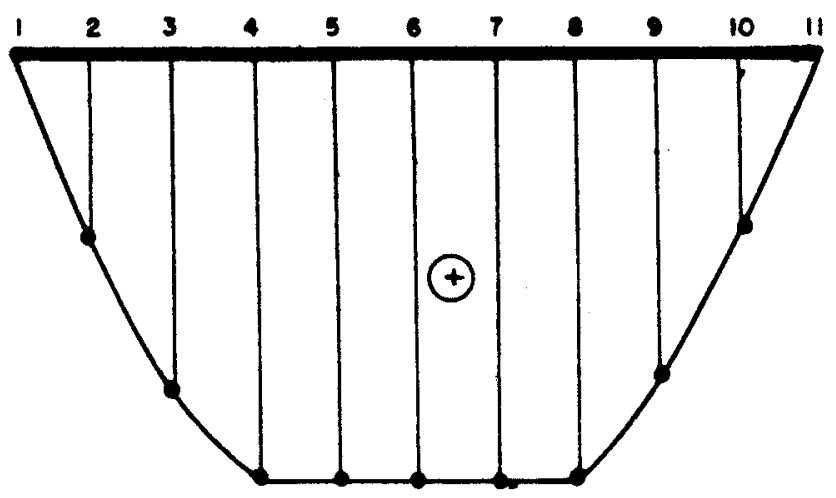

Figura D.2 - Diagrama de Momento Fletor - Carga Móvel 


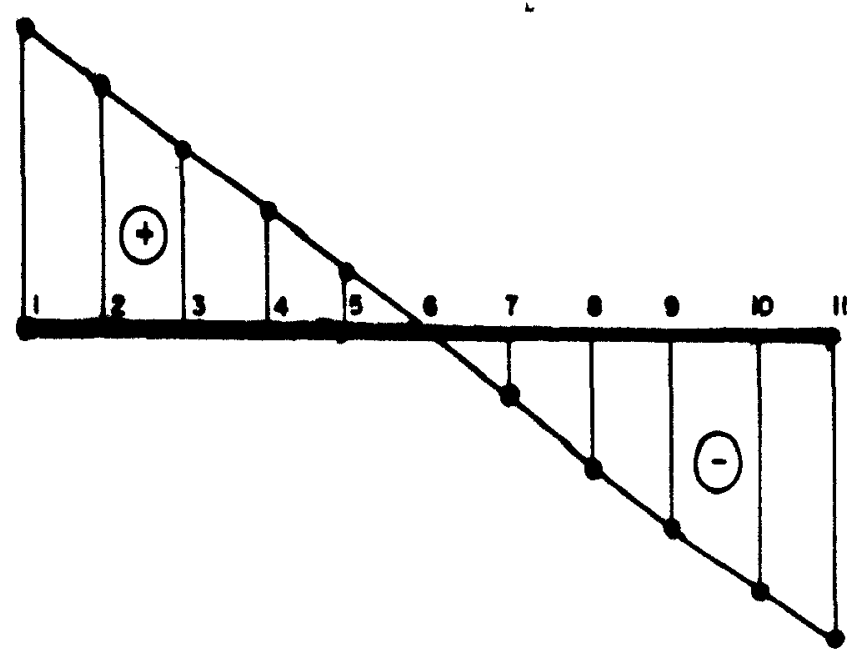

Figura D.3 - Diagrama de Forca Cortante - Carga Permanente

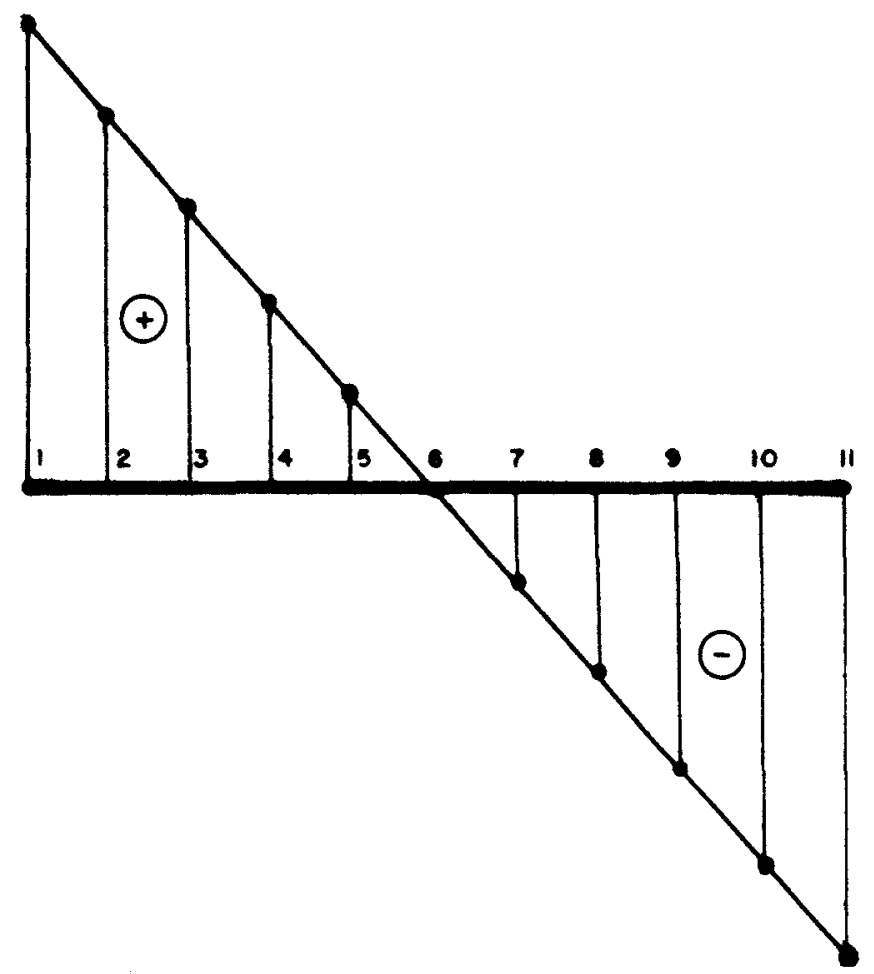

Figura D.4 - Diagrama de Força Cortante - Carga Móvel 


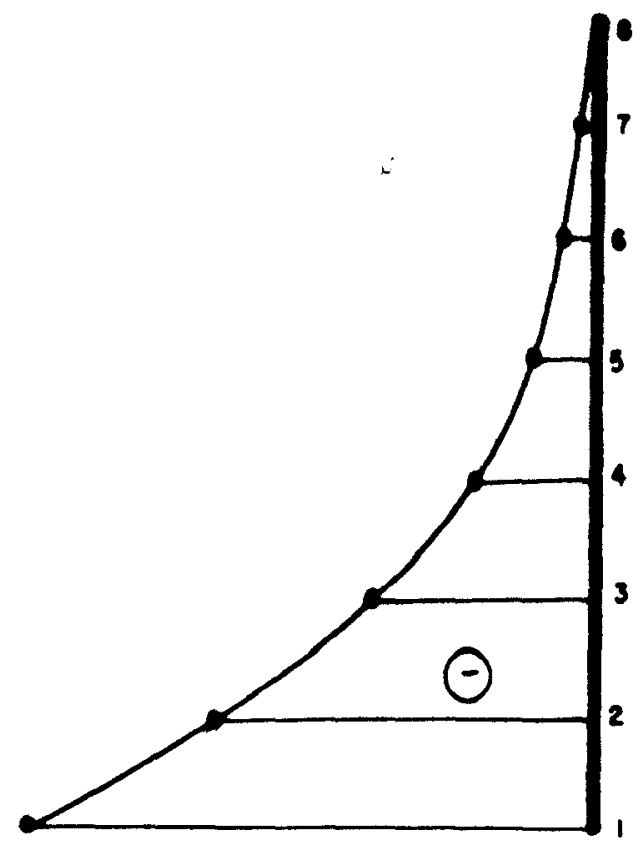

Figura D.5 - Diagrama de Momento Fletor. Empuxo de terra

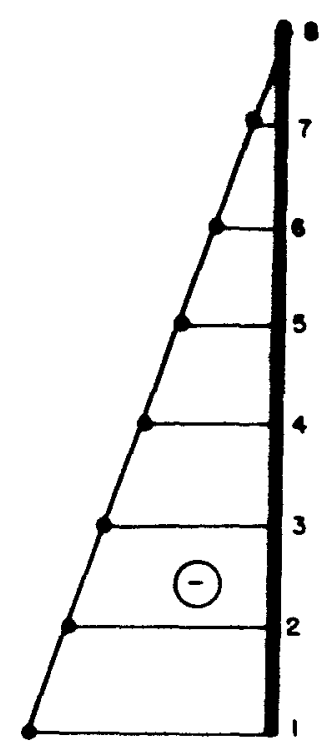

Figura D.6 - Diagrama de Momento Fletor. Temperatura/Retração 


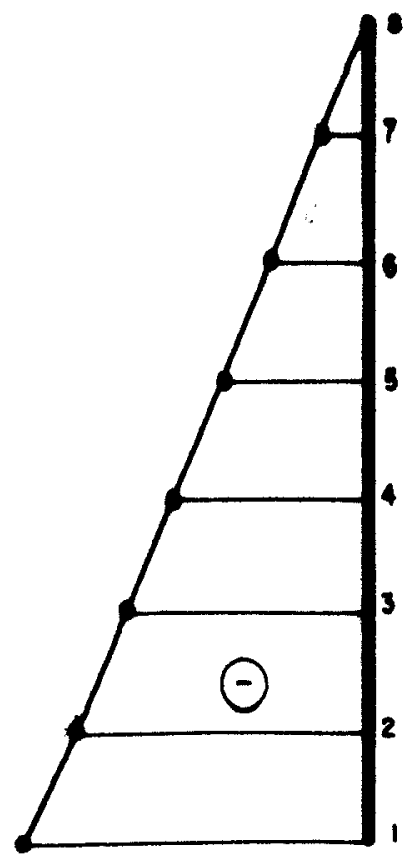

Figura D.7 - Diagrama de Momento Fletor. Aceleraça/frenagem

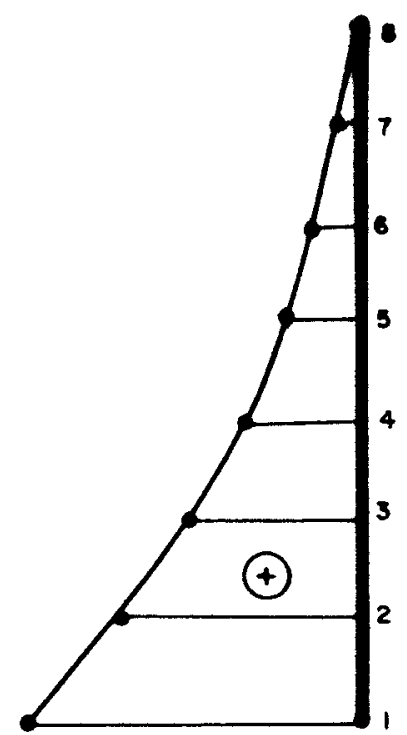

Figura D.8 - Diagrama de Força Cortante. Empuxo de Terra 


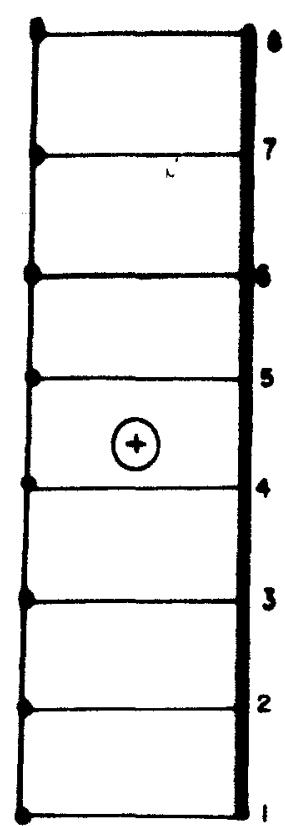

Figura D.9 - Diagrama de Força Cortante. Temperatura/Retração

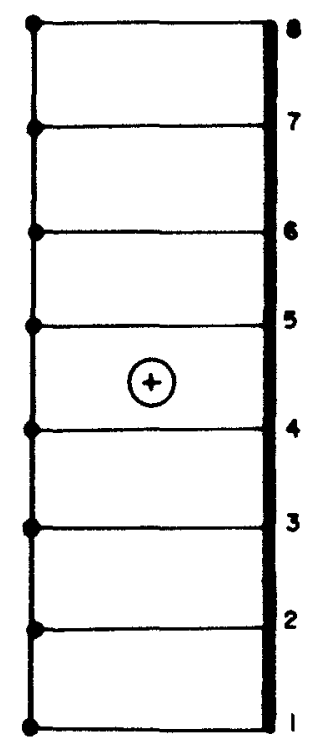

Figura D.10 - Diagrama de Força Cortante. Aceleração/Frenagem 


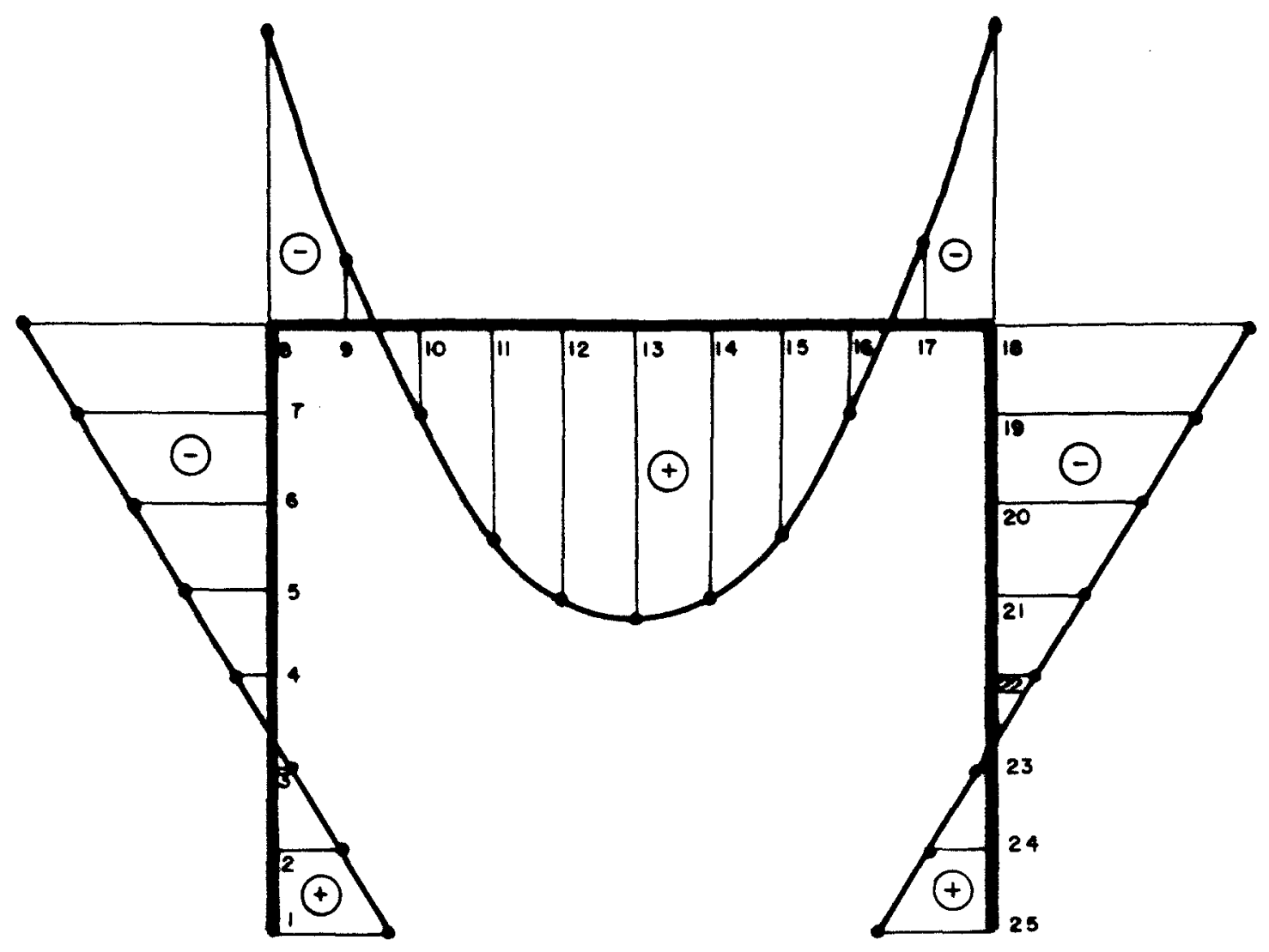

Figura D.11 - Diagrama de Momento Fletor - Peso Próprio 


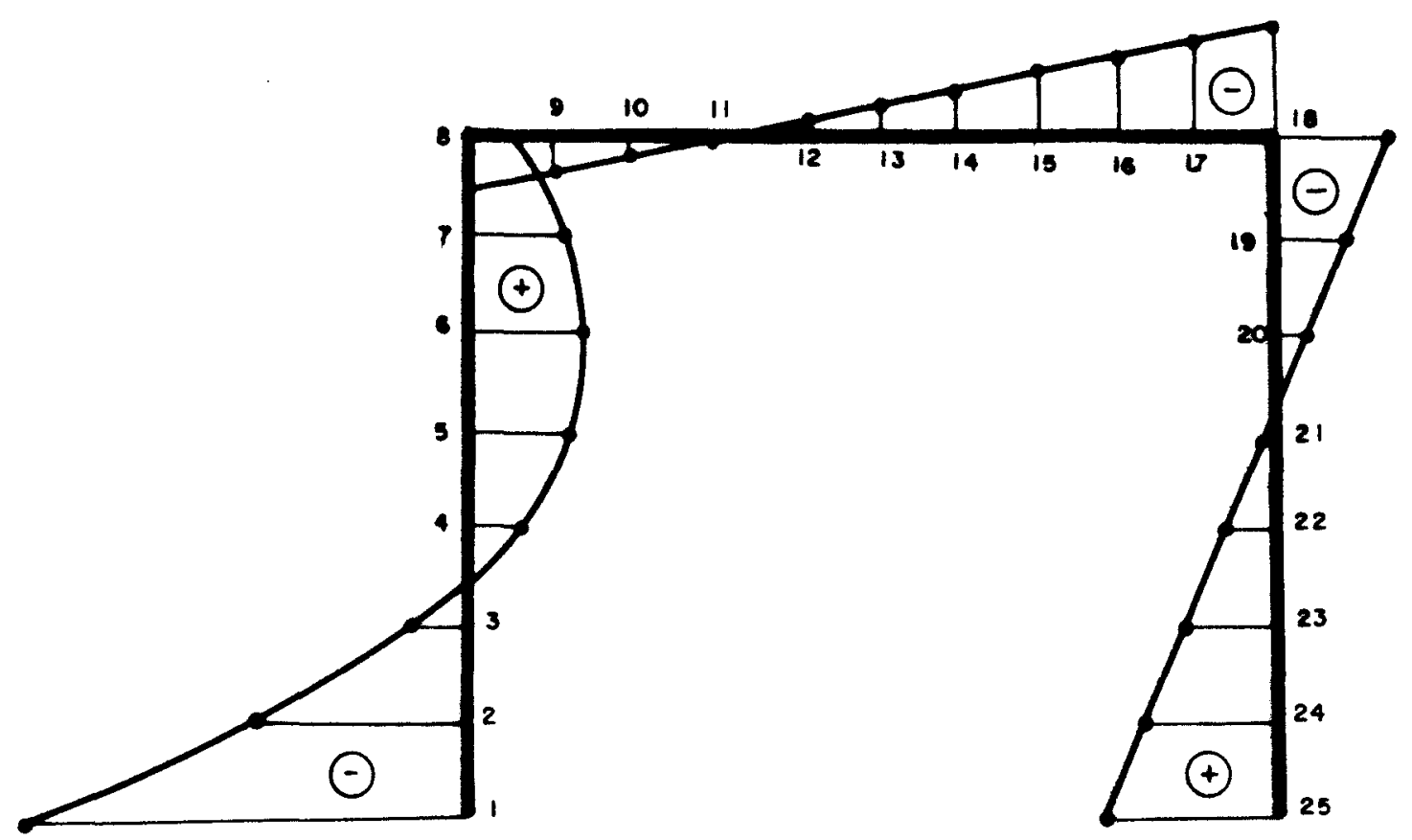

Figura D.12 - Diagrama de Momento Fletor Empuxo Ativo 


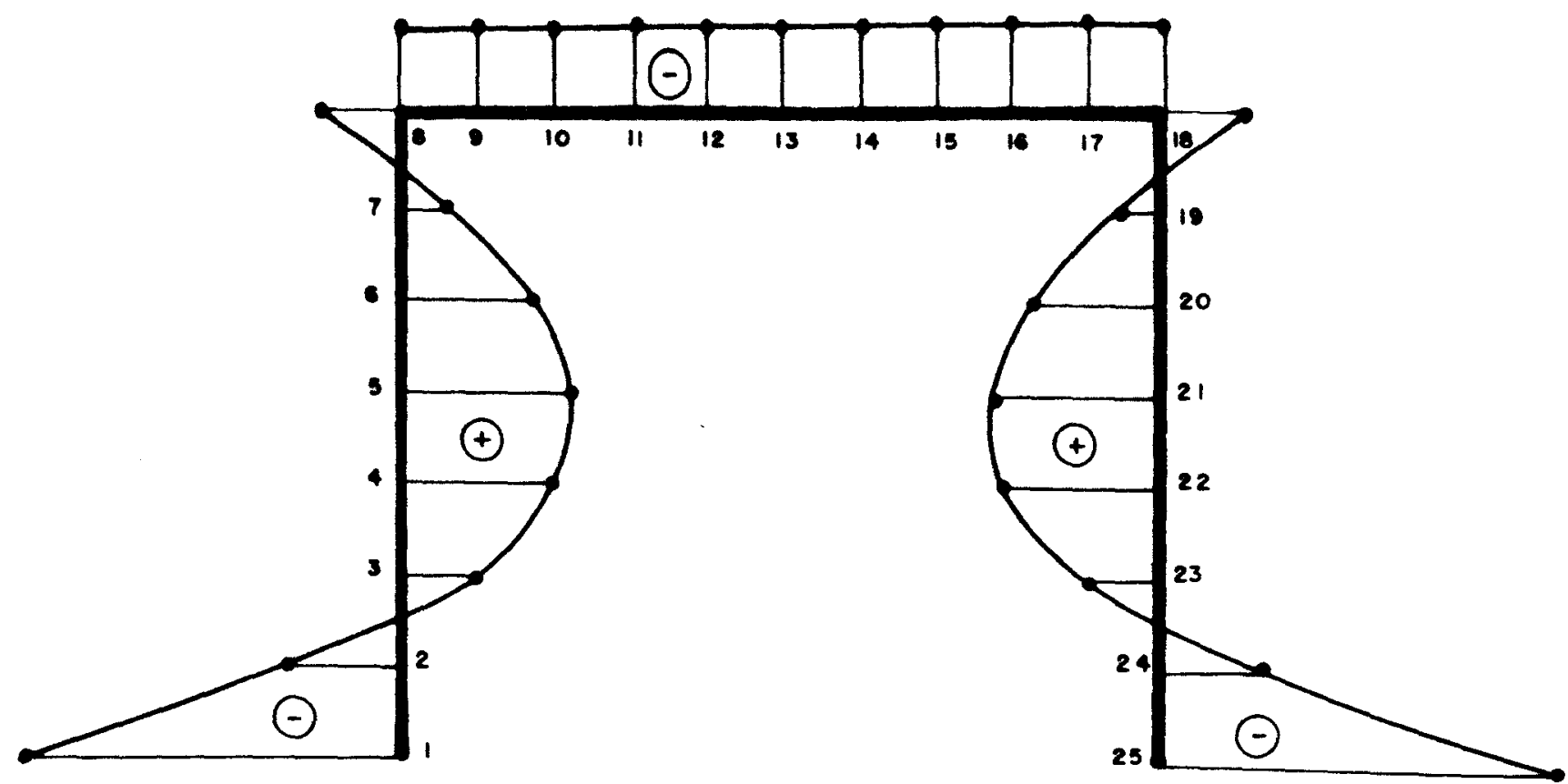

Figura D.13 - Diagrama de Momento Fletor. Empuxo Repouso 


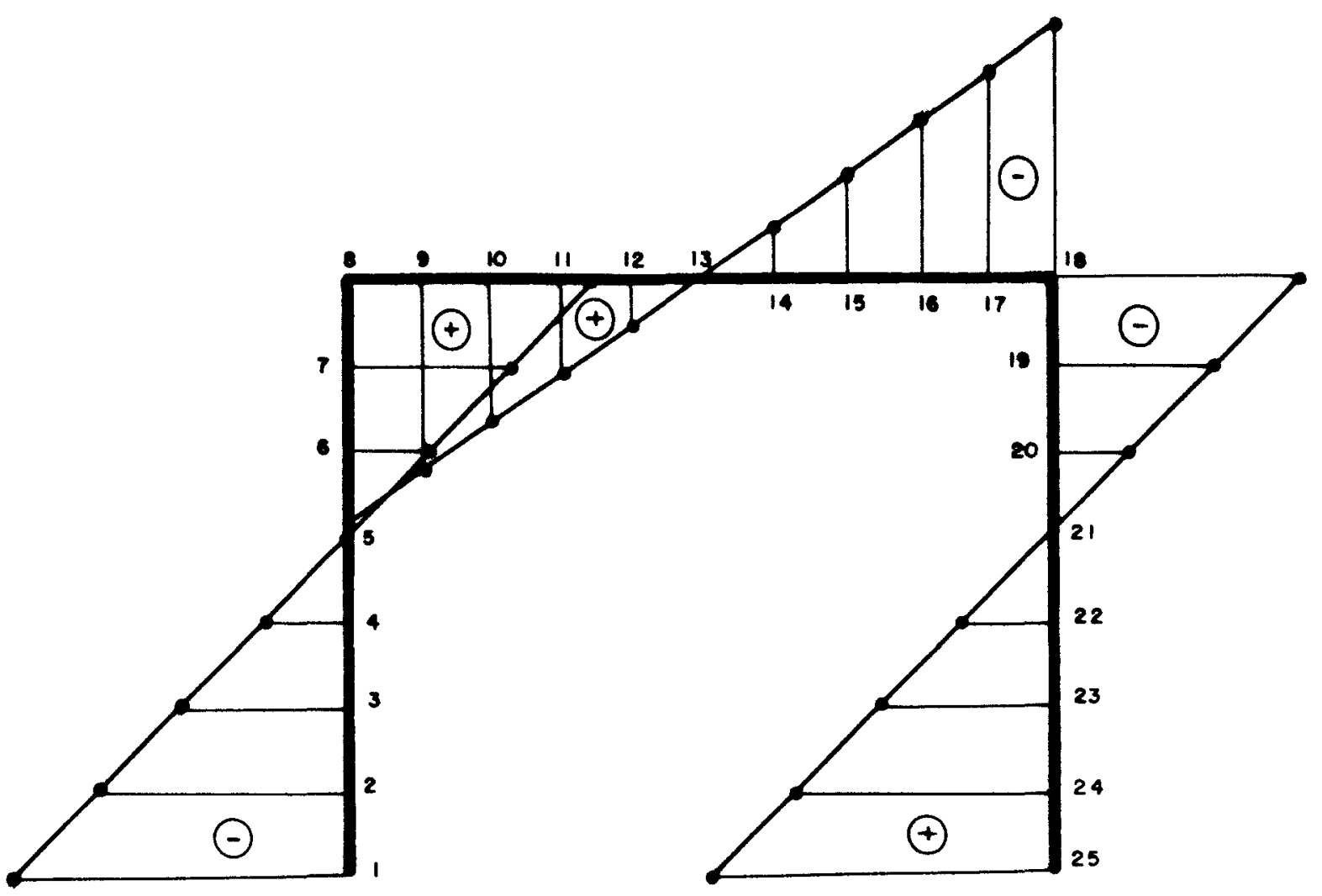

Figura D.14 - Diagrama de Momento Fletor. Aceleração/Frenagem 


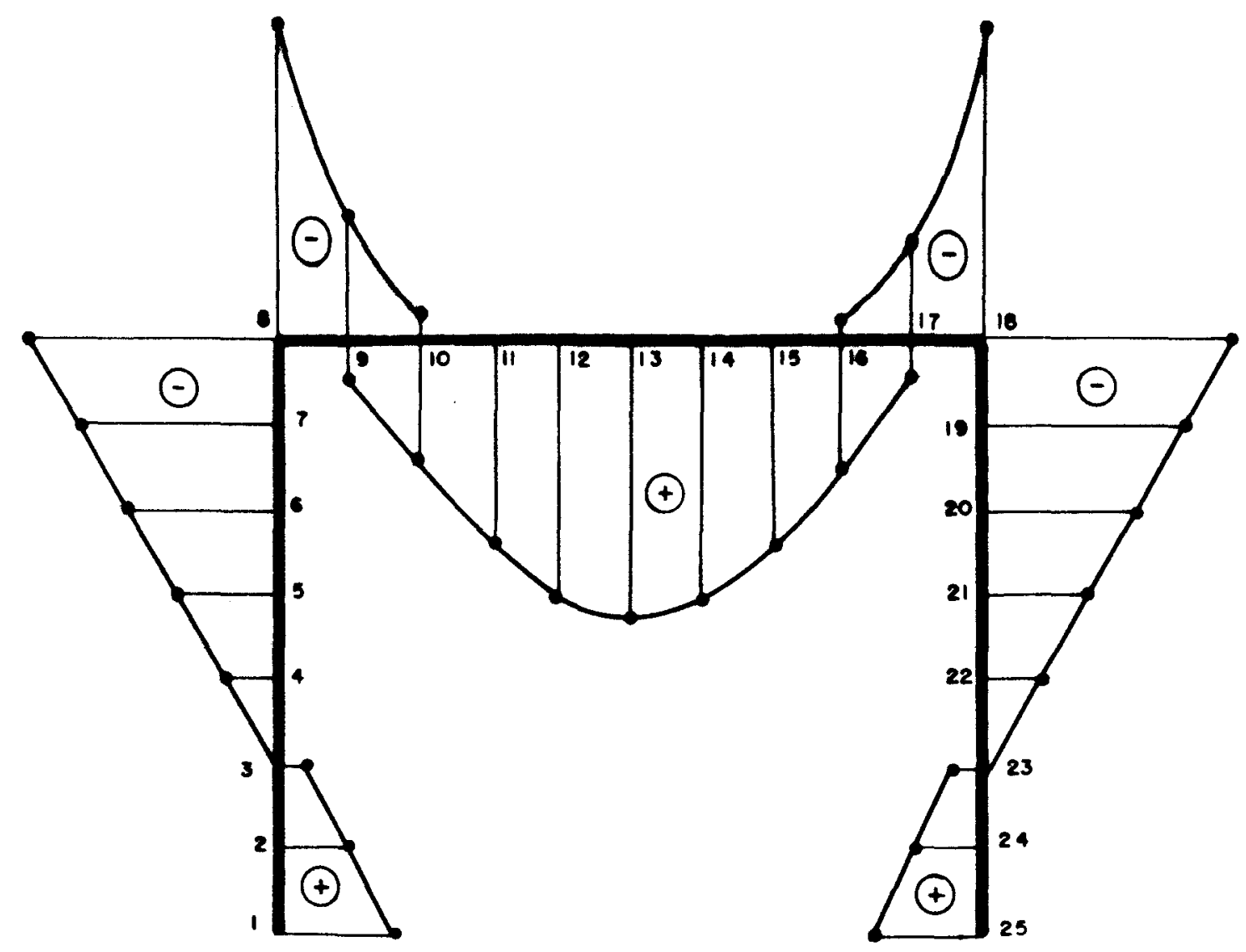

Figura D.15 - Diagrama de Momento Fletor - Carregamento Móvel 


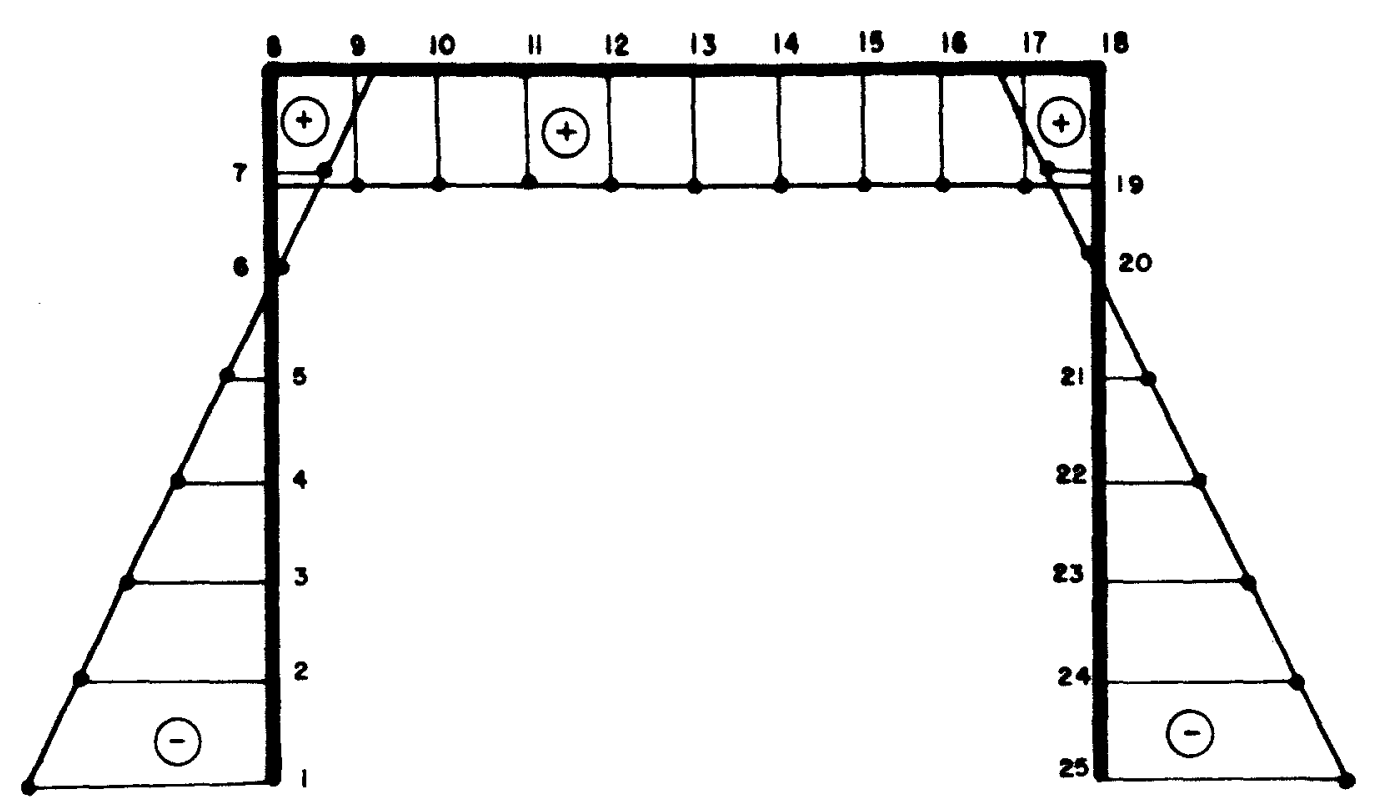

Figura D.16 - Diagrama de Momento Fletor - Temperatura/Retraça 


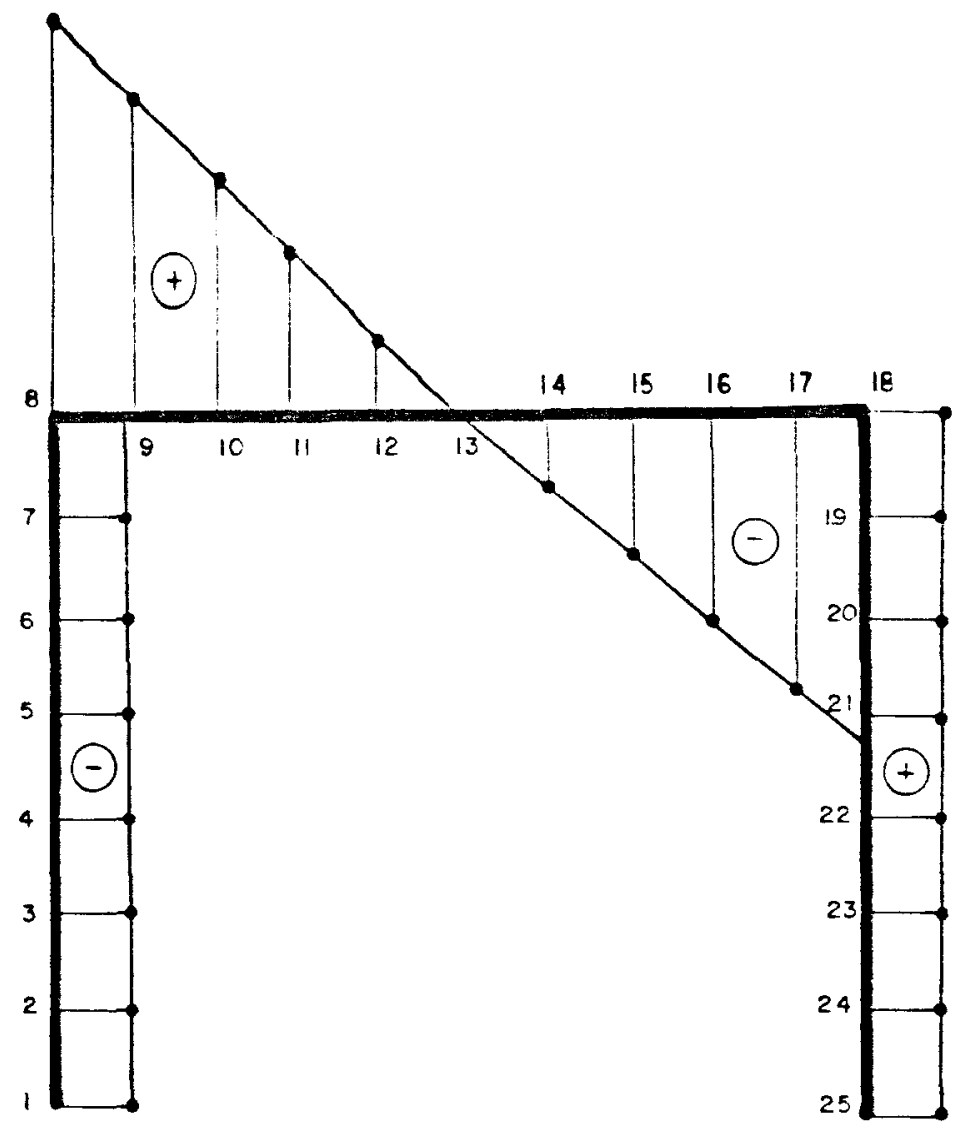

Figura D.17 - Diagrama de Força Cortante. Peso Próprio 


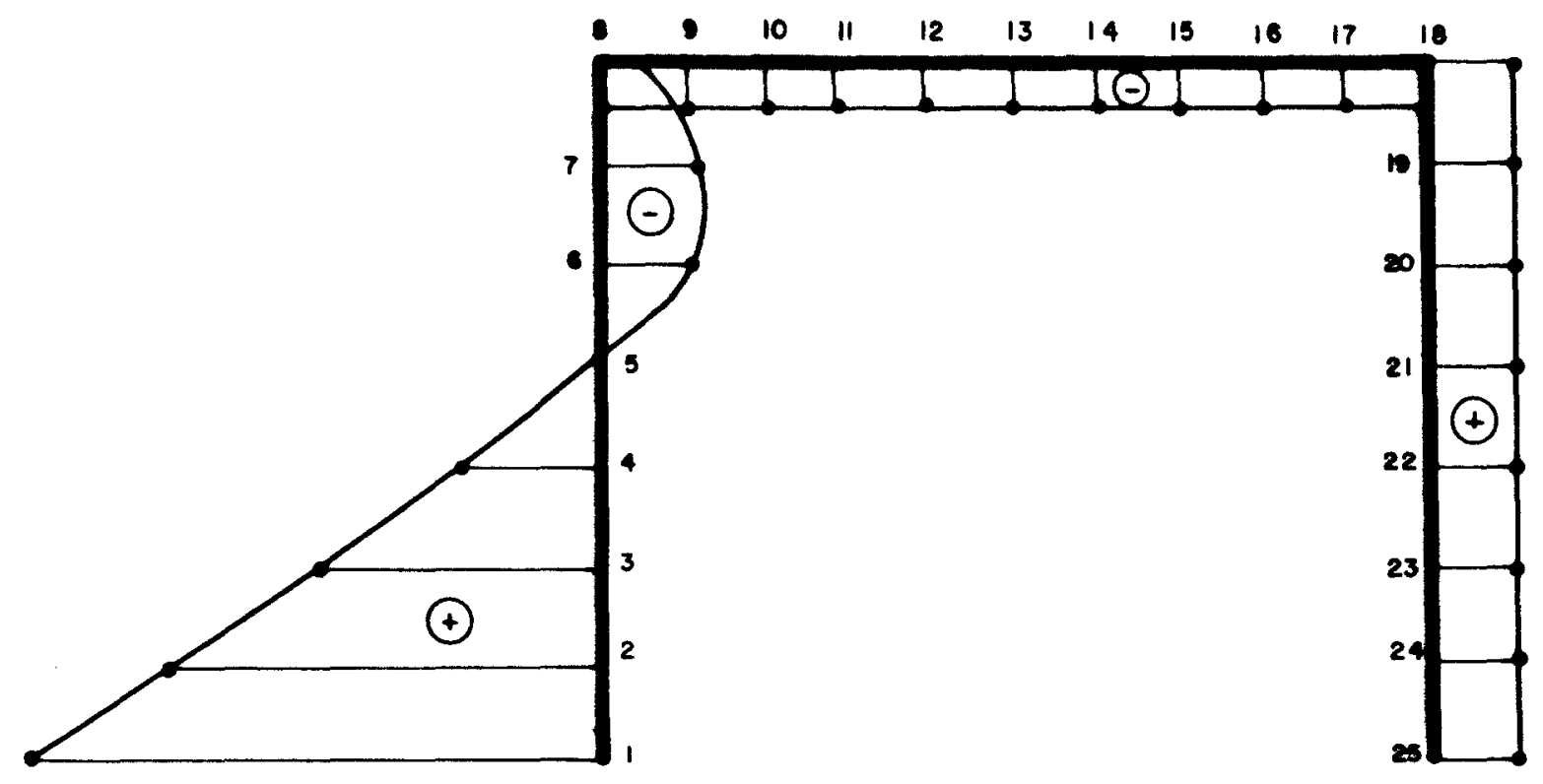

Figura D.18 - Diagrama de Força Cortante. Empuxo Ativo 


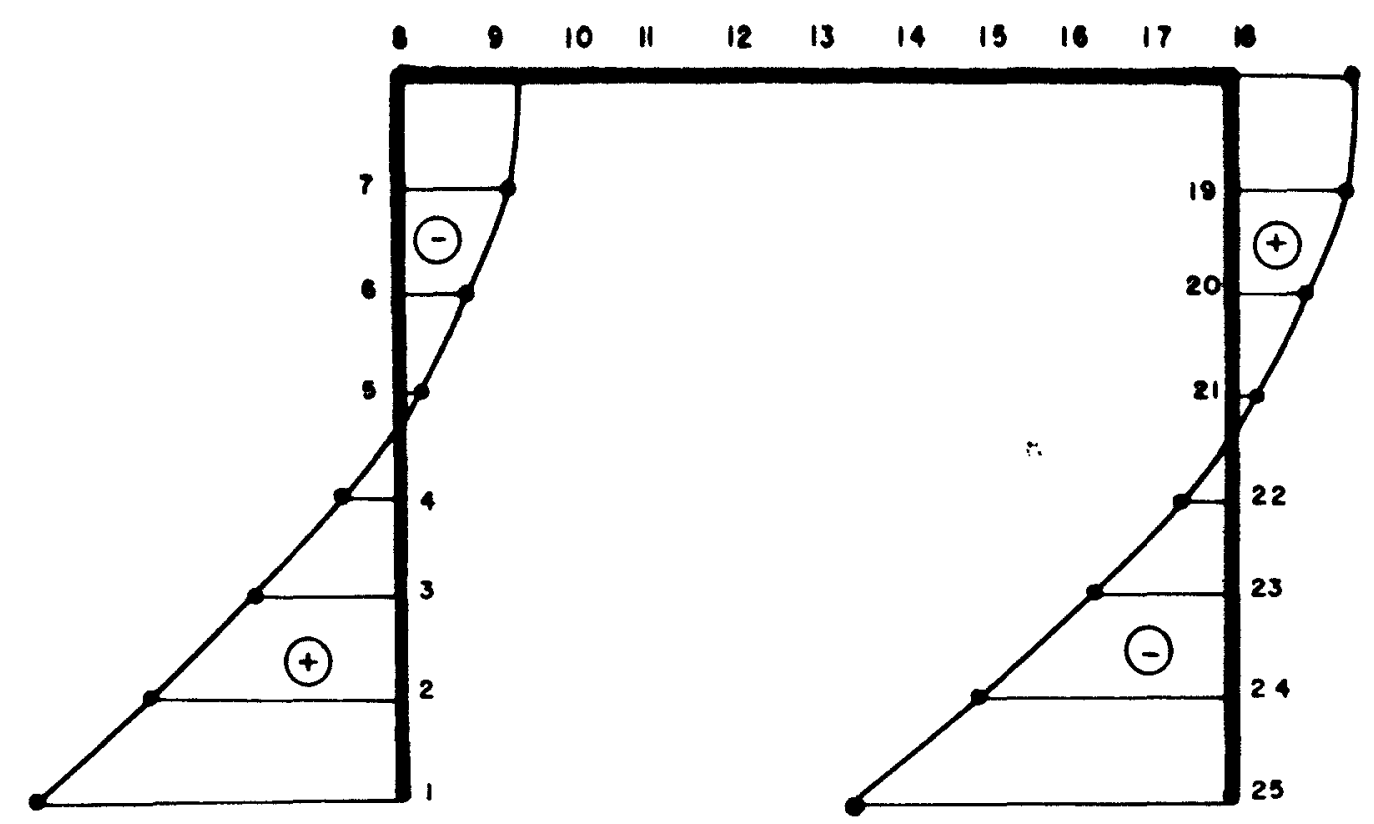

Figura D.19 - Diagrama de Força Cortante- Empuxo Repouso 


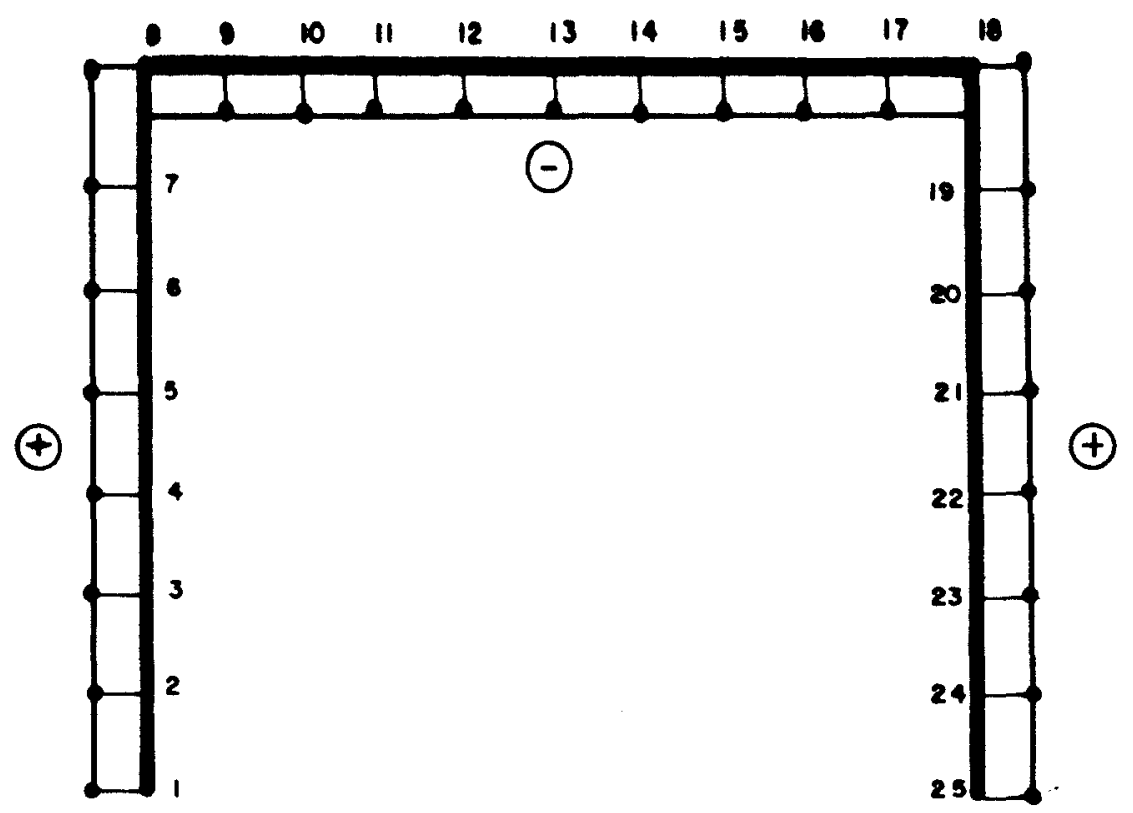

Figura D.20 - Diagrama de Força Cortante - Aceleração/Frenagem 


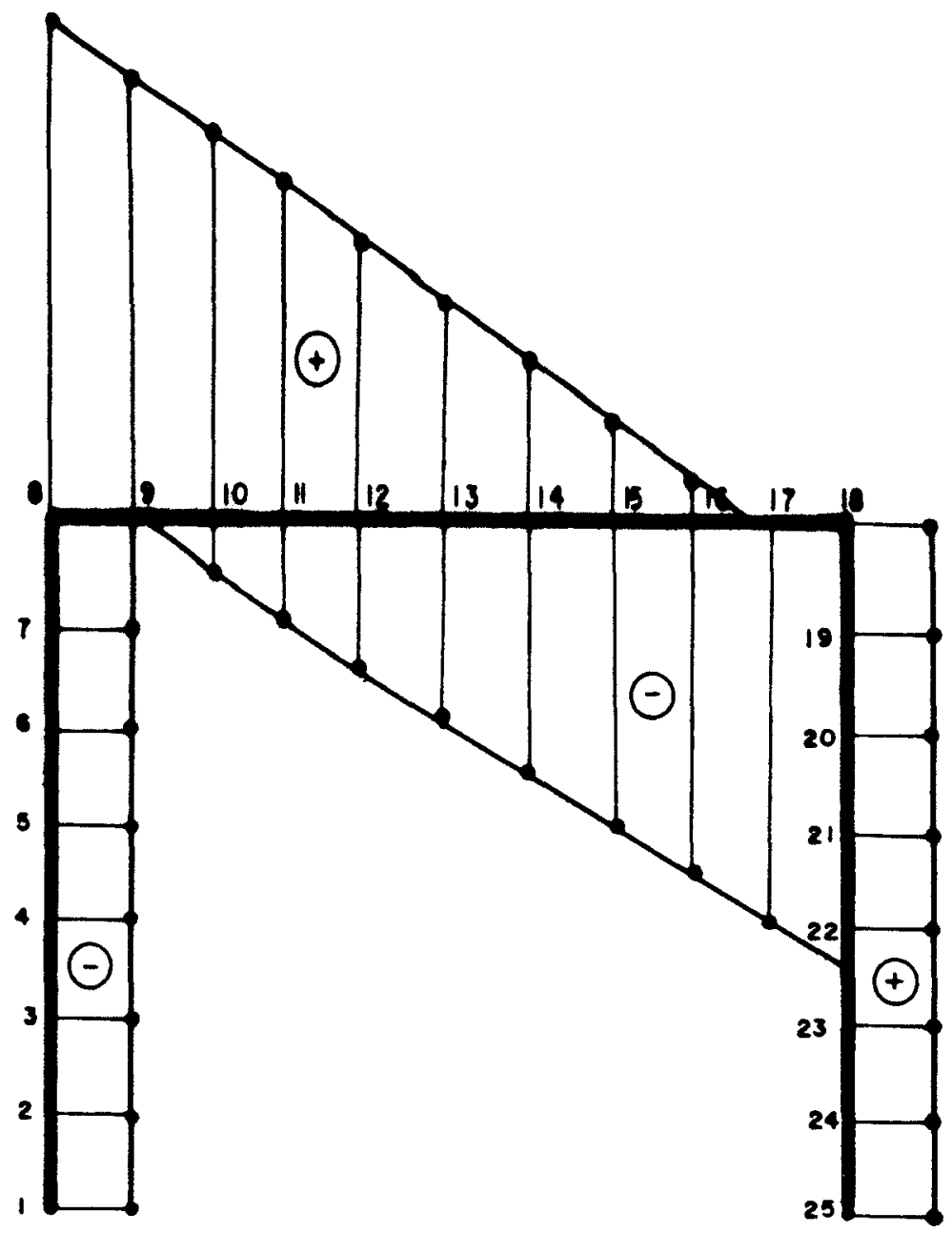

Figura D.21 - Diagrama de For ça Cortante Carregamento Móvel 


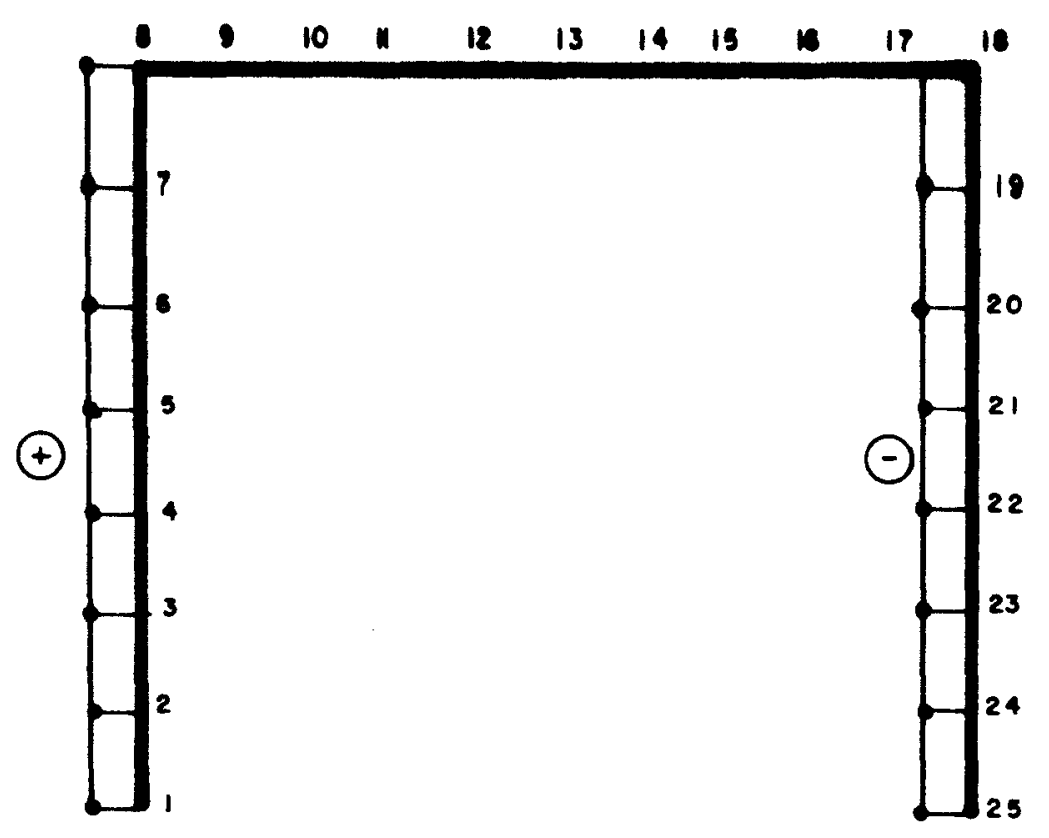

Figura D.22 - Diagrama de Força Cortante. Temperatura/retração 


\section{REFERENNCIAS BIBLIOGRÁFICAS}

[1] ASSOCIAÇÃO BRASILEIRA DE NORMAS TÉCNICAS. NBR $\underline{8681}=$ Ações e segurança nas estruturas. Rio de Janeiro, 1984.

[2] ASSOCIAÇÃO BRASILEIRA DE NORMAS TÉCNICAS. NBR $7188=$ Carga móvel em ponte rodoviária e passarela de pedestre. Rio de Janeiro, 1984.

[3] ASSOCIAÇÃO BRASILEIRA DE NORMAS TÉCNICAS. NBR $7197=$ Projeto de estruturas de concreto protendido Rio de Janeiro, 1989.

[4] ASSOCIAÇÃO BRASILEIRA DE NORMAS TÉCNICAS. NBR $\underline{9062}=$ Projeto e execução de estruturas de concreto pré-moldado. Rio de Janeiro, 1985.

[5] ASSOCIAÇÃO BRASILEIRA DE NORMAS TÉCNICAS. NBR $6118=$ Projeto e execução de obras de concreto armado e protendido. Rio de Janeiro, 1982.

[6] ASSOCIAÇÃO BRASILEIRA DE NORMAS TÉCNICAS. NBR $7187=$ Projeto e execução de pontes de concreto armado e protendido. Rio de Janeiro, 1986.

[7] BALLARIN, Adriano Wagner. Dimensionamento da ligação concreto pré-moldado = concreto moldado 'in 10co' $\mathrm{em}$ estruturas compostas. São Carlos: Departamento de Estruturas - EESC, 1990. 26p. (Trabalho apresentado à disciplina Estruturas Pré-moldadas de concreto)

[8] BURKE Jr, Martin P. Integral Bridges. Transportation Research Record. Washington, D.C., 1990. n.1275, 53-61. 
[9] COMITÉ EURO-INTERNATIONAL DU BETóN. Recommandations internacionales CEB-FIP pour le calcul et l'exécution des ouvrages en béton. Paris, 1970. p.27-35. (Bul. d'Inf. n.73, fasc. 4).

[10] CONSULTORIA E PROJETOS DE ENGENHARIA DE ESTRUTURAS. PSI na SP-310. São Carlos [199-]. 40p. (Memória de cálculo).

[11] EL DEBS, M.K., TAKEYA, Toshiaki. Pontes de concreto. São Carlos: Departamento de Estruturas - EESC, 1990. (Notas de aula, fascículos 1 à 5).

[12] EL DEBS, M.K. Contribuição ao emprego de pré-moldados de concreto em infraestrutura urbana e em estradas. São Carlos: Escola de Engenharia de São Carlos, 1991. 282p. (Tese de livre-docência em estruturas).

[13] FEDERATION INTERNATIONALE DE LA PRE CONTRAINTE. Shear at the interface of precast and in situ concrete. Paris, 1982. 31p. (Guide to Good Practice).

[14] FERNANDEZ CASADO, C. Puentes de hormigon armado pretensado. Madrid: Dossat, $1965 . \quad 2 . v$. (Morfologia y Construccion, vol.2).

[15] FERNANDEZ ORDOÑEZ, J.A. et alii. Prefabricacion: teoría y prática. Barcelona: Editores Técnicos Asociados, 1974. 2.v.

[16] GAIOTO, Nélio. Estruturas de arrimo e empuxos de terra. São Carlos: Escola de Engenharia de São Carlos, 1979. (Publicação 001/87, reimpressão).

[17] GREIMANN, Lowell F., ABENDROTH, Robert E. Rational design approach for integral abutment bridge piles. 
Transportation Research Record. Washington D.C., 1989. n. $1223,12-23$.

[18] GREKOW, Arcady, ISNARD, Vadim, MROZOWICZ, Paul. Formulário del ingeniero. Bilbao: Urmo, 1971. 708p.

[19] GUERRIN, A. Tratado de Concreto Armado. Rio de Janeiro: Hemus, 1955. 6.v. (As Fundações, vol 2).

[20] HILL, J.J, SHIROLE, A.M. Economic and performance considerations for short-span bridge replacement structures. Transportation Research Record. washington D.C., 1984. n.950, 33-38.

[21] KONCZ, T. Manual de la construcción prefabricada. 2.ed. Madrid: Hermann Blume, $1975 . \quad$ v.1. (Tradução da 3.ed. de: Handbuch der Fertigteilbauweise).

[22] LEONHARDT, Fritz, MÖNIG, Eduard. Princípios básicos sobre a armação de estruturas de concreto armado. Rio de Janeiro: Interciência, 1978. (Construções de concreto, vol.3).

[23] LEONHARDT, Fritz. Princípios básicos da construção de pontes de concreto. Rio de Janeiro: Interciência, 1979. 6.v. (Construções de concreto, vol.6).

[24] MAтTOCK, A. H. Anchorage of stirrups in a thin cast-in-place topping. PCI Journal, Nov./Dec. 1987.

[25] MOKK, I. Construcciones con materiales prefabricados de hormigon armado. Bilbao: Urmo, 1969. 555p. (Traduzido por J. M. Urcelay).

[26] MOLITERNo, Antonio. Caderno de muros de arrimo. São 
Paulo: Edgard Blücher, 1980. 194p.

[27] MONTANARI, Ilio. Tabelas para pontes em laje contínua. São Carlos: Escola de Engenharia de São Carlos, 1976. (Publicação ñ 169).

[28] MONTOYA, P. J., MESEGUER, A., MORAN, F. Hormigon Armado. 7.ed. Barcelona: Gustavi Gili, 1973. 2v.

[29] MORAES, Marcelo da Cunha. Estruturas de Fundação. 3.ed. São Paulo: Mc Graw-Hill, 1976. 264p.

[30] PFEIL, Walter. Concreto armado: dimensionamento. 2.ed. Rio de Janeiro: Livros Técnicos e Científicos, 1975. $368 \mathrm{p}$.

[31] PFEIL, Walter. Pontes em concreto armado. 4.ed. Rio de Janeiro: Livros Técnicos e Científicos, 1990. $2 . v$.

[32] PINHEIRO, Libânio Miranda. Concreto armado = tabelas e ábacos. São Carlos: Escola de Engenharia de São Carlos, 1986. (Publicação 016/90, reimpressão).

[33] PRESTRESSED CONCRETE INSTITUTE. Precast prestressed concrete short span bridges: spans up to 100 feet. Chicago/Illinois, 1975.

[34] RÜSCH, H. Berechnungstafeln für rechtwinklige fahrbahnplatten von straßenbrücken. 6.ed. Berlim: W. Ernst und Sohn, 1965. (DAfStb Cad. 106).

[35] SANTOS, Lauro Modesto dos, et al. Edifícios de concreto armado. São Paulo, 1984. (Curso FDTE / EDUSP / IPT, manuscrito). 
[36] SOMERVILLE, G. Industrializacion de las estructuras para puentes de luces medias. In: Puentes $y$ pasos elevados para carreteras y vias urbanas. Barcelona: Éditores Técnicos Asociados, 1971. p.31-70.

[37] SÜSSEKIND, José Carlos. Curso de concreto. 5.ed. Rio de Janeiro: Globo, 1987. 2.v. (vol.2: 3.ed.). 